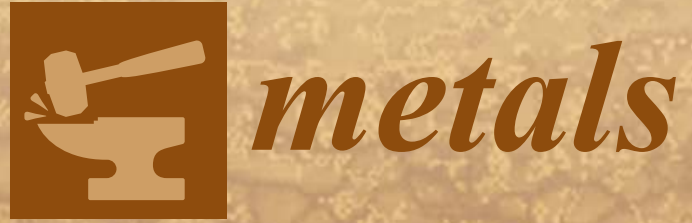

\title{
Titanium Alloys 2017
}
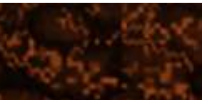

Edited by

Mark T. Whittaker

Printed Edition of the Special Issue Published in Metals. 
Titanium Alloys 2017 



\section{Titanium Alloys 2017}

Special Issue Editor

Mark T. Whittaker

MDPI • Basel • Beijing • Wuhan • Barcelona • Belgrade

\section{MDPI}


Special Issue Editor

Mark T. Whittaker

Swansea University

UK

\author{
Editorial Office \\ MDPI \\ St. Alban-Anlage 66 \\ Basel, Switzerland
}

This is a reprint of articles from the Special Issue published online in the open access journal Metals (ISSN 2075-4701) from 2017 to 2018 (available at: https://www.mdpi.com/journal/metals/special_ issues/titanium-2017)

For citation purposes, cite each article independently as indicated on the article page online and as indicated below:

LastName, A.A.; LastName, B.B.; LastName, C.C. Article Title. Journal Name Year, Article Number, Page Range.

\title{
ISBN 978-3-03897-304-1 (Pbk)
}

ISBN 978-3-03897-305-8 (PDF)

Cover image courtesy of Fengyong Wu.

Articles in this volume are Open Access and distributed under the Creative Commons Attribution (CC BY) license, which allows users to download, copy and build upon published articles even for commercial purposes, as long as the author and publisher are properly credited, which ensures maximum dissemination and a wider impact of our publications. The book taken as a whole is (C) 2018 MDPI, Basel, Switzerland, distributed under the terms and conditions of the Creative Commons license CC BY-NC-ND (http:/ / creativecommons.org/licenses/by-nc-nd/4.0/). 


\section{Contents}

About the Special Issue Editor $\ldots \ldots \ldots \ldots \ldots \ldots \ldots \ldots$ vii

Mark T. Whittaker

Titanium Alloys 2017

Reprinted from: Metals 2018, 8, 319, doi: $10.3390 /$ met8050319 _ . . . . . . . . . . . . . 1

Changzhou Yu, Peng Cao and Mark Ian Jones

Titanium Powder Sintering in a Graphite Furnace and Mechanical Properties of Sintered Parts

Reprinted from: Metals 2017, 7, 67, doi: 10.3390/met7020067 . . . . . . . . . . . . . 3

Changzhou Yu, Peng Cao and Mark Ian Jones

Microstructural Evolution during Pressureless Sintering of Blended Elemental Ti-Al-V-Fe

Titanium Alloys from Fine Hydrogenated-Dehydrogenated Titanium Powder

Reprinted from: Metals 2017, 7, 285, doi: 10.3390/met7080285 . . . . . . . . . . . . . . . 17

Elena N. Korosteleva, Victoria V. Korzhova and Maksim G. Krinitcyn

Sintering Behavior and Microstructure of TiC-Me Composite Powder Prepared by SHS

Reprinted from: Metals 2017, 7, 290, doi: 10.3390/met7080290 . . . . . . . . . . . . . . . 36

Nina Radishevskaya, Olga Lepakova, Natalia Karakchieva, Anastasiya Nazarova, Nikolai Afanasiev, Anna Godymchuk and Alexander Gusev

Self-Propagating High Temperature Synthesis of $\mathrm{TiB}_{2}-\mathrm{MgAl}_{2} \mathrm{O}_{4}$ Composites

Reprinted from: Metals 2017, 7, 295, doi: 10.3390/met7080295 . . . . . . . . . . . . . . 46

Dongjun Wang, Hao Yuan and Jianming Qiang

The Microstructure Evolution, Mechanical Properties and Densification Mechanism of TiAl-Based Alloys Prepared by Spark Plasma Sintering

Reprinted from: Metals 2017, 7, 201, doi: 10.3390/met7060201 . . . . . . . . . . . . . . . 5

Fengyong $\mathrm{Wu}$, Wenchen $\mathrm{Xu}$, Xueze Jin, Xunmao Zhong, Xingjie Wan, Debin Shan and Bin Guo

Study on Hot Deformation Behavior and Microstructure Evolution of Ti-55 High-Temperature Titanium Alloy

Reprinted from: Metals 2017, 7, 319, doi: 10.3390/met7080319 . . . . . . . . . . . . . . . 64

Xiaoguang Fan, Qi Li, Anming Zhao, Yuguo Shi and Wenjia Mei

The Effect of Initial Structure on Phase Transformation in Continuous Heating of a TA15

Titanium Alloy

Reprinted from: Metals 2017, 7, 200, doi: $10.3390 / \operatorname{met} 7060200 \ldots \ldots \ldots \ldots$. . . . . . . . . 81

Shuyu Sun and Weijie Lu

Effect of Hybrid Reinforcements on the Microstructure and Mechanical Properties of Ti-5Al-5Mo-5V-Fe-Cr Titanium Alloy

Reprinted from: Metals 2017, 7, 250, doi: 10.3390/met7070250 . . . . . . . . . . . . . 93

Hongbo Ba, Limin Dong, Zhiqiang Zhang and Xiaofei Lei

Effects of Trace $\mathrm{Si}$ Addition on the Microstructures and Tensile Properties of Ti-3Al-8V-6Cr-4Mo-4Zr Alloy

Reprinted from: Metals 2017, 7, 286, doi: 10.3390/met7080286 . . . . . . . . . . . . . . . 101 
Le Chang, Chang-Yu Zhou and Xiao-Hua He

The Effects of Prestrain and Subsequent Annealing on Tensile Properties of CP-Ti

Reprinted from: Metals 2017, 7,99, doi: 10.3390/met7030099 . . . . . . . . . . . . . . . . 109

Guangbao Mi, Kai Yao, Pengfei Bai, Congqian Cheng and Xiaohua Min

High Temperature Oxidation and Wear Behaviors of Ti-V-Cr Fireproof Titanium Alloy

Reprinted from: Metals 2017, 7, 226, doi: 10.3390/met7060226.

Xiaocong He, Cong Deng and Xianlian Zhang

Fretting Behavior of SPR Joining Dissimilar Sheets of Titanium and Copper Alloys

Reprinted from: Metals 2016, 6, 312, doi: 10.3390/met6120312 . . . . . . . . . . . . . . . . . . . 135 


\section{About the Special Issue Editor}

Mark T. Whittaker is an Associate Professor in the Institute of Structural Materials at Swansea University and has produced over 70 publications, including three invited book chapters and 50 papers in leading international journals on topics including titanium alloys, high temperature lifing, thermo-mechanical fatigue and modern creep lifing approaches. He is also a board member of the IOM3 Structure and Properties of Materials committee. His current research programmes involve sponsorship from Rolls-Royce, EPSRC and TIMET UK. He has over 15 years of experience in a wide range of alloys. He is also heavily involved in research into the thermo-mechanical fatigue behaviour and creep lifing of alloys for the power generation/aerospace sectors, with particular expertise in property extrapolation using the recently developed 'Wilshire equations'. 



\title{
Editorial
}

\section{Titanium Alloys 2017}

\author{
Mark T. Whittaker \\ Institute of Structural Materials, Bay Campus, Swansea University, Swansea SA1 8EN, UK; \\ m.t.whittaker@swansea.ac.uk
}

Received: 20 April 2018; Accepted: 1 May 2018; Published: 5 May 2018

\section{Introduction and Scope}

Although titanium was originally discovered in the 18th century [1], significant developments in the titanium industry only occurred in the middle of the 20th century. These changes resulted from the emergence of the gas turbine engine and led to the development of industries focussing on titanium sponge production in USA, Europe, and Japan [2]. Since that time, the aerospace sector has dominated the titanium use worldwide. The metal has applications in both engines and airframe structures. Titanium has a highly desirable combination of properties, which include excellent corrosion resistance, a high strength-to-weight ratio, and good fatigue resistance. Such qualities enable extensive applications, and only its high extraction and processing costs restrict further implementation.

Although the aerospace industry faces challenges related to increasing operating temperatures and the development of polymer-based composites, innovative solutions, including metal-matrix composites and titanium aluminides, provide pathways for future development. Furthermore, improvements in extractive metallurgy and processing methods have made titanium-based alloys more accessible to alternative industries. Industries currently utilising these materials include the sports, biomedical, and marine sectors.

\section{Contributions}

As part of this Special Issue, I am delighted to present a collection of high-quality papers which cover a range of topics from the extensive field of titanium alloys, including processing, mechanical properties, microstructural evolution, titanium-based composites, and titanium aluminides. The paper by $\mathrm{Yu}$ et al. [3] provides an insight into the possibilities of isothermal atmospheric sintering of commercially pure titanium powders, generating satisfactory mechanical properties. A second paper by the authors continues the theme of sintered titanium powders, this time investigating the microstructural evolution of Ti-Al-V-Fe alloys [4]. Titanium-based composites, also produced by a vacuum sintering process, have also found an application in the rapidly developing field of additive manufacturing, and the paper by Korosteleva et al. [5] is an interesting investigation into the latest development of these materials. Similarly, titanium boride-based composites as heat insulating materials are an example of a material with a more unique application [6].

As more traditional applications are supplemented by exciting new opportunities, it is clear that extensive research opportunities are likely to exist in the titanium industry for the foreseeable future. Currently, an active area of research regards titanium aluminides, where the difficulties of these low-ductility materials are offset by their potential for weight saving and higher-temperature operation. The interesting work by Wang et al. [7] relating microstructure and mechanical properties is a welcome addition to this compilation.

The more traditional areas of research into microstructure and mechanical properties of titanium alloys, however, continue to provide fascinating and industrially relevant research. Processing parameters and their effect on microstructure is a focus of the work presented by Wu et al. [8], and structure evolution is also considered in the work by Fan et al. [9]. It is always fascinating to see papers in an area of my 
own previous research interest, namely, the mechanical properties of titanium alloys, and the paper by Sun et al. [10] aptly describes the effects of hybrid reinforcements on a titanium alloy. Similarly, the work by Ba et al. [11] examines the effect of silicon addition on both microstructure and tensile properties and provides an interesting read, as does the work by Chang on CP titanium [12]. Fretting and wear behaviour is an important application-based topic and is currently being actively researched in titanium alloys, as evidenced here by the papers by Mi et al. [13] and He et al. [14].

The titanium industry faces many challenges in the modern world, but the flexibility of the material and its ability to adapt to an ever-widening range of industrial applications illustrates the broad scope of opportunities for continuing research. It is my hope that this collection of papers indicates the strength and continuing diversity of titanium alloys and provides a valuable addition to an already comprehensive field of research.

Conflicts of Interest: The author declares no conflict of interest.

\section{References}

1. Bomberger, H.B.; Froes, F.H.; Morton, P.H. Titanium Technology: Present Status and Future Trends; TDA: Dayton, OH, USA, 1985; p. 3.

2. Lutjering, G.; Williams, J.C. Titanium; Springer: New York, NY, USA, 2003; p. 2.

3. Yu, C.; Cao, P.; Jones, M.I. Titanium Powder Sintering in a Graphite Furnace and Mechanical Properties of Sintered Parts. Metals 2017, 7, 67. [CrossRef]

4. Yu, C.; Cao, P.; Jones, M.I. Microstructural Evolution during Pressureless Sintering of Blended Elemental Ti-Al-V-Fe Titanium Alloys from Fine Hydrogenated-Dehydrogenated Titanium Powder. Metals 2017, 7, 285. [CrossRef]

5. Korosteleva, E.N.; Korzhova, V.V.; Krinitcyn, M.G. Sintering Behavior and Microstructure of TiC-Me Composite Powder Prepared by SHS. Metals 2017, 7, 290. [CrossRef]

6. Radishevskaya, N.; Lepakova, O.; Karakchieva, N.; Nazarova, A.; Afanasiev, N.; Godymchuk, A.; Gusev, A. Self-Propagating High Temperature Synthesis of $\mathrm{TiB}_{2}-\mathrm{MgAl}_{2} \mathrm{O}_{4}$ Composites. Metals 2017, 7, 295. [CrossRef]

7. Wang, D.; Yuan, H.; Qiang, J. The Microstructure Evolution, Mechanical Properties and Densification Mechanism of TiAl-Based Alloys Prepared by Spark Plasma Sintering. Metals 2017, 7, 201. [CrossRef]

8. Wu, F.; Xu, W.; Jin, X.; Zhong, X.; Wan, X.; Shan, D.; Guo, B. Study on Hot Deformation Behavior and Microstructure Evolution of Ti55 High-Temperature Titanium Alloy. Metals 2017, 7, 319. [CrossRef]

9. Fan, X.; Li, Q.; Zhao, A.; Shi, Y.; Mei, W. The Effect of Initial Structure on Phase Transformation in Continuous Heating of a TA15 Titanium Alloy. Metals 2017, 7, 200. [CrossRef]

10. Sun, S.; Lu, W. Effect of Hybrid Reinforcements on the Microstructure and Mechanical Properties of Ti-5Al-5Mo-5V-Fe-Cr Titanium Alloy. Metals 2017, 7, 250. [CrossRef]

11. Ba, H.; Dong, L.; Zhang, Z.; Lei, X. Effects of Trace Si Addition on the Microstructures and Tensile Properties of Ti-3Al-8V-6Cr-4Mo-4Zr Alloy. Metals 2017, 7, 286. [CrossRef]

12. Chang, L.; Zhou, C.; He, X. The Effects of Prestrain and Subsequent Annealing on Tensile Properties of CP-Ti. Metals 2017, 7, 99. [CrossRef]

13. Mi, G.; Yao, K.; Bai, P.; Cheng, C.; Min, X. High Temperature Oxidation and Wear Behaviors of Ti-V-Cr Fireproof Titanium Alloy. Metals 2017, 7, 226. [CrossRef]

14. He, X.; Deng, C.; Zhang, X. Fretting Behavior of SPR Joining Dissimilar Sheets of Titanium and Copper Alloys. Metals 2016, 6, 312. [CrossRef]

(C) 2018 by the author. Licensee MDPI, Basel, Switzerland. This article is an open access article distributed under the terms and conditions of the Creative Commons Attribution (CC BY) license (http:/ / creativecommons.org/licenses/by/4.0/). 


\title{
Titanium Powder Sintering in a Graphite Furnace and Mechanical Properties of Sintered Parts
}

\author{
Changzhou Yu, Peng Cao * and Mark Ian Jones * \\ Department of Chemical and Materials Engineering, The University of Auckland, Private Bag 92019, \\ Auckland 1142, New Zealand; cyu060@aucklanduni.ac.nz \\ * Correspondences: p.cao@auckland.ac.nz (P.C.); mark.jones@auckland.ac.nz (M.I.J.); Tel.: +64-9-923-6924 (P.C.) \\ Academic Editor: Mark T. Whittaker \\ Received: 23 January 2017; Accepted: 20 February 2017; Published: 22 February 2017
}

\begin{abstract}
Recent accreditation of titanium powder products for commercial aircraft applications marks a milestone in titanium powder metallurgy. Currently, powder metallurgical titanium production primarily relies on vacuum sintering. This work reported on the feasibility of powder sintering in a non-vacuum furnace and the tensile properties of the as-sintered Ti. Specifically, we investigated atmospheric sintering of commercially pure (C.P.) titanium in a graphite furnace backfilled with argon and studied the effects of common contaminants $(C, O, N)$ on sintering densification of titanium. It is found that on the surface of the as-sintered titanium, a severely contaminated porous scale was formed and identified as titanium oxycarbonitride. Despite the porous surface, the sintered density in the sample interiors increased with increasing sintering temperature and holding time. Tensile specimens cut from different positions within a large sintered cylinder reveal different tensile properties, strongly dependent on the impurity level mainly carbon and oxygen. Depending on where the specimen is taken from the sintered compact, ultimate tensile strength varied from 300 to $580 \mathrm{MPa}$. An average tensile elongation of 5\% to 7\% was observed. Largely depending on the interstitial contents, the fracture modes from typical brittle intergranular fracture to typical ductile fracture.
\end{abstract}

Keywords: titanium alloys; sintering; powder metallurgy; fracture

\section{Introduction}

Structural applications of titanium and its alloys are limited because of the high cost of production despite the fact that titanium exhibits admirable combined properties such as high strength-to-weight ratio and excellent corrosion resistance [1,2]. In comparison with the mainstream titanium production processes such as casting and wrought, the major advantage of powder metallurgical (PM) methods including conventional press-and-sinter and novel additive manufacturing [3,4] is the potential of cost reduction resulting from its near-net-shaping ability [5]. In recent major milestone developments in the PM titanium industry, near-net-shaped Ti-6Al-4V products have been approved for commercial airplane components by Boeing (Seattle, WA, USA) [5]. The manufacture of titanium powder metal products has received standardized quality management system AS9100/ISO9001 certification in April 2013 [6]. Titanium powders are generally sintered under vacuum rather than in an atmosphere such as argon or helium so as to obtain high densification and superior mechanical properties [7]. Vacuum sintering with a pressure of the order of $10^{-2}$ Pa or lower [8-11] can effectively control the active reaction between titanium and interstitial impurities such as oxygen, nitrogen and carbon. The mechanical properties of as-sintered titanium are highly sensitive to the interstitials $[5,12]$. For example, in samples with a similar sintered density of $98 \%$, the ductility of press-and-sintered commercial purity titanium with an oxygen content of $3000 \mathrm{ppm}$ (elongation: $11 \%$ ) is less than $1 / 3$ of that for Ti containing 700 ppm oxygen (elongation: 37.1\%) [7,13]. Vacuum sintering can also 
remove detrimental volatiles such as chlorides that pre-exist in titanium sponges and help with densification $[13,14]$. However, vacuum sintering is a batch process and has high capital equipment requirement. Possible continuous mass production is suggested to be realized by atmospheric sintering so as to reduce the production cost [14].

In 1937, Kroll conducted the first sintering trials of 14 Ti binary alloys in argon atmosphere [13]. Subsequent work in the late 1940s and early 1950s saw some other examples of the sintering of titanium mill products $[7,15]$. Limberg et al. [16] studied the influence of sintering atmosphere on sintering behavior of a titanium aluminide Ti-45Al-5Nb-0.2B-0.2C (at. \%) through altering the argon atmosphere pressure (from 10 to $80 \mathrm{kPa}$ ) in comparison with sintering under vacuum $\left(10^{-3} \mathrm{~Pa}\right)$. In their study, the residual porosity of sintered specimens increased proportionally with applied argon pressure to $1.1 \%$ at the maximum pressure $(80 \mathrm{kPa})$, but no other pronounced microstructural difference such as grain size was observed due to the various sintering atmosphere pressures [16]. Limberg et al.'s study also shows that the pressure of the sintering atmosphere had no obvious effect on the tensile properties of the as-sintered compacts and all sintered specimens exhibited similar ultimate tensile strength (around $630 \mathrm{MPa})$ and elongation $(0.15 \%-0.19 \%)$ [16]. Since titanium has a high affinity with nitrogen, oxygen, hydrogen and carbon, atmospheric sintering typically has to be conducted in an inert atmosphere such as argon [17]. Even then, purification of the inert atmosphere is still required [15] before a titanium powder compact enters into the hot zone because even small amounts of reactive gases (nitrogen, oxygen and hydrogen) are detrimental and make sintered specimens brittle. To address this issue, Arensburger et al. developed a purification setup by allowing argon flowing through pre-heated titanium sponges $\left(900-1000{ }^{\circ} \mathrm{C}\right)$ [17]. An alternative solution is to reduce the oxygen partial pressure in the argon gas further by utilizing reactions with graphite materials in the furnace such as in a KYK Oxynon furnace (Kanto Yakin Kogyo, Shinomiya, Japan) [18-20]. As a result, extremely low oxygen pressure can be generated by the reaction between oxygen and carbon, which is deemed to be able to reduce oxides such as titanium oxide $\left(\mathrm{TiO}_{2}\right)$ into metal. The Oxynon furnace has been used for titanium sintering in argon since 2002. However, a recent comparative study revealed that the ductility of commercially pure (C.P.) Ti sintered in the Oxynon furnace is much lower than that sintered under vacuum, although the oxygen and carbon contents in titanium sintered in Oxynon furnace were lower than those in vacuum [18]. This signifies the necessity of investigating what causes the difference between sintering in argon and vacuum.

The reports on the atmospheric sintering of titanium powder are very limited. Our previous work using a furnace constructed of graphite heating elements and liners showed that the presence of impurities resulted in a thick porous contaminated scale, which was identified as titanium oxycarbonitride $(\mathrm{Ti}(\mathrm{CNO}))$ [21]. This is a follow-up study, which aims to understand the effects of possible contaminants on the sintering and properties of C.P. Ti during sintering in a common graphite furnace.

\section{Materials and Methods}

\subsection{Materials, Compaction and Sintering}

Hydrogenated-dehydrogenated (HDH) C.P. titanium powder (particle size $<75 \mu \mathrm{m}$, nominal impurities provided by the supplier: $0.4060 \mathrm{wt} \% \mathrm{O}, 0.0470 \mathrm{wt} \% \mathrm{C}, 0.0070 \mathrm{wt} \% \mathrm{~N}$ ) was supplied by Xi'an Lilin Ltd., Xi'an, China. The powder morphology and particle size distribution have been reported previously [22]. The powders were pressed uniaxially under a compaction pressure of $400 \pm 50 \mathrm{MPa}$ into small disc samples $12 \mathrm{~mm}$ in diameter and 5 to $8 \mathrm{~mm}$ thick. These compacts had a green density of $\sim 77 \%$ theoretical density. The green compacts were then sintered at three different temperatures $\left(1100,1250\right.$ and $\left.1400{ }^{\circ} \mathrm{C}\right)$ and three different holding times $(4,6$ and $8 \mathrm{~h})$. In order to track possible interstitial diffusion from the atmosphere and understand its effects on mechanical properties, a large cylindrical compact (32 $\mathrm{mm}$ in diameter and 30 to $40 \mathrm{~mm}$ high) was uniaxially pressed at a pressure of $200 \mathrm{MPa}$ followed by cold isostatic pressing (CIP) under a pressure of $600 \mathrm{MPa}$. This large 
green compact had a density of $87 \%$. The large cylindrical compact was then sintered at a temperature of $1250{ }^{\circ} \mathrm{C}$ for $4 \mathrm{~h}$. Tensile specimens were machined from different positions of this large cylinder.

The graphite furnace employed in this work (Mellen, WI, USA) has three sets of graphite heating elements and uses graphite liners for insulation. The hot zone is $20 \mathrm{~cm} \times 20 \mathrm{~cm} \times 20 \mathrm{~cm}$. The compacts were placed on a boron nitride plate at the center of the hot zone. After the compacts were loaded, the furnace was evacuated to a vacuum level of 0.1 to $0.01 \mathrm{~Pa}$ and heated to $850{ }^{\circ} \mathrm{C}$ with a heating rate of $5^{\circ} \mathrm{C} \cdot \mathrm{min}^{-1}$. During this preheating, argon was purged a few times to remove possible volatiles before argon gas backfilling. In order to avoid possible gas leaking at high temperatures, at this stage, argon gas (purity 99.99\%) was backfilled to the furnace and a pressure of $1.1 \mathrm{~atm}\left(1.1 \times 10^{5} \mathrm{~Pa}\right)$ was maintained until completion of sintering. The positive net furnace pressure is designed to avoid possible inwards airflow from ambient atmosphere.

\subsection{Characterization}

The sintered density was measured by the Archimedes method according to the ASTM B962-14 standard. Metallographic specimens were prepared as per the standard metallographic procedures. The polished cross sections were etched with Kroll's reagent (2 mL HF, $4 \mathrm{~mL} \mathrm{HNO}, 100 \mathrm{~mL} \mathrm{H}_{2} \mathrm{O}$ ). Microstructural observations were carried out using an environmental scanning electron microscope (ESEM, Quanta 200F, FEI, Hillsboro, OR, USA), equipped with energy dispersive spectrometry (EDS) and an Olympus BX60M optical microscopy (Olympus, Waltham, MA, USA) coupled with polarized light optics. The average grain size was measured as per the linear intercept method described in the ASTM E112-12 standard. The pore size was estimated using an Image-J software (ImageJ Developers, National Institutes of Health, Bethesda, MD, USA). A Bruker D2 PHASER (Bruker AXS, Karlsruhe, Germany) X-ray diffraction (XRD) machine was employed to identify phase constituents. The patterns were collected over a $2 \theta$ range of $20^{\circ}$ to $80^{\circ}$ with a step size of $0.02^{\circ}$. Oxygen, nitrogen and carbon contents in the as-received titanium powder and the sintered compacts were measured using a LECO oxygen-nitrogen analyzer (TCH-600, Leco, St Joseph, MI, USA) and carbon-sulfur analyzer (CS-444, Leco, St Joseph, MI, USA).

\subsection{Mechanical Testing}

Tensile slices were cut from the as-sintered large cylinder after removal of the contaminated scale, as shown in Figure 1. The contaminated scale layer is designated as S1 and this porous scale contains many cracks and can be easily removed to expose the interior bulk titanium. The S2 specimen cut $1.5 \mathrm{~mm}$ beneath the surface scale contains visible pores and is believed to contain too high impurity levels and therefore is not suitable for tensile testing. The slices S3 to S7 do not have visible pores with naked eyes and were then further machined into standard tensile specimens $(\sim 2 \mathrm{~mm} \times 2 \mathrm{~mm}$ cross-section, $16 \mathrm{~mm}$ shoulder-to-shoulder length, and $10 \mathrm{~mm}$ gauge length). Tensile testing was performed on an Instron 3367 machine (Instron, Norwood, MA, USA) with a crosshead speed of $0.1 \mathrm{~mm} \cdot \mathrm{min}^{-1}$ (initial strain rate: $1.67 \times 10^{-4} \mathrm{~s}^{-1}$ ). The precise displacement was determined using an extensometer with a gauge length of $8 \mathrm{~mm}$ (model: 2630-120, Instron Co., Norwood, MA, USA). 

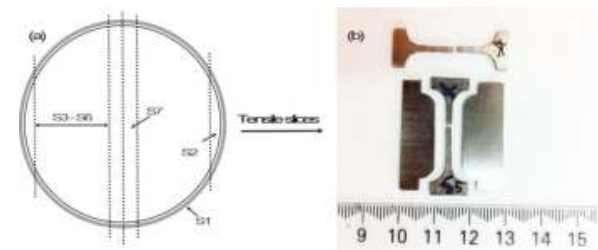

Figure 1. (a) Schematic illustration of the cylinder and the seven slices cut from the cylinder, only slices S3 to S7 were further machined for tensile test and (b) the tensile specimens after fracture. S1 was the outer scale, S2 to S7 were the slices cut from outer slice to the interior slices. S7 slices were cut from the central of the sintered large cylinder.

\section{Results}

\subsection{Sintering Densification}

The sintered density (relative to theoretical density) and densification parameter are illustrated in Figure 2, as a function of sintering temperature and holding time. Densification parameter, $\varphi$, is calculated according to Equation (1) [23]

$$
\varphi=\left(\rho_{s}-\rho_{g}\right) /\left(\rho_{t h}-\rho_{g}\right)
$$

where $\rho_{s}, \rho_{g}$ and $\rho_{t h}$ are sintered density, green density and theoretical density, respectively. The value of $\varphi$ represents how much porosity in the green compact has been removed by sintering. In general, the sintered densities in all small samples (i.e., the $12 \mathrm{~mm}$-in-diameter samples) were low and in the range of $82.5 \%$ to $92.5 \%$ of theoretical density (see Figure $2 \mathrm{a}$ ). A higher sintering temperature and/or longer hold increased the sintered density and densification (Figure 2b). However, it must be noted that the density was measured by weighing the entire sintered compact and therefore included the contaminated porous surface scale.

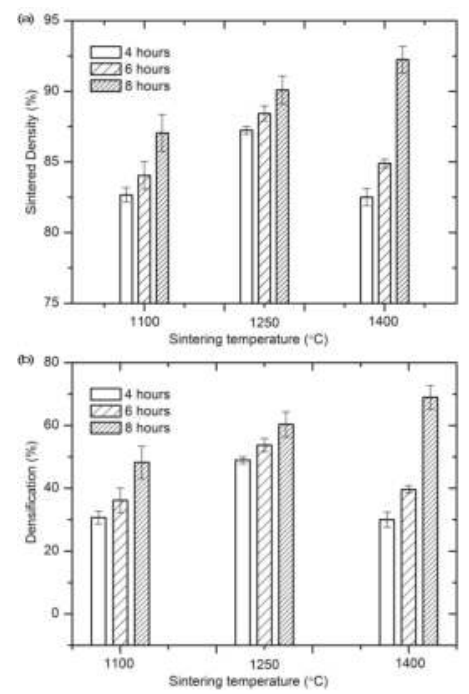

Figure 2. Effects of sintering temperature and holding time on relative sintered density (a) and densification parameter $(\mathbf{b})$. 


\subsection{Microstructural Observation}

Figure 3 presents an example of the compacts sintered at the three temperatures for $4 \mathrm{~h}$. The metallographic observations of the cross sections of these compacts clearly show a fairly thick contamination scale on the compact surface. This porous layer was 300-500 $\mu \mathrm{m}$ thick, regardless of the sintering temperature. Separation between this layer and the remaining compact is visible. XRD and EDS analyses suggest that this layer is $\mathrm{Ti}(\mathrm{CNO})$ [21] and the formation mechanism will be discussed in subsequent Section 4.2.
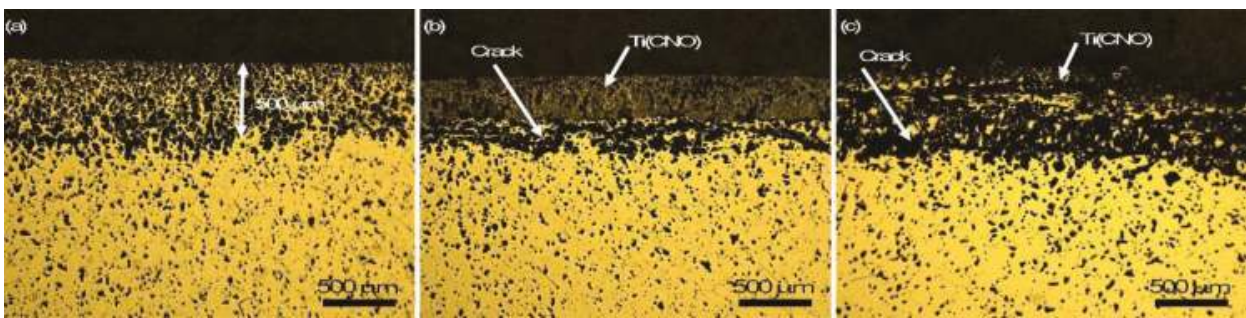

Figure 3. Micrographs of the cross-sections of sintered small compacts at different sintering temperatures: (a) $1100{ }^{\circ} \mathrm{C}$; (b) $1250{ }^{\circ} \mathrm{C}$; and (c) $1400{ }^{\circ} \mathrm{C}$. All compacts were sintered for $4 \mathrm{~h}$ at the respective temperature.

The microstructures in the interior of the sintered compacts were observed after the outermost layer was removed. Under the polarized light microscope, macropores were evident in all the cases, as shown in Figure 4. The pore size and morphology are dependent on the sintering temperature. For instance, after being sintered at $1100{ }^{\circ} \mathrm{C}$ for $4 \mathrm{~h}$, the pore shape is irregular and interconnected. This implies that, under this sintering condition, the compact might be still in the early stage of densification (Figure $4 \mathrm{a}$ ). By increasing the holding time to $8 \mathrm{~h}$, the number and size of pores decreased, although the majority of pores was still of irregular shape (Figure 4d). Pore spheroidizing occurred at higher sintering temperatures of 1250 and $1400{ }^{\circ} \mathrm{C}$, in which cases the pores were spherical and isolated. Sintering at $1250{ }^{\circ} \mathrm{C}$ led to most pores being located either along grain boundaries or at the triple junctions (Figure $4 \mathrm{~b}$ ). At $1400{ }^{\circ} \mathrm{C}$, some of these pores became trapped within grains as a result of grain growth in the later stages of sintering (Figure $4 \mathrm{c}$ ). In addition to the pore morphology, the pore size is also related to the sintering conditions. The compact sintered at $1250^{\circ} \mathrm{C}$ for $4 \mathrm{~h}$ contained pores of typically $20-40 \mu \mathrm{m}$ in size (Figure $4 \mathrm{~b}$ ). The average pore size observed in the compact sintered at $1400{ }^{\circ} \mathrm{C}$ increased to $50 \mu \mathrm{m}$ (Figure $4 \mathrm{c}$ ). When the holding time was increased to $8 \mathrm{~h}$, these small pores vanished and the number of pores decreased in both 1250 and $1400{ }^{\circ} \mathrm{C}$ sintered compacts (Figure $4 \mathrm{e}, \mathrm{f}$ ).

\subsection{Close-Up Observation of Surface Contaminants}

The surfaces of the sintered compacts, regardless of sintering temperature, show powdery morphology (Figure 5). To a much lesser content, some sinter-necks could be found. Shiny carbon particles were also visible on the sample surface. This is validated by the EDS analysis. Further evidence presented in the subsequent Section 3.4 suggests that this thick layer of surface contaminant is a compound containing $\mathrm{Ti}, \mathrm{C}, \mathrm{N}$ and $\mathrm{O}$. 

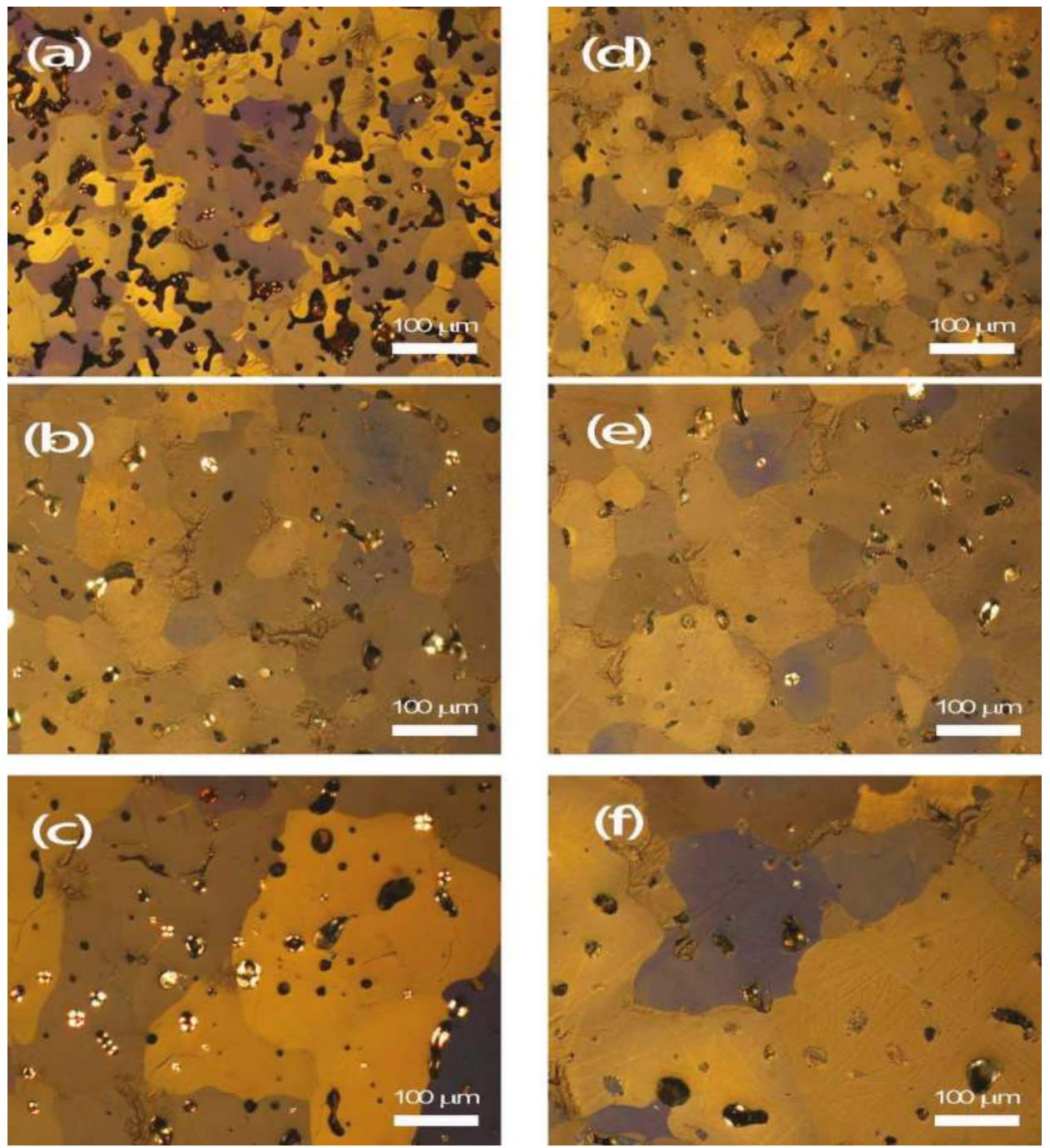

Figure 4. Microstructure of the cross sections of sintered small compacts at various sintering conditions. The micrographs were taken under polarized light microscopy. The compacts were sintered at various temperatures for different holding times: (a) $1100{ }^{\circ} \mathrm{C} / 4 \mathrm{~h}$; (b) $1250{ }^{\circ} \mathrm{C} / 4 \mathrm{~h}$; (c) $1400{ }^{\circ} \mathrm{C} / 4 \mathrm{~h}$; (d) $1100{ }^{\circ} \mathrm{C} / 8 \mathrm{~h} ;$ (e) $1250{ }^{\circ} \mathrm{C} / 8 \mathrm{~h}$; and (f) $1250{ }^{\circ} \mathrm{C} / 8 \mathrm{~h}$. 

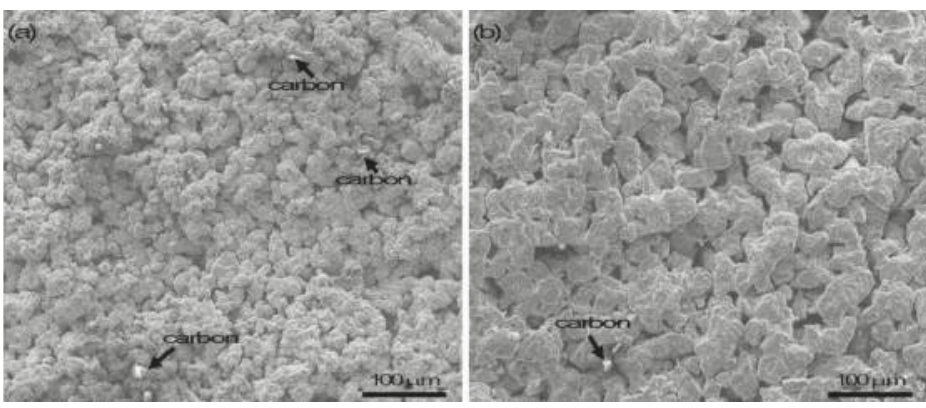

Figure 5. Surface morphologies of the small compacts sintered at $1250{ }^{\circ} \mathrm{C}$ (a) and $1400{ }^{\circ} \mathrm{C}(\mathbf{b})$, respectively. Sintering time was $4 \mathrm{~h}$.

\subsection{Phase Characterization of the Surface and the Interior}

Figure 6 compares the XRD patterns taken from the surface and the cross section of the compact interior for samples sintered for $4 \mathrm{~h}$. It is evident that the main phase constituents depend on the sintering temperature. At $1100{ }^{\circ} \mathrm{C}$, three main phases are identified, i.e., $\mathrm{Ti}_{2} \mathrm{O}$ (JCPDS \# 73-1582), TiC (JCPDS \# 73-0472) and $\mathrm{TiC}_{0.2} \mathrm{~N}_{0.8}$ (JCPDS \# 76-2484), while at 1250 and $1400{ }^{\circ} \mathrm{C}$, only $\mathrm{Ti}\left(\mathrm{C}_{0.53} \mathrm{~N}_{0.32} \mathrm{O}_{0.19}\right.$ ) is present (JCPDS \# 50-0681). In contrast, the only phase observed in the interior of samples sintered at all temperatures is $\alpha$-Ti (JCPDS \# 44-1294) without any other phases present.
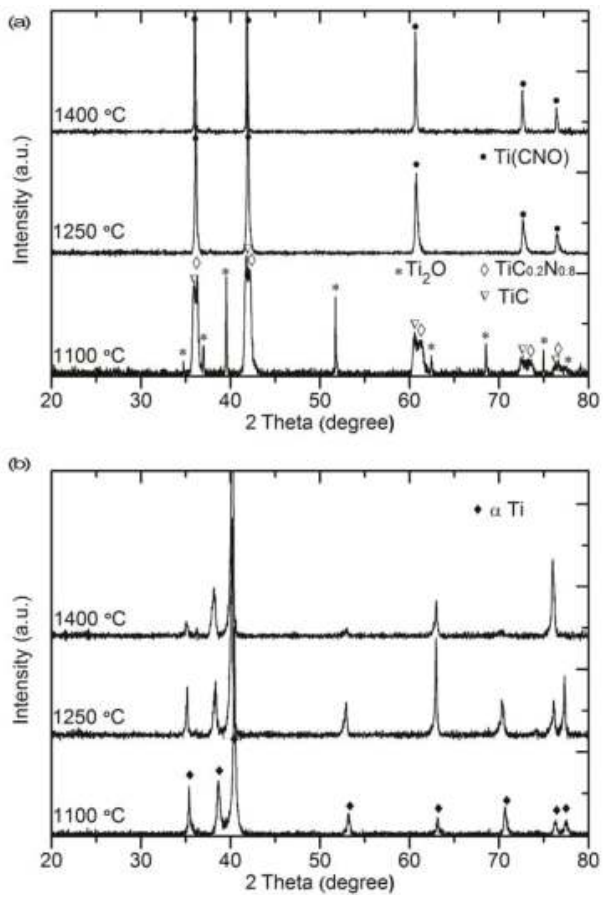

Figure 6. X-ray diffraction (XRD) patterns of the as-sintered small Ti compacts (a) on the surface and (b) cross-sections of compact interior. The compact was sintered for $4 \mathrm{~h}$ at 1100, 1250 and $1400{ }^{\circ} \mathrm{C}$, respectively. 


\subsection{Mechanical Properties and Fractography}

Typical stress-strain curves of the tensile specimens taken from three different positions in the sintered cylinder are shown in Figure 7. The contaminated surface scale was removed from the large cylinder. It is clear that specimen S3, which was taken $2 \mathrm{~mm}$ underneath the outermost surface, failed prior to yielding. Specimen S4 sliced $4 \mathrm{~mm}$ underneath the outermost surface attained a minor plastic strain of $1.5 \%$. Specimens taken from further inside demonstrated much greater plastic strain-up to $10 \%$ for specimen S5. The average tensile properties of the specimens taken from the different positions are presented in Figure $7 \mathrm{~b}$. An average of $\sim 6 \%$ plastic strain was obtained in the tensile specimens that were taken from the compact interior while a negligible plastic strain for the specimens was taken close to the contaminated surface. For the specimens taken from the interior, the yield strength (YS) was in the range of 385 to $500 \mathrm{MPa}$ and ultimate tensile strength (UTS) varied from 470 to $580 \mathrm{MPa}$. In addition, the Young's moduli of all the specimens were similar (100 to $110 \mathrm{GPa}$ ), which correspond to the sintered densities $(95.3 \%$ to $95.9 \%$, Table 1$)$.
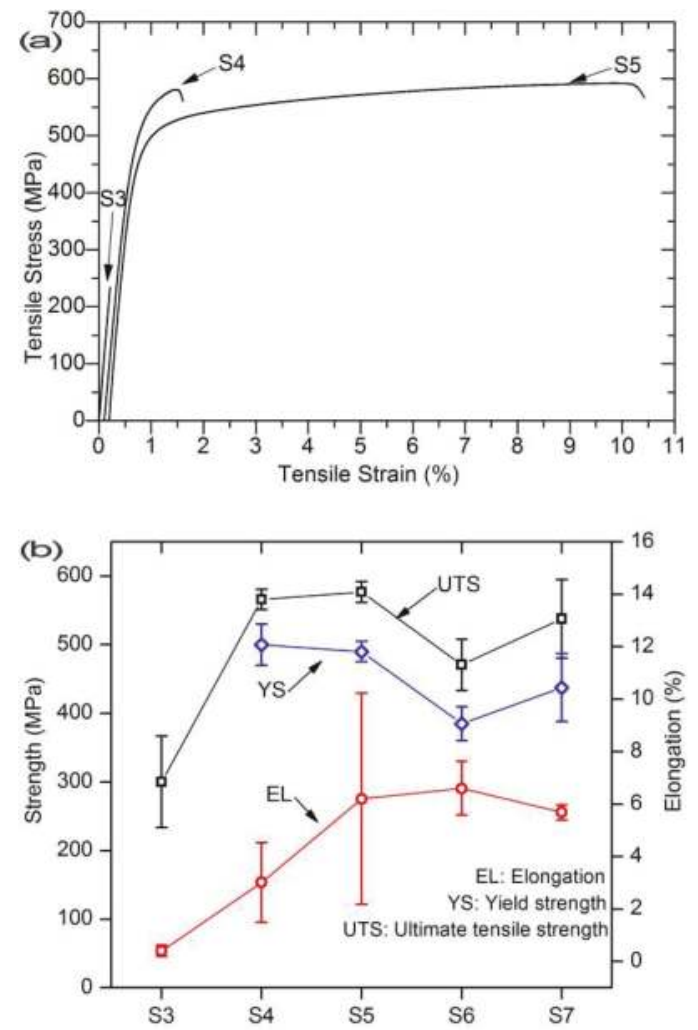

Figure 7. (a) Representative engineering stress-strain curves and (b) a summary of tensile mechanical properties for slices cut from different positions of the sintered cylinder.

Table 1. Sintered density in terms of percentage of theoretical density for slices taken from the large cylinder.

\begin{tabular}{cccccc}
\hline Slices & S3 & S4 & S5 & S6 & S7 \\
\hline Sintered density (\%) & $95.7 \pm 0.1$ & $95.6 \pm 0.3$ & $95.9 \pm 1.0$ & $95.3 \pm 0.1$ & $95.8 \pm 0.2$ \\
\hline
\end{tabular}


Figure 8 shows the fracture surface of the specimens S4 and S5. Smooth facets and river patterns are visible in $\mathrm{S4}$ (Figure 8a), which indicate a brittle fracture mode. On the other hand, many dimples can be found in specimen S5, indicating a ductile fracture mode. Similar fracture features were observed on the fractured surface of specimens S6 and S7.
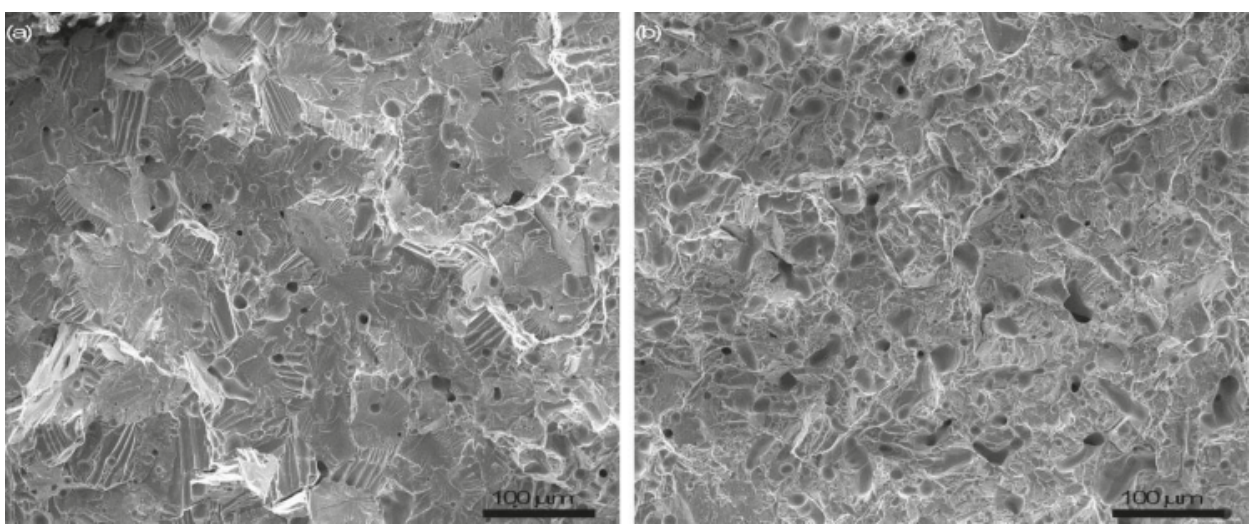

Figure 8. Fracture surfaces of tensile slices from sintered titanium samples: (a) S4 and (b) S5.

\section{Discussion}

\subsection{Densification}

As shown in Figure 2, the sintered density increases by $5 \%-10 \%$ with increasing of the holding time from 4 to $8 \mathrm{~h}$ for all three temperatures. This increase is expected because powder densification by sintering is accomplished through diffusion. For the same reason, increasing sintering temperature also results in a higher sintered density. However, as pointed out in Section 3.1, the measured sintered density does not reflect the densification level because of the presence of the porous contaminated scale. In order to evaluate the effect of temperature and holding time on densification, the contaminated surface scale should be removed before the density is measured. After removing the contaminated layer, the density of the sintered compacts is presented in Figure 9, as a function of sintering temperature and holding time. The favoring effect of increasing temperature or holding time is obvious. This is in accordance with the microstructural observations (Figure 4). Although low densities were observed in the small sintered compacts (Figure 9), the densification data of the large cylinder indicates a $96 \%$ relative density achieved after sintering at $1250{ }^{\circ} \mathrm{C}$ for $4 \mathrm{~h}$ (Table 2). It is noted that a sintered density ranging from $95 \%$ to $99 \%$ is common in PM Ti-6Al-4V if the blended elemental approach is used [24]. However, it needs to point out that a sintered density $>98 \%$ is necessary for PM Ti products to achieve similar static property levels to wrought Ti. The use of fine particles, high compaction pressure and proper sintering conditions could readily achieve such a densification level. Such a level of densification in Ti powder products is acceptable for non-fatigue applications [4,14]. 


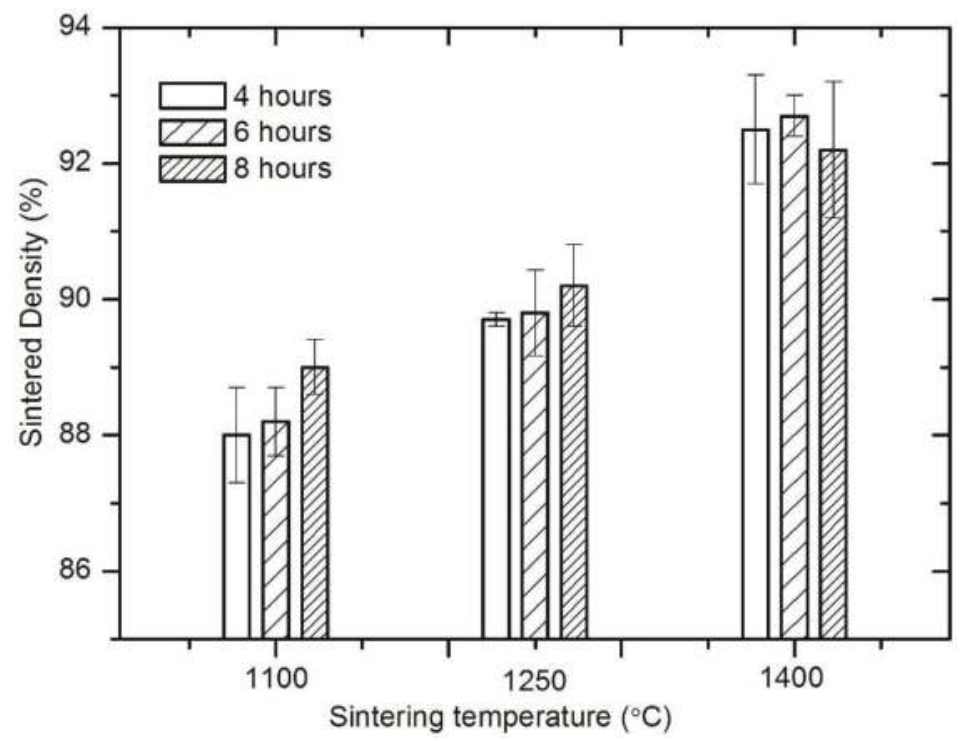

Figure 9. Relative sintered densities of compacts after removing contaminated scale.

Table 2. Densities and densification level for large cylinder prepared for tensile testing. CIP: Cold isostatic pressing.

\begin{tabular}{cccc}
\hline Specimen & Green Density (600 MPa CIP, \%) & Sintered Density (\%) & Densification (\%) \\
\hline Cylinder & 87.0 & 95.8. & 69.2 \\
\hline
\end{tabular}

\subsection{The Formation of Contaminated Surface Layer and the Effect of Interstitials on Mechanical Properties}

In contrast to the sintered compact interior where only $\alpha$-Ti phase is present, the surface of the sintered compact is a complex compound $\mathrm{Ti}(\mathrm{CNO})$. The carbon is thought to arise from the graphite heating elements and insulation liner material within the furnace, while nitrogen may originate from backfilled argon and oxygen from the raw powder and argon. In order to further understand the formation of the surface scale resulting from the contamination of interstitials, a formation mechanism is schematically shown in Figure 10.

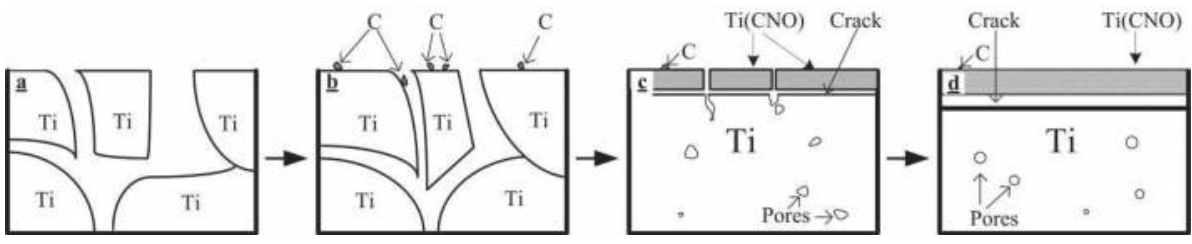

Figure 10. Schematic of the formation process of the contaminated scale. (a) Starting powder compact; (b) contaminants such as $\mathrm{C}$ are deposited on the Ti powder particles; (c) Ti reacts with the contaminants forming $\mathrm{Ti}(\mathrm{CNO})$. Cracking occurs as a result of different coefficients of thermal expansion; (d) larger cracks and more pores are formed at a higher temperature.

Upon heating, the residual carbon in the furnace or newly evaporated carbon from the graphite heating element would deposit on the compact surface (Figure 10b) and react with Ti. Meanwhile, 
the oxygen and nitrogen in the backfilled argon are also involved in this reaction and, consequently, a complicated $\mathrm{Ti}(\mathrm{CNO})$ solution of $\mathrm{TiC}, \mathrm{TiN}$ and $\mathrm{TiO}$ forms (Figure 10c). The formed $\mathrm{Ti}(\mathrm{CNO})$ film is porous. During sintering, the powder compact starts to densify and contraction occurs, which poses a significant stress between the $\mathrm{Ti}(\mathrm{CNO})$ film and the underlying Ti. The interfacial stress can also be caused by the difference in the coefficients of thermal expansion between $\mathrm{Ti}(\mathrm{CNO})$ and $\mathrm{Ti}$. Such interfacial stress is the cause of the many cracks and porous structure of the Ti(CNO) compound (Figure 10d).

The formation of the $\mathrm{Ti}(\mathrm{CNO})$ compound would prevent the interior from interstitial contamination if the film were dense and intact, which is supported by a study of Lefebvre et al., who observed that the $\mathrm{O}$ content in Ti solid solution remained constant although the thickness of the surface oxide layer increased [25]. Unfortunately, this does not seem true in our study. Only when the residual interstitials are completely consumed or the sintering procedure is terminated does the $\mathrm{Ti}(\mathrm{CNO})$ layer stop growing. This explains a constant thickness of Ti(CNO) of approximately $300 \mu \mathrm{m}$ regardless of sintering temperature (for the same sintering time). In other words, the outermost layer on the titanium powder compact acts as a scavenger of interstitials.

The analyses of interstitials on the transverse of the sintered compact indicate that $\mathrm{C}$ and $\mathrm{O}$ diffuse inwards, as shown in Figure 11. The observed O content at position S2 to S7 (the center) ranges from $0.7 \%$ to $0.4 \%$. The carbon content varies from 1000 to $300 \mathrm{ppm}$. In spite of a possible scavenging effect of the outermost layer on the Ti compact, it seems impossible to avoid the inward diffusion of the interstitials. Only the very interior of the compact appears to not have been contaminated-for instance, specimens S5 and S6 in the large cylindrical compact (Figure 11).

Apparently, the measured tensile properties largely depend on the interstitials, on top of porosity, present in the specimens. Interstitials, usually represented by oxygen, can increase strength but reduce ductility dramatically [26]. It has been extensively reported that oxygen levels $\sim 0.3 \mathrm{wt} \%$ significantly reduce the ductility of PM C.P. Ti to $11 \%$ from $37 \%$ at $0.07 \% \mathrm{O}$ (with the same sintered density) [7]. A similar finding was also reported in C.P. Ti produced by metal injection moulding and sintering [27]. At the same densification level, tensile specimen S3 does not show any plastic deformation and its UTS value is also much lower than other specimens. Such poor properties are ascribable to the extremely high C ( 0.1 wt \%) and O content $(0.6 \mathrm{wt} \%)$. Specimen S4, which contains $0.5 \% \mathrm{O}$ and $0.05 \% \mathrm{C}$, does show a small plastic strain (average 3\%, Figure $7 \mathrm{~b}$ ). On the other hand, specimen $\mathrm{S} 5$ contains $0.4 \% \mathrm{O}$ and $0.04 \% \mathrm{C}$ and therefore demonstrates much greater plastic elongation. When the other impurities are taken into account, an oxygen equivalent $\mathrm{O}_{\mathrm{eq}}=\mathrm{O}+2 \mathrm{~N}+0.75 \mathrm{C}$ is usually used to reflect the effect of the interstitials [28,29]. An oxygen equivalent level higher than $0.4 \%$ for C.P. Ti is likely unacceptable. The same oxygen threshold applies for Ti-6Al-4V alloy [30]. In this present study, specimens S5 and S6 demonstrated the highest ductility, which is in accordance with their oxygen equivalents. Specimen S5 had an $\mathrm{O}_{\text {eq }}$ level of $0.47 \%$ while $\mathrm{S} 4$ had $0.60 \%$ oxygen equivalent. The ductility obtained in this study is in agreement with an early study by Kusaka et al. [27] who observed an elongation of $~ 7.0 \%$ in the as-sintered C.P. Ti that had a density of $99 \%$. Such ductility is slightly lower than that specified in the newest ASTM B988-13 for Grade 5 PM (i.e., 9\% elongation).

Although the high levels of impurities in the starting powder did not affect the densification of C.P. Ti, the resultant mechanical properties suffer significantly from the presence of these impurities. In order to mitigate the adverse effect of interstitials, not only reasonably low impurity levels are required, but also the sintering atmosphere should be controlled. It is expected that if some purifying media are placed surrounding the powder compact to be sintered, the contaminated surface could be minimized. Our additional experiments show that a contamination-free sintering could be accomplished by a proper wrapping of the Ti compact. In this separate study, we used HDH Ti powder (O: $0.29 \%, C: 0.04 \%$ and particle size $<75 \mu \mathrm{m}$ ) as raw material and a Ti sponge as the scavenger to sinter $\mathrm{Ti}$ in the same graphite furnace with identical sintering parameters. The sintered Ti demonstrated an elongation of $\sim 16 \%$. 


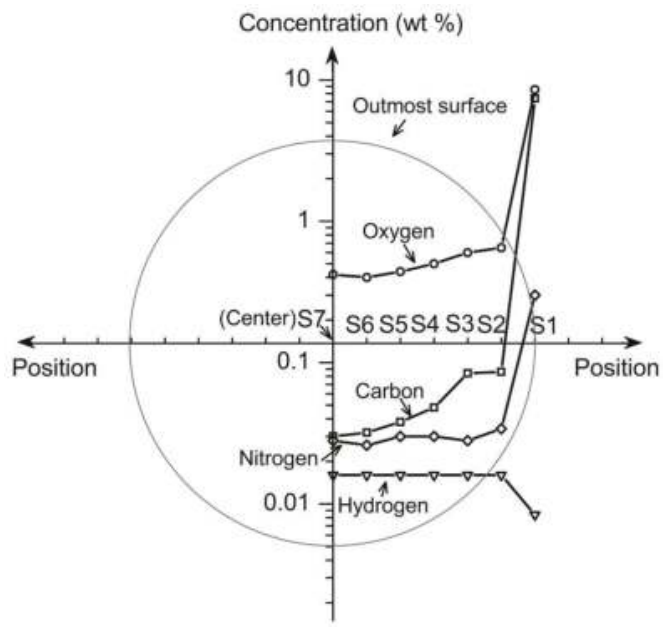

Figure 11. The distribution of interstitial contents at varied slices taken from different positions. Superimposed is the contour of the cylindrical compact.

The fractography results (Figure 8) suggest that the fracture mode is also strongly related to the interstitials, particularly $\mathrm{O}$ and $\mathrm{C}$. At a low level of $\mathrm{C}$ and $\mathrm{O}$, the sintered Ti-6Al-4V fails through microvoid nucleation, growth and coalescence, which results in a typical dimple rupture. However, at a high level of $\mathrm{C}$ and $\mathrm{O}$, the sintered Ti-6Al-4V fails via cleavage and an intergranular fracture mode. Macroscopically, a fracture at $45^{\circ}$ with respect to the tension axis was observed in a relatively low-interstitial specimen (S7, Figure $12 \mathrm{~b})$, whereas a flat $\left(0^{\circ}\right)$ rupture was observed in a high-interstitial specimen (S3, Figure 12a). The critical levels seem to be $0.05 \% \mathrm{C}$ and $0.3 \%$ to $0.4 \% \mathrm{O}$ for the ductile-to-brittle transition. This follows the general consensus that an oxygen level $>0.3 \%$ is detrimental to the ductility of the PM Ti-6Al-4V [26]. The same speculation could be also applicable to other Ti alloys, while the critical values for $\mathrm{C}$ and $\mathrm{O}$ contents might be different. It is postulated that, at different interstitial levels, the dislocation mechanisms might be different as well. Further transmission electron microscopic (TEM) investigations are necessary. In addition to the interstitial contents, the morphology and size of the pores also affect the fracture behavior. A small pore size and spherical pore shape would favor the ductile fracture mode from a fracture mechanics point of view.

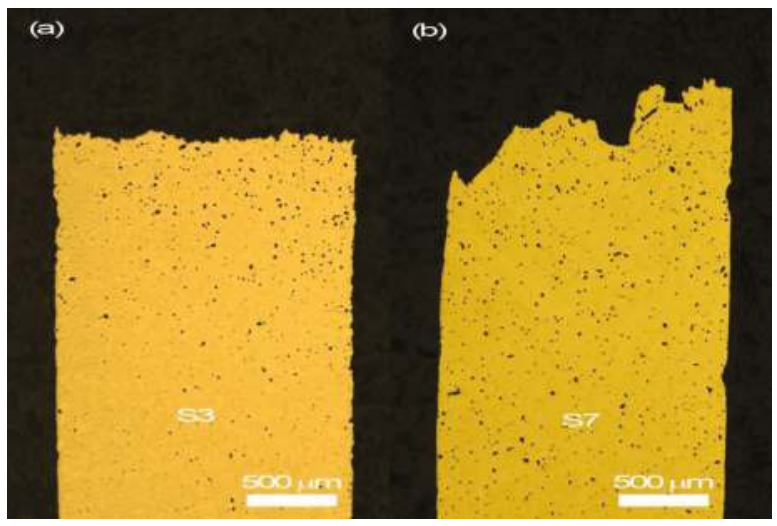

Figure 12. Macroscopic fracture surface of the tensile specimens (a) S3 and (b) S7. 


\section{Conclusions}

This work investigated the sintering of commercially pure titanium powders in a graphite furnace backfilled with argon. A complex compound Ti(CNO) was formed on the surface with a thickness of 300-500 $\mu \mathrm{m}$. The interiors of sintered specimens were pure single $\alpha$-Ti phase. The formation of $\mathrm{Ti}(\mathrm{CNO})$ is caused by the residual interstitials in the furnace from the raw powder and in the argon gas used for backfilling. Densification was enhanced by increasing sintering temperature and/or holding time. Tensile properties were largely determined by the interstitial contents for samples where the sintered density reached at least $96 \%$. With $0.04 \% \mathrm{C}$ and $0.4 \% \mathrm{O}$ contents, the sintered Ti shows an average of $6 \%$ elongation with yield strength of 385 to $490 \mathrm{MPa}$. On the other hand, for the sintered specimens containing higher $\mathrm{C}$ and $\mathrm{O}$ contents, the ductility was significantly reduced. The critical level of $\mathrm{C}$ and $\mathrm{O}$ content for ductile-to-brittle transition appeared to be $\sim 0.04 \% \mathrm{C}$ and $0.3 \%$ to $0.4 \%$ O. This work indicates that it is feasible to realize isothermal atmospheric sintering of C.P. HDH titanium powders in argon atmosphere in a graphite furnace and satisfactory mechanical properties can be achieved.

Acknowledgments: This work was financially supported by the Ministry of Business, Innovation and Employment (MBIE), New Zealand.

Author Contributions: Changzhou Yu conducted experimental work as part of his Ph.D project. He also analyzed the data. Peng Cao conceived and co-designed the experiments, analyzed the data and revised the manuscript. Mark Ian Jones discussed the results and revised the manuscript. Mark Ian Jones and Peng Cao were the supervisors of Changzhou Yu.

Conflicts of Interest: The authors declare no conflict of interest. The founding sponsors had no role in the design of the study; in the collection, analyses, or interpretation of data; in the writing of the manuscript, and in the decision to publish the results.

\section{References}

1. Donachie, J.M.J. Titanium-A Technical Guide, 2nd ed.; ASM International: Materials Park, OH, USA, 2000.

2. Froes, F.H. Titanium-Physical Metallurgy, Processing, and Applications; ASM International: Materials Park, OH, USA, 2015.

3. Zhang, L.-C.; Attar, H. Selective Laser Melting of Titanium Alloys and Titanium Matrix Composites for Biomedical Applications: A Review. Adv. Eng. Mater. 2016, 18, 463-475. [CrossRef]

4. Abkowitz, S.; Rowell, D. Superior Fatigue Properties for Blended Elemental P/M Ti-6Al-4V. JOM 1986, 38, 36-39. [CrossRef]

5. Henriques, V.A.R.; Galvani, E.T.; Petroni, S.L.G.; Paula, M.S.M.; Lemos, T.G. Production of Ti-13Nb-13Zr alloy for surgical implants by powder metallurgy. J. Mater. Sci. 2010, 45, 5844-5850. [CrossRef]

6. Whittaker, P. Dynamet Technology Approved by Boeing as Qualified Supplier for Powder Metallurgy Titanium Alloy Products. Available online: http://www.pm-review.com/dynamet-technologyapproved-by-boeing-as-qualified-supplier-for-powder-metallurgy-titanium-alloy-products/ (accessed on 22 January 2017).

7. Qian, M. Cold compaction and sintering of titanium and its alloys for near-net-shape or preform fabrication. Int. J. Powder Metall. 2010, 46, 29-44.

8. Bolzoni, L.; Esteban, P.G.; Ruiz-Navas, E.M.; Gordo, E. Mechanical behaviour of pressed and sintered titanium alloys obtained from prealloyed and blended elemental powders. J. Mech. Behav. Biomed. Mater. 2012, 14, 29-38. [CrossRef] [PubMed]

9. Fujita, T.; Ogawa, A.; Ouchi, C.; Tajima, H. Microstructure and properties of titanium alloy produced in the newly developed blended elemental powder metallurgy process. Mater. Sci. Eng. A 1996, 213, 148-153. [CrossRef]

10. Yang, Y.F.; Luo, S.D.; Bettles, C.J.; Schaffer, G.B.; Qian, M. The effect of Si additions on the sintering and sintered microstructure and mechanical properties of Ti-3Ni alloy. Mater. Sci. Eng. A 2011, 528, 7381-7387. [CrossRef]

11. Yang, Y.F.; Luo, S.D.; Schaffer, G.B.; Qian, M. The Sintering, Sintered Microstructure and Mechanical Properties of Ti-Fe-Si Alloys. Metall. Mater. Trans. A 2012, 43, 4896-4906. [CrossRef] 
12. Xu, Q.; Gabbitas, B.; Matthews, S.; Zhang, D. The development of porous titanium products using slip casting. J. Mater. Process. Technol. 2013, 213, 1440-1446. [CrossRef]

13. Kroll, W. Malleable Alloys of Titanium. Z. Metall. 1937, 29, 189-192.

14. Qian, M.; Schaffer, G.B.; Bettles, C.J. Sintering of Titanium and its Alloys, in Sintering of Advanced Materials: Fundamentals and Processes; Fang, Z.Z., Ed.; Woodhead Publishing: Philadelphia, PA, USA, 2010; pp. 324-355.

15. Dean, R.S.; Wartman, F.S.; Hayes, E.T. Ductile Titanium-Its Fabrication and Physical Properties. Trans. Am. Inst. Mining Met. Eng. 1946, 166, 381-389.

16. Limberg, W.; Ebel, T.; Pyczak, F.; Schimansky, F.P. Influence of the sintering atmosphere on the tensile properties of MIM-processed Ti 45Al 5Nb 0.2B 0.2C. Mater. Sci. Eng. A 2012, 552, 323-329. [CrossRef]

17. Arensburger, D.S.; Pugin, V.S.; Fedorchenko, I.M. Properties of electrolytic and reduced titanium powders and sinterability of porous compacts from such powders. Sov. Powder Metall. Met. Ceram. 1968, 7, 362-367. [CrossRef]

18. Heaney, D.F.; German, R.M. Proceedings of PM 2004 Powder Metallurgy World Congress; European Powder Metallurgy Association: Vienna, Austria, 2004; pp. 222-227.

19. Kanto Yakin Kogyo Co. Available online: http://www.k-y-k.co.jp/en/product01.html (accessed on 22 January 2017).

20. Metal Powder Reports. Furnace Masters Difficult Metals. Met. Powder Rep. 2004, 59, 12.

21. Yu, C.; Cao, P.; Jones, M.I. Effect of Contaminants on Sintering of Ti and Ti-6Al-4V Alloy Powders in an Argon-Back-Filled Graphite Furnace. Key Eng. Mater. 2012, 520, 139-144. [CrossRef]

22. Yu, C.Z.; Jones, M.I. Investigation of chloride impurities in hydrogenated-dehydrogenated Kroll processed titanium powders. Powder Metall. 2013, 56, 304-309. [CrossRef]

23. German, R.M. Sintering Theory and Practice; Wiley: New York, NY, USA, 1996.

24. Hausner, H.H.; Smith, G.D.; Antes, H.W. Modern Development in Powder Metallurgy, Volume 13: Ferrous and Nonferrrous Materials; Metal Powder Industries Federation: Prinston, NJ, USA, 1981; pp. 537-549.

25. Lefebvre, L.P.; Baril, E. Effect of Oxygen Concentration and Distribution on the Compression Properties on Titanium Foams. Adv. Eng. Mater. 2008, 10, 868-876. [CrossRef]

26. Conrad, H. Effect of interstitial solutes on the strength and ductility of titanium. Prog. Mater Sci. 1981, 26, 123-403. [CrossRef]

27. Kusaka, K.; Kohno, T.; Kondo, T.; Horata, A. Tensile Behavior of Sintered Titanium by MIM Process. J. Jpn. Soc. Powder Powder Metall. 1995, 42, 383-387. [CrossRef]

28. Conrad, $\mathrm{H}$. The rate controlling mechanism during yielding and flow of $\alpha$-titanium at temperatures below 0.4 TM. Acta Metall. 1966, 14, 1631-1633. [CrossRef]

29. Okazaki, K.; Conrad, H. Effects of interstitial content and grain size on the strength of titanium at low temperatures. Acta Metall. 1973, 21, 1117-1129. [CrossRef]

30. Wang, H.; Fang, Z.Z.; Sun, P. A critical review of mechanical properties of powder metallurgy titanium. Int. J. Powder Metall. 2010, 46, 45-57.

(C) 2017 by the authors. Licensee MDPI, Basel, Switzerland. This article is an open access article distributed under the terms and conditions of the Creative Commons Attribution (CC BY) license (http:/ / creativecommons.org/licenses/by/4.0/). 
Article

Microstructural Evolution during Pressureless Sintering of Blended Elemental Ti-Al-V-Fe Titanium Alloys from Fine Hydrogenated-Dehydrogenated Titanium Powder

\author{
Changzhou Yu, Peng Cao * and Mark Ian Jones * \\ Department of Chemical and Materials Engineering, The University of Auckland, Private Bag 92019, \\ Auckland 1142, New Zealand; cyu060@aucklanduni.ac.nz \\ * Correspondences: p.cao@auckland.ac.nz (P.C.); mark.jones@auckland.ac.nz (M.I.J.); \\ Tel.: +64-9-9236924 (P.C.); +64-9-9234548 (M.I.J.)
}

Received: 10 June 2017; Accepted: 24 July 2017; Published: 26 July 2017

\begin{abstract}
A comprehensive study was conducted on microstructural evolution of sintered Ti-Al-V-Fe titanium alloys utilizing very fine hydrogenation-dehydrogenation (HDH) titanium powder with a median particle size of $8.84 \mu \mathrm{m}$. Both micropores (5-15 $\mu \mathrm{m})$ and macropores $(50-200 \mu \mathrm{m})$ were identified in sintered titanium alloys. Spherical micropores were observed in Ti-6Al-4V sintered with fine $\mathrm{Ti}$ at the lowest temperature of $1150^{\circ} \mathrm{C}$. The addition of iron can help reduce microporosity and improve microstructural and compositional homogenization. A theoretical calculation of evaporation based on the Miedema model and Langmuir equation indicates that the evaporation of aluminum could be responsible for the formation of the macropores. Although reasonable densification was achieved at low sintering temperatures (93-96\% relative density) the samples had poor mechanical properties due mainly to the presence of the macroporosity and the high inherent oxygen content in the as-received fine powders.
\end{abstract}

Keywords: titanium alloys; sintering; powder metallurgy; microstructural evolution

\title{
1. Introduction
}

Sintering is by far the most common consolidation method in titanium powder metallurgy. The initial stage of sintering can be empirically modeled in terms of isothermal neck growth as measured by the neck size ratio $X / D[1]$ :

$$
(X / D)^{n}=B t / D^{m}
$$

where $D$ is the particle diameter, $X=$ neck diameter, $t=$ isothermal sintering time, and $B$ is a collection of material and geometric constants. The values of $n, m, B$ depend on the mechanism of mass transport. The above empirical equation indicates that sintering is highly sensitive to the particle size, with a smaller particle size giving rise to more rapid densification.

The sintering data compiled by Robertson et al. confirms that a finer particle size is beneficial for titanium powder densification [2]. However titanium powders with very fine particle size are not usually available, particularly if a low impurity level is required. A particle size of -100 mesh $(<150 \mu \mathrm{m}),-200$ mesh $(<75 \mu \mathrm{m})$, or -325 mesh $(<45 \mu \mathrm{m})$, is most commonly used [3-5]. A recent study reports a novel technique to produce titanium powder with a mean particle size of $<10 \mu \mathrm{m}[6]$. However, the powder reported has a high impurity content of oxygen ( $>0.8 \mathrm{wt} \%)$ [6]. It is known that high oxygen content can adversely affect mechanical properties, especially ductility $[4,5,7]$, and therefore the aim of this research is primarily to investigate the feasibility of using a very fine titanium powder 
to sinter titanium products and investigate the effects of these fine powders on densification. Ti-6Al-4V is known as a "work-horse" $\alpha+\beta$ titanium alloy, which has high strength and good ductility. However, the $\beta$-stabilizing element vanadium is not only expensive but also toxic to human beings if used as an implant [8]. For blended elemental sintering of Ti-6Al-4V, better sinterability can be obtained using a master alloy powder (Al-V) than when using elemental aluminum and vanadium [9]. Our first objective of this work was to investigate the sinterability of Ti-6Al-4V by using fine titanium powder and $\mathrm{Al}-\mathrm{V}$ master alloy powder $(60 \mathrm{wt} \% \mathrm{Al}, 40 \mathrm{wt} \% \mathrm{~V})$.

Current titanium powder metallurgy research has been largely devoted to cost reduction in titanium components by both developing cost-effective powder manufacturing and developing low-cost titanium alloys [10-12]. In the development of low-cost titanium alloys, the introduction of iron $(\mathrm{Fe})$ as a $\beta$-Ti stabilizer into the alloy compositions has been widely explored for powder metallurgical titanium alloys [13,14].

Iron is much cheaper than titanium, and the application of $5 \% \mathrm{Fe}$ is equivalent to saving the use of $5 \% \mathrm{Ti}[15,16]$. The sinterability of titanium alloys can be enhanced by the addition of iron since the mobility of titanium atoms is accelerated by the rapid diffusion of iron $[13,17,18]$. The fast diffusion of iron in titanium alloy is evidenced by the fact that iron is essentially uniform in a blended elemental Ti-10V-2Fe-3Al alloy when heated at $5{ }^{\circ} \mathrm{C} / \mathrm{min}$ to $1200{ }^{\circ} \mathrm{C}$ [19]. Ti-10V-2Fe-3Al $(\mathrm{O} \leq 0.13 ; \mathrm{N} \leq 0.05$; $\mathrm{C} \leq 0.05 ; \mathrm{H} \leq 0.015$; all in wt \%), assigned formally as TIMETAL ${ }^{\circledR} 10-2-3$, has been realized for aircraft under-carriage applications [14,19]. Further experiments indicate that the enhancement in sinterability observed through the addition of fine iron powder (mean particle size $=8 \mu \mathrm{m}$ ) is not seen when working with coarser iron powder (mean particle size $=97 \mu \mathrm{m}$ ) [20].

Iron is a strong $\beta$ phase stabilizer and suppresses the formation of the $\alpha$ phase and the eutectoid transformation $\beta \rightarrow \alpha+$ TiFe when it cools below $595^{\circ} \mathrm{C}$, thus avoiding the formation of the brittle TiFe phase [21]. Such a phenomenon is also observed and validated by the recent research works conducted by Bolzoni et al. [11,12]. In addition to the fast diffusion mobility, iron additions also change the sequence of chemical homogenization for other alloying elements such as $\mathrm{Al}, \mathrm{V}$ [14]. In another study, Yang et al. found a linear drop in ductility in Ti-xFe-0.5Si alloys with increasing Fe content from $3 \%$ to $6 \%$. Such ductility drop is largely because the $\alpha$-Ti phase becomes thinner and more acicular with increasing Fe [22].

The second objective of this work was to investigate the sintering behavior of low-cost Ti-Al-V-Fe titanium alloys with fine particle titanium powders through varying the amount of expensive master $60 \mathrm{Al}-40 \mathrm{~V}$ powder and low-cost iron powder. The effect of the master alloy powder during sintering on sinterability is also discussed.

\section{Experimental Procedures}

\subsection{Materials}

The starting material for these experiments was a fine Ti powder produced from Ti sponge fines which were hydrogenated at $700{ }^{\circ} \mathrm{C}$ with a holding time of $2 \mathrm{~h}$ followed by $5 \mathrm{~h}$ ball milling. In this way, fine titanium hydride was produced with a median particle size $<3 \mu \mathrm{m}$. An inhibitor ( $\mathrm{NaCl}$ ) was introduced for the coating of titanium hydride powder, which was further dehydrogenated at $630{ }^{\circ} \mathrm{C}$ for $2 \mathrm{~h}$. The fine hydrogenation-dehydrogenation (HDH) titanium powders were water-leached by deionized water in order to remove the inhibitor. The median particle size was $<10 \mu \mathrm{m}$. More detailed description of the fine Ti production process can be seen in the literature [6].

The fine titanium powder (O: $0.82 \mathrm{wt} \%, \mathrm{C}: 0.058 \mathrm{wt} \%, \mathrm{H}: 0.414 \mathrm{wt} \%, \mathrm{~N}: 0.575 \mathrm{wt} \%$ ) was utilized to investigate the interaction effect of fine particle size and high impurity content on sintering and densification, with the understanding that the high impurity content of this powder may not result in outstanding mechanical properties. A commercially available $60 \mathrm{Al}-40 \mathrm{~V}$ master alloy powder (-120 mesh; O: $0.18 \mathrm{wt} \%$, C: $0.029 \mathrm{wt} \%, \mathrm{H}: 0.0005 \mathrm{wt} \%, \mathrm{~N}: 0.16 \mathrm{wt} \%)$ and iron powder (-300 mesh; O: $0.67 \mathrm{wt} \%$, C: $0.041 \mathrm{wt} \%, \mathrm{H}: 0.0022 \mathrm{wt} \%$, N: $0.262 \mathrm{wt} \%)$ supplied by Beijing Youxinglian Nonferrous 
Metals Co. Ltd., Beijing, China, was employed to balance the designed alloy composition into Ti $(0.6 \mathrm{Al}-0.4 \mathrm{~V})_{10-x} \mathrm{Fe}_{x}$, where $x=0,2,4$, and 6 . i.e., the Fe content ranged from 0 to $6 \mathrm{wt} \%$ as a replacement for the master alloy in a Ti-6Al-4V composition. The effect of beta stabilizing elements is generally quantified by an equivalent molybdenum (Mo), as given by:

$$
\begin{aligned}
(\mathrm{Mo})_{\mathrm{eq}}= & (\mathrm{Mo})+0.67(\mathrm{~V})+0.44(\mathrm{~W})+0.28(\mathrm{Nb})+0.22(\mathrm{Ta})+ \\
& 2.9(\mathrm{Fe})+1.6(\mathrm{Cr})+1.25(\mathrm{Ni})+1.7(\mathrm{Mn})+1.7(\mathrm{Co})-1.0(\mathrm{Al})
\end{aligned}
$$

The calculated equivalent Mo values for the Ti-4.8Al-3.2V-2Fe, Ti-3.6Al-2.4V-4Fe, and Ti-2.4Al-1.6V-6Fe are 3.1, 9.6, and 16 respectively. As such the Ti-4.8Al-3.2V-2Fe and Ti-3.6Al-2.4V-4Fe can be regarded $\alpha / \beta$ alloys while the Ti-2.4Al-1.6V-6Fe is a metastable $\beta$ alloy.

\subsection{Press-and-Sinter}

Compacts were uniaxially pressed at a constant pressure of $300 \mathrm{MPa}$ into two different cylindrical sizes: $16 \mathrm{~mm}$ diameter with 5-6 $\mathrm{mm}$ thickness, and $45 \mathrm{~mm}$ diameter with 3-4 mm thickness. No lubricants were added in the powder mixture, or applied on the die walls. The green density for all four alloys was $62.9 \pm 0.5 \%$. Compacts with dia $=16 \mathrm{~mm}$ were used for sintering densification calculations and the dia $=45 \mathrm{~mm}$ samples were sintered for tensile testing. Vacuum sintering (vacuum level: $2 \times 10^{-3} \mathrm{~Pa}$ ) was conducted in a high-temperature Mo-heating-element furnace (Dingli, Changsha, China) at 1150,1250 , and $1350{ }^{\circ} \mathrm{C}$ with a soaking time of $3 \mathrm{~h}$. The racking material was molybdenum plate. The specific heating profile is demonstrated in Figure 1.

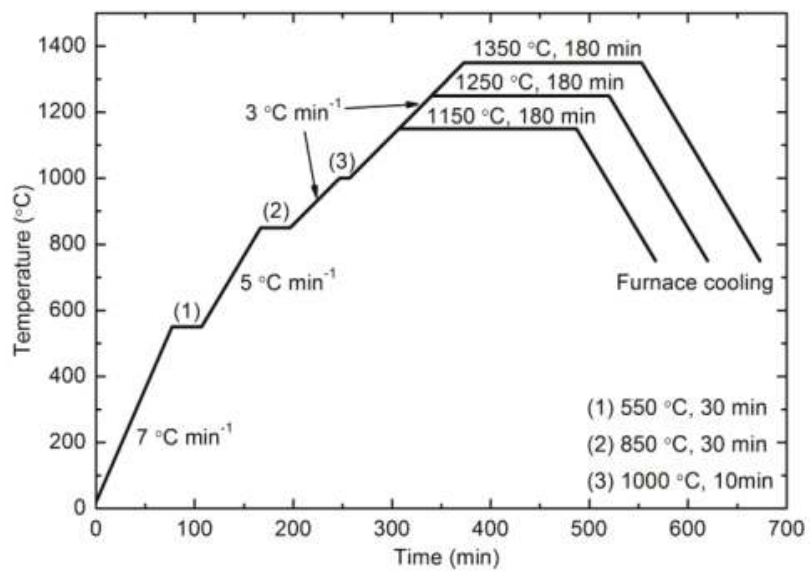

Figure 1. Heating schedule for blended elemental sintered titanium alloys.

The initial heating rate was set at $7^{\circ} \mathrm{C} \cdot \mathrm{min}^{-1}$ from room temperature to $550{ }^{\circ} \mathrm{C}$. A holding time of $30 \mathrm{~min}$ was introduced at both 550 and $850{ }^{\circ} \mathrm{C}$ and a 10 -min holding time at $1000{ }^{\circ} \mathrm{C}$ were used to prevent the possible pore formation caused by the exothermal reaction between titanium and the master alloy or iron powder, and to allow sufficient time for homogeneous elemental diffusion [23]. A slower heating rate of $3-5{ }^{\circ} \mathrm{C} \cdot \mathrm{min}^{-1}$ was employed from $1000{ }^{\circ} \mathrm{C}$ to the final sintering temperature for the same reason.

\subsection{Characterization and Mechanical Testing}

The particle size distribution was analyzed by a particle size analyzer (Mastersizer 2000, Malvern Instruments, Malvern, UK). The sintered density was measured according to the Archimedes method described in ASTM B962-08. Each data point was averaged from 3-5 specimens. Fine polishing was 
conducted with OP-S, a colloidal silica suspension with $10 \%$ hydrogen peroxide $\left(\mathrm{H}_{2} \mathrm{O}_{2}\right)$, where the size of the colloidal silica is $\sim 40 \mathrm{~nm}$. Microstructural morphology observations were conducted on an environmental scanning electron microscope (ESEM) (Quanta 200F, FEI, Hillsboro, OR, USA) using both back-scattered and secondary electron modes. Semi-quantitative compositional analysis was carried out by energy dispersive spectrometry (EDS, Pegasus detector, EDAX Inc., Mahwah, NJ, USA). Both elemental X-ray mapping and X-ray line scans were carried out using standardless quantification techniques. An accelerating voltage of $20 \mathrm{kV}$ was employed. X-ray diffraction (XRD) analysis to determine phase constituents was carried out on a D2 PHASER (Bruker, Karlsruhe, Germany) equipped with $\mathrm{Cu}$ X-ray source. X-ray patterns were collected over a scan range from $2 \theta$ of $20-80^{\circ}$ with a step size of $0.02^{\circ}$.

Tensile specimens were machined from the sintered specimens in compliance with ISO 2892-1:2009 $(\sim 2.65 \mathrm{~mm} \times 2.65 \mathrm{~mm}$ cross-section, $15 \mathrm{~mm}$ gauge length and $20 \mathrm{~mm}$ parallel length), and tested on an Instron mechanical tester (Model: 3367, Instron Co., Norwood, MA, USA) with a crosshead speed of $0.1 \mathrm{~mm} \cdot \mathrm{min}^{-1}$ (initial strain rate: $1.1 \times 10^{-4} \mathrm{~s}^{-1}$ ). The precise displacement was determined using an extensometer with a gauge length of $8 \mathrm{~mm}$ (Model: 2630-120, Instron Co., Norwood, MA, USA). Three tensile specimens were prepared for each data point.

\section{Results}

\subsection{Characteristics of As-Received Powders}

The micrographs of as-received powders are shown in Figure 2 including fine titanium, iron and $60 \mathrm{Al}-40 \mathrm{~V}$ master alloy powder as well as the particle size distribution of fine titanium and $60 \mathrm{Al}-40 \mathrm{~V}$ powders.
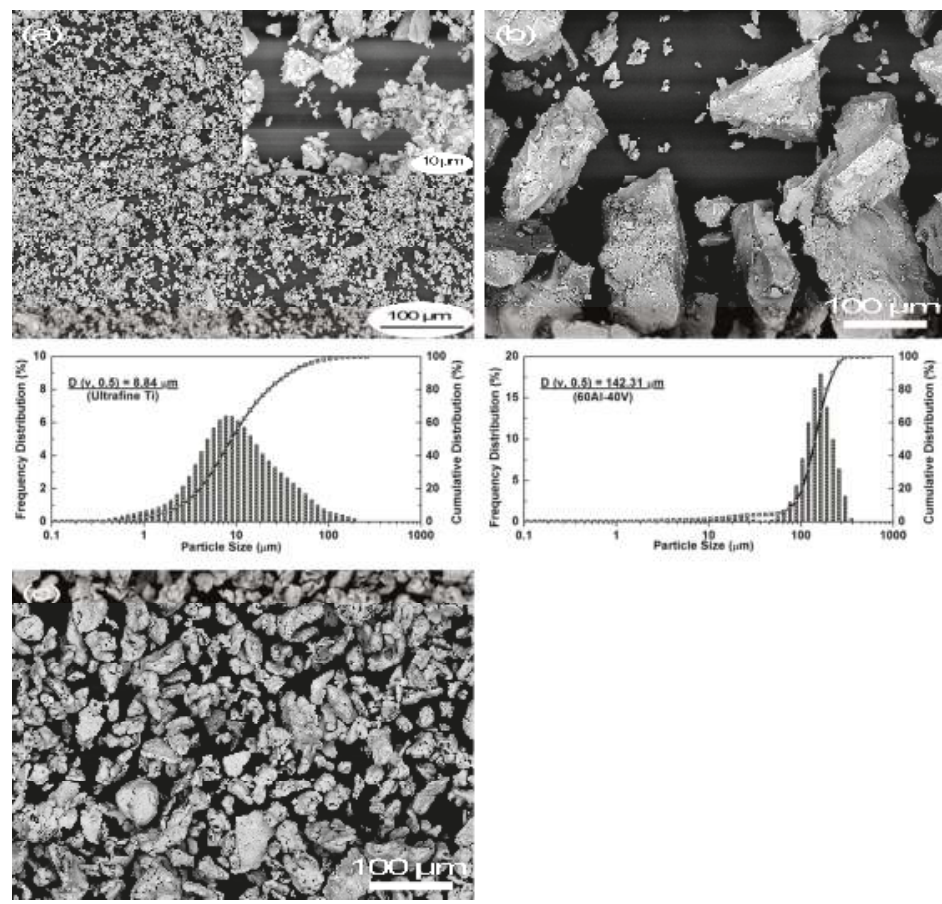

Figure 2. Scanning electron microscope (SEM) images and particle size distribution of (a) fine Ti, (b) 60Al-40V master alloy and (c) Fe powders. 
All three powders show angular morphologies, with Figure 2a demonstrating that the fine Ti had a much finer particle size than the 60Al-40V (Figure 2b) and iron (Figure 2c) powders. This was validated by particle size distribution analysis, which illustrates the median particle sizes of fine Ti and master powder were 8.84 and $142.31 \mu \mathrm{m}$, respectively. The diameter of most iron particles was less than $50 \mu \mathrm{m}$ estimated from Figure 2c, which is in accordance with its nominal particle size ( -300 mesh). XRD patterns of each powder are given in Figure 3.

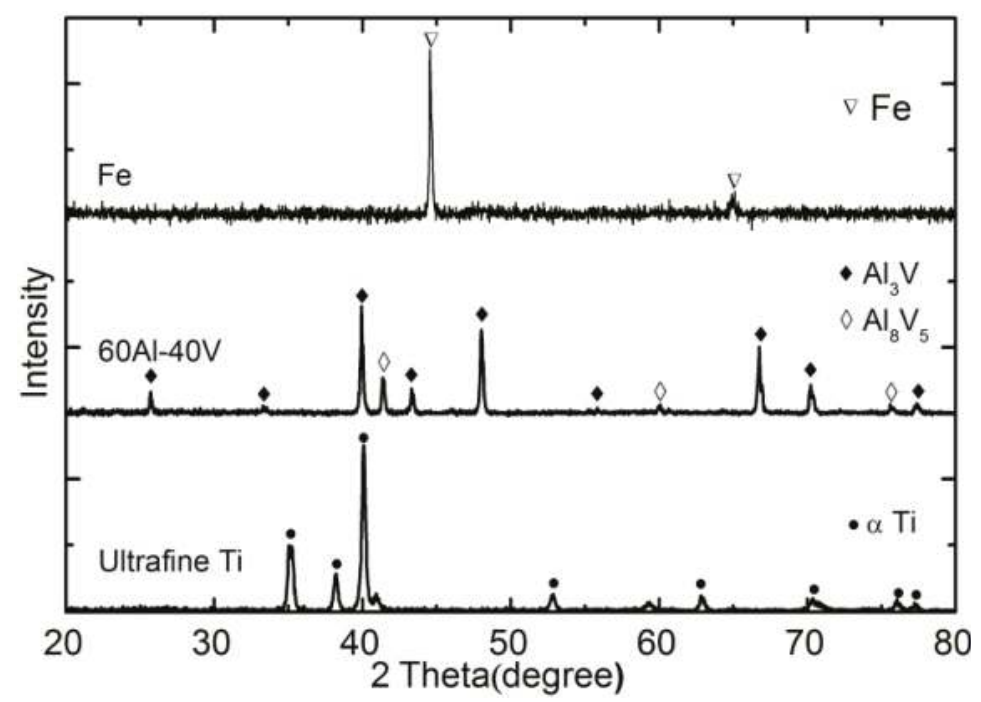

Figure 3. X-ray diffraction (XRD) patterns of as-received powders.

The pattern from the reduced elemental iron powder is indexed as pure iron by JCPDS 87-0721 [24]. The master alloy powder $(60 \mathrm{Al}-40 \mathrm{~V})$ is mainly ascribed to $\mathrm{Al}_{3} \mathrm{~V}$ (JCPDS 07-0399) with a small amount of $\mathrm{Al}_{8} \mathrm{~V}_{5}$ (JCPDS 71-0141) [25]. The fine Ti is mainly composed of $\alpha$-Ti referenced by JCPDS 44-1294 and some minor titanium oxides.

\subsection{Densification}

The effect of iron content on the relative sintered density and densification level is illustrated in Figure 4 for specimens uniaxially pressed at a constant compaction pressure of $300 \mathrm{MPa}$ and sintered at different temperatures.

The relative density increases with iron content at sintering temperatures of 1150 and $1250{ }^{\circ} \mathrm{C}$ (Figure 4a). However at a sintering temperature of $1350^{\circ} \mathrm{C}$ the iron content seems to have little effect on the relative sintered density. As expected, a higher sintering temperature causes an increased sintered density and this effect was more pronounced for the Ti-6Al-4V than for the specimens with Fe. The densification level offers an evaluation method for porosity elimination level of green compacts by sintering. Figure $4 \mathrm{~b}$ demonstrates that specimens with $6 \% \mathrm{Fe}$ sintered at $1350{ }^{\circ} \mathrm{C}$ have the highest densification level, where $\sim 90 \%$ of the porosity of the original green compacts has been eliminated by sintering. The lowest densification level is observed in the Ti-6Al-4V specimens sintered at $1150{ }^{\circ} \mathrm{C}$, where $\sim 20 \%$ of the original porosity of the green compacts remains after sintering. 

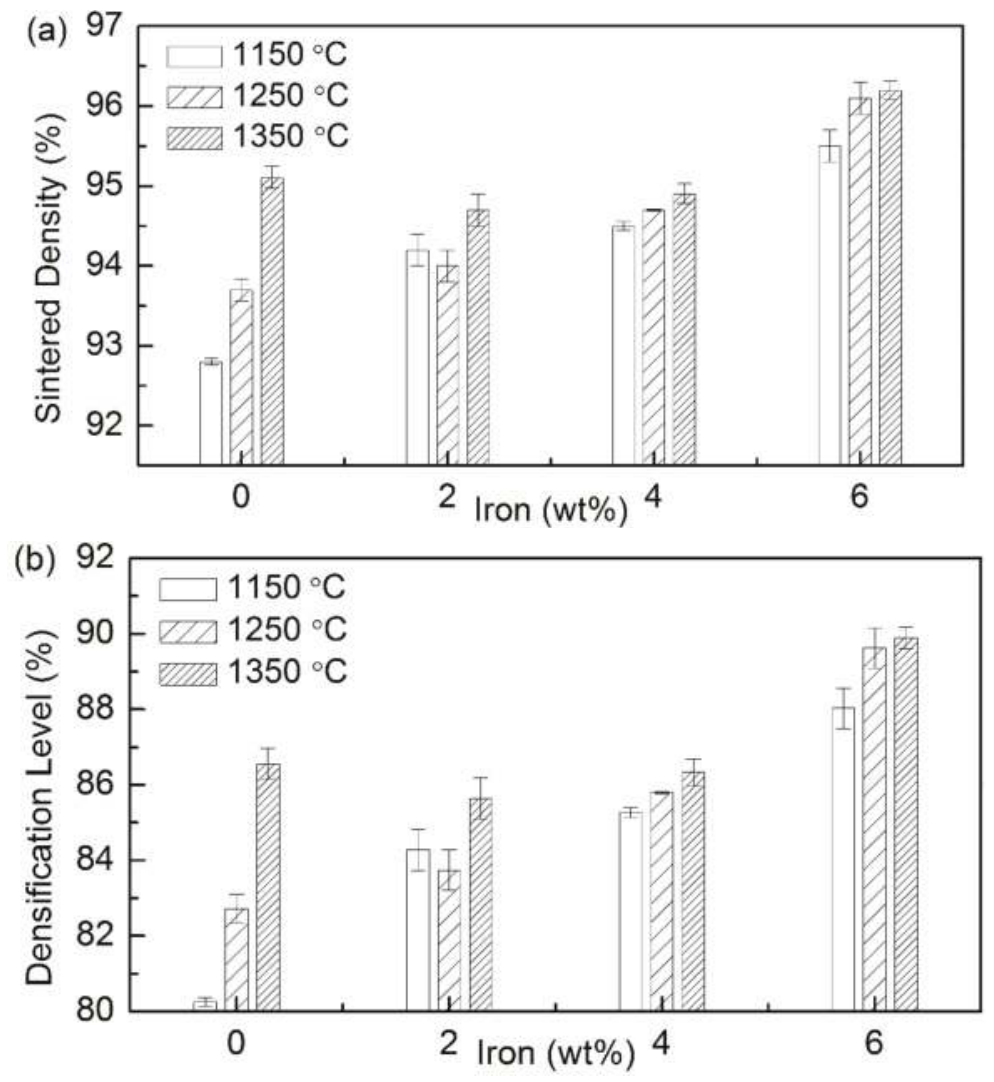

Figure 4. Relative density (a) and densification level (b) as a function of iron content for samples sintered at different temperatures.

\subsection{Microstructure Observation and Compositional Analysis}

Microstructural images taken from cross-sections of the specimens sintered at various temperatures and compositions are shown in Figure 5, and confirm the density measurements.

When sintered at temperatures of 1150 and $1250^{\circ} \mathrm{C}$, the porosity decreased with increasing $\mathrm{Fe}$ content. At the highest temperature $\left(1350^{\circ} \mathrm{C}\right)$ the relative sintered density of the sample with $2 \mathrm{wt} \%$ Fe has the lowest density and the microstructure shows the highest porosity seen in Figure 5(b3). In comparison, the least porosity is observed in the cross-section of the specimen with $6 \%$ Fe shown in Figure 5(d3) which has the highest relative sintered density.

Two different types of pores are also observed in Figure 5 in regard to the pore size and shape. Irregular-shaped macropores with an average size of 50-200 $\mu \mathrm{m}$ are noted in all specimens under different sintering temperatures and compositions. The amount of these macropores decreased with the addition of iron content when sintered at either 1150 or $1250{ }^{\circ} \mathrm{C}$. At $1350^{\circ} \mathrm{C}$, a large quantity of irregular-shaped macropores is observed in specimens with $2 \mathrm{wt} \% \mathrm{Fe}$. The other type of pores observed is spherical with an average diameter of 5-15 $\mu \mathrm{m}$. A large number of these micropores are distributed throughout the cross-section of the $1150{ }^{\circ} \mathrm{C}$ sintered Ti-6Al-4V, and decreases with increasing sintering temperature. Interestingly, there are only very few micropores observed on the cross-sections of sintered alloys containing iron although their diameter is slightly larger than those in Ti-6Al-4V. 


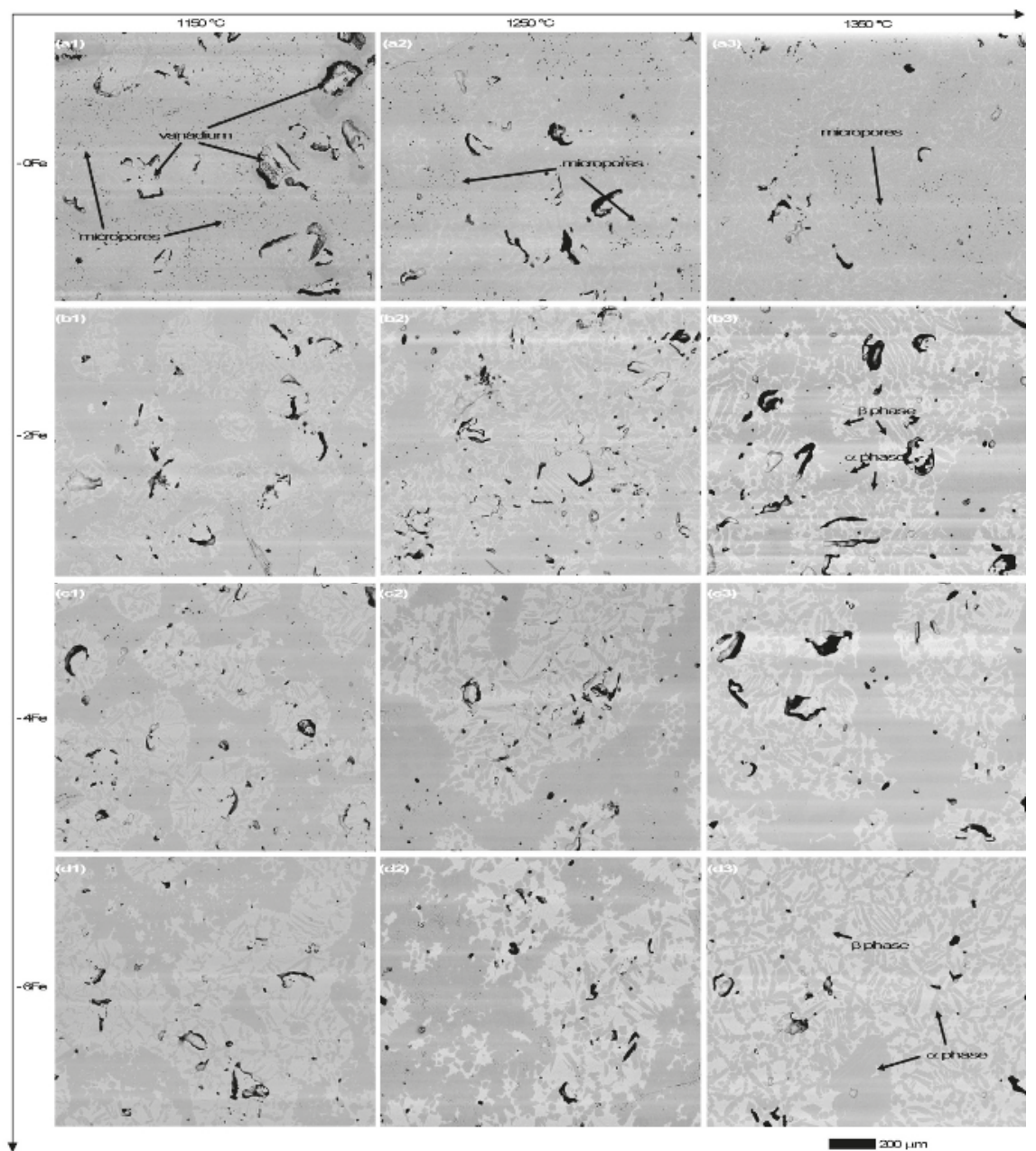

Figure 5. Cross-sectional SEM images of sintered titanium alloys at various temperatures and compositions. The horizontal axis represents the sintering temperature, while the vertical axis represents the iron content.

As also shown in Figure 5, the microstructures show two distinct regions or phases which appear as light and dark contrast in the SEM micrographs, with an increase in the light phase observed with increasing Fe content. It is also observed that the darker contrast regions appear to be in two different morphologies, with smaller needle-like or acicular grains and some much larger particles or grains. In order to further understand these microstructures, compositional analysis was conducted on Ti-6Al-4V sintered at 1150 and $1250^{\circ} \mathrm{C}$ including EDS line scanning (Figure 6) and EDS mapping (Figure 7). 

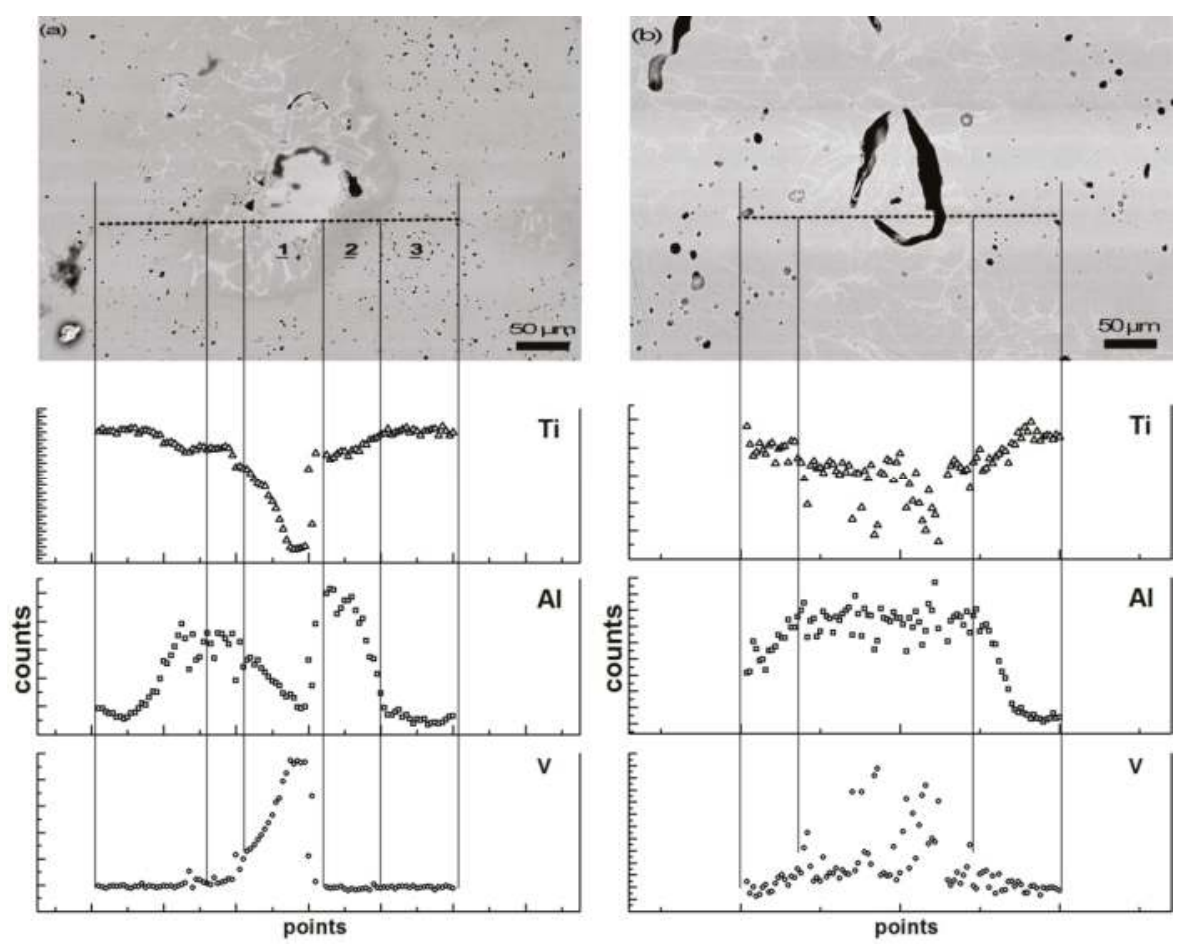

Figure 6. Energy dispersive spectrometry (EDS) line scanning of blended elemental Ti-6Al-4V specimens sintered at (a) $1150{ }^{\circ} \mathrm{C}$ and (b) $1250^{\circ} \mathrm{C}$.
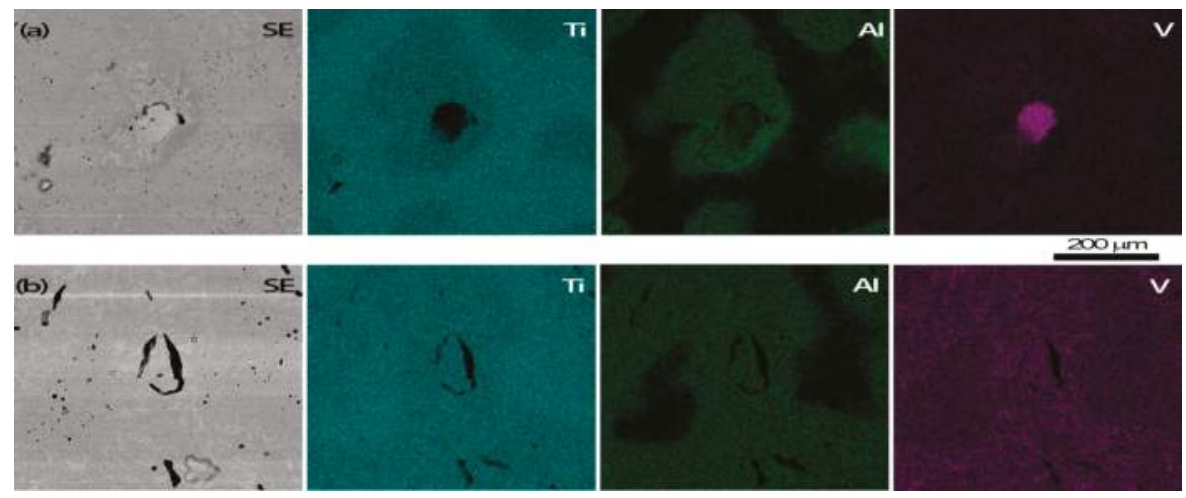

Figure 7. EDS mapping of blended elemental Ti-6Al-4V specimens sintered at (a) $1150{ }^{\circ} \mathrm{C}$ and (b) $1250{ }^{\circ} \mathrm{C}$.

The image in Figure 6 shows a line scan across the area containing the macropores typically seen in the cross-section of Ti-6Al-4V (Figure 5).

For the sample sintered at $1150{ }^{\circ} \mathrm{C}$, the line scan (Figure 6a) is classified into three different regions depending on the color contrast. The light contrast regions (particularly the particle at the center of the pore) are rich in vanadium and contain no $\mathrm{Al}$ or Ti. The darkest contrast region around the pore contains both $\mathrm{Al}$ and Ti but no $\mathrm{V}$. Moving away from the pore into the mid-contrast, matrix region 
there is an increase in the Ti content and a corresponding decrease in Al. The sample sintered at the higher temperature (Figure $6 \mathrm{~b}$ ) shows a much more homogenous distribution of all three elements although vanadium is slightly elevated in the lighter contrast regions.

EDS mapping was also carried out on the same sample to investigate the element distribution as highlighted in Figure 7.

The mapping results are in agreement with the line scanning observation in Figure 6. Figure 7a shows that region 1 is noticeably rich in vanadium whereas region 2 is rich in aluminum. Also, the intensity of titanium decreases gradually from region 3 to region 1 for specimens sintered at $1150{ }^{\circ} \mathrm{C}$. At the higher sintering temperature (Figure $7 \mathrm{~b}$ ), the diffusion area of aluminum became distinctly wider and titanium achieved a more homogeneous elemental distribution when compared with sintering at $1150{ }^{\circ} \mathrm{C}$. A remarkable difference was also witnessed for vanadium, which was no longer isolated in discrete particles but was much more homogeneously distributed. EDS line scanning and mapping of specimens with $4 \mathrm{wt} \%$ iron are highlighted in Figure 8 when sintering at the highest temperature $\left(1350^{\circ} \mathrm{C}\right)$.
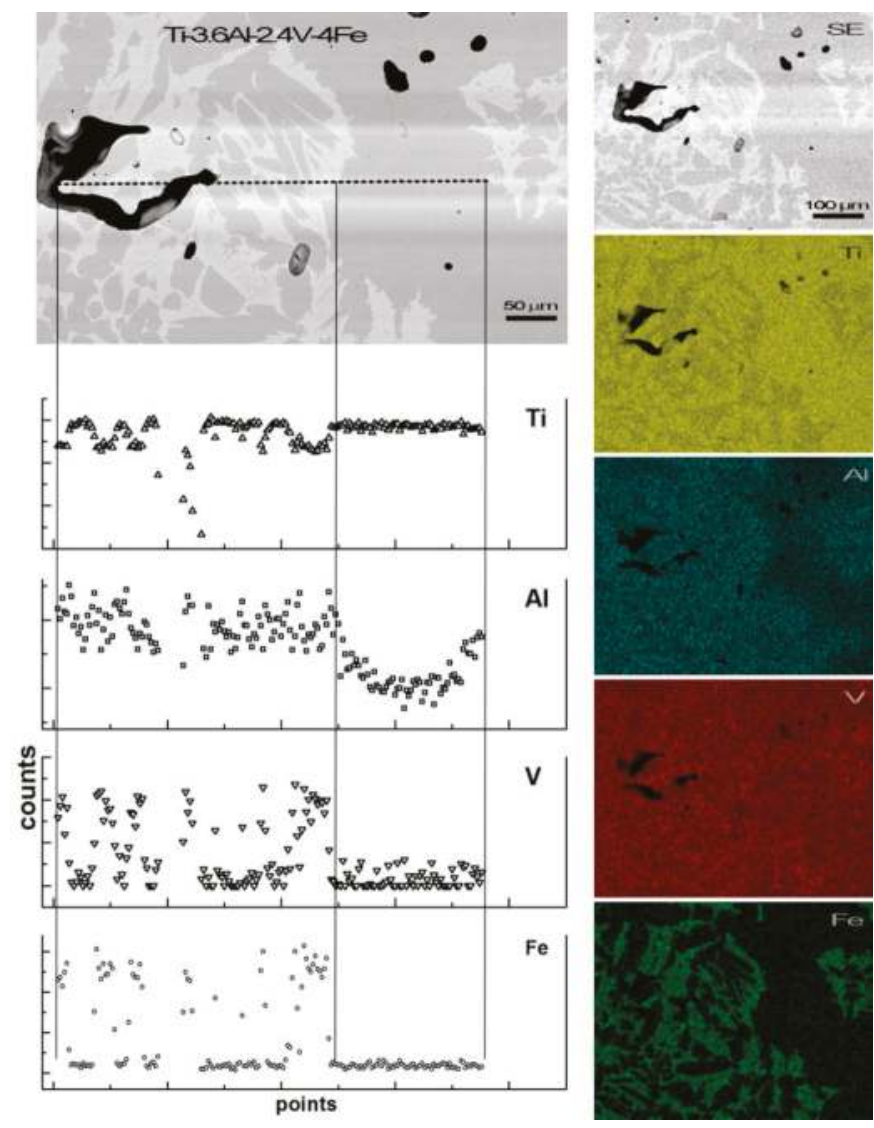

Figure 8. EDS mapping (right column) and EDS line scanning (left column) of Ti-3.6Al-2.4V-4Fe sintered at $1350{ }^{\circ} \mathrm{C}$.

In Figure 8, inhomogeneous microstructural zones can also be distinguished by dark and light contrast regions. It is observed from the corresponding EDS line scanning and mapping that iron is 
rich in grains within the light region and is absent in the darker regions. The intensity of aluminum in the blocky darker regions is slightly weaker than those in the lighter contrast areas while the Ti concentration shows the opposite trend, being lower in the lighter regions than in the darker grains. Comparing sintering at the highest temperature (Figure 8 ) to lower temperatures shown in Figures 6 and 7, improved elemental distribution homogeneity is observed. For example, the contrast of aluminum shown by EDS mapping in Figure 8 is not as strong as shown in Figure 7.

\subsection{Phase Determination}

The phase analysis of sintered titanium alloys is demonstrated in Figure 9, including the XRD patterns of Ti-6Al-4V sintered under different sintering temperatures (Figure 9a) and the Ti-Al-V-Fe alloys sintered under a constant temperature of $1350^{\circ} \mathrm{C}$ (Figure $9 \mathrm{~b}$ ).
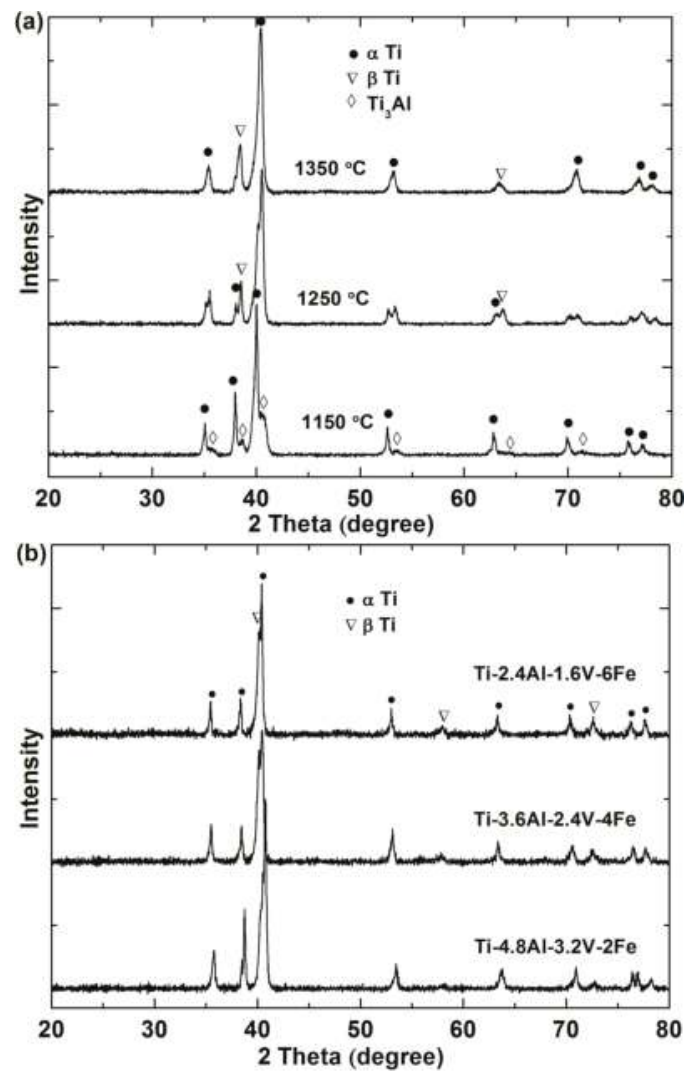

Figure 9. XRD patterns of (a) Ti-6Al-4V sintered at various temperatures and (b) Ti-Al-V-Fe of various Fe concentrations sintered at $1350{ }^{\circ} \mathrm{C}$.

The XRD patterns of specimens sintered at $1150{ }^{\circ} \mathrm{C}$ (Figure 9a), show that the samples consisted of $\alpha-, \beta$-Ti with some $\mathrm{Ti}_{3} \mathrm{Al}$ peaks [26]. The presence of the $\mathrm{Ti}_{3} \mathrm{Al}$ phase when sintered at lower temperatures is indicative of the alloying process being incomplete at these temperatures and supports the microstructural observations. In Figure $9 b$, peaks attributed to the $\beta$-Ti phase are observed for the sintered Ti-Al-V-Fe alloys, as suggested by the literature $[19,21]$, and their intensity increases with increasing iron content in the alloy composition, This indicates that iron stabilizes the $\beta$ phase in 
titanium alloys and more $\beta$ can be retained after cooling from the sintering temperature if the iron content is increased.

\section{Discussion}

\subsection{Microporosity Formation}

Two different types of pores were formed during sintering, which are defined here as micropores $(5-15 \mu \mathrm{m})$ and macropores $(50-200 \mu \mathrm{m})$ as shown in Figure 5. The micropores observed in Figure 5 were spherical and isolated in sintered specimens especially in Ti-6Al-4V even at the lowest sintering temperature $\left(1150{ }^{\circ} \mathrm{C}\right)$. Pore spheroidization indicates that sintering had entered into the final stage at this temperature $\left(1150{ }^{\circ} \mathrm{C}\right)$. Although the green density was only about $63 \%$ for all of these samples, the sintered density at this lowest temperature was around $93 \%$ for the Ti-6Al-4V specimen and increased with increasing iron content up to around $96 \%$. It is considered that the reasonably high levels of densification even at low temperatures and for samples with low green density, as evidenced by the densification results and the presence of isolated small pores, is due mainly to the high sintering driving force resulting from the high surface free energy when using the fine titanium powder, and improved diffusion with the additions of iron.

The evolution of the microporosity for samples with different iron contents as a function of temperature can be seen in the SEM fractographs shown in Figure 10.

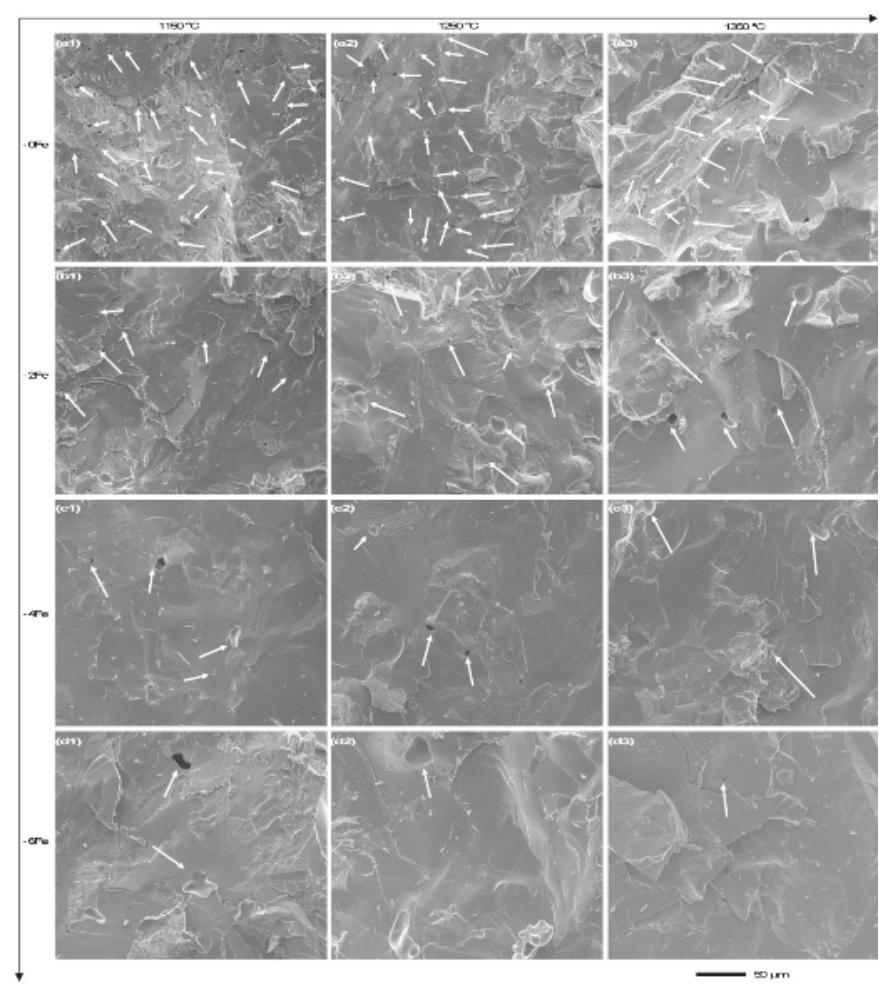

Figure 10. SEM fractographs with micropores of tensile specimens sintered at various temperatures and compositions. 
The micropores shown in Figure 10 are in accordance with the observations made from Figure 5, whereby the Ti-6Al-4V specimens show the largest number of micropores (diameter $<10 \mu \mathrm{m}$ ). Although the amount of microporosity in these samples decreased with sintering temperature, the amount of micropores in the Ti-6Al-4V at any temperature was higher than the titanium alloy specimens containing iron. For the Fe containing samples, the microporisity decreased with increasing iron content. This indicates that the addition of iron is beneficial to elimination of micropores; in other words iron assists in densification during sintering.

The diffusion coefficient of elements follows an Arrhenius relationship:

$$
D=D_{0} \exp (-Q / R T)
$$

where $D_{0}$ is the pre-exponential factor $\left(\mathrm{m}^{2} \cdot \mathrm{s}^{-1}\right), Q$ the activation energy $\left(\mathrm{kJ} \cdot \mathrm{mol}^{-1}\right), R$ the molar gas constant, and $T$ the absolute temperature $(\mathrm{K})$. These parameters can be obtained for both the self-diffusion of $\beta$-Ti and the inter-diffusion of $\mathrm{Al}, \mathrm{V}$, and $\mathrm{Fe}$ in $\beta$-Ti [27] as shown in Table 1.

Table 1. Self-diffusion of $\beta$-Ti and inter-diffusion of $\mathrm{Al}, \mathrm{V}$, and $\mathrm{Fe}$ in $\beta$-Ti [27].

\begin{tabular}{|c|c|c|c|c|}
\hline Specimen & Diffusion Type & Temperature $\left({ }^{\circ} \mathrm{C}\right)$ & $D_{0}\left(m^{2} \cdot s^{-1}\right)$ & $\mathrm{Q}\left(\mathrm{kJ} \cdot \mathrm{mol}^{-1}\right)$ \\
\hline$\beta-\mathrm{Ti}$ & Self diffusion & $899-1540$ & $3.58 \times 10^{-8}$ & 130.6 \\
\hline $\mathrm{Al}$ in $\beta-\mathrm{Ti}$ & Inter-diffusion & $920-1600$ & $1.14 \times 10^{-5}$ & 213.1 \\
\hline $\mathrm{V}$ in $\beta-\mathrm{Ti}$ & Inter-diffusion & $902-1543$ & $3.1 \times 10^{-8}$ & 134.8 \\
\hline $\mathrm{Fe}$ in $\beta-\mathrm{Ti}$ & Inter-diffusion & $969-1645$ & $7.8 \times 10^{-7}$ & 132.3 \\
\hline
\end{tabular}

Diffusion coefficients were calculated using the data presented in Table 1 and the ratio of inter-diffusion of the different elements to the self-diffusion in Ti are presented in Figure 11 over the temperature range of $1000-1400{ }^{\circ} \mathrm{C}$.

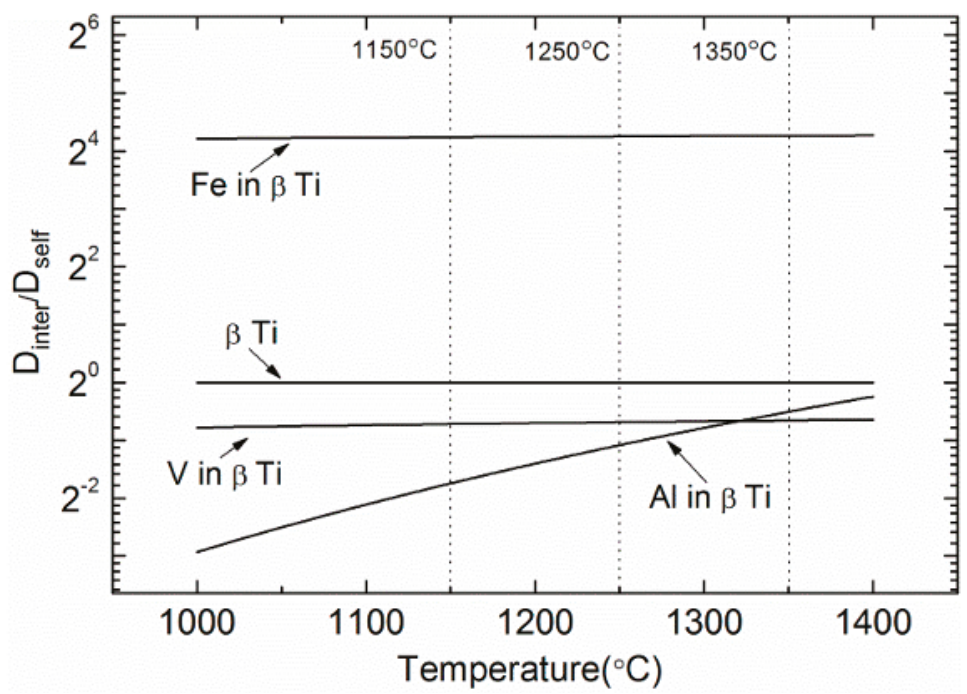

Figure 11. Temperature dependence of ratio of inter-diffusion coefficients to self-diffusion coefficient of $\beta$-Ti.

The inter-diffusion coefficient of Fe in $\beta$-Ti is over 16 times higher than the self-diffusion coefficient $(\beta-\mathrm{Ti})$ and is also much higher than the inter-diffusion coefficients of $\mathrm{Al}$ and $\mathrm{V}$ in $\mathrm{Ti}$ (both $<1)$. This indicates that iron is a fast diffuser in $\beta$-Ti, and empirical rules of diffusion suggest that the addition of 
fast diffusers can enhance self-diffusion rates of both the solute and solvent atoms [28]. Additions of a fast diffuser such as iron can therefore enhance the densification of titanium during sintering.

\subsection{Macroporosity Formation}

A fractograph of the Ti- $6 \mathrm{Al}-4 \mathrm{~V}$ sample sintered at $1150{ }^{\circ} \mathrm{C}$ is presented in Figure 12 as well as corresponding compositional analyses. Two macropores $\sim 100 \mu \mathrm{m}$ in diameter are observed in Figure 12, and material with a "coral-like" structure was observed inside the pores. Compositional analysis was conducted on the coral-like material (plot 1) and the more dense surrounding area (plot 2). The EDS spectra and analysis show that the coral-like material was predominantly vanadium $(88.78 \mathrm{wt} \%)$ whilst the surrounding area was composed of titanium (93.82 wt \%) and a small amount of aluminum ( $3.55 \mathrm{wt} \%)$ but no vanadium. The presence of vanadium-rich "coral-like" material with a smooth cellular wall is considered to be correlated with the evaporation of aluminum according to the following analysis.

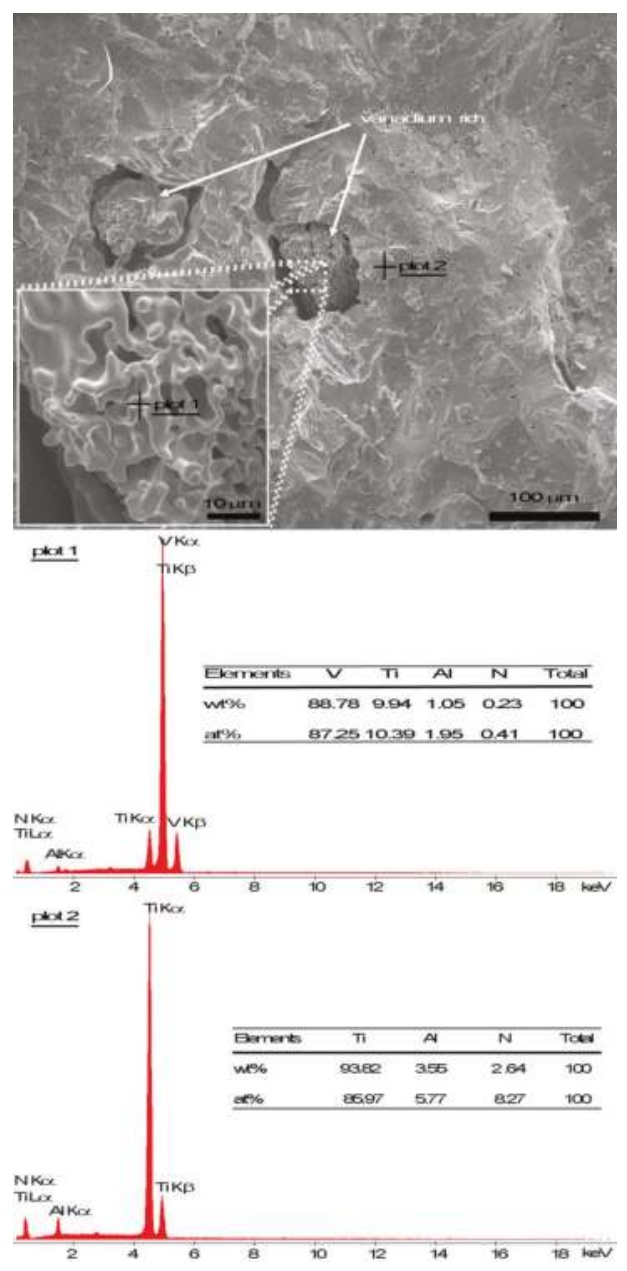

Figure 12. Macropores shown in fracture surface of Ti-6Al-4V specimens sintered at $1150{ }^{\circ} \mathrm{C}$. 
Theoretical calculation of the evaporation of binary alloys can be determined based on the Miedema model and Langmuir equation [23,29,30]. For instance, Guo and co-workers calculated the theoretical elemental evaporation of a Ti-Al melt during casting with this model, which had reasonable agreement with the experimental data [29,30]. Chen et al. [23] and $\mathrm{Xu}$ et al. [31] also utilized this model to calculate the evaporation of PM fabricated Fe-Al and Fe-Mn alloys in good accordance with experimental observations.

The evaporation loss rate $\left(N_{m, A}\right)$ of the component $A$ in a binary $A-B$ alloy system is demonstrated by the Langmuir theory $[29,32]$ :

$$
N_{m, A}=\mathrm{K}_{\mathrm{L}} \times \varepsilon \times\left(P_{A}^{e}-P^{g}{ }_{A}\right) \times \sqrt{M_{A} / T}
$$

The Langmuir constant $\left(\mathrm{K}_{\mathrm{L}}\right)$ is equal to $4.37 \times 10^{-4}$ when the partial pressure is described in Pascal $[29,30] . \varepsilon$ is the condensation constant (for metals $=1$ ) $[29,30] . P_{A}^{e}$ indicates the saturated vapor partial pressure of element $A$ in the system and $P^{g} A$ is the partial pressure of the component. Since the specimens were sintered under high vacuum and the volatiles are reactive with titanium substrate, it is proposed that $P_{A}^{g}$ can be considered to be zero. $M_{A}$ and $T$ are the component's atomic mass and absolute temperature respectively.

The saturated vapor partial pressure $P_{A}^{e}$ can be defined by:

$$
P_{A}^{e}=\chi_{A} \times \gamma_{A} \times P_{A}^{0}
$$

where $\chi_{A}$ and $\gamma_{A}$ indicate the molar fractions and activity coefficient of component $A$ in the binary system. The equilibrium pressure of pure component $A, P_{A}^{0}$ can be calculated for $\mathrm{Al}$ and $\mathrm{V}$ elements by the following formula [33]:

$$
\begin{aligned}
\log _{10} P_{\mathrm{Al}}^{0} & =14.465-17342 T^{-1}-0.7927 \log _{10} T \\
\log _{10} P_{\mathrm{V}}^{0} & =14.75-27132 T^{-1}-0.5501 \log _{10} T
\end{aligned}
$$

The activity coefficient of component $A\left(\gamma_{A}\right)$ in a binary system is given by [34]:

$$
\ln \gamma_{A}=\frac{\Omega}{R T}\left(1-\chi_{A}\right)^{2}
$$

where $R$ is the ideal gas constant and $\Omega$ is an interaction parameter which can be obtained by calculating the molar enthalpy of mixing $\left(\Delta H_{m i x}\right)$ for the binary system [34]:

$$
\Delta H_{\text {mix }}=\Omega \times \chi_{A} \times \chi_{B}
$$

where $\chi_{A}$ and $\chi_{B}$ are the molar fractions of component $A$ and $B$ respectively.

Substituting Equation (9) into Equation (8), gives:

$$
\begin{aligned}
\ln \gamma_{B} & =\frac{\chi_{A}}{\mathrm{RT} \chi_{B}} \Delta H_{\text {mix }} \\
\ln \gamma_{A} & =\frac{\chi_{B}}{\mathrm{RT} \chi_{A}} \Delta H_{\text {mix }}
\end{aligned}
$$

Thus, the theoretical evaporation loss rate is dependent on the molar enthalpy of mixing $\left(\Delta H_{m i x}\right)$, which can be determined using the model of Miedema [35]:

$$
\Delta H_{m i x}=\frac{2 \mathrm{P} f\left(c^{s}\right)\left(\chi_{A} \mathrm{~V}_{A}^{2 / 3}+\chi_{B} \mathrm{~V}_{B}^{2 / 3}\right)}{\left(\mathrm{n}_{\mathrm{ws}}^{\mathrm{A}}\right)^{-1 / 3}+\left(\mathrm{n}_{\mathrm{ws}}^{\mathrm{B}}\right)^{-1 / 3}} \times\left[-\left(\varphi_{A}-\varphi_{B}\right)^{2}+\frac{\mathrm{Q}}{\mathrm{P}}\left(\mathrm{n}_{\mathrm{ws}}^{A}{ }^{1 / 3}-\mathrm{n}_{\mathrm{ws}}^{B}{ }^{1 / 3}\right)^{2}-\mathrm{R} / \mathrm{P}\right]
$$


where $f\left(c^{s}\right)$ is given by:

$$
f\left(c^{s}\right)=f\left(\chi_{A}^{s} \chi_{B}^{s}\right)=\chi_{A} \chi_{B} \mathrm{~V}_{A}^{2 / 3} \mathrm{~V}_{B}^{2 / 3} /\left(\chi_{A} \mathrm{~V}_{A}^{2 / 3}+\chi_{B} \mathrm{~V}_{B}^{2 / 3}\right)^{2}
$$

$\mathrm{V}_{A}^{2 / 3}, \mathrm{~V}_{B}^{2 / 3}, \mathrm{n}_{\mathrm{ws}}^{A}{ }^{1 / 3}, \mathrm{n}_{\mathrm{ws}}^{B}{ }^{1 / 3}, \mathrm{Q}, \mathrm{P}, \mathrm{R}, \varphi_{A}$, and $\varphi_{B}$ are all constants and are available in the literature [35]. Once the molar enthalpy of mixing is determined, the activity coefficients of $\mathrm{Al}$ and $\mathrm{V}$ can be calculated from Equations (10) and (11) and combined with the equilibrium pressure (Equations (6) and (7)) to give the saturated vapor pressure (Equation (5)) and ultimately the evaporation rate (Equation (4)).

The weight ratio of $\mathrm{Al}$ to $\mathrm{V}$ in the $60 \mathrm{wt} \% \mathrm{Al}-40 \mathrm{wt} \% \mathrm{~V}$ master alloy results in an atomic ratio of $\mathrm{Al}$ to $\mathrm{V}$ of 17:6. Using these values and the model described above, the dependence of the saturated vapor pressure and evaporation rate on temperature is plotted in Figure 13.

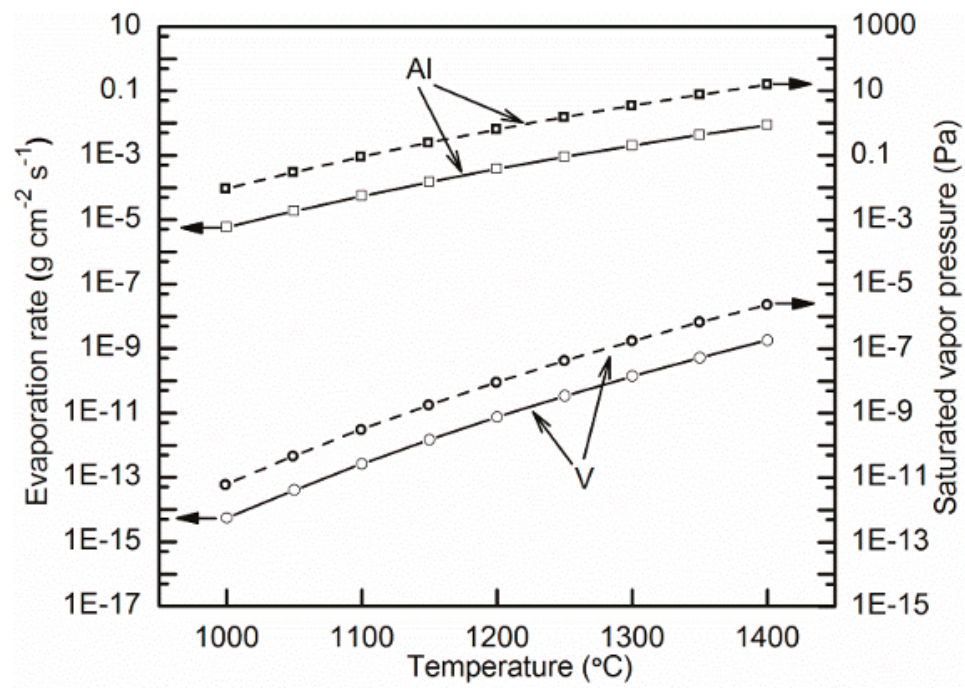

Figure 13. The dependence of evaporation rate and saturated vapor pressure on temperature.

From Figure 13 it can be seen that the saturation vapor pressure of aluminum is $9.2 \times 10^{-3} \mathrm{~Pa}$ at a temperature of $1000{ }^{\circ} \mathrm{C}$ and increases with temperature. This is higher than the furnace vacuum level of $2 \times 10^{-3} \mathrm{~Pa}$ thus suggesting that the $\mathrm{Al}$ is in a state of free evaporation $[29,30]$. The evaporation rate of aluminum and vanadium are $1.48 \times 10^{-4}$ and $1.48 \times 10^{-12} \mathrm{~g} \cdot \mathrm{cm}^{-2} \cdot \mathrm{s}^{-1}$ respectively at a temperature of $1150{ }^{\circ} \mathrm{C}$ seen from Figure 13. The median diameter of the master powder particles was $142.31 \mu \mathrm{m}$ as shown in Figure 1. Assuming the particle is spherical and the compositional ratio is constant, the mass of aluminum and vanadium in this particle would be 3.15 and $2.1 \mu \mathrm{g}$, respectively. When sintering was conducted at the lowest temperature $\left(1150^{\circ} \mathrm{C}\right)$ with a holding time of $3 \mathrm{~h}$, the total loss of aluminum and vanadium by evaporation would be $1.02 \times 10^{3}$ and $1.02 \times 10^{-5} \mu \mathrm{g}$ respectively. It can be seen that the evaporation loss of aluminum is three orders of magnitude higher than the actual content, whereas, the evaporation of vanadium can be neglected compared with its original mass. This indicates that aluminum had completed the evaporation process before the sintering ends, which is validated by the observation that aluminum is almost non-existent inside the pore shown in Figure 12. It is therefore suggested that the macropores are formed due to the high saturated vapor pressure resulting in the evaporation of aluminum and leaving a vanadium rich region inside the pores whose shape and size are taken from original master particles. These macropores would dramatically decrease both tensile strength and ductility. 


\subsection{Microstructural Evaluation and Phase Transformation}

Haase et al. [25] sintered c.p. Ti powder $(<150 \mu \mathrm{m})$ blended with a $60 \mathrm{Al}-40 \mathrm{~V}$ master powder $(<160 \mu \mathrm{m})$ prepared by equal-channel angular pressing and the investigation revealed retarded dissolution of master alloy particles due to the formation of Al-rich and V-rich layers, which were assumed to be comprised of intermetallic phases [25]. Therefore, for blended elemental Ti-6Al-4V sintered at $1150{ }^{\circ} \mathrm{C}$ shown in Figures 6a and 7a, the phase of region 2 (Figure 6a) can be suggested as $\alpha_{2}-\mathrm{Ti}_{3} \mathrm{Al}$ [36], which is in agreement with the phase determination illustrated in Figure 9a. Moreover, the diffusion of elements in $\alpha_{2}-\mathrm{Ti}_{3} \mathrm{Al}$ is much slower than in $\beta$-Ti, for example the diffusion coefficient of $\mathrm{Al}$ in $\beta$-Ti is almost $2-3$ orders of magnitude higher than in $\alpha_{2}-\mathrm{Ti}_{3} \mathrm{Al}$ [36]. Therefore, such intermetallic phase may be considered to be a diffusion barrier for vanadium diffusion which was left by the evaporation of aluminum from the master alloy powders. As indicated by Equation (3) the diffusion coefficient increases with temperature and the intermetallic phases would become no longer stable at higher temperatures $\left(1250\right.$ and $\left.1350{ }^{\circ} \mathrm{C}\right)$ compared with $1150{ }^{\circ} \mathrm{C}$. This is in accordance with the observation shown in the literature [25]. Therefore, only $\alpha$-Ti phase was observed at higher temperature with no intermetallic phase as shown in Figure 9a.

The light region shown in Figure 5 is considered to be $\beta$ phase because of the abundance of $\beta$-stabilizers such as iron and vanadium. The dark region is suggested to be $\alpha$ phase at high temperature $\left(1250\right.$ and $\left.1350^{\circ} \mathrm{C}\right)$ including both the blocky regions and acicular grains. Interestingly, the two different "alpha" morphologies are not consistent in composition. In the larger, blocky regions the $\mathrm{Al}$ content is much lower and this is thought to be a result of incomplete diffusion of the alloying elements into the Ti matrix because of the distance from the master alloy particle which is the source of aluminum. This is compatible with the unusual microstructural observation.

\subsection{Mechanical Properties}

Although the microporosity was reduced with the addition of iron, the mechanical properties of these samples were poor: fracture strength in the range of 20 to $100 \mathrm{MPa}$, with no or little plastic deformation. This is thought to be due to the macroporosity in the sintered samples and high oxygen content in the as-received titanium powders. High oxygen levels in particular are detrimental to the mechanical properties in PM Ti components [4,5,7]. The dependence of oxygen content on median particle size for $\mathrm{HDH}$ titanium powder is summarized from the literature $[4,37]$ in Figure 14.

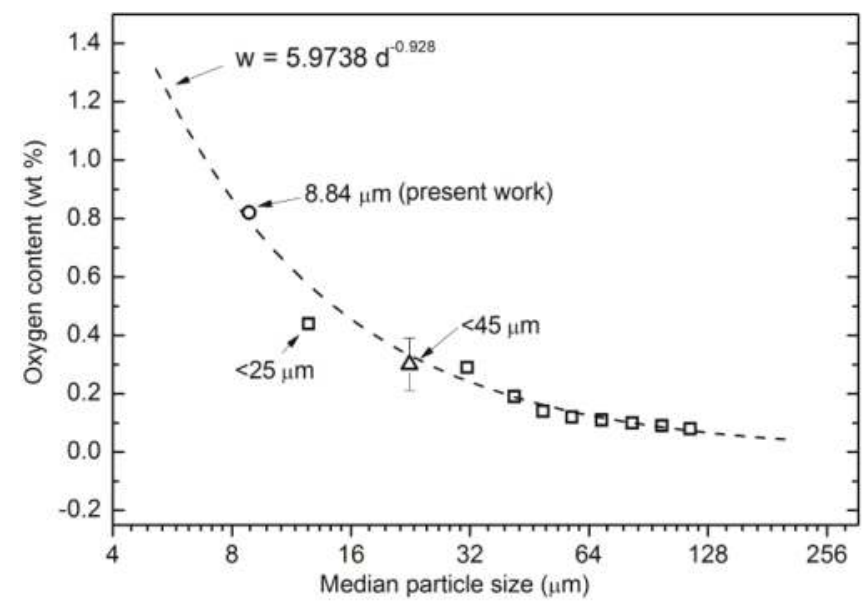

Figure 14. Dependence of oxygen content on median particle size of hydrogenation-dehydrogenation $(\mathrm{HDH})$ titanium powder. 
The correlation between oxygen content and median particle size shown in Figure 14 can be expressed by a power-law equation:

$$
w=5.9738 d^{-0.928}
$$

where $w$ is the oxygen content (wt \%) and $d$ is the median particle size $(\mu \mathrm{m})$. The relationship between oxygen content $(0.82 \mathrm{wt} \%)$ and the median particle size $(8.84 \mu \mathrm{m})$ of the fine powder used in this work fits well with this relationship. Since oxygen has high solubility in $\beta$-Ti [38], the oxygen element, in the form of oxides on titanium particle surfaces, will enter into the $\beta$-Ti lattice and therefore, the oxide layer on the titanium particle surface does not affect the densification of blended alloys [5]. However, the oxygen dissolved in $\beta$ phase would precipitate as oxides at a temperature below the $\beta$ transus, and these brittle oxides tend to precipitate at grain boundaries. This work has shown that although good densification can be obtained at low temperatures when using the fine titanium powder, the high levels of oxygen impurities results in poor mechanical properties. In order to remedy the poor mechanical properties, the amount of oxides should be reduced and the oxides should not be at the grain boundaries. One strategy is to use an oxygen scavenging element, which has significant solubility in titanium and has more affinity for oxygen than $\mathrm{Ti}$, thus forming non-Ti oxides that are located in the titanium grain interior. Some rare earth elements might serve this purpose $[39,40]$. Another strategy is to use post-sinter thermomechanical treatments to mechanically move the oxides from grain boundaries to the grain interior.

\section{Conclusions}

Four different blended elemental titanium alloys were designed and sintered through varying the weight percentage of a fine Ti powder with (Al-V) master alloy and iron powders. Spherical micropores were formed during sintering with fine titanium powder even at the lowest sintering temperature for Ti-6Al-4V. With the addition of Fe, the microporosity was reduced and improved microstructural and compositional homogenization was observed. This is due to fast diffusion of iron in titanium thereby enhancing densification. However, the tensile mechanical properties of these blended elemental titanium alloys were poor with values of $<100 \mathrm{MPa}$ tensile strength and almost no elongation. This was mainly caused by high impurity content in the as-received powders and the formation of macropores around the original master alloy particles. Incomplete dissociation of the master alloy particles caused severe evaporation of aluminum resulting in the formation of macropores during sintering.

Although reasonable densification could be obtained with fine titanium powders and this could be improved with the addition of iron, the properties were low because of the high inherent oxygen and macroporosity and therefore special precautions have to be taken when using these powders.

Acknowledgments: This work was supported by Ministry of Business Innovation and Employment (MBIE).

Author Contributions: Changzhou Yu conducted the experimental work as part of his Ph.D. study. He also analyzed the data. Peng Cao and Mark Ian Jones conceived and designed the experiments and analyzed the data. Peng Cao revised the manuscript. Mark Ian Jones discussed the results. Peng Cao and Mark Ian Jones were the supervisors of Changzhou Yu.

Conflicts of Interest: The authors declare no conflict of interest. The founding sponsors had no role in the design of the study; in the collection, analyses, or interpretation of data; in the writing of the manuscript, and in the decision to publish the results.

\section{References}

1. German, R.M. Powder Metallurgy and Particulate Materials Processing; Metal Powder Industries Federation: Princeton, NJ, USA, 2005.

2. Robertson, I.M.; Schaffer, G.B. Some effects of particle size on the sintering of titanium and a master sintering curve model. Metall. Mater. Trans. A 2009, 40, 1968-1979. [CrossRef] 
3. Luo, S.D.; Yan, M.; Schaffer, G.B.; Qian, M. Sintering of Titanium in Vacuum by Microwave Radiation. Metall. Mater. Trans. A 2011, 42, 2466-2474. [CrossRef]

4. Robertson, I.M.; Schaffer, G.B. Review of densification of titanium based powder systems in press and sinter processing. Powder Metall. 2010, 53, 146-162. [CrossRef]

5. Qian, M. Cold compaction and sintering of titanium and its alloys for near-net-shape or preform fabrication. Int. J. Powder Metall. 2010, 46, 29-44.

6. He, W.; Weng, Q.G.; He, Y.H.; Jiang, Y. Preparation of ultrafine Ti powder by inhibitor coated/HDH combined method. Powder Metall. 2013, 56, 239-244. [CrossRef]

7. Wang, H.T.; Fang, Z.Z.; Sun, P. A critical review of mechanical properties of powder metallurgy titanium. Int. J. Powder Metall. 2010, 46, 45-57.

8. Geetha, M.; Singh, A.K.; Asokamani, R.; Gogia, A.K. Ti based biomaterials, the ultimate choice for orthopaedic implants-A review. Prog. Mater. Sci. 2009, 54, 397-425. [CrossRef]

9. Ivasishin, O.M.; Savvakin, D.G.; Froes, F.; Mokson, V.C.; Bondareva, K.A. Synthesis of alloy Ti-6Al-4V with low residual porosity by a powder metallurgy method. Powder Metall. Met. Ceram. 2002, 41, 382-390. [CrossRef]

10. Peter, W.; Chen, W.; Yamamoto, Y.; Dehoff, R.; Muth, T.; Nunn, S.; Kiggans, J.; Clark, M.; Sabau, A.; Gorti, S.; et al. Current Status of Ti PM: Progress, Opportunities and Challenges. Key Eng. Mater. 2012, 520, 1-7. [CrossRef]

11. Bolzoni, L.; Ruiz-Navas, E.M.; Gordo, E. Understanding the properties of low-cost iron-containing powder metallurgy titanium alloys. Mater. Des. 2016, 110, 317-323. [CrossRef]

12. Bolzoni, L.; Ruiz-Navas, E.M.; Gordo, E. Quantifying the properties of low-cost powder metallurgy titanium alloys. Mater. Sci. Eng. A 2017, 687, 47-53. [CrossRef]

13. Wei, W.; Liu, Y.; Zhou, K.; Huang, B. Effect of Fe addition on sintering behaviour of titanium powder. Powder Metall. 2003, 46, 246-250. [CrossRef]

14. Savvakin, D.G.; Carman, A.; Ivasishin, O.M.; Matviychuk, M.V.; Gazder, A.A.; Pereloma, E.V. Effect of Iron Content on Sintering Behavior of Ti-V-Fe-Al Near-beta Titanium Alloy. Metall. Mater. Trans. A 2012, 43, 716-723. [CrossRef]

15. Qian, M.; Yang, Y.F.; Yan, M.; Luo, S.D. Design of low cost high performance powder metallurgy titanium alloys: Some basic considerations. Key Eng. Mater. 2012, 520, 24-29. [CrossRef]

16. Esteban, P.G.; Ruiz-Navas, E.M.; Bolzoni, L.; Gordo, E. Low-cost titanium alloys? Iron may hold the answers. Met. Powder Rep. 2008, 63, 24-27. [CrossRef]

17. Liu, Y.; Chen, L.F.; Tang, H.P.; Liu, C.T.; Liu, B.; Huang, B.Y. Design of powder metallurgy titanium alloys and composites. Mater. Sci. Eng. A 2006, 418, 25-35. [CrossRef]

18. Carman, A.; Zhang, L.C.; Ivasishin, O.M.; Savvakin, D.G.; Matviychuk, M.V.; Pereloma, E.V. Role of alloying elements in microstructure evolution and alloying elements behaviour during sintering of a near-beta titanium alloy. Mater. Sci. Eng. A 2011, 528, 1686-1693. [CrossRef]

19. Yang, Y.F.; Luo, S.D.; Schaffer, G.B.; Qian, M. Sintering of Ti-10V-2Fe-3Al and mechanical properties. Mater. Sci. Eng. A 2011, 528, 6719-6726. [CrossRef]

20. Esteban, P.G.; Ruiz-Navas, E.M.; Gordo, E. Influence of Fe content and particle size the on the processing and mechanical properties of low-cost Ti-xFe alloys. Mater. Sci. Eng. A 2010, 527, 5664-5669. [CrossRef]

21. Chen, B.Y.; Hwang, K.S.; Ng, K.L. Effect of cooling process on the alpha phase formation and mechanical properties of sintered Ti-Fe alloys. Mater. Sci. Eng. A 2011, 528, 4556-4563. [CrossRef]

22. Yang, Y.F.; Luo, S.D.; Schaffer, G.B.; Qian, M. The Sintering, Sintered Microstructure and Mechanical Properties of Ti-Fe-Si Alloys. Metall. Mater. Trans. A 2012, 43A, 4896-4906. [CrossRef]

23. Chen, G.; Cao, P.; He, Y.H.; Shen, P.Z.; Gao, H.Y. Effect of aluminium evaporation loss on pore characteristics of porous FeAl alloys produced by vacuum sintering. J. Mater. Sci. 2012, 47, 1244-1250. [CrossRef]

24. Kang, K.S.; Kim, C.H.; Cho, W.C.; Bae, K.K.; Woo, S.W.; Park, C.S. Reduction characteristics of $\mathrm{CuFe}_{2} \mathrm{O}_{4}$ and $\mathrm{Fe}_{3} \mathrm{O}_{4}$ by methane; $\mathrm{CuFe}_{2} \mathrm{O}_{4}$ as an oxidant for two-step thermochemical methane reforming. Int. J. Hydrogen Energy 2008, 33, 4560-4568. [CrossRef]

25. Haase, C.; Lapovok, R.; Ng, H.P.; Estrin, Y. Production of Ti-6Al-4V billet through compaction of blended elemental powders by equal-channel angular pressing. Mater. Sci. Eng. A 2012, 550, 263-272. [CrossRef] 
26. Bolzoni, L.; Esteban, P.G.; Ruiz-Navas, E.M.; Gordo, E. Mechanical behaviour of pressed and sintered titanium alloys obtained from prealloyed and blended elemental powders. J. Mech. Behav. Biomed. Mater. 2012, 14, 29-38. [CrossRef] [PubMed]

27. Neumann, G.; Tuijn, C. Self-Diffusion and Impurity Diffusion in Pure Metals: Handbook of Experimental Data; Elservier: Amsterdam, The Netherlands, 2008; Volume 14, pp. 1-349.

28. Yang, Y.F.; Luo, S.D.; Bettles, C.J.; Schaffer, G.B.; Qian, M. The effect of Si additions on the sintering and sintered microstructure and mechanical properties of Ti-3Ni alloy. Mater. Sci. Eng. A 2011, 528, 7381-7387. [CrossRef]

29. Su, Y.Q.; Guo, J.J.; Jia, J.; Liu, G.Z.; Liu, Y.A. Composition control of a TiAl melt during the induction skull melting (ISM) process. J. Alloys Compd. 2002, 334, 261-266.

30. Guo, J.J.; Liu, Y.; Su, Y.Q.; Ding, H.S.; Liu, G.Z.; Jia, J. Evaporation behavior of aluminum during the cold crucible induction skull melting of titanium aluminum alloys. Metall. Mater. Trans. B 2000, 31B, 837-844. [CrossRef]

31. Xu, Z.; Hodgson, M.A.; Chang, K.; Chen, G.; Yuan, X.; Cao, P. Effect of Sintering Time on the Densification, Microstructure, Weight Loss and Tensile Properties of a Powder Metallurgical Fe-Mn-Si Alloy. Metals 2017, 7,81. [CrossRef]

32. Langmuir, I. The Vapor Pressure of Metallic Tungsten. Phys. Rev. 1913, 2, 329-342. [CrossRef]

33. Alcock, C.B. Vapor pressure of the metallic elements-Equations. In CRC Handbook of Chemistry and Physics (Internet Version 2013), 93rd ed.; Haynes, W.M., Ed.; CRC Press: Boca Raton, FL, USA, 2013; pp. 125-126.

34. Porter, D.A.; Easterling, K.E.; Sherif, M.Y. Phase Transformations in Metals and Alloys, 3rd ed.; CRC Press: Boca Raton, FL, USA, 2009.

35. Miedema, A.R.; de Chatel, P.F.; de Boer, F.R. Cohesion in alloys-Fundamentals of a semi-empirical model. Physica B 1980, 100, 1-28. [CrossRef]

36. Mishin, Y.; Herzig, C. Diffusion in the Ti-Al system. Acta Mater. 2000, 48, 589-623. [CrossRef]

37. McCracken, C. Production of Fine Titanium Powders via the Hydrid-Dehydride (HDH) Process. PIM Int. 2008, 2, 55-57.

38. Massalski, T.D. Binary Alloys Phase Diagams; Okamoto, H., Subramanian, P.R., Kasprzak, L., Eds.; ASM International: Geauga County, OH, USA, 1990.

39. Yan, M.; Liu, Y.; Liu, Y.B.; Kong, C.; Schaffer, G.B.; Qian, M. Simultaneous gettering of oxygen and chlorine and homogenization of the beta phase by rare earth hydride additions to a powder metallurgy Ti-2.25Mo-1.5Fe alloy. Scr. Mater. 2012, 67, 491-494. [CrossRef]

40. Luo, S.D.; Yang, Y.F.; Schaffer, G.B.; Qian, M. The effect of a small addition of boron on the sintering densification, microstructure and mechanical properties of powder metallurgy Ti-7Ni alloy. J. Alloys Compd. 2013, 555, 339-346. [CrossRef]

(C) 2017 by the authors. Licensee MDPI, Basel, Switzerland. This article is an open access article distributed under the terms and conditions of the Creative Commons Attribution (CC BY) license (http:/ / creativecommons.org/licenses/by/4.0/). 
Article

\title{
Sintering Behavior and Microstructure of TiC-Me Composite Powder Prepared by SHS
}

\author{
Elena N. Korosteleva ${ }^{1,2, *}$, Victoria V. Korzhova ${ }^{2}$ and Maksim G. Krinitcyn ${ }^{1,2}$ \\ 1 Department of High Technology Physics in Mechanical Engineering, Tomsk Polytechnic University, \\ 30 Lenin av., 634050 Tomsk, Russia; krinmax@gmail.com \\ 2 Institute of Strength Physics and Materials Science of Siberian Branch of the Russian Academy of Sciences, \\ 2/4, pr. Akademicheskii, 634055 Tomsk, Russia; vicvic5@mail.ru \\ * Correspondence: elenak@ispms.tsc.ru; Tel.: +7-903-913-8002
}

Received: 29 June 2017; Accepted: 27 July 2017; Published: 31 July 2017

\begin{abstract}
Titanium, its alloys, and refractory compounds are often used in the compositions of surfacing materials. In particular, under the conditions of electron-beam surfacing the use of synthesized composite powder based on titanium carbide with a metal binder (TiC-Me) has a positive effect. These powders have been prepared via the self-propagating high-temperature synthesis (SHS) present in a thermally-inert metal binder. The initial carbide particle distribution changes slightly in the surfacing layer in the high-energy rapid process of electron-beam surfacing. However, these methods also have their limitations. The development of technologies and equipment using low-energy sources is assumed. In this case, the question of the structure formation of composite materials based on titanium carbide remains open, if a low-energy and prolonged impact in additive manufacturing will be used. This work reports the investigation of the sintered powders that were previously synthesized by the layerwise combustion mode of a mixture of titanium, carbon black, and metal binders of various types. The problems of structure formation during vacuum sintering of multi-component powder materials obtained as a result of SHS are considered. The microstructure and dependences of the sintered composites densification on the sintering temperature and the composition of the SH-synthesized powder used are presented. It has been shown that under the conditions of the nonstoichiometric synthesized titanium carbide during subsequently vacuum sintering an additional alloy formation occurs that can lead to a consolidation (shrinkage) or volumetric growth of sintered TiC-Me composite depending on the type of metal matrix used.
\end{abstract}

Keywords: titanium carbide; self-propagating high-temperature synthesis (SHS); metal binder; composite powders; sintering

\section{Introduction}

Titanium-based materials possess many unique properties that enable them to be used in a wide range of applications in various industries [1-6]. Titanium-containing materials are in demand both as casting alloys and as powder composites. Interest in the powder composite materials, in particular, has grown considerably with the development of additive manufacturing, including surfacing processes and 3D-printing of finished parts and products. The desire to create volumetric printing products with complex surface geometry gave an additional incentive for the study of powder materials containing titanium [4-6]. Composites based on titanium carbide occupy a special place among the known groups of titanium materials. The high melting point, high strength, high thermal conductivity, stability in aggressive media and low abrasion make titanium carbide indispensable in a many areas of human activity [1-6]. Titanium carbide is remarkable in that, according to the equilibrium state diagram, it has a wide homogeneity region in the titanium-carbon system [7]. The boundaries of this interval have not yet been fully studied, but it can be assumed that it is wider than $40-50$ at $\%$ of carbon at room 
temperature. $\mathrm{TiC}$ has a structure similar to that of $\mathrm{NaCl}$ (Bi) The carbon is usually located in the lattice between the points of the lattice, forming an interstitial solution. It was found that decreasing carbon content decreases the lattice period and hardness $[2,3]$.

Most studies have been shown that $\mathrm{TiC}$ of stoichiometric composition is difficult to produce. A number of researchers note that it is impossible to obtain $\mathrm{TiC}$ in which all interstitial sites are occupied by carbon atoms [8-10]. One of the reasons is the ability of oxygen and nitrogen atoms to penetrate into the $\mathrm{TiC}$ lattice together with carbon atoms. The $\mathrm{TiO}$ and $\mathrm{TiN}$ phases also have a lattice similar to the $\mathrm{NaCl}$ (Bi) lattice and are isomorphous with TiC. Therefore, oxygen and nitrogen pose great difficulties in obtaining pure TiC. Production of titanium carbide with the self-propagating high-temperature synthesis (SHS) method is characterized by the fact that the combustion reaction in the compact of titanium powder and carbon black completes in just a few seconds [11-18]. The synthesis is most often carried out in a protective inert atmosphere. In addition, raw titanium must contain the least possible amount of impurities, including oxygen. The combination of the structural characteristics of the hard inclusions (titanium carbide) and the metal binder (matrix) provides the functional properties of the composite material. There are many methods of producing metal matrix composites with titanium carbide [19-27]. Classical methods of powder metallurgy (sintering, hot pressing and extrusion) and combination of them with mechanical activation or chemical-thermal processes can be used. In addition, the structure formation of the metal matrix composite can occur both as a result of heat treatment of a powder's mixture containing a metal base with titanium carbide, and as a result of the synthesis of titanium with carbon components and other metals. In the first case, it is difficult to use a large amount of titanium carbide. In the second case, the excess carbon content is desirable in order to achieve an acceptable volume fraction of carbide. The method of producing a metal matrix composite by the SHS method is quite simple when the synthesis takes place directly during the reaction of titanium and carbon in the presence of a thermally-inert metal matrix [28-30]. In this case, a structure with carbides surrounded by a metal binder is formed directly during the synthesis process. This method allows us to achieve the optimum volume fraction, and a homogeneous distribution with a high degree of dispersion of titanium carbide that has a positive effect on the properties of the metal matrix composite. Such characteristics are difficult to achieve with the conventional method of introducing the titanium carbide into a metal matrix. As a rule, such a synthesized compact is quite fragile and easily subjected to grinding. After grinding, the resulting powder product is sieved into fractions. As a result, the finished powder can be obtained with a predetermined structure of a metal matrix composite based on titanium carbide. Subsequently, the synthesized powder can be used as consumables (feedstock) for surfacing processes and other additive production. The behavior of such powders under the conditions of the electron beam surfacing can be assessed by us already, where high-energy fast processes are realized. However, at the moment it is difficult to answer how the synthesized composite powders will behave under low-energy prolonged impact. This paper presents the results of our research, which were carried out in order to explain the behavior of such non-equilibrium heterogeneous structures during subsequent heat treatment.

\section{Materials and Methods}

\subsection{Materials and Experimental Procedure}

The powder materials under study were obtained in two stages:

(1). Synthesis of the powder base from the reaction mixture by a layerwise combustion mode in an argon atmosphere, followed by milling of the synthesized material and sieving of the necessary fraction.

(2). Vacuum sintering of the synthesized powders into compacts.

Standardized industrial powders were used in the experiment:

Titanium TPP-8 (POLEMA JSC, Tula, Russia) with dispersion 50-130 $\mu \mathrm{m}$;

Carbon black P-803 (Omsk Carbon Group, Omsk, Russia) $(<0.1 \mu \mathrm{m})$;

High-speed steel R6M5 (POLEMA JSC, Tula, Russia) (50-100 $\mu \mathrm{m})$; 
High-chromium cast iron PG-S27 (POLEMA JSC, Tula, Russia) $(50-100 \mu \mathrm{m})$;

Nickel-based self-fluxing alloy PR-N77H15S3R2 (POLEMA JSC, Tula, Russia) (50-100 $\mu \mathrm{m})$.

The titanium powder TPP- 8 contains no less than $99.4 \%$ of the primary component, and no more than $0.33 \%$ iron, $0.12 \%$ chlorine, and $0.1 \%$ oxygen. The high-speed steel powder contains $1 \%$ carbon, alloying dopants ( $\mathrm{Cr}, 4 \%$; W, $6.5 \%$; $\mathrm{Mo}, 5 \%$; V, $2 \%$ ) and impurities $(\mathrm{Si}, 0.5 \%$; $\mathrm{Mn}, 0.55 \%$; Ni, $0.4 \%)$.

Powder mixing was carried out in stationary conditions using axial mixing machine SMU-PB-180 (Agromash, Moscow, Russia). The metal binder content is determined by the maximally possible volume fraction of the thermally-inert metal component that still permits the initiation and realization of the SHS process in a mixture of titanium, carbon black, and the chosen metal matrix powders. Calculation of the initial powder mixture was made based on the assumption that the estimated volume fraction of equiatomic titanium carbide is formed during SHS. The following compositions were chosen (Table 1).

Table 1. Compositions of experimental powder mixtures (SHS: Self-propagating high-temperature synthesis).

\begin{tabular}{cc}
\hline Composition Number & $\begin{array}{c}\text { The Calculated Content of Phases in the SHS Powders } \\
\text { (with the Assumption of Equiatomic TiC Formation) }\end{array}$ \\
\hline 1 & $\mathrm{TiC}+50 \mathrm{vol} \% \mathrm{Ti}$ \\
2 & $\mathrm{TiC}+60 \mathrm{vol} \% \mathrm{Ti}$ \\
3 & $\mathrm{TiC}+50 \mathrm{vol} \%$ high-chromium cast iron \\
4 & $\mathrm{TiC}+50 \mathrm{vol} \%$ high-speed steel \\
5 & $\mathrm{TiC}+20 \mathrm{vol} \%$ nickel-based self-fluxing alloy \\
6 & $\mathrm{TiC}+30 \mathrm{vol} \%$ nickel-based self-fluxing alloy \\
7 & $\mathrm{TiC}+40 \mathrm{vol} \%$ nickel-based self-fluxing alloy \\
8 & $\mathrm{TiC}+50 \mathrm{vol} \%$ nickel-based self-fluxing alloy \\
\hline
\end{tabular}

The powder compositions were pressed into cylindrical compacts $35 \mathrm{~mm}$ in diameter to facilitate the passage of the combustion front. Then the compacts were placed in a reactor for synthesis in a layerwise combustion mode using argon gas with an excess pressure of about $0.5 \mathrm{~atm}$. The reaction of layerwise combustion was initiated using short-term heating by means of a molybdenum filament of an igniting tablet pressed from the powder mixture of titanium and silicon corresponding to the stoichiometric composition $\mathrm{Ti}_{5} \mathrm{Si}_{3}$. The combustion product remains of titanium silicide were removed after synthesis; the reacted compact was milled and sieved into fractions. Using this procedure, synthesized powders of all investigated compositions containing titanium carbide were obtained [28-32]. The typical microstructure and morphology of the studied synthesized powder compositions are shown in Figure 1. The finest fraction (not exceeding $50 \mu \mathrm{m}$ ) was selected for studying the behavior of composite powders under vacuum sintering. Cylindrical specimens pressed using a plasticizer with residual porosity not exceeding $45 \%$ were placed in a vacuum furnace and heated in vacuum at $10^{-2} \mathrm{~Pa}$ with a heating rate of $3-5{ }^{\circ} \mathrm{C} \cdot \mathrm{min}^{-1}$ to achieve sintering temperatures of $1300{ }^{\circ} \mathrm{C}$ and $1350{ }^{\circ} \mathrm{C}$. The holding time at the sintering temperature was $3 \mathrm{~h}$.

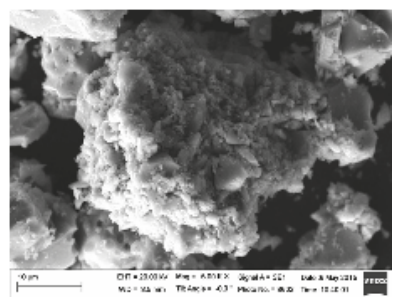

(a)

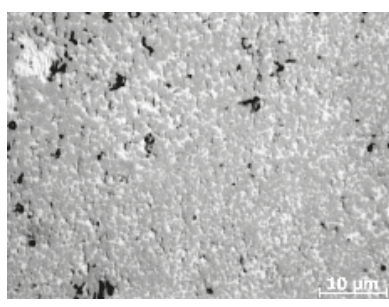

(b)

Figure 1. Cont. 


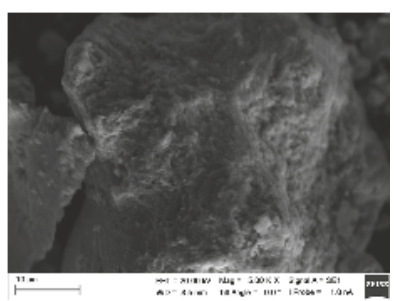

(c)

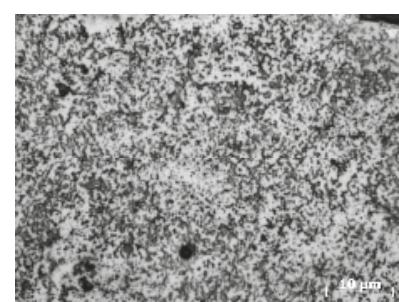

(d)

Figure 1. Morphology and microstructure of the following powder composites: (a,b) TiC-50\% binder of high-chromium cast iron; and (c,d) TiC-50\% binder of high-speed steel.

\subsection{Characterisation}

The density of specimens was measured before and after sintering by the Archimedes method according to the ASTM B962-17 standard. Metallographic specimens were prepared using the standard metallographic procedures: grinding with abrasive materials; fine polishing and etching in Keller's reagent ( $95 \mathrm{~mL} \mathrm{H}_{2} \mathrm{O} ; 2.5 \mathrm{~mL} \mathrm{HNO}_{3} ; 1.5 \mathrm{~mL} \mathrm{HCl} ; 1 \mathrm{~mL} \mathrm{HF}$ ) for 5-10 s. An AXIOVERT-200MAT metallographic microscope (Carl Zeiss, Oberkochen, Germany) and a LEO EVO 50 scanning electron microscope (Carl Zeiss, Oberkochen, Germany) were used for the analysis of the SHS-powder morphology, the microstructure of the SHS-powder, and the sintered compacts. The phase composition was determined by $\mathrm{X}$-ray analysis using $\mathrm{Co}_{\alpha}$. For phase identification and calculation of the lattice parameters of the phases was used the X-ray data of the ASTM data file and the software package PDWin (4.0, NPP Bourevestnik, Saint-Petersburg, Russia, 2015).

\section{Results}

The results of vacuum sintering of SH-synthesized metal-matrix powders based on titanium carbide are presented in Figure 2. These results are best analyzed by the change in density before and after sintering. The density of the green compacts varies from $3.1 \mathrm{~g} / \mathrm{cm}^{2}$ to $3.7 \mathrm{~g} / \mathrm{cm}^{2}$, depending on the metal binder used. Our estimates show that this density corresponds to approximately $60-70 \%$ of the theoretical maximum for the respective system. In our studies, we preferred to use the actual density values of the sintered compacts. The porosity was determined by the metallographic method (quantitative metallography). In multicomponent powder materials, it is difficult to calculate the theoretical density of sintered compacts to estimate their residual porosity, since the real phase relationship after sintering is unknown.

The experimental results show that vacuum sintering at $1300-1350{ }^{\circ} \mathrm{C}$ has a significant effect on the structure formation of composite materials sintered from $\mathrm{SH}$-synthesized powders, i.e., from the already-reacted powder composition. The process of diffusion interaction was once again activated during the subsequent sintering. Comparing the values of densification for different compositions in Figure 2, it is evident that the qualitative composition of the metal matrix affects the sinterability of the composite powder compacts.

Titanium, as a metallic binder, will be well-sintered in any temperature range (Figure 3). Its inclusions, which stimulate densification of the compact during sintering, are insignificant (by volume) relative to the dominant titanium carbide (Figure 2a). However, the interaction of free surfaces of "titanium-titanium" is not the only factor leading to shrinkage of the samples. According to microstructure analysis, an additional carbon migration occurs during sintering, which increases the proportion of non-stoichiometric titanium carbide (Figure 3b). 


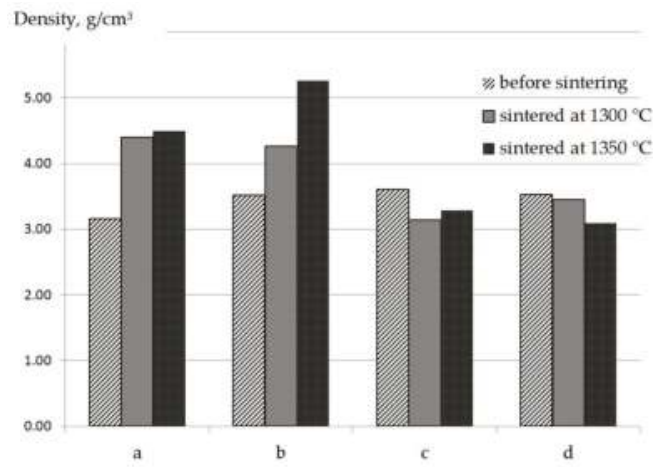

Figure 2. Density change of TiC-Me (titanium carbide with metal binder) compacts sintered at different temperature: (a) TiC-50\% Ti; (b) TiC-50\% high-chromium cast iron; (c) TiC-50\% nickel-based self-fluxing alloy; (d) TiC-50\% high-speed steel.

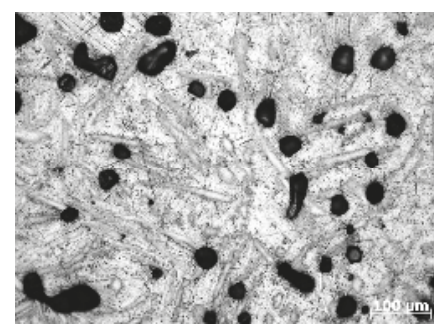

(a)

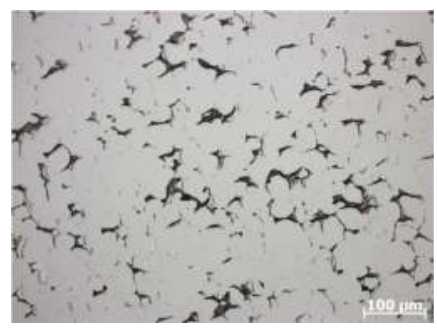

(b)

Figure 3. Microstructure of titanium powder: (a) TiC-50\% Ti synthesized powder before sintering at $1350{ }^{\circ} \mathrm{C}$; (b) after sintering at $1350{ }^{\circ} \mathrm{C}$.

Composite powders with a high-chromium cast iron binder also densify well (Figure 4). In this case, it can be assumed that the fixed carbon, which is a component of the cast iron alloy, acts as an activator of sintering. Evidently, its affinity to titanium is stronger than the bond with iron and other alloying components (chrome) that are alloy additives of cast iron.

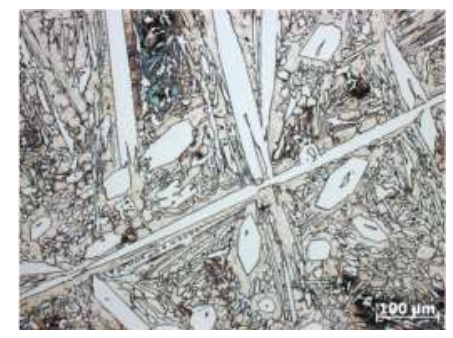

(a)

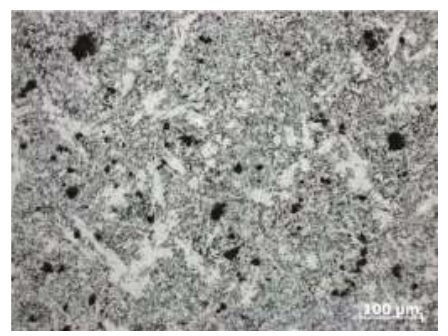

(b)

Figure 4. Microstructure of high-chromium cast iron powder: (a) TiC-50\% high-chromium cast iron binder synthesized powder before sintering at $1300^{\circ} \mathrm{C} ;(\mathbf{b})$ after sintering at $1300^{\circ} \mathrm{C}$. 
The use of other alloys (high-speed steel and nickel-based self-fluxing alloy) as a metallic binder demonstrates the opposite effect (Figure 5). Vacuum sintering of these synthesized powders causes the residual porosity increase that leads to a density decrease.

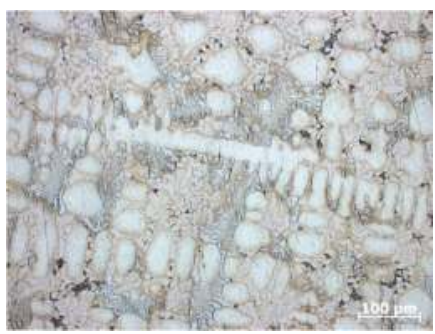

(a)

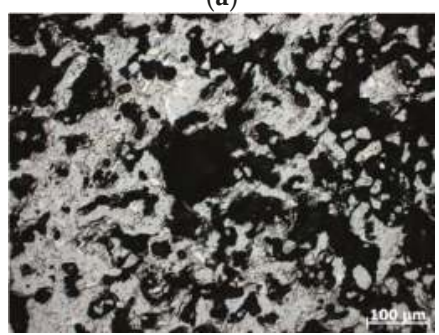

(c)

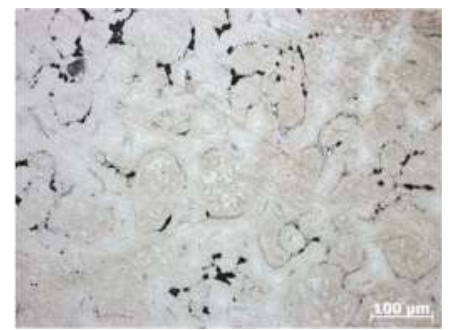

(b)

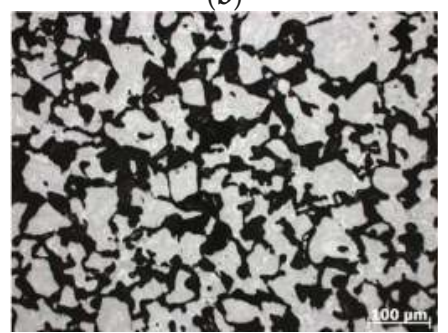

(d)

Figure 5. Sintered at $1300{ }^{\circ} \mathrm{C}$ : (a) microstructure of nickel-based self-fluxing alloy powder; (b) high-speed steel powder; (c) TiC-50\% nickel-based self-fluxing alloy synthesized powder; and (d) TiC-50\% high-speed steel synthesized powder.

Although the powders of high-speed steel and nickel-based self-fluxing alloys themselves are well-sintered (Figure 5a,b), in the presence of the titanium carbide the "negative" redistribution of the carbon takes place towards the metallic binder. This is assisted by the presence of carbon-active components in the alloys of high-speed steel and nickel-based self-fluxing alloy: Tungsten and molybdenum in high-speed steel and chromium in the nickel-based self-fluxing alloy, where nickel can also have an active influence on the titanium bound in the carbide.

It was found that the non-equilibrium metal-matrix structure of the powders formed as a result of SHS by the layerwise combustion method consisting mainly of non-stoichiometric titanium carbide [30,31]. Many works are devoted to the non-stoichiometricity of titanium carbide [6,8-10]. Unfortunately, there are not enough publications showing the influence of this factor on the various processes of structure formation. Our research shows that subsequent heat treatment in the mode of vacuum sintering activates the tendency of the system to approach a more equilibrated state through the redistribution of fixed carbon. In fact, despite the high affinity of carbon to titanium, some carbon atoms leave the lattice of titanium carbide, which already has a carbon deficit. Some coarsening and coalescence of the carbide particles after vacuum sintering occurs in comparison with the distribution and dispersion of carbide inclusions in the synthesized powders before heat treatment (Figure 6).

Figure 7 shows the effect of temperature on the sinterability of TiC-50\% Ti SHS-powders. The metal binder type of synthesized powders have different effects on the sinterability of compacts. In the case of a maximum binder content of titanium, high-chromium cast iron, and a nickel alloy. An increase in temperature from $1300{ }^{\circ} \mathrm{C}$ to $1350{ }^{\circ} \mathrm{C}$ stimulates densification; in the case of a high-speed steel binder, however, the density at $1350{ }^{\circ} \mathrm{C}$ was less than at $1300^{\circ} \mathrm{C}$. It is supposed by us that the temperature of $1350{ }^{\circ} \mathrm{C}$ is insufficient to cause the shrinkage process to become dominant. At this temperature, the alloy formation local processes continue, causing the formation of rigid skeletons. 


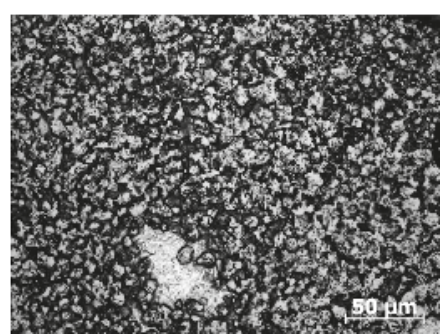

(a)

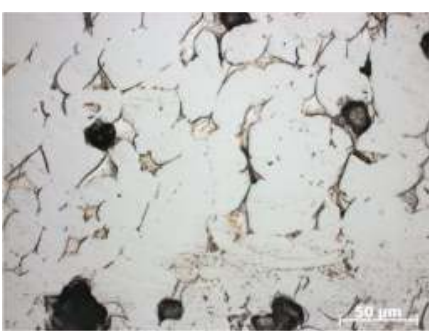

(b)

Figure 6. Microstructure of TiC-50\% Ti synthesized powder: (a) Before sintering at $1350{ }^{\circ} \mathrm{C}$ and (b) after sintering at $1350{ }^{\circ} \mathrm{C}$.

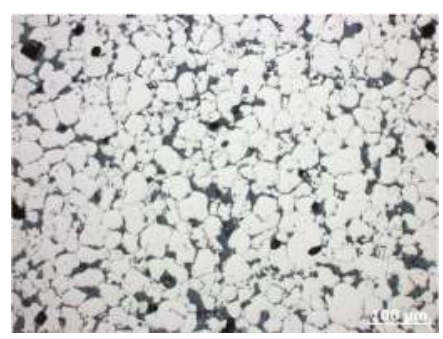

(a)

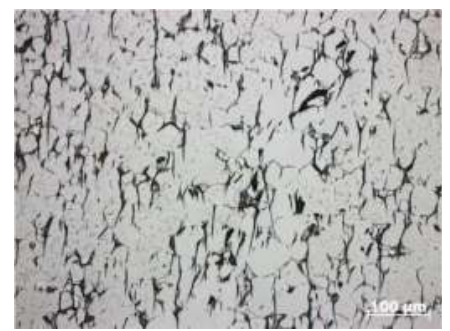

(b)

Figure 7. Microstructure of TiC-50\% Ti synthesized powder sintered at: (a) $1300{ }^{\circ} \mathrm{C}$ and (b) $1350{ }^{\circ} \mathrm{C}$.

In the latter compositions, a rigid skeleton is formed from the high-alloy metal binder already at $130{ }^{\circ} \mathrm{C}$. This rigid skeleton prevents consolidation of the material with an increasing temperature up to the melting point of the binder.

At the same time, there is no noticeable qualitative change in the phase composition of the synthesized powder materials after sintering (Figure 8). The main phases were recognized, and were identical both for synthesized powder and for sintered compacts from them. The formation of any additional phases was not detected. However, a number of the X-ray diffraction (XRD) lines have a superposed view that may indicate the possibility of the existence of additional phases in small volume fractions. It is assumed that additional structural studies are needed in this case.

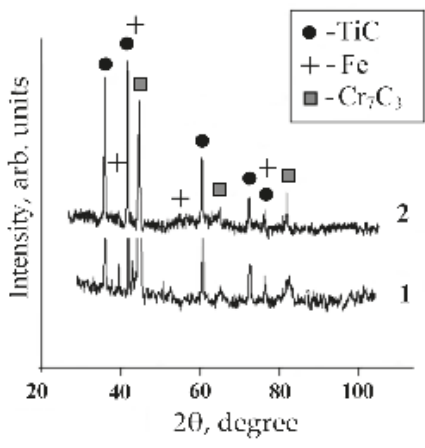

(a)

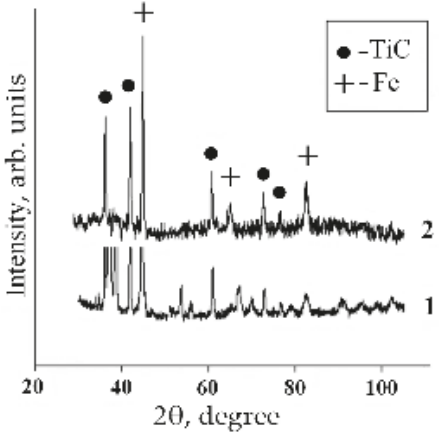

(b)

Figure 8. Cont. 


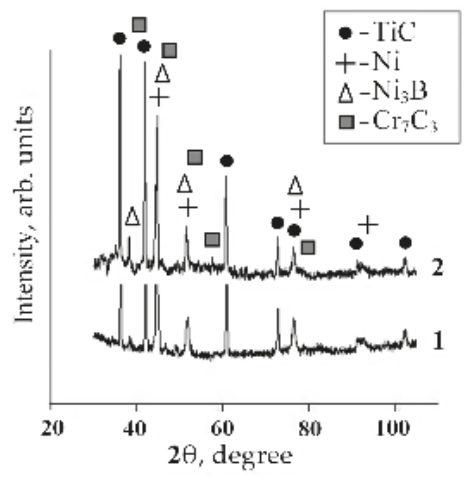

(c)

Figure 8. XRD patterns of the SHS-powder materials before (1) and after (2) sintering at $1350{ }^{\circ} \mathrm{C}$ : (a) TiC-50\% high-chromium cast iron binder; (b) TiC-50\% high-speed steel binder; (c) TiC-50\% binder of nickel-based self-fluxing alloy. (SHS: Self-propagating high-temperature synthesis).

The volume fraction of the metal binder affects the density change of the sintered materials depending on its type. In the case of titanium binder, an increase in its bulk content contributes to the shrinkage of the sintered compacts. In the case of a nickel alloy matrix, on the contrary, an increase in the volume fraction of the binder leads to an increased volume growth of the compacts sintered at $1300{ }^{\circ} \mathrm{C}$ (Table 2). When the temperature reaches $1350{ }^{\circ} \mathrm{C}$, the densification processes starts to dominate for the compositions with $40-50 \%$ nickel-based binder.

Table 2. Relative densification of the SHS compacts with various volume content of metal binder sintered at $1350{ }^{\circ} \mathrm{C}$.

\begin{tabular}{ccc}
\hline \multirow{2}{*}{ Composition } & \multicolumn{2}{c}{ Relative Densification, $\%$} \\
\cline { 2 - 3 } & $\boldsymbol{T}_{\mathbf{s i n}}=\mathbf{1 3 0 0}{ }^{\circ} \mathbf{C}$ & $\boldsymbol{T}_{\text {sin }}=\mathbf{1 3 5 0}{ }^{\circ} \mathbf{C}$ \\
\hline $\mathrm{TiC}+50$ vol \% Ti & 40.1 & 42.0 \\
$\mathrm{TiC}+60$ vol \% Ti & 43.2 & 50.6 \\
$\mathrm{TiC}+20$ vol \% nickel-based self-fluxing alloy & -10.2 & -14.1 \\
$\mathrm{TiC}+30$ vol \% nickel-based self-fluxing alloy & -11.3 & -12.5 \\
$\mathrm{TiC}+40$ vol \% nickel-based self-fluxing alloy & -12.9 & -9.2 \\
$\mathrm{TiC}+50$ vol \% nickel-based self-fluxing alloy & -13.5 & -8.1 \\
\hline
\end{tabular}

\section{Discussion}

The results of our research show that metal matrix composites "TiC-metal binder" synthesized from powders in a layerwise combustion mode have a non-stoichiometric composition and are in a non-equilibrium state. It is assumed by us that carbon rearrangement occurs not only in the carbide phase, but also at the interface between $\mathrm{TiC}$ and the metal matrix upon subsequent heat treatment. Powder-synthesized composite materials of the type "TiC-high-chromium cast iron" and "TiC-Ti" exhibit significant densification during vacuum sintering at temperatures starting from $1250^{\circ} \mathrm{C}$, up to $1300^{\circ} \mathrm{C}$. Conversely, use of high-speed steel and nickel-based self-fluxing alloy as the metal binder leads to an increased pore fraction by volume and, as a result, to an increased volume growth of specimens during sintering. The rise of the temperature up to $1350{ }^{\circ} \mathrm{C}$ only increases this expansion. For these multicomponent composites it is necessary to change a composition of synthesized powder by means of metal binder addition. The ability of the two studied compositions ("TiC-high-chromium cast iron" and "TiC-Ti") to significantly densify during sintering at temperatures lower than the melting 
point of the metal matrix may be of interest for the design of equipment for additive manufacturing, including 3D-printing of composite materials at reduced temperatures.

Acknowledgments: The research was funded from Russian Science Foundation, grant number 17-19-01425. The experimental calculations were carried out at Tomsk Polytechnic University within the framework of Tomsk Polytechnic University Competitiveness Enhancement Program grant.

Author Contributions: Elena N. Korosteleva conceived and designed the experiments, analyzed the data, and planned the manuscript; Victoria V. Korzhova conducted the experimental work for XRD analysis and discussed the results; Maksim G. Krinitcyn carried out the experiments for sintering and microstructure analysis.

Conflicts of Interest: The authors declare no conflict of interest.

\section{References}

1. Cui, C.; Hu, B.; Zhao, L.; Liu, S. Titanium alloy production technology, market prospects and industry development. Mater. Des. 2011, 32, 1684-1691. [CrossRef]

2. Pierson, H.O. Handbook of Refractory Carbides and Nitrides: Properties, Characteristics, Processing and Applications, 1st ed.; Noyes publications: Westwood, NJ, USA, 1996.

3. Weimer, A.W. Carbide, Nitride and Boride Materials Synthesis and Processing; Springer Science \& Business Media: Dordrecht, The Netherlands, 2012.

4. Herderick, E. Additive manufacturing of metals: A review. Mater. Sci. Technol. 2011, 1413-1425.

5. Gong, X.; Anderson, T.; Chou, K. Review on powder-based electron beam additive manufacturing technology. Manuf. Rev. 2014, 1. [CrossRef]

6. Shabalin, I.L.; Luchka, M.V.; Shabalin, L.I. Vacuum SHS in systems with group IV transition metals for production of ceramic compositions. Phys. Chem. Solid State 2007, 8, 159-175.

7. Okamoto, H. Phase Diagrams for Binary Alloys, 2nd ed.; ASM International: Materials Park, OH, USA, 2010; pp. 176-189.

8. Wanjara, P.; Drew, R.A.L.; Root, J.; Yue, S. Evidence for stable stoichiometric $\mathrm{Ti}_{2} \mathrm{C}$ at the interface in $\mathrm{TiC}$ particulate reinforced Ti alloy composites. Acta Mater. 2000, 48, 1443-1450. [CrossRef]

9. Quinn, C.J.; Kohlstedt, D.L. Solid-state reaction between titanium carbide and titanium metal. J. Am. Ceram. Soc. 1984, 67, 305-310. [CrossRef]

10. Yang, Y.F.; Wang, H.Y.; Zhang, J.; Zhao, R.Y.; Liang, Y.H.; Jiang, Q.C. Lattice parameter and stoichiometry of $\mathrm{TiC}_{\mathrm{x}}$ produced in the $\mathrm{Ti}-\mathrm{C}$ and $\mathrm{Ni}$-Ti-C systems by self-propagating high-temperature synthesis. J. Am. Ceram. Soc. 2008, 91, 2736-2739. [CrossRef]

11. Merzhanov, A.G. History and recent developments in SHS. Ceram. Int. 1995, 21, 371-379. [CrossRef]

12. Merzhanov, A.G. Combustion processes that synthesize materials. J. Mater. Process. Technol. 1996, 56, $222-241$. [CrossRef]

13. Munir, Z.A.; Anselmi-Tamburini, U. Self-propagating exothermic reactions: the synthesis of high-temperature materials by combustion. Mater. Sci. Rep. 1989, 3, 277-365. [CrossRef]

14. LaSalvia, J.C.; Meyer, L.W.; Meyers, M.A. Densification of reaction-synthesized titanium carbide by high-velocity forging. J. Am. Ceram. Soc. 1992, 75, 592-602. [CrossRef]

15. Strutt, E.R.; Olevsky, E.A.; Meyers, M.A. Combustion synthesis/quasi-isostatic pressing of TiC-NiTi cermets: Processing and mechanical response. J. Mater. Sci. 2008, 43, 6513-6526. [CrossRef]

16. Samokhin, A.V.; Alekseev, N.V.; Sinayskiy, M.A.; Tsvetkov, J.V. Thermodynamic model of high-temperature synthesis of oxygen-free titanium compounds from titanium tetrachloride. Contemp. Eng. Sci. 2015, 8, 1449-1460. [CrossRef]

17. Nersisyan, H.H.; Lee, J.H.; Won, C.W. Self-propagating high-temperature synthesis of nano-sized titanium carbide powder. J. Mater. Res. 2002, 17, 2859-2864. [CrossRef]

18. Kobashi, M.; Ichioka, D.; Kanetake, N. Combustion synthesis of porous TiC/Ti composite by a self-propagating mode. Materials 2010, 3, 3939-3947. [CrossRef]

19. Gülsoy, H.O.; Gunay, V.; Baykara, T. Influence of TiC, TiN and TiC(N) additions on sintering and mechanical properties of injection moulded titanium based metal matrix composites. Powder Metall. 2015, 58, 30-35. [CrossRef]

20. Kim, Y.J.; Chung, H.; Kang, S.J. In situ formation of titanium carbide in titanium powder compacts by gas-solid reaction. Compos. Part A Appl. Sci. Manuf. 2001, 32, 731-738. [CrossRef] 
21. Roger, J.; Gardiola, B.; Andrieux, J.; Viala, J.C.; Dezellus, O. Synthesis of Ti matrix composites reinforced with TiC particles: thermodynamic equilibrium and change in microstructure. J. Mater. Sci. 2017, 52, 4129-4141. [CrossRef]

22. El-Eskandarany, M.S. Structure and properties of nanocrystalline TiC full-density bulk alloy consolidated from mechanically reacted powders. J. Alloys Compd. 2000, 305, 225-238. [CrossRef]

23. Winkler, B.; Juarez-Arellano, E.A.; Friedrich, A.; Bayarjargal, L.; Yan, J.; Clark, S.M. Reaction of titanium with carbon in a laser heated diamond anvil cell and reevaluation of a proposed pressure-induced structural phase transition of TiC. J. Alloys Compd. 2009, 478, 392-397. [CrossRef]

24. Yan, Y.; Zheng, Y.; Yu, H.; Bu, H.; Cheng, X.; Zhao, N. Effect of sintering temperature on the microstructure and mechanical properties of $\mathrm{Ti}(\mathrm{C}, \mathrm{N})$-based cermets. Powder Metall. Met. Ceram. 2007, 46, 449-453. [CrossRef]

25. Viljus, M.; Pirso, J.; Juhani, K.; Letunovitš, S. Structure Formation in Ti-C-Ni-Mo Composites during Reactive Sintering. Mater. Sci. 2012, 18, 62-65. [CrossRef]

26. Luo, S.D.; Li, Q.; Tian, J.; Wang, C.; Yan, M.; Schaffer, G.B.; Qian, M. Self-assembled, aligned TiC nanoplatelet-reinforced titanium composites with outstanding compressive properties. Scr. Mater. 2013, 69, 29-32. [CrossRef]

27. Li, S.; Sun, B.; Imai, H.; Kondoh, K. Powder metallurgy Ti-TiC metal matrix composites prepared by in situ reactive processing of Ti-VGCFs system. Carbon 2013, 61, 216-228. [CrossRef]

28. Kalambaeva, S.S.; Korosteleva, E.N.; Pribytkov, G.A. Structure of Composite Powders "TiC-high Chromium Cast Iron Binder" Produced by SHS Method. In Proceedings of the International Conference on Mechanical Engineering, Automation and Control Systems, Tomsk, Russia, 16-18 October 2014. [CrossRef]

29. Krinitcyn, M.G.; Pribytkov, G.A.; Durakov, V.G. Structure and properties of electron beam coatings, overlaid of SHS composite powders "TiC-Ti", synthesized in air. Key Eng. Mater. 2016, 685, 719-723. [CrossRef]

30. Korosteleva, E.N.; Pribytkov, G.A.; Krinitcyn, M.G.; Baranovskii, A.V.; Korzhova, V.V.; Strelnitskij, V.E. Fabrication of "TiC-HSS steel binder" composite powders by self-propagating high temperature synthesis. Key Eng. Mater. 2016, 712, 195-199. [CrossRef]

31. Korosteleva, E.N.; Pribytkov, G.A.; Krinitcyn, M.G.; Baranovskii, A.V.; Korzhova, V.V. Problems of Development and Application of Metal Matrix Composite Powders for Additive Technologies. IOP Conf. Ser. Mater. Sci. Eng. 2016, 140. [CrossRef]

32. Dudina, D.V.; Pribytkov, G.A.; Krinitcyn, M.G.; Korchagin, M.A.; Bulina, N.V.; Bokhonov, B.B.; Batraev, I.S.; Rybin, D.K.; Ulianitsky, V.Y. Detonation spraying behavior of $\mathrm{TiC}_{\mathrm{x}}-\mathrm{Ti}$ powders and the role of reactive processes in the coating formation. Ceram. Int. 2016, 42, 690-696. [CrossRef]

(C) 2017 by the authors. Licensee MDPI, Basel, Switzerland. This article is an open access article distributed under the terms and conditions of the Creative Commons Attribution (CC BY) license (http:/ / creativecommons.org/licenses/by/4.0/). 


\title{
Article \\ Self-Propagating High Temperature Synthesis of $\mathrm{TiB}_{2}-\mathrm{MgAl}_{2} \mathrm{O}_{4}$ Composites
}

\author{
Nina Radishevskaya ${ }^{1}$, Olga Lepakova ${ }^{1}$, Natalia Karakchieva ${ }^{2, *}$, Anastasiya Nazarova ${ }^{1}$, \\ Nikolai Afanasiev ${ }^{1}$, Anna Godymchuk ${ }^{3,4}$ and Alexander Gusev ${ }^{4,5}$ \\ 1 Tomsk Scientific Centre SB RAS, Tomsk 634055, Russia; osm.ninaradi@yandex.ru (N.R.); \\ klavdievna.k@yandex.ru (O.L.); osm.nazarova@yandex.ru (A.N.); Af42@yandex.ru (N.A.) \\ 2 Physical-Technical Institute, Tomsk State University, Tomsk 634050, Russia \\ 3 Department of Nanomaterials and Nanotechnologies, National Research Tomsk Polytechnic University, \\ Tomsk 634050, Russia; godymchuk@mail.ru \\ 4 Department of Functional Nanosystems and High-Temperature Materials, \\ National University of Science and Technology MISIS, Moscow 119991, Russia; nanosecurity@mail.ru \\ 5 Research Institute of Environmental Science and Biotechnology, G.R. Derzhavin Tambov State University, \\ Tambov 392000, Russia \\ * Correspondence: kosovanatalia@yandex.ru; Tel.: +7-382-241-2319
}

Received: 27 June 2017; Accepted: 27 July 2017; Published: 3 August 2017

\begin{abstract}
Metal borides are widely used as heat-insulating materials, however, the range of their application in high-temperature conditions with oxidative medium is significantly restricted. To improve the thermal stability of structural materials based on titanium boride, and to prevent the growth of $\mathrm{TiB}_{2}$ crystals, additives based on alumina-magnesia spinel with chemical resistant and refractory properties have been used. The aim of this work is to study the structure of $\mathrm{TiB}_{2}$ with alumina-magnesia spinel additives obtained by self-propagating high-temperature synthesis (SHS). $\mathrm{TiB}_{2}$ structure with uniform fine-grained distribution was obtained in an $\mathrm{MgAl}_{2} \mathrm{O}_{4}$ matrix. The material composition was confirmed by X-ray diffraction analysis (DRON-3M, filtered Co k $\alpha$-emission), FTIR spectroscopy (Thermo Electron Nicolet 5700, within the range of $1300-400 \mathrm{~cm}^{-1}$ ), and scanning electron microscopy (Philips SEM 515). The obtained material represents a composite, where the particles of $\mathrm{TiB}_{2}$ with a size of $5 \mu \mathrm{m}$ are uniformly distributed in the alloy of alumina-magnesia spinel.
\end{abstract}

Keywords: titanium diboride; alumina-magnesia spinel; self-propagating high-temperature synthesis; composites

\section{Introduction}

Self-propagating high-temperature synthesis (SHS) is used to develop new technologies for the production of refractory nonmetallic composite materials with defined properties. In spite of the fact that metal carbides and borides are widely used as insulation materials, the range of their application in oxidative mediums at high temperatures is very restricted. To increase the refractory properties of metal carbides and borides, alumina-magnesia spinel $\mathrm{MgAl}_{2} \mathrm{O}_{4}$ with the melting temperature of $2105{ }^{\circ} \mathrm{C}$, which corresponds to the high level of refractoriness [1], is used as an additive.

Magnesium and aluminothermic synthesis is widely used for the production of refractory ceramic materials, e.g., with the use of metallothermic reduction in a $\mathrm{TiO}_{2}-\mathrm{MgO}-\mathrm{Al}_{2} \mathrm{O}_{3}-\mathrm{Al}$ system, the refractory materials based on $\mathrm{MgAl}_{2} \mathrm{O}_{4}$ and titanium carbonitrides are obtained [2]. High-strength porous ceramic material, containing in its composition $\mathrm{MgAl}_{2} \mathrm{O}_{4}, \mathrm{TiB}_{2}, \mathrm{TiO}_{2}, \mathrm{Al}_{4} \mathrm{~B}_{2} \mathrm{O}_{6}$, and $\mathrm{Mg}_{2} \mathrm{~B}_{2} \mathrm{O}_{5}$ was obtained in a $\mathrm{TiO}_{2}-\mathrm{B}_{2} \mathrm{O}_{3}-\mathrm{Al}$ system with $\mathrm{MgO}$ additives. This material can be used as a catalyst at temperatures of $600{ }^{\circ} \mathrm{C}-700{ }^{\circ} \mathrm{C}$ in an open atmosphere [3]. Moreover, aluminum is widely used in the synthesis of composite materials. In the structure of composites, the intermetallic matrices from 
both $\mathrm{TiAl} / \mathrm{Ti}_{3} \mathrm{Al}$ and $\mathrm{MgAl}_{2} \mathrm{O}_{4}$ are incorporated [4]. In all of the abovementioned works, $\mathrm{MgAl}_{2} \mathrm{O}_{4}$ is synthesized in the form of particles.

Another method of heat-resistant composite production is through titanium diboride synthesis from its elements with the use of chemical-resistant and refractory alumina-magnesia spinel $\left(\mathrm{MgAl}_{2} \mathrm{O}_{4}\right)$. This method allows decelerating high-temperature solid-phase oxidative reactions in the process of material exploitation.

The aim of this work is to study the phase composition and microstructure of a $\mathrm{TiB}_{2}+\mathrm{MgAl}_{2} \mathrm{O}_{4}$ heat-resistant composite obtained by self-propagating high-temperature synthesis with $\mathrm{MgAl}_{2} \mathrm{O}_{4}$ additives of different concentrations.

At high temperatures $\left(\sim 3000{ }^{\circ} \mathrm{C}\right)$, spinel melts and spreads along the surface of $\mathrm{TiB}_{2}$ grains, forming the matrix that protects the $\mathrm{TiB}_{2}$ grain surface with the spinel.

\section{Materials and Methods}

To prepare reaction mixtures, dried in a vacuum at temperature of $200{ }^{\circ} \mathrm{C}$ for $2 \mathrm{~h}$, titanium powders (TPP-8, JSC "Avisma"; titanium composition 96 wt \%; particle size < $160 \mu \mathrm{m}$ ), amorphous boron (B-99A-TU-6-02-585-75), and alumina-magnesia spinel (TU 6-09-01-136) were used. Four mixtures of different compositions were prepared: (1) $90 \%(\mathrm{Ti}+2 \mathrm{~B})+10 \% \mathrm{MgAl}_{2} \mathrm{O}_{4}$; (2) $75 \%(\mathrm{Ti}+2 \mathrm{~B})+25 \% \mathrm{MgAl}_{2} \mathrm{O}_{4}$; (3) $60 \%(\mathrm{Ti}+2 \mathrm{~B})+40 \% \mathrm{MgAl}_{2} \mathrm{O}_{4}$; (4) $50 \%(\mathrm{Ti}+2 \mathrm{~B})+50 \% \mathrm{MgAl}_{2} \mathrm{O}_{4}$. Powders were thoroughly mixed to obtain homogenous blends. Then, from the obtained mixtures, porous (40-45\%) cylindrical particles were formed with a diameter of $20 \mathrm{~mm}$ and a length of 30-32 $\mathrm{mm}$ by using a hydraulic press. Self-propagating high-temperature synthesis was conducted in a constant pressure setup in argon atmosphere at a pressure of $\sim 6$ atm. Samples ignition was carried out using an ignition mixture of powders $(\mathrm{Ti}+2 \mathrm{~B})$ with the help of a tungsten filament, which was supplied with a short-term electrical impulse. The maximal combustion temperature was detected by the tungsten-rhenium thermocouple BP5-BP20 with a diameter of $100 \mu \mathrm{m}$. Temperature registration was conducted with the use of an analog-to-digital converter LA-20USB connected with a personal computer.

The compositions of the obtained materials were proved by X-ray phase analyses (Dron-3M, filtered Co k $\alpha$-emission, Saint Petersburg, Russia), IR spectroscopy (FTIR spectrometer Nicolet-5700, Thermo Electron Corporation, Atkinson, USA). Measurements were carried out using an add-in device of scattering reflection in $\mathrm{KBr}$ at a frequency interval of $1300-400 \mathrm{~cm}^{-1}$. To study the microstructure, an optical microscope (Axiovert 200M, OM, Karl Zeiss, Germany) and a scanning electron microscope (SEM-515, Philips, Amsterdam, The Netherlands) were used.

\section{Results and Discussion}

Among gas-free systems, the Ti-B system is characterized by the highest exothermicity. For a powder mixture with the ratio of components Ti:B $=1: 2$ the adiabatic temperature of combustion is $\mathrm{Tad}=3190 \mathrm{~K}$ [5]. Alumina-magnesia spinel $\mathrm{MgAl}_{2} \mathrm{O}_{4}$ is inert in relation to the mixture Ti-2B. In Table 1, the physicochemical properties of spinel are presented [6,7].

Table 1. Physicochemical properties of compounds.

\begin{tabular}{cccc}
\hline Compound & Melting Temperature, ${ }^{\circ} \mathbf{C}$ & Density, $\mathbf{g} / \mathbf{c m}^{\mathbf{3}}$ & $-\Delta \boldsymbol{H}^{\circ}{ }_{\text {orm }}, \mathbf{~ k J} / \mathbf{m o l}$ \\
\hline $\mathrm{MgAl}_{2} \mathrm{O}_{4}$ & 2135 & 3.8 & 2307.8 \\
$\mathrm{TiB}_{2}$ & 2850 & $4.45-4.50$ & 293.3 \\
$\mathrm{MgTiO}_{3}$ & 1680 & 3.91 & 1573.6 \\
$\alpha-\mathrm{Al}_{2} \mathrm{O}_{3}$ & 2045 & 3.99 & 1675.0 \\
\hline
\end{tabular}

Figure 1 shows the combustion thermogram of the $\mathrm{TiB}_{2}(75 \mathrm{wt} \%)+\mathrm{MgAl}_{2} \mathrm{O}_{4}(25 \mathrm{wt} \%)$ system. The maximal combustion temperature is $2300^{\circ} \mathrm{C}$, which is higher than the spinel melting temperature. Synthesis was conducted layer-by-layer in the steady state combustion conditions. Similar combusting 
conditions were observed for $\mathrm{Ti}+2 \mathrm{~B}+x \mathrm{Cu}$ and $\mathrm{Ti}+2 \mathrm{~B}+x \mathrm{Fe}$ systems. Depending on their content, different metal alloys partially or fully surround particles of titanium borides $[8,9]$.

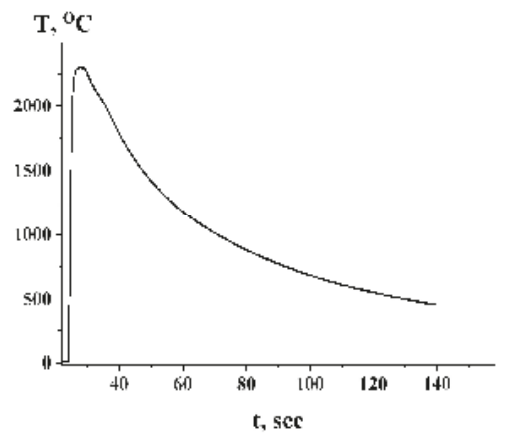

Figure 1. Combustion thermogram of the $\mathrm{TiB}_{2}(75 \mathrm{wt} \%)+\mathrm{MgAl}_{2} \mathrm{O}_{4}(25 \mathrm{wt} \%)$ system.

Studies on the microstructure of the composite blends based on $\mathrm{TiB}_{2}$ with different $\mathrm{MgAl}_{2} \mathrm{O}_{4}$ compositions showed that, depending on the amount of added spinel, the composite structure change (Figure 2). If the amount of added $\mathrm{MgAl}_{2} \mathrm{O}_{4}$ is $<10 \%$, the grains of titanium diboride in the microstructure of the composite are partially surrounded by a solidified alloy of $\mathrm{MgAl}_{2} \mathrm{O}_{4}$ (Figure 2a). The best results were obtained at a spinel composition of $25 \%$. The fine-grain microstructure from $\mathrm{TiB}_{2}$ grains (light crystals) was observed, which is fully surrounded by spinel (dark areas). When $40 \% \mathrm{MgAl}_{2} \mathrm{O}_{4}$ was added to the blend during the synthesis, the formation of a non-homogeneous structure was observed. The structure contains areas with the fine-grained titanium diboride and adjusting areas from alumina-magnesia spinel (Figure 2c).

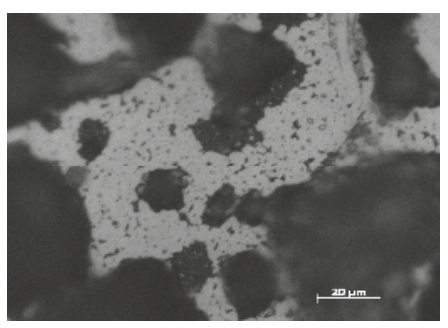

(a)

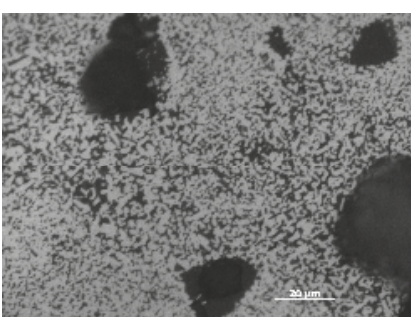

(b)

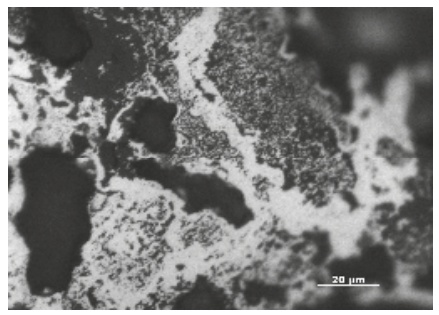

(c)

Figure 2. Microstructure of SHS composites based on titanium diboride with additions of $\mathrm{MgAl}_{2} \mathrm{O}_{4}$ : (a) $90 \%(\mathrm{Ti}+2 \mathrm{~B})+10 \% \mathrm{MgAl}_{2} \mathrm{O}_{4} ;$ (b) $75 \%(\mathrm{Ti}+2 \mathrm{~B})+25 \% \mathrm{MgAl}_{2} \mathrm{O}_{4} ;\left(\right.$ c) $60 \%(\mathrm{Ti}+2 \mathrm{~B})+40 \% \mathrm{MgAl}_{2} \mathrm{O}_{4}$.

When $45 \% \mathrm{MgAl}_{2} \mathrm{O}_{4}$ is added to the composite, the mixture does not burn in this case, because $\mathrm{MgAl}_{2} \mathrm{O}_{4}$ is inert. 
Complete information on the structure of the product formed during SHS can be obtained by analyses of fracture surfaces, studied with scanning electron microscopy. Figure 3 shows the microstructure of fractures of SHS ceramic samples based on titanium diboride with the addition of $25 \% \mathrm{MgAl}_{2} \mathrm{O}_{4}$ (Figure 3a,b), and $0 \% \mathrm{MgAl}_{2} \mathrm{O}_{4}$ (Figure 3c,d).

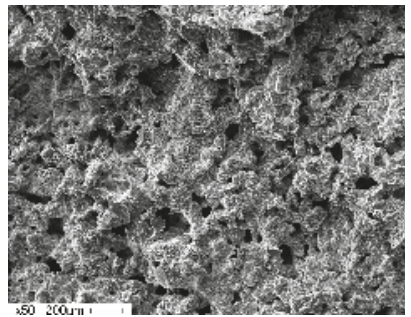

(a)

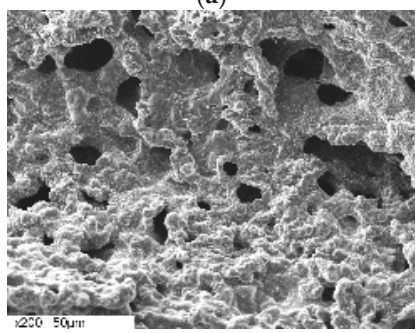

(c)

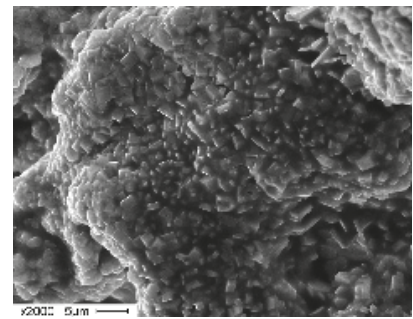

(b)

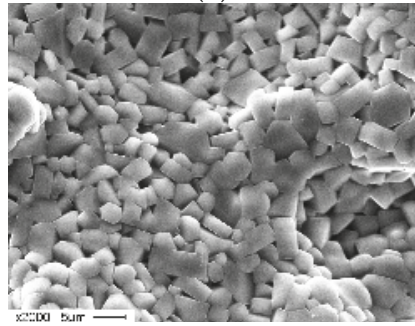

(d)

Figure 3. Fractures of SHS samples: $(\mathbf{a}, \mathbf{b}) 75 \%(\mathrm{Ti}+2 \mathrm{~B})+25 \% \mathrm{MgAl}_{2} \mathrm{O}_{4} ;(\mathbf{c}, \mathbf{d})(\mathrm{Ti}+2 \mathrm{~B})$.

As can be seen from Figure 3, the addition of $25 \% \mathrm{MgAl}_{2} \mathrm{O}_{4}$ leads to the decreasing of $\mathrm{TiB}_{2}$ crystals $(\sim 2 \mu \mathrm{m})$, which are surrounded by a solidified alloy of alumina-magnesia spinel. The microstructure of the SHS sample with $\mathrm{Ti}+2 \mathrm{~B}$ composition is formed by large $\mathrm{TiB}_{2}$ faceted crystals.

Figure 4 shows the diffraction patterns of $\mathrm{TiB}_{2}$ composites with different amounts of spinel. X-ray diffraction analyses showed that in the composition of alumina-magnesia spinel, there is $12 \mathrm{wt} \%$ of $\mathrm{MgAl}_{2} \mathrm{O}_{4}$. Figure 4 shows that spinel is identified in the composite containing $25 \mathrm{wt} \%$ of $\mathrm{MgAl}_{2} \mathrm{O}_{4}$, though, metallographically the spinel is identified at $10 \mathrm{wt} \%$ of $\mathrm{MgAl}_{2} \mathrm{O}_{4}$.

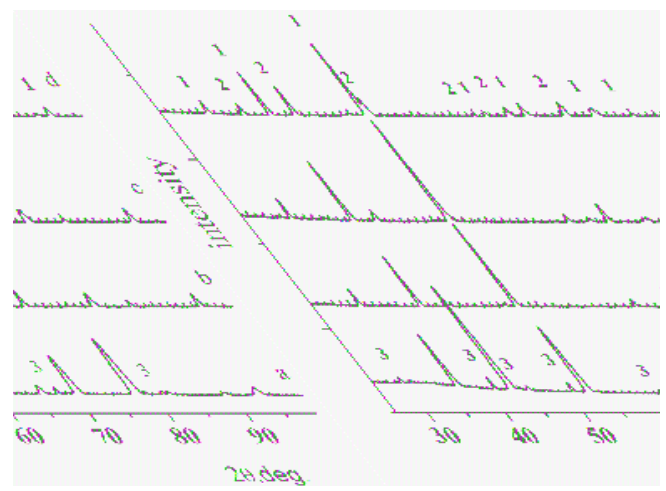

Figure 4. X-ray diffraction patterns of $\mathrm{TiB}_{2}$ composites with different contents of alumina-magnesia spinel: (a) $\mathrm{MgAl}_{2} \mathrm{O}_{4}$; (b) $\mathrm{TiB}_{2}+10 \% \mathrm{MgAl}_{2} \mathrm{O}_{4}$; (c) $\mathrm{TiB}_{2}+25 \% \mathrm{MgAl}_{2} \mathrm{O}_{4}$; (d) $\mathrm{TiB}_{2}+40 \% \mathrm{MgAl}_{2} \mathrm{O}_{4}$. $1-\mathrm{TiB}_{2}, 2-\mathrm{MgAl}_{2} \mathrm{O}_{4}, 3-\mathrm{Al}_{2} \mathrm{O}_{3}$. 
The composite with the fine-grained microstructure containing 25 wt \% of $\mathrm{MgAl}_{2} \mathrm{O}_{4}$ was studied by FTIR spectroscopy. Figure 5 shows the FTIR spectrum of $\mathrm{MgAl}_{2} \mathrm{O}_{4}, \mathrm{TiB}_{2}-\mathrm{MgAl}_{2} \mathrm{O}_{4}$ composite, corundum, and $\mathrm{TiB}_{2}$.

Figure 5 (pattern 1) shows that alumina-magnesia spinel has two different absorption bands with maximums at $692.0 \mathrm{~cm}^{-1}$ and $540.0 \mathrm{~cm}^{-1}$, related to the tetrahedral coordinated magnesium $\mathrm{MgO}_{4}$ and octahedral coordinated aluminum of $\mathrm{AlO}_{6}$. The small peak in the frequency range of $800-900 \mathrm{~cm}^{-1}$ proves the presence of $\mathrm{Al}_{2} \mathrm{O}_{3}$ in spinel content. Irregularity of the spinel structure leading to a change of binding force in the cation sub-lattice is identified by the emergence of an absorption band at $558.7 \mathrm{~cm}^{-1}$ [10].

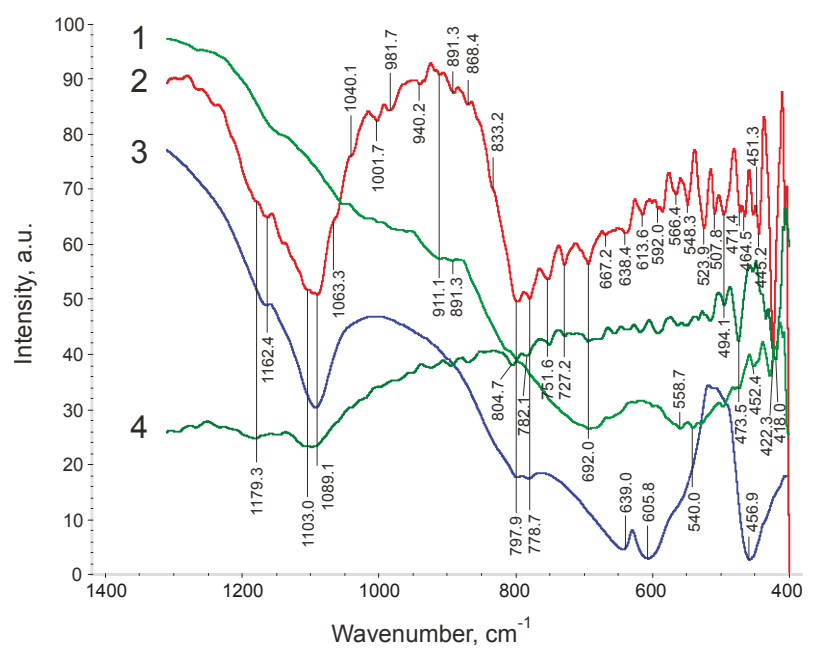

Figure 5. FTIR spectrum in the frequency range of 400-1300 $\mathrm{cm}^{-1}$ : (1) $\mathrm{MgAl}_{2} \mathrm{O}_{4}$; (2) $\mathrm{TiB}_{2}$ composite $25 \mathrm{wt} \%$ of $\mathrm{MgAl}_{2} \mathrm{O}_{4} ;$ (3) gray corundum; (4) $\mathrm{TiB}_{2}$.

FTIR spectrum of composite $\left(\mathrm{TiB}_{2}+25 \mathrm{wt} \%\right.$ of $\left.\mathrm{MgAl}_{2} \mathrm{O}_{4}\right)$ consists of numerous absorption bands typical for titanium diboride, spinel, and corundum (pattern 2).

According to the burning thermogram for the $75 \mathrm{wt} \% \mathrm{TiB}_{2}+25 \mathrm{wt} \% \mathrm{MgAl}_{2} \mathrm{O}_{4}$ system, the burning temperature is $2300{ }^{\circ} \mathrm{C}$. Therefore, $\mathrm{MgAl}_{2} \mathrm{O}_{4}$ is partially decomposed with corundum formation.

$$
\mathrm{MgAl}_{2} \mathrm{O}_{4} \stackrel{T}{\rightarrow} \quad \mathrm{Al}_{2} \mathrm{O}_{3}+\mathrm{MgO}
$$

Pattern 3 shows the FTIR spectrum of gray corundum. Along with absorption bands at $639.0 \mathrm{~cm}^{-1}$, $605.8 \mathrm{~cm}^{-1}$, and $456.9 \mathrm{~cm}^{-1}$ typical for octahedral coordinated aluminum $\mathrm{AlO}_{6}$ in $\alpha-\mathrm{Al}_{2} \mathrm{O}_{3}$, there are absorption bands at $1089.1 \mathrm{~cm}^{-1}, 797.9 \mathrm{~cm}^{-1}$, and $778.7 \mathrm{~cm}^{-1}$, related to the tetrahedral coordinated aluminum $\mathrm{AlO}_{4}$ [11]. The same absorption bands are observed in the composite spectrum.

It is well known that $\alpha-\mathrm{Al}_{2} \mathrm{O}_{3}$ contains aluminum atoms which are octahedrally coordinated by oxygen [10,12]. According to the literature data [13], the gray color of corundum is caused by the presence of aluminous spinel $\mathrm{AlOAl}_{2} \mathrm{O}_{3}$. This spinel was identified during the electrocorundum synthesis in reducing medium [13]. The melting temperature of spinel is $1980{ }^{\circ} \mathrm{C}$ [1].

At the interference level, the absorption bands at $940.2 \mathrm{~cm}^{-1}, 727.2 \mathrm{~cm}^{-1}$, and $507.8 \mathrm{~cm}^{-1}$ are observed. They can be referred to $\mathrm{MgTiO}_{3}$ [12]. The formation of $\mathrm{MgTiO}_{3}$ is possible during the synthesis at the phase boundary between $\mathrm{TiB}_{2}$ and $\mathrm{MgAl}_{2} \mathrm{O}_{4}$.

Oxygen and $\mathrm{MgO}$ can be borrowed during the thermal decomposition of spinel. In this case, aluminum is moved from an octahedral coordination to a tetrahedral one with the formation of both $\mathrm{MgTiO}_{3}$ and aluminous spinel with an intensive absorption band at $1089.1 \mathrm{~cm}^{-1}$. It is well-known [14] 
that at high temperatures over $\mathrm{Al}_{2} \mathrm{O}_{3}$, the gas phase is formed as a result of thermal dissociation. The gas phase contains aluminum sub-oxides $\mathrm{Al}_{2} \mathrm{O}$ and $\mathrm{AlO}^{-}$.

$$
\mathrm{Al}_{2} \mathrm{O}_{3} \stackrel{T}{\rightarrow} \quad \mathrm{Al}_{2} \mathrm{O} \uparrow+\mathrm{O}_{2} \uparrow
$$

Aluminum sub-oxides can also participate in the formation of aluminous spinel $\mathrm{AlOAl}_{2} \mathrm{O}_{3}$.

$$
2 \mathrm{Al}_{2} \mathrm{O}_{3}+\mathrm{Al}_{2} \mathrm{O}+\mathrm{O} \rightarrow 2 \mathrm{AlOAl}_{2} \mathrm{O}_{3}
$$

The FTIR spectrum of this composite (pattern 2) represents the envelope line along the spectrum of alumina-magnesia spinel. The overlap of numerous bond oscillation frequencies, related to the $\mathrm{TiB}_{2}$, corundum, aluminous spinel, and $\mathrm{MgTiO}_{3}$, is observed.

Studies showed that the obtained composite consists of $\mathrm{TiB}_{2}$ fine grains, which are homogeneously distributed in the alumina-magnesia matrix containing $\alpha-\mathrm{Al}_{2} \mathrm{O}_{3}$. Traces of $\mathrm{MgTiO}_{3}$ and aluminous spinel are also present in the composite.

According to the literature data [5], $12 \mathrm{~mol} \%$ of $\mathrm{MgO}$ and $85.5 \mathrm{~mol} \%$ of $\mathrm{Al}_{2} \mathrm{O}_{3}$ can be dissolved in alumina-magnesia spinel. In Table 2, the eutectic melting temperatures in the $\mathrm{MgO}-\mathrm{Al}_{2} \mathrm{O}_{3}$ system are presented.

Table 2. Eutectic melting temperatures in the $\mathrm{MgO}-\mathrm{Al}_{2} \mathrm{O}_{3}$ system.

\begin{tabular}{ccc}
\hline Chemical Compounds in Eutectics & $\mathbf{A l}_{2} \mathbf{O}_{3}$ Composition, wt $\%$ & Melting Temperature, ${ }^{\circ} \mathbf{C}$ \\
\hline $\mathrm{MgO}_{1} \mathrm{MgAl}_{2} \mathrm{O}_{4}$ & 55 & 1995 \\
$\mathrm{MgAl}_{2} \mathrm{O}_{4}, \mathrm{Al}_{2} \mathrm{O}_{3}$ & 98 & 1920 \\
\hline
\end{tabular}

Melting temperatures of $\mathrm{TiB}_{2}, \alpha-\mathrm{Al}_{2} \mathrm{O}_{3}, \mathrm{MgTiO}_{3}$, and $\mathrm{MgAl}_{2} \mathrm{O}_{4}$ as well as their eutectics are presented in Tables 1 and 2. As can be seen from Table 2, all values of the melting temperatures are very high, which proves that the obtained ceramic material is refractory.

\section{Conclusions}

It was shown that structure with a homogeneous fine-grained distribution of $\mathrm{TiB}_{2}$ grains was obtained by using $25 \mathrm{wt} \%$ of $\mathrm{MgAl}_{2} \mathrm{O}_{4}$.

The formed surface layer of $\mathrm{MgAl}_{2} \mathrm{O}_{4}$ on the grains boundary of $\mathrm{TiB}_{2}$ serves as a blocking protection from titanium diboride oxidation and prevents the growth of $\mathrm{TiB}_{2}$ crystals.

A partial decomposition of spinel occurred during the composite synthesis. This is proved by the presence of $\mathrm{MgTiO}_{3}$ and corundum traces in the composite, which were identified by FTIR spectroscopy.

Acknowledgments: The work was carried out with financial support from the Ministry of Education and Science of the Russian Federation in the framework of Increase Competitiveness Program of MISIS.

Author Contributions: Nina Radishevskaya performed FTIR-spectroscopy experiments and analyzed the data; Olga Lepakova conducted the microstructure research of samples; Natalia Karakchieva conducted the X-ray phase analyses of samples; Anastasiya Nazarova conducted the synthesis of samples; Nikolai Afanasiev wrote the paper; Anna Godymchuk and Alexander Gusev studied SHS characteristics, such as combustion temperature and combustion wave propagation mode and velocity.

Conflicts of Interest: The authors declare no conflict of interest. The founding sponsors had no role in the design of the study; in the collection, analyses, or interpretation of data; in the writing of the manuscript, and in the decision to publish the results.

\section{References}

1. Li, Y.B.; Li, N.; Ruan, G.Z.; Li, X.H. Reaction in the aluminotheric reduction nitridation reaction to synthesize $\mathrm{MgAl}_{2} \mathrm{O}_{4} /$ TiN. Ceram. Int. 2005, 31, 825-829. [CrossRef] 
2. Omid, E.K.; Naghizadeh, R.; Rezaie, H.R. Synthesis and comparison of $\mathrm{MgAl}_{2} \mathrm{O}_{4}-\mathrm{Ti}(\mathrm{C}, \mathrm{N})$ composites using aluminothermic-carbothermal reduction and molten salts routes. J. Ceram. Process. Res. 2013, 14, 445-447.

3. Bae, Y.; Jun, B. Preparation of ultrafine $\mathrm{TiC}, \mathrm{MgAl}_{2} \mathrm{O}_{4}$ and $\mathrm{AlON}$ composite powder using chemical furnace. J. Ceram. Process. Res. 2008, 9, 661-665.

4. Zaki, Z.I.; Ahmed, Y.M.Z.; Abdel Gawad, S.R. In situ synthesis of porous magnesia spinel/ $\mathrm{TiB}_{2}$ composite by combustion technique. J. Ceram. Soc. Jpn. 2009, 117, 719-723. [CrossRef]

5. Horvitz, D.; Gotman, I. Pressure-assisted DHD synthesis of $\mathrm{MgAl}_{2} \mathrm{O}_{4}-\mathrm{TiAl}$ in Situ composites with interpenetrating networks. Acta Mater. 2002, 50, 1961-1971. [CrossRef]

6. Horoshavin, L.B. Spinel Nanorefractory Materials; UB RAS: Ekaterinburg, Russia, 2009; p. 600.

7. Merzhanov, A.G. Processes of Burning and Materials Synthesis; ISMAN: Chernogolovka, Russia, 1998; p. 511.

8. Lepakova, O.K.; Raskolenko, L.G.; Maksimov, Y.M. Self-propagating high-temperature synthesis of composite material $\mathrm{TiB}_{2}-$ Fe. J. Mater. Sci. 2004, 39, 3723-3732. [CrossRef]

9. Vadchenko, S.G.; Filimonov, I.A. Burning modes of diluted system Ti + 2B. Phys. Burn. Combust. 2003, 39, 48-55.

10. Barabanov, V.F.; Goncharov, G.N.; Zorina, M.L. Modern Physical Methods on Geochemistry; Leningrad University: Pushkin, Russia, 1990; p. 390.

11. Chernyakova, K.V.; Vrubelevskii, I.A.; Ivanovskaya, M.I.; Kotikov, D.A. Defective structure of anode alumina oxide, formed by method of bilateral anodic oxidation. J. Appl. Spectrosc. 2012, 79, 83-89.

12. Nakamoto, K. IK-Spektry i Spektry KR Neorganicheskikh i Koordinatsionnykh Soedinenii (Infrared and Raman Spectra of Inorganic and Coordination Compounds); Mir: Moscow, Russia, 1991; p. 536.

13. Solodkii, E.N.; Solodkii, N.F. Reasons for coloring corundum ceramics. Glass Ceram. 2000, 11, $24-26$.

14. Kulikov, I.S. Metals Deoxidation; Metallurgy: Moscow, Russia, 1975; p. 504.

(c) 2017 by the authors. Licensee MDPI, Basel, Switzerland. This article is an open access article distributed under the terms and conditions of the Creative Commons Attribution (CC BY) license (http:/ / creativecommons.org/licenses/by/4.0/). 
Article

\title{
The Microstructure Evolution, Mechanical Properties and Densification Mechanism of TiAl-Based Alloys Prepared by Spark Plasma Sintering
}

\author{
Dongjun Wang ${ }^{1,2, *}$, Hao Yuan ${ }^{3}$ and Jianming Qiang ${ }^{3}$ \\ 1 National Key Laboratory for Precision Hot Processing of Metals, Harbin Institute of Technology, \\ Harbin 150001, China \\ 2 Key Laboratory of Micro-Systems and Micro-Structures Manufacturing, Ministry of Education, \\ Harbin 150001, China \\ 3 School of Materials Science and Engineering, Harbin Institute of Technology, Harbin 150001, China; \\ yh18345168977@gmail.com (H.Y.); q2564108815@gmail.com (J.Q.) \\ * Correspondence: dongjunwang@hit.edu.cn; Tel.: +86-451-8640-2590; Fax: +86-451-8641-8714
}

Academic Editor: Mark T. Whittaker

Received: 27 April 2017; Accepted: 26 May 2017; Published: 2 June 2017

\begin{abstract}
The microstructure evolution and mechanical properties of a Ti-Al-Cr-Nb alloy prepared by spark plasma sintering (SPS) at different temperatures and stresses were investigated in detail. Sintering temperature plays a key role in the densification process and phase transformation, which determines the microstructure. The mechanical properties of the sintered alloys depend on the microstructure caused by the sintering. Furthermore, the densification process and mechanism of TiAl-based metallic powders during SPS were studied based on experimental results and theoretical analysis, the results of which will help fabricate these kinds of intermetallic alloys using a powder metallurgy technique and accelerate their industrial applications.
\end{abstract}

Keywords: intermetallics; aerospace; powder metallurgy; microstructure evolution; mechanical property; densification

\section{Introduction}

Alloys based on the intermetallic phase $\gamma$-TiAl are increasingly used as potential replacements for nickel-based superalloys in different application fields, e.g., turbine blades, space vehicles, and stationary turbines [1,2]. TiAl-based alloys have attracted this attention due to their low density (about $4 \mathrm{~g} / \mathrm{cm}^{3}$ ), high yield strength at high temperature, good oxidation resistance, and corrosion resistance $[3,4]$.

TiAl-based alloys can usually be produced by conventional casting or ingot metallurgy, etc. However, microstructural defects such as porosity, coarse grain and composition heterogeneity, and low material utilization ratio of TiAl-based alloys hinder their actual engineering applications. The mechanical properties of TiAl-based alloys mainly depend on their microstructure [5,6], and thus the alloys are regularly forcibly treated using hot isostatic processing (HIP), or hot processing $[7,8]$ to eliminate porosity or refine grains, which can improve their performance, but inversely gives rise to a longer manufacturing duration and higher cost of investment.

In recent years, powder metallurgy (PM) has been considered as an alternative processing technique for the preparation of TiAl-based alloys as the near-net-shape forming method $[9,10]$. Furthermore, TiAl-based metallic powders with fine grains and homogeneous composition can be obtained during a gas atomization process. Afterwards, the atomized powders usually consolidate into bulk by hot pressing, or the HIP method [11]. Particularly, spark plasma sintering (SPS) can 
satisfactorily compact powders through high intensity pulsed direct current and stress, and it is currently attracting the attention of the industrial field due to its advantages such as rapidity, cheapness, and simplicity [12-14]. Lin et al. [15] fabricated a high Nb-containing Ti-45Al-8.5Nb-(W, B, Y) alloy using the SPS and HIP methods. Couret et al. [16] obtained a near-lamellar Ti-48Al-2W-0.02B alloy and the effects of B addition were investigated. Liu et al. [17] conducted spark plasma sintering of a beta phase-containing Ti-44Al-3Nb-1Mo-1V-0.2Y alloy with potentially good hot deformability. To fabricate TiAl-based alloys with considerable properties through the PM route, it is necessary to carry out a densification process by which the alloys with high density are obtained. Moreover, the sintering parameters can affect the phase morphology and thus influence the mechanical properties. To attempt the near-net fabrication of TiAl alloys and parts utilized at a temperature of $\sim 800{ }^{\circ} \mathrm{C}$, it was of importance to understand the relationship between the sintering process, densification, microstructure, and properties of TiAl-based alloys during sintering, which can provide and supply more information about this alloy using the PM technique.

In this paper, based on the study of the microstructure evolution and mechanical properties of TiAl-based alloys prepared by SPS, the effect of parameters on the densification process was analyzed, leading to a more basic understanding of intermetallic alloys for fabrication using the PM technique.

\section{Materials and Methods}

Gas atomized TiAl powders (Ti-46.5Al-2.15Cr-1.90 Nb, atomic percent) with sizes between 20 and $80 \mu \mathrm{m}$ were prepared and sintered using 3.20-MK-V SPS equipment for $7 \mathrm{~min}$ at different temperatures $\left(900,1050,1100,1150\right.$, and $\left.1250{ }^{\circ} \mathrm{C}\right)$ under a pressure of $50 \mathrm{MPa}$. For comparison, more samples were sintered under pressures of 10 and $30 \mathrm{MPa}$ at $1150^{\circ} \mathrm{C}$, as well as under pressure of $50 \mathrm{MPa}$ at $1000{ }^{\circ} \mathrm{C}$. The sintering temperatures were measured with a pyrometer on the external surface of the graphite molds. The pressure and temperature started simultaneously at the time of zero and the pressure was kept constant during sintering. The heating rate was initially $120 \mathrm{~K} / \mathrm{min}$, and was reduced to $20 \mathrm{~K} / \mathrm{min}$ for the last $100 \mathrm{~K}$ to mitigate temperature overshooting. The temperatures given in this paper were the monitored temperatures. After holding at the sintering temperature, the heating current and the pressure were released, followed by sample cooling in the SPS chamber. Two typical samples were fabricated with cylindrical shapes of $\Phi 20 \mathrm{~mm} \times 10 \mathrm{~mm}$ and $\Phi 45 \mathrm{~mm} \times 15 \mathrm{~mm}$, respectively. The structural characteristics were investigated by X-ray diffraction (XRD, D/Max-RA diffractometer (Rigaku Corporation, Tokyo, Japan), operated with $\mathrm{Cu} \mathrm{K} \alpha$ ), differential thermal analysis (DTA, NETZSCH STA 449C, NETZSCH company, Selb, Germany), and scanning electron microscopy (SEM, Quanta200FEG, FEI company, Hillsboro, OR, USA), equipped with energy dispersive spectroscopy (EDS, FEI company, Hillsboro, OR, USA). For the SEM analysis, the back-scattered electron (BSE) detector (FEI company, Hillsboro, OR, USA) was used. The densities of the sintered samples were determined using the "Archimedes" method. Micro-hardness was measured using a Matsuzawa SeikiMHT-1 micro-hardness tester ((MATSUZAWA SEIKI Co. LTD, Tokyo, Japan) under a load of $50 \mathrm{~g}$. The mechanical responses with a dimension of $\Phi 3 \mathrm{~mm} \times 4.5 \mathrm{~mm}$ (aspect ratio of 1.5) were evaluated by the quasi-static compression test at room temperature with a strain rate of $5 \times 10^{-4} \mathrm{~s}^{-1}$. The two sides of each specimen were carefully ground and polished until they were parallel to each other in order to mitigate the effect of friction during tests. The fracture surfaces of the samples were also examined by SEM (secondary electron detector).

\section{Results and Discussion}

\subsection{Microstructure Evolution}

Figure 1 shows the XRD patterns of the TiAl powders and the samples sintered at different temperatures. For the atomized powders, they were mainly composed of a single $\alpha_{2}$ phase due to the rapid cooling rate. Similar phase constitution has been reported in small size TiAl powders prepared by gas atomization in Reference [18]. These results also suggested that the atomized powders 
were in a non-equilibrium state caused by rapid solidification. The diffraction patterns of samples after sintering were similar. As can be seen, the sharp diffraction peaks belonging to $\mathrm{TiAl}$ and $\mathrm{Ti}_{3} \mathrm{Al}$ confirmed that the TiAl-based alloys after SPS contained substantive amounts of $\gamma$ (e.g., dark phase in Figure 2D,E), and $\alpha_{2}$ phases (e.g., bright phase in Figure 2D,E). Moreover, the bulk TiAl-based alloy with a dimension of $\Phi 45 \mathrm{~mm} \times 15 \mathrm{~mm}$ and cylinder-shaped part with the dimension of $\Phi 30$ (internal diameter 10) $\mathrm{mm} \times 30 \mathrm{~mm}$ prepared by SPS are shown in the inset of Figure 1 . One can see that the spark plasma sintered TiAl-based alloy exhibited a shining metallic luster in appearance.

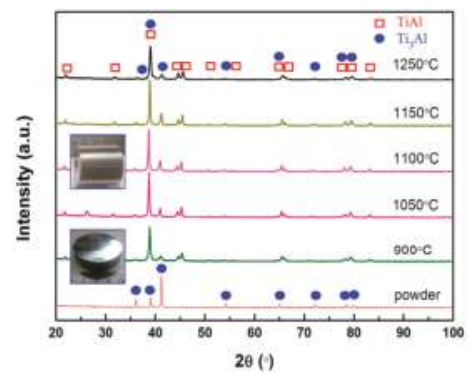

Figure 1. X-ray diffraction patterns of the samples.

The SEM observations of the powders and samples sintered at different temperatures are shown in Figure 2. As can be seen, the powder exhibited a dendritic-like microstructure containing a large amount of out-of-equilibrium $\alpha_{2}$ phase (Figure 2A). Based on EDS analysis, the composition of metallic powders was $\mathrm{Ti}_{50.46} \mathrm{Al}_{45.61} \mathrm{Cr}_{1.99} \mathrm{Nb}_{1.94}$ (at \%), which was close to the nominal composition of this alloy.

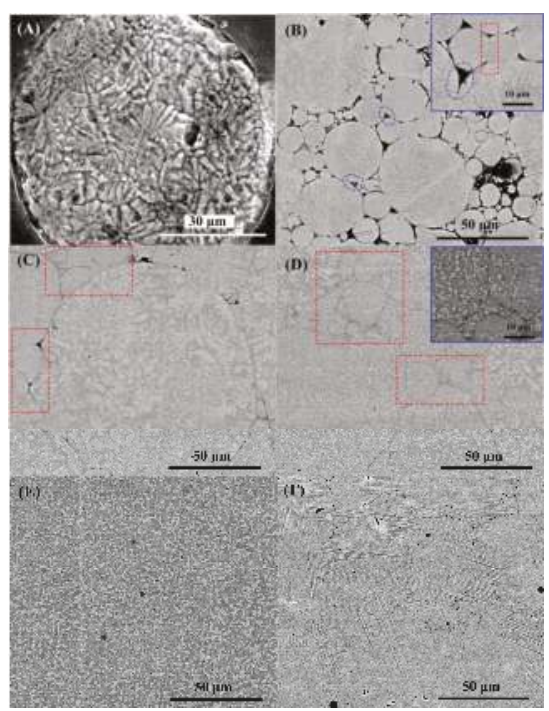

Figure 2. Scanning electron microscopy (SEM) images of the atomized powder (A) and the sintered samples at (B) $900{ }^{\circ} \mathrm{C}$; (C) $1050{ }^{\circ} \mathrm{C}$; (D) $1100{ }^{\circ} \mathrm{C}$; (E) $1150{ }^{\circ} \mathrm{C}$; and (F) $1250{ }^{\circ} \mathrm{C}$.

For the sample consolidated at $900{ }^{\circ} \mathrm{C}$, the microstructure had significant porosity, especially at triple contact areas of powder particles (blue dashed region of Figure 2B). It was also noted that the plastic deformation of some small powders occurred at this temperature (red dashed region of inset of 
Figure 2B), suggesting that densification initially took place. When the sintering temperature increased to $1050^{\circ} \mathrm{C}$ (Figure 2C), a few pores could still be seen, although a more compact microstructure was obtained. Moreover, more deformed features of small powders were observed (red dashed region in Figure 2C). With an increase in temperature to $1100^{\circ} \mathrm{C}$ (Figure 2D), macroscopic pores disappeared post-sintering. However, the grain boundaries (GBs) were still visible at the contact areas among the deformed powders (e.g., red dashed region), which indicates that plastic deformation plays a key role in the densification process. In addition, compared with the alloys at lower sintering temperatures (Figure 2B,C), the non-equilibrium dendritic microstructure (Figure 2A) of the powders disappeared for the sample sintered at $1100{ }^{\circ} \mathrm{C}$ (inset of Figure 2D). With further increases in temperature (Figure 2E), one could see a highly dense microstructure of the alloy sintered at $1150^{\circ} \mathrm{C}$ without GBs observed, revealing a high sintering density and sufficient densification at this temperature. It is also of importance to note that a double-phase microstructure was obtained. From a chemical composition perspective, the composition of the bright $\alpha_{2}$ phase was $\mathrm{Ti}_{53.98} \mathrm{Al}_{41.85} \mathrm{Cr}_{2.24} \mathrm{Nb}_{1.94}$ (at \%, relatively rich in $\mathrm{Ti}$ ), and that of the dark $\gamma$ phase was $\mathrm{Ti}_{47.48} \mathrm{Al}_{48.76} \mathrm{Cr}_{1.90} \mathrm{Nb}_{1.86}$ (at \%, relatively rich in $\mathrm{Al}$ ). Aside from the compact microstructure, the sample sintered at $1250{ }^{\circ} \mathrm{C}$ exhibited lamella morphology (Figure 2F). As shown, this lamella microstructure contained homogeneous lamellar colonies $\alpha_{2} / \gamma$. Moreover, the composition of these lamellas was $\mathrm{Ti}_{49.63} \mathrm{Al}_{46.40} \mathrm{Cr}_{2.15} \mathrm{Nb}_{1.82}$ (at \%) based on EDS, which is close to the nominal composition of this alloy.

To verify the phase transformation point of TiAl-based powders, a DTA analysis was conducted, and the experimental curve is shown in Figure 3. In this curve, two endothermal peaks based on phase transformation were observed. Based on this, the eutectoid temperature $\left(T_{e}\right)$ and the $\alpha$ transus temperature $\left(T_{\alpha}\right)$ of the powders were estimated to be approximately 1260 and $1315{ }^{\circ} \mathrm{C}$, respectively. During the SPS, the temperature can induce phase transformation and thus affect the microstructure and densification. For a given experiment, the actual temperature could even be $160^{\circ} \mathrm{C}$ higher than the monitored SPS temperature [19]. When the sintering temperature was $1150^{\circ} \mathrm{C}$, it was deduced that the actual temperature of the powders could be higher than $1260^{\circ} \mathrm{C}\left(T_{e}\right)$. In this case, the sample was composed of $\gamma$ phase and $\alpha$ phase ( $\alpha+\gamma$ phase region) at this sintering temperature. Upon cooling, the $\alpha$ phase transformed into an ordered $\alpha_{2}$ phase, while the $\gamma$ phase remained and a double-phase microstructure formed for the sintered sample (Figure 2E). When the powders were sintered at $1250{ }^{\circ} \mathrm{C}$, the actual temperature could be above $T_{\alpha}$, thus the microstructure consisted of $\alpha$ grains in this situation. During cooling, the formation of a lamellar microstructure (Figure 2F) took place following the evolution of $\alpha \rightarrow \alpha+\gamma \rightarrow \alpha_{2}+\gamma$. Meanwhile, it was also of interest to note that the dendritic-like microstructure of rapid atomized powders was not seen after densification. To understand this, it is well documented that recrystallization can occur dynamically during densification of the powders [12]. Since a clear tendency to recrystallize can occur in the deformed zones [20], the deformation of metallic powders (Figure 2B-D) during densification will result in recrystallization, and in turn an equilibrium microstructure, due to a large amount of stored deformation energy.

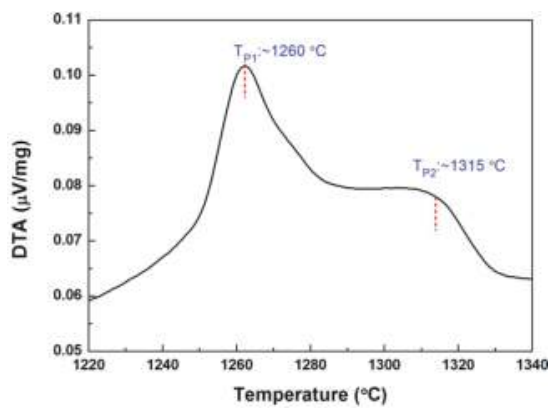

Figure 3. Differential thermal analysis curve of the powder sample. 


\subsection{Mechanical Property}

The density and micro-hardness of the samples sintered at different temperatures were investigated and are shown in Table 1. One can clearly see that the density and hardness of the sample with a lower sintering temperature exhibited relatively smaller values due to numerous pores after sintering, e.g., $900{ }^{\circ} \mathrm{C}$. When the sintering temperature increased to $1050,1100,1150$, and $1250{ }^{\circ} \mathrm{C}$, the density increased sharply and then nearly kept at constant. Furthermore, the hardness of the samples sintered at higher temperatures was also similar, which indicates that hardness is mainly dependent on density.

Table 1. Mechanical properties of TiAl-based alloys sintered at different temperatures.

\begin{tabular}{cccccc}
\hline Temperature $\left({ }^{\circ} \mathrm{C}\right)$ & $\mathbf{9 0 0}$ & $\mathbf{1 0 5 0}$ & $\mathbf{1 1 0 0}$ & $\mathbf{1 1 5 0}$ & $\mathbf{1 2 5 0}$ \\
\hline Density $\left(\mathrm{g} / \mathrm{cm}^{3}\right)$ & 3.392 & 3.944 & 3.966 & 3.967 & 3.965 \\
Hardness $(\mathrm{HV})$ & 278.6 & 413.0 & 420.0 & 417.0 & 430.0 \\
\hline
\end{tabular}

The relationship between fracture true strength, plastic strain, and sintering temperature is shown in Figure 4, as are the true stress-true strain curves of the sintered samples. When the sintering temperature was low $\left(900^{\circ} \mathrm{C}\right)$, the sample broke with no plastic strain and a very low fracture strength of $\sim 350 \mathrm{MPa}$. Many pores in this sample (Figure 2B) resulted in its weak compressive response. When the sintering temperature rose to 1050 and $1100{ }^{\circ} \mathrm{C}$, the densification process gradually took place and more compact microstructures were achieved (Figure 2C,D). Therefore, the mechanical performances of these two samples were significantly improved compared with samples sintered at lower temperatures, e.g., the fracture true strength and plastic strain of the samples sintered at 1050 and $1100{ }^{\circ} \mathrm{C}$ were $1795 \mathrm{MPa}$ and $24.8 \%$, and $1754 \mathrm{MPa}$ and $26.2 \%$, respectively. As shown, the sample sintered at $1150{ }^{\circ} \mathrm{C}$ with high density (Figure $2 \mathrm{E}$ ) had optimal compressive properties at room temperature. The fracture true strength was $1820 \mathrm{MPa}$ and the plastic true strain could also be as high as $32.6 \%$. Although the density was like that of the sample sintered at $1150{ }^{\circ} \mathrm{C}$, both the fracture strength and the plastic strain of the sample sintered at $1250^{\circ} \mathrm{C}$ dramatically decreased. Based on the above composition results, it was noted that the change of composition before and after sintering was slight, suggesting that a homogeneous composition was obtained during SPS. Further to composition, it is well known that the mechanical properties of alloys are determined by the microstructure, namely the synergetic effect of density and phase transformation for the sintered TiAl-based alloys. For the sample sintered at $1150{ }^{\circ} \mathrm{C}$, the high strength and considerable plasticity was attributed to the high density and small grain size. However, the poor strength and limited plasticity of the lamellar microstructure $\left(1250{ }^{\circ} \mathrm{C}\right)$ was caused by the lack of texture [19]. Therefore, the dislocations could propagate more easily and thus initiate the crack, which eventually led to the rapid failure of the sample. It can be concluded from the abovementioned results that the temperature of SPS has two main roles: (1) giving rise to densification; (2) changing the microstructure through phase transformation. Thus, to improve the mechanical properties of TiAl-based alloys, the PM technique can provide a simplified route, i.e., the combined processing for fabrication and microstructural optimization for the required composition. 


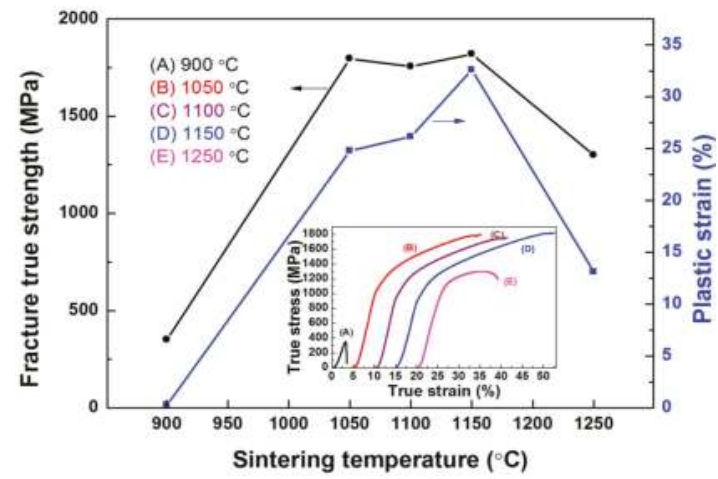

Figure 4. Room temperature compressive properties of the sintered TiAl alloys. The true stress-strain curves have been off-set for better visualization.

The typical fracture morphologies of the sintered samples are presented in Figure 5. Based on Figure 5A, one can see melt-like features at the triple junctions of powder particles, suggesting that spark plasma sintering promotes integration among the contact areas of the particles. Nevertheless, it was evident that a few globate powder particles were removed from the surface by external loading, which agrees with the high porosity and poor mechanical properties of the sample sintered at $900{ }^{\circ} \mathrm{C}$ (Figure $2 \mathrm{~B}$ and Table 1). For the sample sintered at $1150{ }^{\circ} \mathrm{C}$ (Figure 5B), intergranular fracture characteristics were observed. This fracture morphology was like that of the as-cast TiAl-based alloys, indicating its high density and good mechanical properties. When the sintering temperature increased to $1250^{\circ} \mathrm{C}$, cracks were seen on the fracture surface. In particular, the lamella-like imprints dominated the fracture morphology and further confirmed the lamellar microstructure of the sample sintered at this temperature.

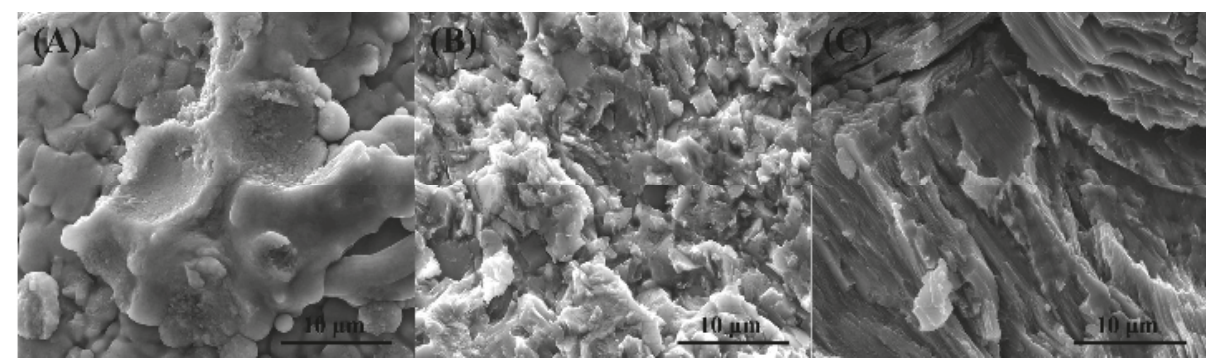

Figure 5. Fracture morphologies of the sintered samples: (A) $900{ }^{\circ} \mathrm{C}$; (B) $1150{ }^{\circ} \mathrm{C}$; (C) $1250{ }^{\circ} \mathrm{C}$.

\subsection{Densification Process}

To better understand the effect of sintering parameters on the densification of TiAl-based metallic powders during SPS, a model suggested by Bernard-Granger and Guizard [21] was used to analyze the sintering process. In this model, the flow stress for high-temperature deformation of the alloy is described as a function of strain rate $(\dot{\varepsilon})$ and temperature $(T)$ by Equation (1) [22].

$$
\dot{\varepsilon}=\frac{\mathrm{d} \varepsilon}{\mathrm{d} t}=\mathrm{A} \frac{D G_{0} b}{k T}\left(\frac{b}{d}\right)^{p}\left(\frac{\sigma}{G_{0}}\right)^{n}
$$


where $\dot{\varepsilon}$ is the strain rate; A is the constant; $D$ is the diffusion coefficient; $G_{0}$ is the shear modulus; $b$ is the Burgers vector; $k$ is Boltzmann's constant; $T$ is temperature; $d$ is grain size; $\sigma$ is the macroscopic applied stress; $p$ is the inverse grain size exponent; $n$ is the stress exponent; and $t$ is time.

During sintering, the strain rate is compared to the densification rate as per Equation (2) [23].

$$
\dot{\varepsilon}=\frac{1}{\rho} \frac{\mathrm{d} \rho}{\mathrm{d} t}
$$

where $\rho$ is the density. By taking the integral transformation of Equation (2), one can obtain Equation (3):

$$
\varepsilon=\ln \rho
$$

As per Equations (1)-(3), there are three main factors that determine the densification $(\rho)$ during sintering: the diffusion coefficient $D$, the temperature $T$, and the applied stress $\sigma$. It is well documented that the diffusion coefficient $D$ is mainly dominated by temperature; namely, the higher the temperature, the larger the diffusion coefficient. Therefore, when the temperature rises, the macroscopic sintering density increases and is maintained at nearly constant (Table 1).

In addition, based on the experimental data, the relationships between temperature, punch displacement, and sintering time were recorded, and a typical result of the sample sintered at $1150{ }^{\circ} \mathrm{C}$ is shown in Figure 6. During SPS, sintering can be divided into different stages to analyze the densification [24,25]. As shown in Figure 6, there were two clear sintering stages in our study, namely curve A-B and curve B-C-D for the displacement data. For the first stage (curve A-B), the punch displacement decreased due to the powder thermal expansion caused by the increase in temperature. The second stage (curve B-C-D) was important for densification, and the density increased sharply in accordance with the increase in temperature and punch displacement.

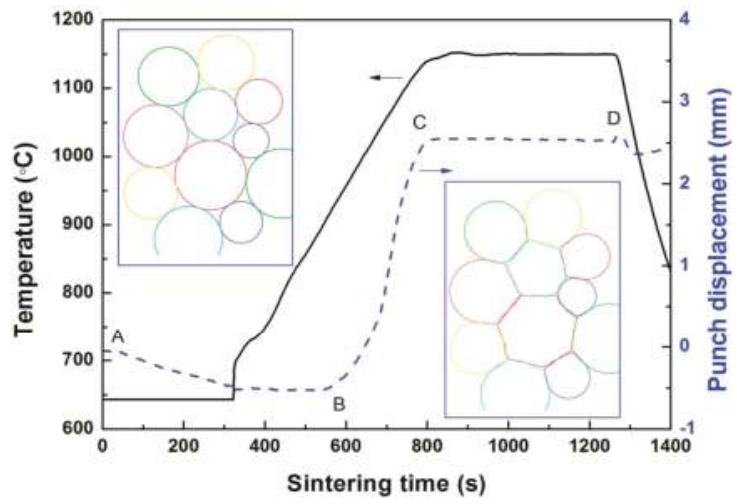

Figure 6. Temperature and punch displacement curves versus time for sintering at $1150{ }^{\circ} \mathrm{C}$.

It was noted that sintering involved several mechanisms microscopically operating simultaneously over these stages. Plastic deformation, e.g., in the form of dislocation movement, can play a role in densification [26]. During sintering, the loose powders initially encounter each other through the combined effect of temperature and sintering stress (upper left inset of Figure 6). When sintered at $900{ }^{\circ} \mathrm{C}$, the particles were in contact and were forced to deform, followed by the formation of sintering necks (inset of Figure 2B). Due to the applied pressure, densification took place through the plastic deformation of the powder particles and the dislocation emitted atoms as it moved close to the neck. However, this densification was not sufficient, and many large pores were visible (Figure 2B). In particular, the pores at the contacts of the powder particles exhibited sharp cusps (blue dashed region of Figure 2B) at this temperature. It is well known that the vacancy concentration that can act as 
an atomic diffusion path under a curved surface, depends on the curvature of the two perpendicular radii of curvature for the surface. Based on the two-sphere sintering model, the particle surface is convex and the sintering bond is concave, thus there will be a vacancy concentration gradient between these two [27]. Moreover, the solid surface energy—due to a concave curvature at the neck-also generates capillary stress as a driving force for atom diffusion. Therefore, the result is that vacancy flows away from the neck and atomic diffusion moves into the neck, resulting in the blunting of sharp cusps for the pores. Nevertheless, the pore cusps for the sample sintered at $900{ }^{\circ} \mathrm{C}$ (blue dashed region of Figure 2B) suggested that the diffusion mechanism played a minor role during this initial stage of densification and the deformation was considered as a dominant mechanism in this stage. By increasing the sintering temperature $\left(1050-1100^{\circ} \mathrm{C}\right)$, densification could be further associated with more plastic deformation of the particles (red dashed regions in Figure 2C,D) due to lower yield stress with increased temperatures. It was obvious that some small rounded powders deformed into elliptic shapes or even irregular shapes to fill the vacancies. The plastic deformation led to the flattening of contact areas and the reduction of porosity (Figure 2C,D), as demonstrated in the lower right inset of Figure 6. For the sample sintered at $1150{ }^{\circ} \mathrm{C}$ (Figure 2E), sufficient densification occurred and a nearly full dense microstructure was obtained.

In contrast, at the areas of the powder contacts during SPS there was current through the powder particles. Coupled with the plastic deformation discussed above, electro-thermal and heat transfer can occur at the contact interface when axial pressure applied. It is well known that motion such as thermal diffusion caused by heat transfer can promote mass transfer driven by Gibbs-Thomson driving forces [20], which is also responsible for interface bonding and causes densification from a microscopic perspective. After neck formation through deformation in the initial stage $\left(900^{\circ} \mathrm{C}\right)$, the grain boundaries formed within the neck (Figures 7a and 2B-D) between individual particles as random grain contacts led to misaligned crystals [28]. When the sintering temperature (such as $1000{ }^{\circ} \mathrm{C}$ ) increased, the diffusion mechanism significantly affected densification in comparison with lower temperatures. The evident sharp cusps (Figure 2B) of the pores were blunted and the pore structure became rounded (Figure $7 \mathrm{~b}$ ). In addition, blunted neck morphology between adjacent particles was observed and typical results are shown in the red dashed regions in Figure $7 \mathrm{~b}$. Similar neck features were also seen in the samples sintered at 1050 and $1100{ }^{\circ} \mathrm{C}$. Based on the above discussions, our results indicate that the diffusion mechanism occurred at a relatively higher temperature and the atoms diffusion (caused by capillary stress due to concave curvature) was performed to remove this curvature gradient. During diffusion, the collaborated mass moved from the solid particle to deposit on the pores, i.e., the atoms moved along the particle surfaces (surface diffusion), along grain boundaries (grain boundary diffusion), and through the lattice interior (volume diffusion). A schematic illustration of the microscopic diffusion paths and interface bonding during the densification of TiAl powders is shown in Figure 7a. Although the surface diffusion produced neck growth, it did not lead to a change in particle spacing [29], that is, no densification occurred since the mass flow originated and terminated at the particle surface. Densification took place only by bulk transport, as the mass responsible for growing the sintering neck comes from inside the powder particles, for example, from grain boundary diffusion and volume diffusion [30]. As seen in Figure 7a, the crystalline solid powders joined at the interparticle neck with a misalignment of crystal planes, resulting in a grain boundary where defective atomic bonding enabled rapid atomic diffusion and thus contributed to the densification [31]. Furthermore, effective volume diffusion involved the motion of vacancies along the lattice paths and a counter flow of atoms into the pores, which required relatively higher activation energy. Compared with volume diffusion activated at higher temperatures, there existed a sufficient grain boundary area due to the small particle size of this work (Figures 2B-D and 7b). Therefore, the grain boundary diffusion was considered as the dominant diffusion densification mechanism. Based on the above analysis, the sintering necks would form and gradually grow among adjacent particles through the synergetic mechanism of deformation and thermal diffusion. Thus, the pores were filled and the microstructure became compacted. 


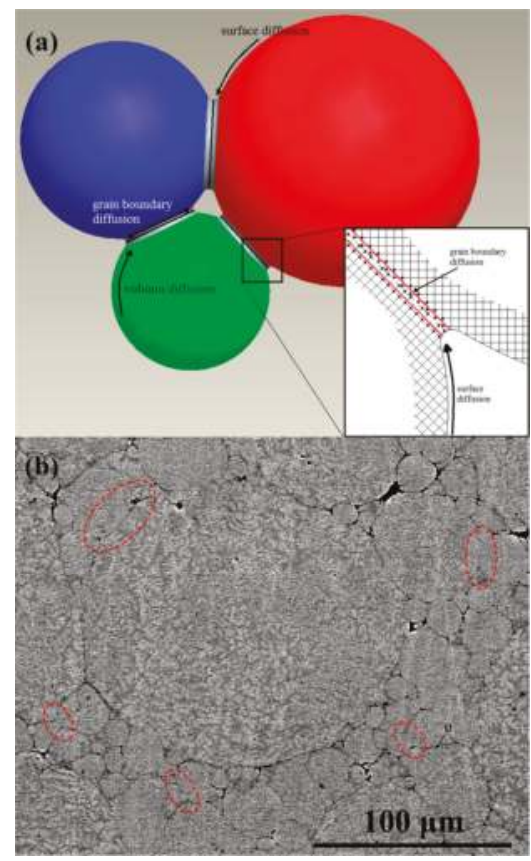

Figure 7. Schematic illustration of diffusion paths and interface bonding during spark plasma sintering (SPS) densification of TiAl powders (a); and the microstructure of the sample sintered at $1000{ }^{\circ} \mathrm{C}(\mathbf{b})$.

Besides temperature, it was also noted from Equations (1)-(3) that the applied stress could affect densification. To verify the influence of sintering stress, more samples were sintered at $1150{ }^{\circ} \mathrm{C}$ under different applied stresses, as shown in Table 2. As seen, a higher sintering density was obtained by applying larger sintering stress. Thus, the imposition of higher sintering pressure on powder-powder interfaces led to more severe deformation and accelerated the mass transport of the particles, which could promote the densification as per the abovementioned discussions.

Table 2. Sintering densities of TiAl-based alloys under different stresses at $1150^{\circ} \mathrm{C}$.

\begin{tabular}{cccc}
\hline Stress (MPa) & $\mathbf{1 0}$ & $\mathbf{3 0}$ & $\mathbf{5 0}$ \\
\hline Density $\left(\mathrm{g} / \mathrm{cm}^{3}\right)$ & 3.947 & 3.961 & 3.967 \\
\hline
\end{tabular}

\section{Conclusions}

Sintering temperature mainly determines the densification and phase transformation of TiAl-based metallic powders during SPS. By increasing the temperature, the density of sintered alloys increased and then stayed nearly constant. For the alloys sintered at 1150 and $1250{ }^{\circ} \mathrm{C}$, the microstructures exhibited double-phase and lamellar characteristics, respectively, due to the phase transformation, despite having similar densities. The mechanical properties of the sintered alloys depended on the microstructures caused by sintering conditions, such as porosity and phase morphology. At lower temperatures and stress, the micro-hardness, fracture strength, and plastic strain increased with the increase in density. For alloys with similar densities sintered at a high temperature and stress, the phase morphology affected the mechanical properties. In this work, the alloy sintered at $1150{ }^{\circ} \mathrm{C}$ with a double-phase microstructure showed optimal properties for a fracture true strength of $1820 \mathrm{MPa}$ and a plastic true strain of $32.6 \%$ at a room-temperature compressive test. Thus, sintering 
parameters including temperature and pressure can influence the densification process and a high density can be achieved through sufficient plastic deformation and thermal diffusion, such as the grain boundary diffusion of metallic powders caused by the effect of temperature and pressure.

Acknowledgments: This work is financially supported by the National Natural Science Foundation of China (No. 51674093), the Natural Science Foundation of Heilongjiang Province (No. E201425), the Fundamental Research Funds for the Central Universities (No. HIT.KLOF.2013021 and HIT.MKSTISP.2016019), and the Postdoctoral Scientific Research Development Fund of Heilongjiang Province (No. LBH-Q15040).

Author Contributions: Dongjun Wang conceived and designed the experiments. Hao Yuan and Jianming Qiang searched literatures. Hao Yuan performed the experiments and collected the data. Hao Yuan and Jianming Qiang interpreted the data. Dongjun Wang analyzed the data and wrote the paper.

Conflicts of Interest: The authors declare no conflict of interest.

\section{References}

1. Lagos, M.A.; Agote, I. SPS synthesis and consolidation of TiAl alloys from elemental powder: Microstructure evolution. Intermetallics 2013, 36, 51-56. [CrossRef]

2. Liss, K.D.; Funakoshi, K.I.; Dippenaar, R.J.; Higo, Y.; Shiro, A.; Reid, M.; Suzuki, H.; Shobu, T.; Akita, K. Hydrostatic compression behavior and high-pressure stabilized $\beta$-phase in $\gamma$-based titanium aluminide intermetallics. Metals 2016, 6, 165. [CrossRef]

3. Liu, H.W.; Rong, R.; Gao, F.; Li, Z.X.; Liu, Y.G.; Wang, Q.F. Hot deformation behavior and microstructural evolution characteristics of Ti-44Al-5V-1Cr alloy containing $\left(\gamma+\alpha_{2}+\right.$ B2) phases. Metals 2016, 6, 305. [CrossRef]

4. Clemens, H.; Mayer, S. Design, processing, microstructure, and applications of advanced intermetallic TiAl alloys. Adv. Eng. Mater. 2013, 15, 191-215. [CrossRef]

5. Niu, H.Z.; Chen, Y.Y.; Xiao, S.L.; Xu, L.J. Microstructure evolution and mechanical properties of a novel beta $\gamma$-TiAl alloy. Intermetallics 2012, 31, 225-231. [CrossRef]

6. Edalati, K.; Toh, S.; Iwaoka, H.; Watanabe, M.; Horita, Z.; Kashioka, D.; Kishida, K.; Inui, H. Ultrahigh strength and high plasticity in TiAl intermetallics with bimodal grain structure and nanotwins. Scr. Mater. 2012, 67, 814-817. [CrossRef]

7. Miriyev, A.; Levy, A.; Kalabukhov, S.; Frage, N. Interface evolution and shear strength of Al/Ti bi-metals processed by a spark plasma sintering (SPS) apparatus. J. Alloy Compd. 2016, 678, 329-336. [CrossRef]

8. Sadeghi, E.; Karimzadeh, F.; Abbasi, M.H. Thermodynamic analysis of Ti-Al-C intermetallics formation by mechanical alloying. J. Alloy Compd. 2013, 576, 317-323. [CrossRef]

9. Guillaume, B.G.; Chrisian, G. Spark plasma sintering of a commercially available granulated zirconia powder: I. Sintering path and hypotheses about the mechanism(s) controlling densification. Acta Mater. 2007, 55, 3493-3504.

10. Jiang, D.T.; Hulbert, D.M.; Kuntz, J.D.; Anselmi-Tamburini, U.; Mukherjee, A.K. Spark plasma sintering: A high strain rate low temperature forming tool for ceramics. Mater. Sci. Eng. A 2013, 463, 89-93. [CrossRef]

11. Li, J.; Liu, Y.; Liu, B.; Wang, Y.; Liang, X.; He, Y. Microstructure characterization and mechanical behaviors of a hot forged high $\mathrm{Nb}$ containing PM TiAl alloy. Mater. Charact. 2014, 95, 148-156. [CrossRef]

12. Trzaska, Z.; Couret, A.; Monchoux, J.P. Spark plasma sintering mechanisms at the necks between TiAl powder particles. Acta Mater. 2016, 118, 100-108. [CrossRef]

13. Ghasali, E.; Pakseresht, A.H.; Alizadeh, M.; Shirvanimoghaddam, K.; Ebadzadeh, T. Vanadium carbide reinforced aluminum matrix composite prepared by conventional, microwave and spark plasma sintering. J. Alloy Compd. 2016, 688, 527-533. [CrossRef]

14. Shirvanimoghaddam, K.; Hamim, S.U.; Akbari, M.K.; Fakhrhoseini, S.M.; Khayyam, H.; Pakseresht, A.H.; Ghasali, E.; Zabet, M.; Munir, K.S.; Jia, S.; et al. Carbon fiber reinforced metal matrix composites: Fabrication process and properties. Composites Part A 2017, 92, 70-96. [CrossRef]

15. Wang, Y.H.; Lin, J.P.; He, Y.H.; Wang, Y.L.; Chen, G.L. Microstructures and mechanical properties of Ti-45Al-8.5Nb-(W, B, Y) alloy by SPS-HIP route. Mater. Sci. Eng. A 2008, 489, 55-61. [CrossRef]

16. Voisin, T.; Monchoux, J.P.; Perrut, M.; Couret, A. Obtaining of a fine near-lamellar microstructure in TiAl alloys by spark plasma sintering. Intermetallics 2016, 71, 88-97. [CrossRef] 
17. Liu, X.W.; Zhang, Z.L.; Sun, R.; Liu, F.C.; Fan, Z.T.; Niu, H.Z. Microstructure and mechanical properties of beta TiAl alloys elaborated by spark plasma sintering. Intermetallics 2014, 55, 177-183. [CrossRef]

18. Wang, Y.H.; Lin, J.P.; He, Y.H.; Wang, Y.L.; Chen, G.L. Fabrication and SPS microstructure of Ti-45Al-8.5Nb(W, B, Y) alloying powders. Intermetallics 2008, 16, 215-224. [CrossRef]

19. Couret, A.; Molenat, G.; Galy, J.; Thomas, M. Microstructures and mechanical properties of TiAl alloys consolidated by spark plasma sintering. Intermetallics 2008, 16, 1134-1141. [CrossRef]

20. Jabbar, H.; Couret, A.; Durand, L.; Monchoux, J.P. Identification of microstructural mechanisms during densification of a TiAl alloy by spark plasma sintering. J. Alloy Compd. 2011, 509, 9826-9835. [CrossRef]

21. Lee, G.; Yurlova, M.S.; Giuntini, D.; Grigoryev, E.G.; Khasanov, O.L.; Mckittrick, J.; Olevsky, E.A. Densification of zirconium nitride by spark plasma sintering and high voltage electric discharge consolidation: A comparative analysis. Ceram. Int. 2015, 41, 14973-14987. [CrossRef]

22. Niraj, C.; Koundinya, N.T.B.N.; Srivastav, A.K.; Kottada, R.S. On correlation between densification kinetics during spark plasma sintering and compressive creep of B2 aluminides. Scr. Mater. 2015, 107, 63-66.

23. Lodhe, M.; Chawake, N.; Yadav, D.; Balasubramanian, M. On correlation between $\beta \rightarrow \alpha$ transformation and densification mechanisms in SiC during spark plasma sintering. Scr. Mater. 2016, 115, 137-140. [CrossRef]

24. Voisin, T.; Durand, L.; Karnatak, N.; Gallet, S.L.; Thomas, M.; Berre, Y.L.; Castagné, J.F.; Couret, A. Temperature control during spark plasma sintering and application to up-scaling and complex shaping. J. Mater. Process. Technol. 2013, 213, 269-278. [CrossRef]

25. Ghasali, E.; Shirvanimoghaddam, K.; Pakseresht, A.H.; Alizadeh, M.; Ebadzadeh, T. Evaluation of microstructure and mechanical properties of Al-TaC composites prepared by spark plasma sintering process. J. Alloy Compd. 2017, 705, 283-289. [CrossRef]

26. Wang, J.W.; Wang, Y.; Liu, Y.; Li, J.B.; He, L.Z.; Zhang, C. Densification and microstructural evolution of a high niobium containing TiAl alloy consolidated by spark plasma sintering. Intermetallics 2015, 64, 70-77. [CrossRef]

27. German, R. Sintering from Empirical Observations to Scientific Principles, 1st ed.; Butterworth-Heinemann: Oxford, UK, 2014; pp. 197-198.

28. Zhang, W.; Gladwell, I. Sintering of two particles by surface and grain boundary diffusion-A three dimensional model and numerical study. Comp. Mater. Sci. 1998, 12, 84-104. [CrossRef]

29. Wang, J.C. Analysis of early stage sintering with simultaneous surface and volume diffusion. Metall. Mater. Trans. A 1990, 21, 305-312. [CrossRef]

30. Chng, H.N.; Pan, J. Cubic spline elements for modeling microstructural evolution of materials controlled by solid-state diffusion and grain boundary migration. J. Comp. Phys. 2004, 196, 724-750. [CrossRef]

31. Svoboda, J.; Riedel, H. Quasi-equilibrium sintering for coupled grain boundary and surface diffusion. Acta Metall. Mater. 1995, 43, 499-506. [CrossRef]

(C) 2017 by the authors. Licensee MDPI, Basel, Switzerland. This article is an open access article distributed under the terms and conditions of the Creative Commons Attribution (CC BY) license (http:/ / creativecommons.org/licenses/by/4.0/). 
Article

\title{
Study on Hot Deformation Behavior and Microstructure Evolution of Ti-55 High-Temperature Titanium Alloy
}

\author{
Fengyong $\mathrm{Wu}^{1,2}$, Wenchen $\mathrm{Xu}^{1,2, *}$, Xueze Jin ${ }^{1,2, *}$, Xunmao Zhong ${ }^{1}$, Xingjie Wan ${ }^{1}$, \\ Debin Shan ${ }^{1,2}$ and Bin Guo ${ }^{1,2}$ \\ 1 School of Materials Science and Engineering \& National Key Laboratory for Precision Hot Processing of \\ Metals, Harbin Institute of Technology, Harbin 150001, China; wfy2000cn@163.com (F.W.); \\ zxmhit@126.com (X.Z.); goqa@foxmail.com (X.W.); shandebin@hit.edu.cn (D.S.); bguo@hit.edu.cn (B.G.) \\ 2 National Key Laboratory for Precision Hot Processing of Metals, Harbin Institute of Technology, \\ Harbin 150001, China \\ * Correspondence: xuwc_76@hit.edu.cn (W.X.); jinxzabc@163.com (X.J.); \\ Tel.: +86-451-8641-8732 (W.X.); +86-451-8640-3751 (X.J.)
}

Received: 29 June 2017; Accepted: 11 August 2017; Published: 20 August 2017

\begin{abstract}
The isothermal compression experiment of as-rolled Ti-55 alloy was carried out on a Gleeble-3800 thermal simulation test machine at the deformation temperature range of $700-1050{ }^{\circ} \mathrm{C}$ and strain rate range of $0.001-1 \mathrm{~s}^{-1}$. The hot deformation behavior and the microstructure evolution were analyzed during thermal compression. The results show that the apparent activation energy $Q$ in $\alpha+\beta$ dual-phase region and $\beta$ single-phase region were calculated to be $453.00 \mathrm{KJ} / \mathrm{mol}$ and $279.88 \mathrm{KJ} / \mathrm{mol}$, respectively. The deformation softening mechanism was mainly controlled by dynamic recrystallization of $\alpha$ phase and dynamic recovery of $\beta$ phase. Discontinuous yielding behavior mainly occurred in $\beta$ phase region, which weakened gradually with the increase of deformation temperature $\left(>990^{\circ} \mathrm{C}\right)$ and strain rate $\left(0.01-1 \mathrm{~s}^{-1}\right)$ in $\beta$ phase region. The processing map derived from Murty's criterion was more accurate in predicting the hot workability than that derived from Prasad's criterion. The optimized hot working window was $850-975^{\circ} \mathrm{C} / 0.001-1 \mathrm{~s}^{-1}$, in which sufficient dynamic recrystallization occurred and $\alpha+\beta$-transus microstructure was obtained. When deformed at higher temperature $\left(\geq 1000{ }^{\circ} \mathrm{C}\right)$, coarsened lath-shape $\beta$-transus microstructure was formed, while deformed at lower temperature $\left(\leq 825^{\circ} \mathrm{C}\right)$ and higher strain rate $\left(\geq 0.1 \mathrm{~s}^{-1}\right)$, the dynamic recrystallization was not sufficient, thus flow instability appeared because of shear cracking.
\end{abstract}

Keywords: Ti-55 titanium alloy; hot deformation behavior; dynamic recrystallization; processing map

\section{Introduction}

Ti-55 alloy is a near $\alpha$ titanium alloy with the nominal chemical composition Ti-(5.0-6.0)Al-(3.0-4.0) Sn-(2.5-3.3)Zr-(0.3-1.5)Mo-(0.2-0.7)Ta-(0.2-0.7)Nb-(0.1-0.5)Si (wt \%), which shows high strength and excellent corrosion resistance. Due to the addition of $\mathrm{Si}$, $\mathrm{Ta}$ and $\mathrm{Nb}$ elements, the thermal stability and oxidation resistance are obviously improved, so the alloy can meet the requirement of long-term service with the temperature no less than $550{ }^{\circ} \mathrm{C}$ [1]. As a potential structural material for engine compressor, blade, sheet components in aviation and aerospace industries, Ti-55 alloy has gained increasing attention in China in recent years [2,3].

Similar to other high temperature titanium alloys, such as Ti-1100 and IMI834, this alloy is quite difficult to be formed into a complex shape because of its poor workability and high strength. Moreover, the accurate control of microstructure morphologies and properties of final components is very difficult 
for those high temperature titanium alloys with high alloying elements in forming process $[4,5]$. In order to develop plastic forming methods of high temperature titanium alloys, such as forging, extrusion and sheet hot forming, it is necessary to characterize the deformation behavior, including the flow stress behavior, deformation mechanism and microstructure evolution of the materials. Currently, quite a few investigations have been conducted to analyze the hot deformation behavior of high temperature titanium alloys. For instance, Liu and Bake [6] analyzed the deformation characteristics of IMI685 alloy and revealed its dynamic softening mechanism in $\beta$ phase field, which was helpful for widening its forging temperature range. Wanjara et al. $[4,5]$ explored the flow stress behavior and the microstructure evolution of near- $\alpha$ IMI834 alloy in $\beta$ and $\alpha+\beta$ phase regions, respectively, through isothermal compression experiment. Niu et al. [7] investigated the high temperature behavior of a near- $\alpha$ Ti-600 alloy and determined its optimized superplastic forming window.

Although there is some research on the thermal stability and tensile formability of Ti-55 alloy [1,3,8], the hot compression behavior has been rarely reported, which limits the application of hot plastic forming processes, such as forging and extrusion, to this kind of titanium alloy. In this study, the isothermal compression of Ti-55 titanium alloy has been conducted at different strain rates and temperatures both in the $\alpha+\beta$ and $\beta$ regions. The flow stress behavior has been analyzed and the microstructure evolution has been observed. Subsequently, the processing map has been established to understand the deformation mechanism during hot compression, and the optimum hot working window has been determined for hot processing of Ti-55 alloy.

\section{Materials and Methods}

The starting material used in the study was as-rolled sheet of Ti-55 alloy with the thickness of $12 \mathrm{~mm}$, supplied by Baoji Titanium Industry Company Limited in China. The actual chemical composition ( $w t \%)$ of the present Ti-Al-Sn alloy was determined by an inductively coupled plasma (ICP) test as follows: Al-5.2, Sn-3.3, Zr-2.9, Mo-1.0, Ta-0.4, Nb-0.4, Si-0.2 and the rest Ti. The $\beta$-transus temperature was calculated to be about $990{ }^{\circ} \mathrm{C}$ by a differential thermal analysis (DTA) test and metallographic method. The experimental specimens with dimension of $\Phi 6 \mathrm{~mm} \times 8 \mathrm{~mm}$, whose axial direction was aligned with the sheet thickness direction (i.e., normal direction), were electro-discharge wire cut from the as-rolled sheet for hot compression, as shown in Figure 1. The isothermal compression test was carried out in the temperature range of $700-1050{ }^{\circ} \mathrm{C}$ with $50{ }^{\circ} \mathrm{C}$ intervals and strain rate range of $0.001-1 \mathrm{~s}^{-1}$ on a Gleeble-3800 simulator manufactured by DSI Company, which locate at Sao Paulo, Minnesota, America, with the low vacuum atmosphere of $1 \times 10^{-3}$ Torr. All the specimens were heated to the deformation temperature at a heating rate of $10{ }^{\circ} \mathrm{C} / \mathrm{s}$ and held for $2 \mathrm{~min}$ before hot compression, and the deformation temperature was recorded by $\mathrm{Pt}-\mathrm{Rh}$ thermocouple wires spot-welded in the surface of the hot deformation specimens. In order to maintain the hot deformation microstructure, the specimens were quenched by water immediately after hot compression with $60 \%$ height reduction in low vacuum atmosphere. The tantalum chip of $0.1 \mathrm{~mm}$ was placed between crosshead and specimen to provide lubrication and prevent cementation during hot compression. The specimens were sectioned parallel to the compression axis after hot compression for microstructure observation. The specimens for optical microscopy $(\mathrm{OM})$ observation were etched in a solution of $2 \mathrm{~mL}$ hydrofluoric acid, $4 \mathrm{~mL}$ nitric acid and $94 \mathrm{~mL} \mathrm{H}_{2} \mathrm{O}$. Electropolishing was carried out in a solution of $12.5 \%$ perchloric acid and $87.5 \%$ acetic acid with the voltage of $25 \mathrm{~V}$ and temperature of $-20{ }^{\circ} \mathrm{C}$ to prepare the samples for scanning electron microscopy (SEM) and electron back scattering diffraction (EBSD) analysis. The specimens for transmission electron microscopy (TEM) analysis were mechanically ground to about $100 \mu \mathrm{m}$, followed by two-jet electro polished at an ion voltage of $20 \mathrm{~V}$ under the temperature of about $-20^{\circ} \mathrm{C}$. The SEM, EBSD and TEM testing were conducted on a Quanta 200FEG scanning electron microscope and TecnaiG2F30 transmission electron microscope, respectively, manufactured by FEI Company located at Hillsborough, Oregon, America. 


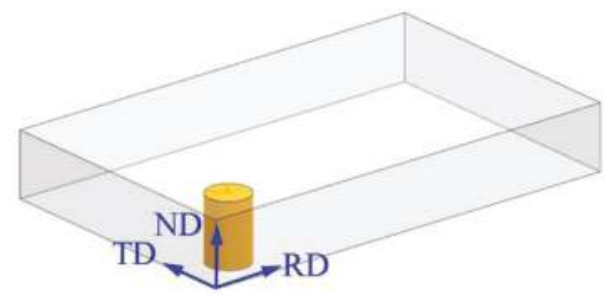

Figure 1. Schematic diagram of specimens cutting from the as-rolled Ti-55 sheet (ND: Normal Direction; RD: Rolling Direction; TD: Transverse Direction).

\section{Results}

\subsection{Flow Stress Behavior}

\subsubsection{Flow Stress-Strain Curves}

Figure 2 shows the stress-strain curves of as-rolled Ti-55 alloy during isothermal compression at different temperatures and strain rates. Clearly, the flow stress increased with the increase of true strain at the initial deformation stage to the peak stress because of work hardening, and then the flow stress decreased with further increase of true strain due to flow softening occurring during hot compression. Besides, the flow stress decreased with increasing deformation temperature and decreasing strain rate, indicating the flow stress was sensitive to deformation temperature and strain rate. When deformed at higher temperature and lower strain rate $\left(\geq 90{ }^{\circ} \mathrm{C}\right.$ and $\left.\leq 0.01 \mathrm{~s}^{-1}\right)$, the flow stress-strain curves reached to steady values with the increase of true strain, indicating the softening mechanism, including dynamic recrystallization (DRX) of $\alpha$ phase or dynamic recovery (DRV) of $\beta$ phase, proceeded quickly to balance the rate of work hardening $[9,10]$. Besides this, the other secondary phase particles rich in $\mathrm{Sn}, \mathrm{Mo}$, Ta and $\mathrm{Nb}$ elements at the grain boundaries may have pinning effect on dislocation motion (see Figure 7a), which partly balanced dynamic softening during hot compression of Ti-55 alloy. However, when deformed in other conditions, such as lower temperature and higher strain rate, the curves exhibited continuous softening behavior after peak stress without the steady-state condition occurring due to insufficient softening behavior.
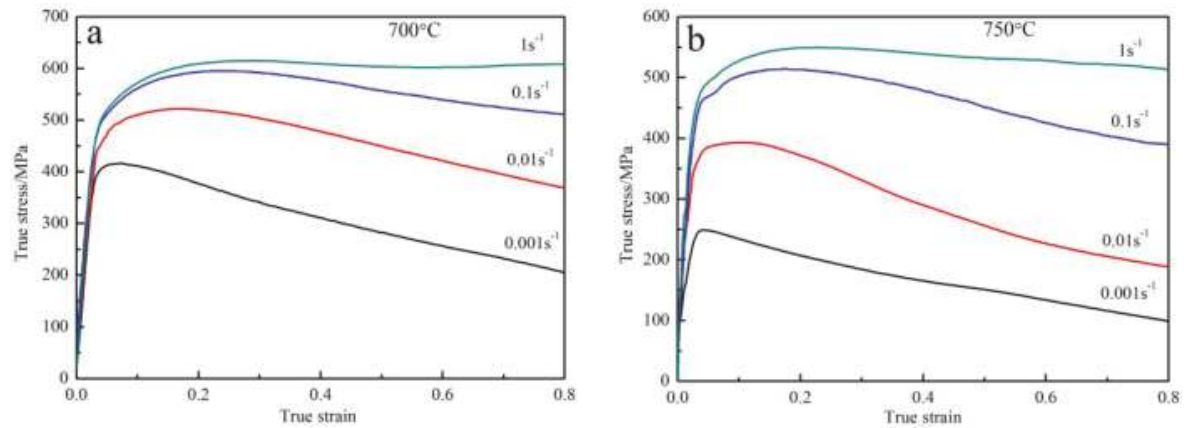

Figure 2. Cont. 

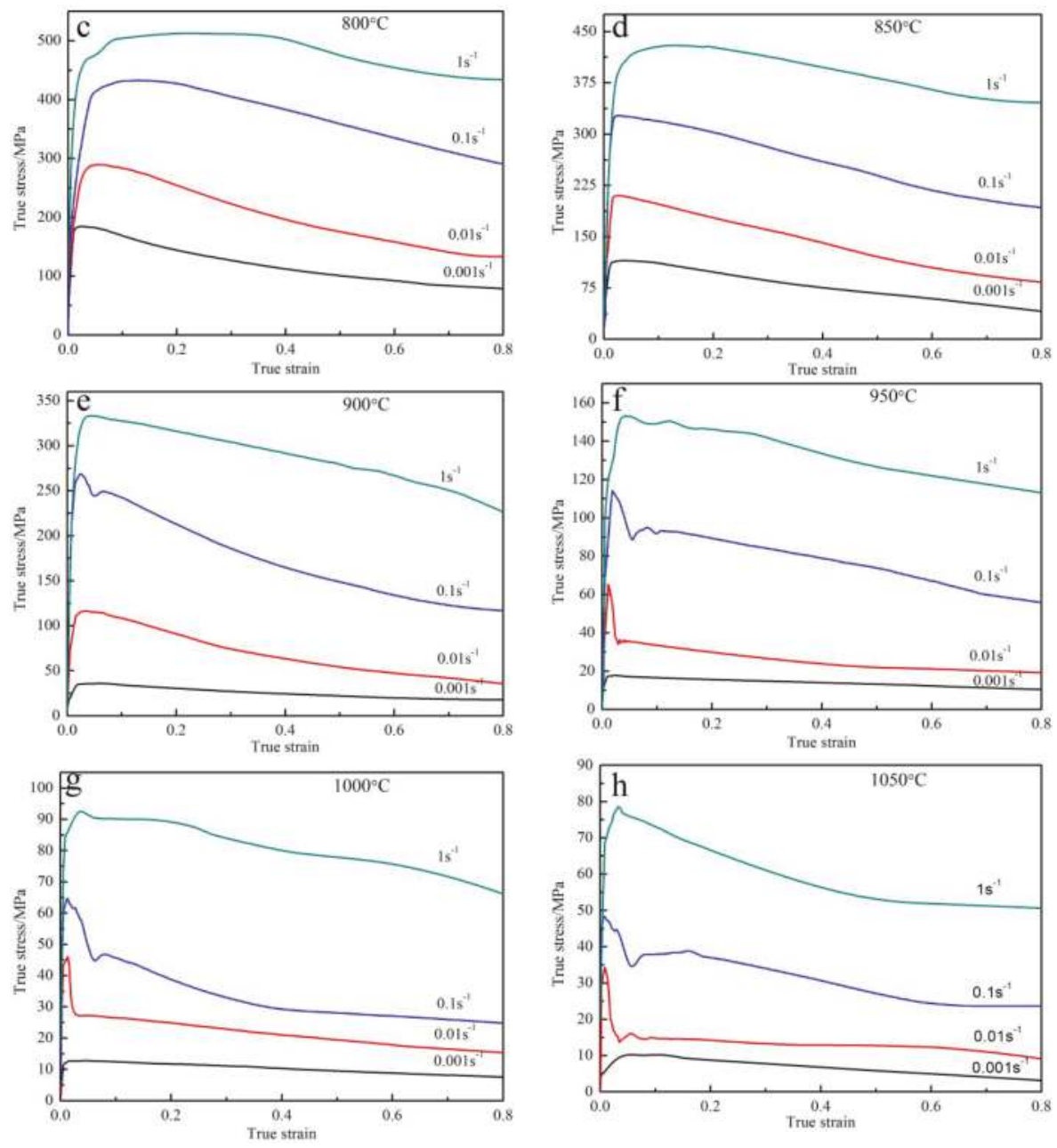

Figure 2. Typical stress-strain curves at different temperatures and strain rates of as-rolled Ti-55 alloy: (a) $700{ }^{\circ} \mathrm{C}$; (b) $750{ }^{\circ} \mathrm{C}$; (c) $800{ }^{\circ} \mathrm{C}$; (d) $850{ }^{\circ} \mathrm{C}$; (e) $900{ }^{\circ} \mathrm{C}$; (f) $950{ }^{\circ} \mathrm{C}$; (g) $1000{ }^{\circ} \mathrm{C}$; (h) $1050{ }^{\circ} \mathrm{C}$.

\subsubsection{Discontinuous Yielding Behavior}

Discontinuous yielding behavior, i.e., the sudden drop of flow stress beyond peak stress, was observed for the deformation conditions performed above $900{ }^{\circ} \mathrm{C}$ at strain rates of $0.01-1.0 \mathrm{~s}^{-1}$, while there was no obvious discontinuous yielding behavior appearing at lower strain rate of $0.001 \mathrm{~s}^{-1}$. Figure 3 shows the magnitude of the yield drop (i.e., $\sigma_{U Y}-\sigma_{L Y}$ ) at various deformation temperatures and strain rates. It can be seen that the yield drop reduced as the temperature increased over $950{ }^{\circ} \mathrm{C}$, and the yield drop occurred only at the middle strain rate of $0.1 \mathrm{~s}^{-1}$ at $900^{\circ} \mathrm{C}$. The discontinuous yielding behavior has been found in many $\beta$ titanium alloys, such as Ti-10V-4.5Fe-1.5Al, Ti-6.8Mo-4.5Fe-1.5Al and Ti40 [11-13]. Recently, this phenomenon has been reported in some $\alpha+\beta$ and near $\alpha$ titanium alloys. For instance, Li et al. and Wang et al. $[14,15]$ discovered the discontinuous flow stress drop in $\alpha$ $+\beta$ alloy Ti-3Al-5V-5Mo and TC8, respectively. In addition, Jia et al. [10] demonstrated the behavior in near $\alpha$ alloy of Ti60. Generally, the discontinuous yield phenomenon could be explained mainly by 
two theories: static theory and dynamic theory. The first theory involved the dislocation locking and unlocking, and the second one associated discontinuous yielding with the abrupt formation of large quantities of new mobile dislocations originated from the grain boundary sources [14]. For titanium alloys, more researchers indicated that the discontinuous yielding should be attributed to dynamic theory, rather than static theory during hot compression at elevated temperatures $[12,16,17]$.
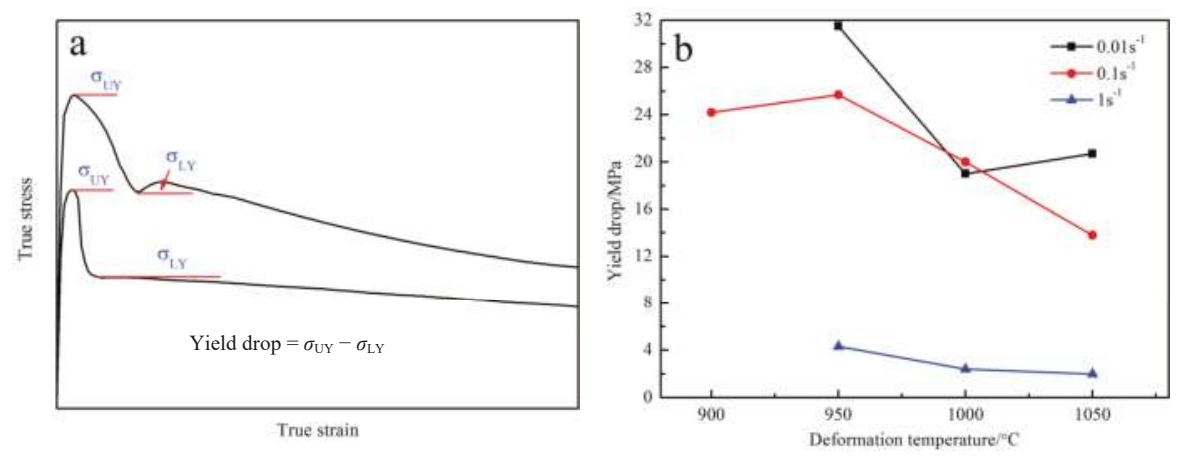

Figure 3. Schematic diagram of yield stress drop (a) and magnitude of yield drop in Ti-55 alloy as a function of temperature and strain rate $(\mathbf{b})$.

However, the influence of processing parameters, such as deformation temperature and strain rate, on the discontinuous yielding was not clearly understood. For the present titanium alloy, the yield drop appeared most pronouncedly at $950{ }^{\circ} \mathrm{C}$ and reduced gradually with further increase of deformation temperature, as shown in Figure $3 \mathrm{~b}$. Usually, the increase of deformation temperature may induce two opposite results. On the one hand, the increase of deformation temperature could enhance the thermal activation to promote the generation of new mobile dislocations. On the other hand, the temperature rising may reduce the dislocation density and weaken the stress concentration to restrain the operation of new mobile dislocation. At lower temperature less than $900{ }^{\circ} \mathrm{C}$, the increase of dislocation density and stress concentration could not operate new mobile dislocations significantly due to lower thermal activation and strong pinning effect of high content of alloy elements of Ti-55 alloy. With the increase of deformation temperature in $\beta$ phase region $\left(>990^{\circ} \mathrm{C}\right)$, the reducing of dislocation density and stress concentration played a main role in restraining the generation of new mobile dislocations, leading to the decrease of the yielding drop.

Besides this, the discontinuous yield behavior weakened progressively with the increase of strain rate from $0.01 \mathrm{~s}^{-1}$ to $1 \mathrm{~s}^{-1}$ in this study. The magnitude of the yield drop changed slightly as the strain rate increased from $0.01 \mathrm{~s}^{-1}$ to $0.1 \mathrm{~s}^{-1}$, and pronouncedly reduced to the minimum when the strain rate increased from $0.1 \mathrm{~s}^{-1}$ to $1 \mathrm{~s}^{-1}$ for all the tests at higher temperatures $\left(>900^{\circ} \mathrm{C}\right)$. A similar evolution tendency was found in the hot compression of Ti60 alloy at the strain rate of $1 \mathrm{~s}^{-1}$ [10]. The possible reason was that high strain rate induced intense work hardening, which may conceal the discontinuous yielding behavior. When the strain rate was too low (less than $0.001 \mathrm{~s}^{-1}$ ), the dislocations were easily propagated and hard to be accumulated, which would lessen the stress concentration and lead to the disappearance of yield drop. Moreover, dynamic recovery rather than dynamic recrystallization was more prone to take place during hot compression in $\beta$ phase region, which reduced dynamic softening of titanium alloy. Therefore, the yield drop at low strain rate of $0.001 \mathrm{~s}^{-1}$ vanished during hot deformation both in $\beta$ and $\alpha+\beta$ phase regions.

\subsection{Kinetic Analysis}

During hot plastic deformation, the relationship among the flow stress, strain rate and deformation temperature can be described by a hyperbolic sine law [18]: 


$$
\dot{\varepsilon}=A\left[\sinh \left(\alpha \sigma_{p}\right)\right]^{n} \exp \left(-\frac{Q}{R T}\right) .
$$

This also can be given by the Zener-Hollomon parameter as follows [19]:

$$
\mathrm{Z}=\dot{\varepsilon} \exp \left(\frac{Q}{R T}\right)=\mathrm{A}\left[\sinh \left(\alpha \cdot \sigma_{p}\right)\right]^{n},
$$

where $Z$ is the Zener-Hollomon parameter; $A, \alpha$ and $n$ is materials constants, and $\alpha=\beta / n_{1}$, $n_{1}=\partial \ln \dot{\varepsilon} / \partial \ln \sigma, \beta=\partial \ln \dot{\varepsilon} / \partial \sigma ; R$ is the gas constant; $\dot{\varepsilon}$ is the strain rate; $\sigma_{p}$ is the peak stress; $T$ is the deformation temperature; $Q$ is the activation energy.

From Equation (1), the activation energy $Q$ can be calculated as:

$$
Q=R\left\{\frac{\partial \ln \dot{\varepsilon}}{\partial \ln \left[\sinh \left(\alpha \sigma_{p}\right)\right]}\right\}_{T}\left\{\frac{\partial \ln \left[\sinh \left(\alpha \sigma_{p}\right)\right]}{\partial\left(\frac{1}{T}\right)}\right\}_{\dot{\varepsilon}} .
$$

By linear regression of the relations of $\sigma_{\mathrm{p}}-\ln \dot{\varepsilon}$ and $\ln \sigma_{\mathrm{p}}-\ln \dot{\varepsilon}$ at different deformation conditions, the value of $\alpha$ was calculated as 0.00573 and 0.0269 in the temperature range of $700-950{ }^{\circ} \mathrm{C}$ and $1000-1050{ }^{\circ} \mathrm{C}$, respectively, as shown in Figure $4 \mathrm{a}, \mathrm{b}$. Through linear fitting of $\ln \left[\sinh \left(\alpha \sigma_{p}\right)\right]$ vs. $\ln \dot{\varepsilon}$ and $\ln \left[\sinh \left(\alpha \sigma_{p}\right)\right]$ vs. $1 / T$ in the temperature ranges of $700-950{ }^{\circ} \mathrm{C}$ and $1000-1050{ }^{\circ} \mathrm{C}$ shown in Figure $4 \mathrm{c}-\mathrm{e}$, the average activation energy $Q$ of as-rolled Ti-55 alloy were calculated to be $453.00 \mathrm{KJ} / \mathrm{mol}$ and $279.88 \mathrm{KJ} / \mathrm{mol}$, respectively. Based on the linear relationship of $\ln \left[\sinh \left(\alpha \sigma_{p}\right)\right]$ vs. $\ln Z$, the stress constant $n$ of as-rolled Ti-55 alloy in the temperature range of $700-950{ }^{\circ} \mathrm{C}$ and $1000-1050{ }^{\circ} \mathrm{C}$ was calculated as 3.3851 and 2.6125, respectively, as shown in Figure 4f. Besides this, the correlation coefficient of as-rolled Ti-55 alloy in the temperature range of $700-950{ }^{\circ} \mathrm{C}$ and $1000-1050{ }^{\circ} \mathrm{C}$ for the linear relationship of $\ln Z$ vs. $\ln \left[\sinh \left(\alpha \sigma_{p}\right)\right]$ were 0.9150 and 0.9500 , indicating it was reliable to describe the hot deformation behavior of as-rolled Ti-55 alloy by using hyperbolic sine law. Therefore, the dependence of peak stress on the strain rate and deformation temperature of as-rolled Ti-55 alloy in the temperature range of $700-900{ }^{\circ} \mathrm{C}$ and $950-1050{ }^{\circ} \mathrm{C}$, respectively, could be expressed as:

$$
\begin{gathered}
\dot{\varepsilon}=5.0129 \times 10^{18}\left[\sinh \left(5.73 \times 10^{-3} \sigma_{p}\right)\right]^{3.3851} \exp \left(-\frac{453000}{8.314 T}\right), \\
\dot{\varepsilon}=2.2101 \times 10^{9}\left[\sinh \left(2.69 \times 10^{-2} \sigma_{p}\right)\right]^{2.6125} \exp \left(-\frac{279880}{8.314 T}\right) .
\end{gathered}
$$
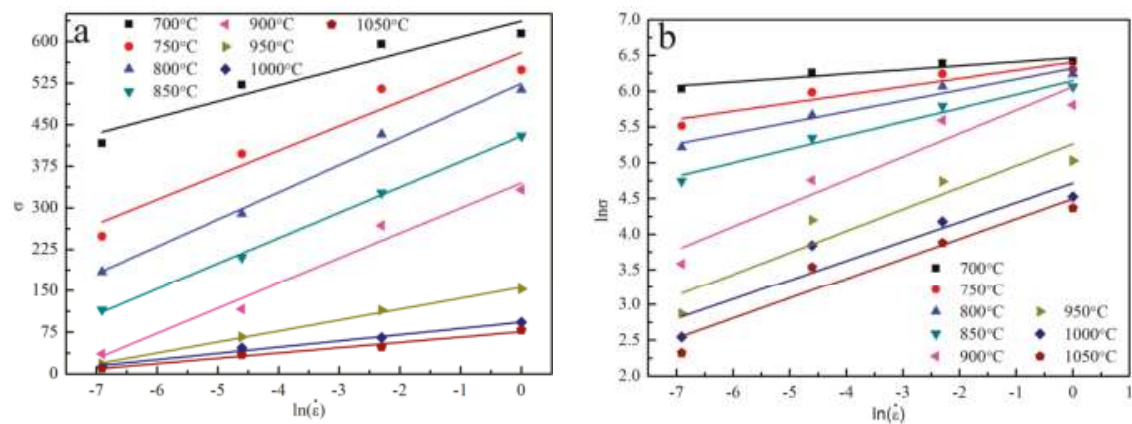

Figure 4. Cont. 

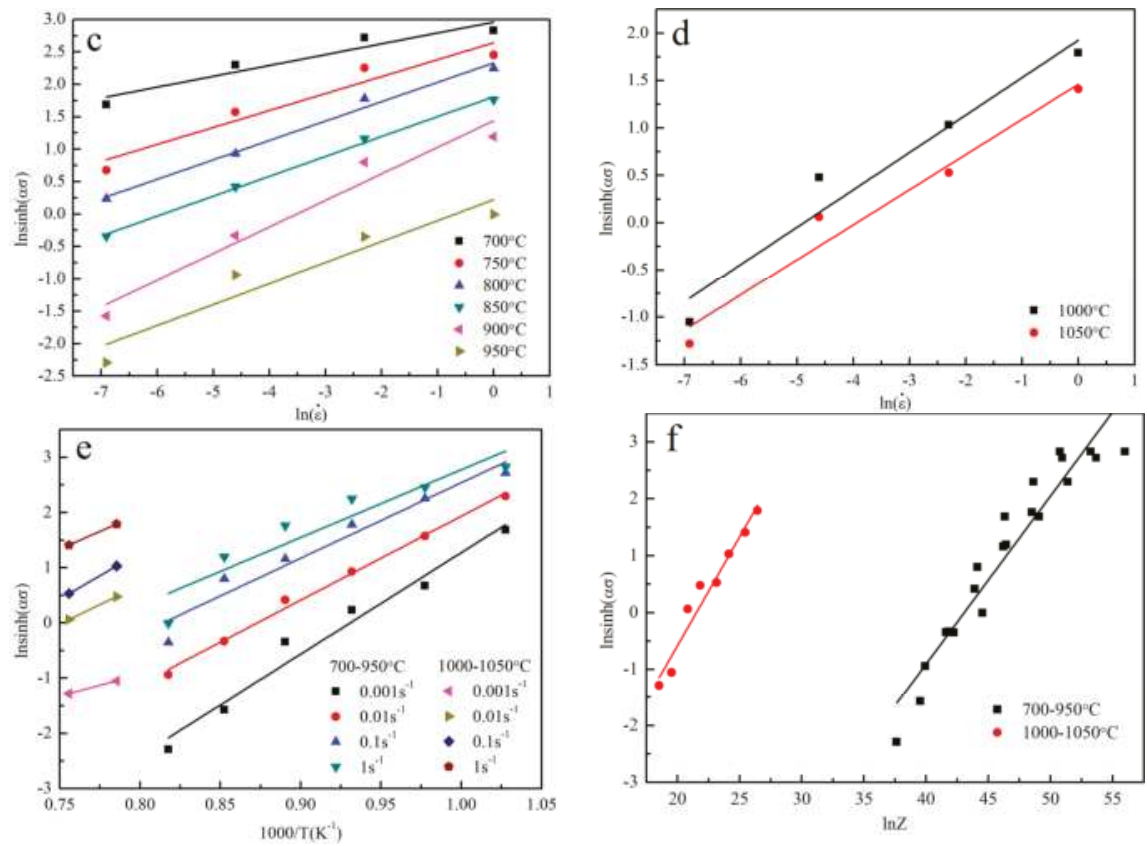

Figure 4. Linear relationships fitting of peak stress with deformation temperature and strain rate for the as-rolled Ti-55 alloy: (a) $\sigma_{p}-\ln \dot{\varepsilon}$; (b) $\ln \sigma_{p}-\ln \dot{\varepsilon}$; (c) and (d) $\ln \left[\sinh \left(\alpha \sigma_{p}\right)\right]-\ln \dot{\varepsilon}$; (e) $\ln \left[\sinh \left(\alpha \sigma_{\mathrm{p}}\right)\right]-1 / T$; (f) $\ln \left[\sinh \left(\alpha \sigma_{\mathrm{p}}\right)\right]-\ln Z$.

The deformation activation energy of as-rolled Ti-55 alloy in $\alpha+\beta$ dual-phase region and $\beta$ single-phase region was calculated to be $453.00 \mathrm{KJ} / \mathrm{mol}$ and $279.88 \mathrm{KJ} / \mathrm{mol}$, respectively, both of which were greater than the lattice self-diffusion energy of $\alpha$-Ti $(150 \mathrm{KJ} / \mathrm{mol})$ and $\beta$-Ti $(153 \mathrm{KJ} / \mathrm{mol})[4,9]$. The results indicated that the main softening mechanism should be dynamic recrystallization in $\alpha+\beta$ dual-phase region and dynamic recovery in $\beta$ single-phase region, respectively $[20,21]$. It should be noted that the activation energy in $\beta$ phase region was mostly reported in the range of $180-220 \mathrm{~kJ} / \mathrm{mol}$ during hot deformation of some titanium alloys [10,21-23], while the activation energy in $\beta$ region of the Ti-55 alloy reached $279.88 \mathrm{~kJ}$, which was higher than other titanium alloys. The possible reason is that the initial material used in this study was an as-rolled sheet, which possessed finer microstructure and intense deformation texture, so it was more difficult to deform plastically during hot compression. Besides, the activation energy in $\alpha+\beta$ dual-phase region was greater than the activation energy in $\beta$ single-phase region, which should be caused by lower deformation temperature and less slip system of $\alpha$ phase (hexagonal close-packed structure, HCP) than $\beta$ phase (body-centered cubic structure, BCC).

\subsection{Microstructure Evolution and Softening Mechanism}

Figure 5 shows the microstructures of the as-rolled sheet and specimens deformed at different conditions. It is evident that the strip-like microstructure of as-rolled Ti-55 alloy was elongated in the rolled direction, as shown in Figure 5a. Due to the relatively lower deformation temperature, the initial large grains were elongated along the flow direction, exhibiting obvious deformation feature under the temperature of $700{ }^{\circ} \mathrm{C}$ and strain rate of $0.01 \mathrm{~s}^{-1}$ (Figure $5 \mathrm{~b}$ ). When the deformation temperature increased to $800{ }^{\circ} \mathrm{C}$, the deformed microstructure was locally globalized, indicating the occurrence of dynamically recrystallization (Figure 5c). As the deformation temperature reached $900{ }^{\circ} \mathrm{C}$, sufficient recrystallization took place, which contributed to the refinement of initial microstructure of the as-rolled 
Ti-55 alloy (Figure 5d). Besides this, the lath-shaped $\beta$-transus microstructure (see Figure $6 \mathrm{~d}$ ) appeared because of the phase transformation from $\alpha$ to $\beta$ during hot deformation and then the re-precipitation of secondary $\alpha$ phase in $\beta$ phase region during the cooling process. After deformation at $950{ }^{\circ} \mathrm{C} / 0.01 \mathrm{~s}^{-1}$, the amount of initial $\alpha$ phase further decreased obviously and the amount of $\beta$-transus microstructure further increased dramatically due to the relatively higher deformation temperature close to $\beta$-transus temperature and relatively lower strain rate (see Figure 5e). When the deformation further increased to $1000{ }^{\circ} \mathrm{C}$ in $\beta$ phase region, the initial $\alpha$ phase totally transformed to coarsened lath-shaped $\beta$-transus microstructure (Figure 5e).

Under the same deformation temperature $\left(900{ }^{\circ} \mathrm{C}\right)$, as the strain rate increased to $0.1 \mathrm{~s}^{-1}$, the elongated $\alpha$ grains could be clearly observed (Figure $5 \mathrm{~g}$ ), indicating less sufficient dynamic recrystallization. When the strain rate decreased to $0.001 \mathrm{~s}^{-1}$, the dynamically recrystallized grains grew slightly and the volume fraction of $\beta$-transus microstructure increased since longer deformation time contributed to the coarsening of recrystallized grains as well as more sufficient phase transformation of $\alpha$ to $\beta$ during hot deformation, as shown in Figure 5h. Hence, both strain rate and deformation temperature exhibited remarkable influence on the microstructure evolution, including dynamic recrystallization and phase transformation of the as-rolled Ti-55 alloy.

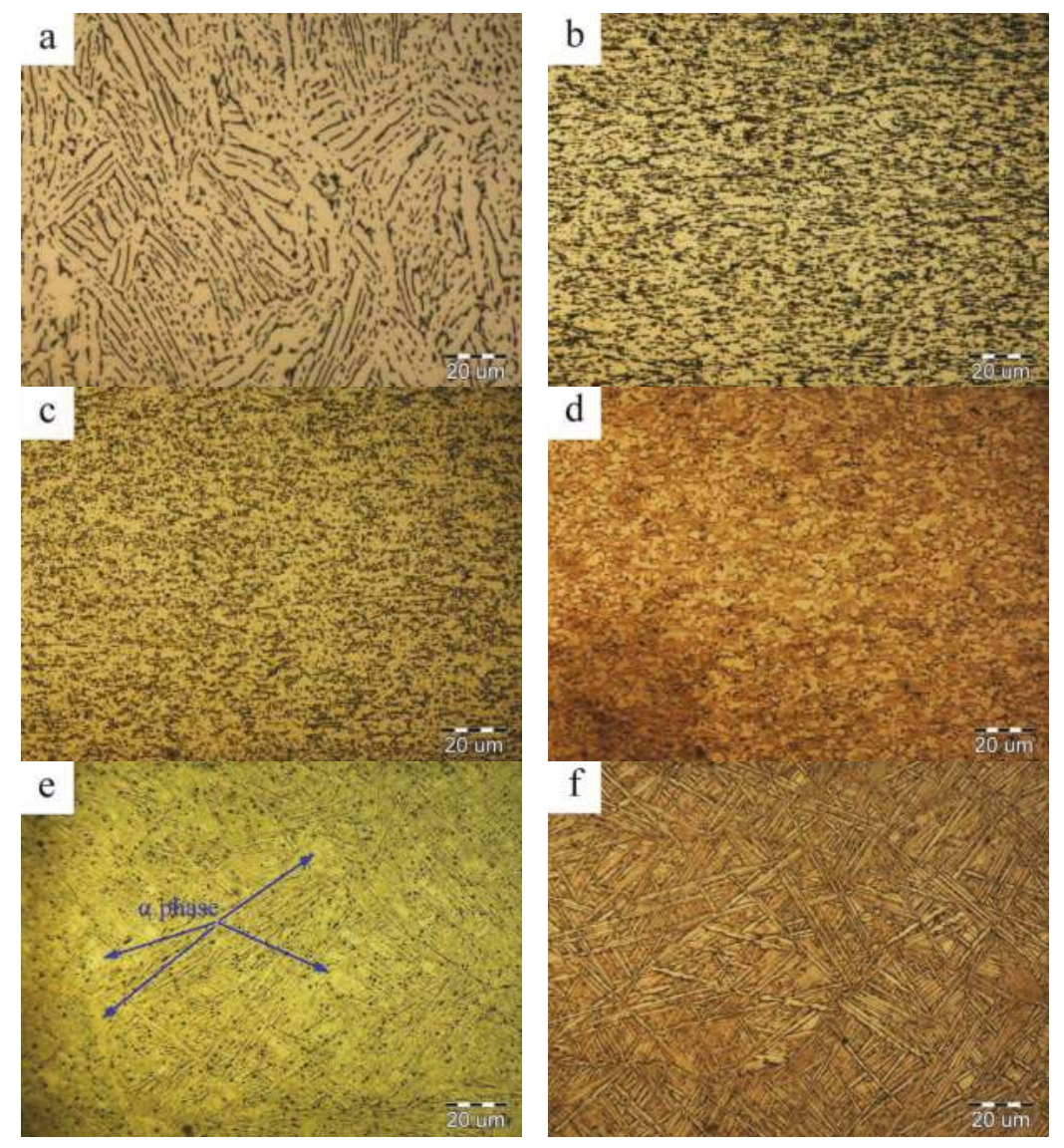

Figure 5. Cont. 

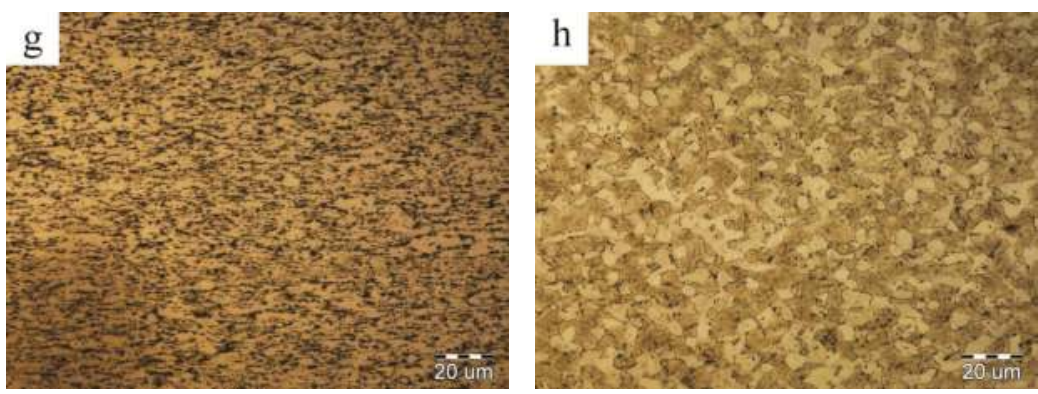

Figure 5. Microstructures of as-rolled sheet and specimens deformed at different temperatures and strain rates of the as-rolled Ti-55 alloy: (a) As-rolled sheet; (b) $700{ }^{\circ} \mathrm{C} / 0.01 \mathrm{~s}^{-1}$; (c) $800{ }^{\circ} \mathrm{C} / 0.01 \mathrm{~s}^{-1}$; (d) $900{ }^{\circ} \mathrm{C} / 0.01 \mathrm{~s}^{-1}$; (e) $950{ }^{\circ} \mathrm{C} / 0.01 \mathrm{~s}^{-1}$; (f) $1000{ }^{\circ} \mathrm{C} / 0.01 \mathrm{~s}^{-1}$; (g) $900{ }^{\circ} \mathrm{C} / 0.1 \mathrm{~s}^{-1}$; (h) $900{ }^{\circ} \mathrm{C} / 0.001 \mathrm{~s}^{-1}$.

Figure 6 shows the EBSD images of as-rolled sheet and deformed microstructure in different processing conditions. It can be found that recrystallization occurred in the initial elongated microstructure along the grain boundaries, as shown in Figure 6a. But there were a lot of low angle boundaries and small amounts of $\beta$ phase retained in $\alpha$ phase matrix because of hot rolling deformation at relatively low temperature in the final pass. After hot compression at $800{ }^{\circ} \mathrm{C}$, compared to the initial rolled microstructure, the fraction of low angle boundary reduced obviously and the area fraction of $\beta$ phase changed slightly because of the relatively low deformation temperature below the $\beta$-transus (see Figure $6 \mathrm{~b}, \mathrm{c}$ ). As the deformation temperature increased to $900{ }^{\circ} \mathrm{C}$ at the strain rate $0.01 \mathrm{~s}^{-1}$, the fraction of low angle boundary continued to reduce, while the area fraction of $\beta$-transus microstructure increased significantly due to higher deformation temperature (see Figure $6 \mathrm{~d}$ ). Besides, with the increase of deformation temperature (Figure $6 c, d$ ) and the decrease of strain rate (Figure $6 b, c)$, the fraction of low angle boundary decreased and the area fraction of $\beta$-transus microstructure increased, as shown in Figure 6e, which was basically consistent with the observation of OM microstructures.
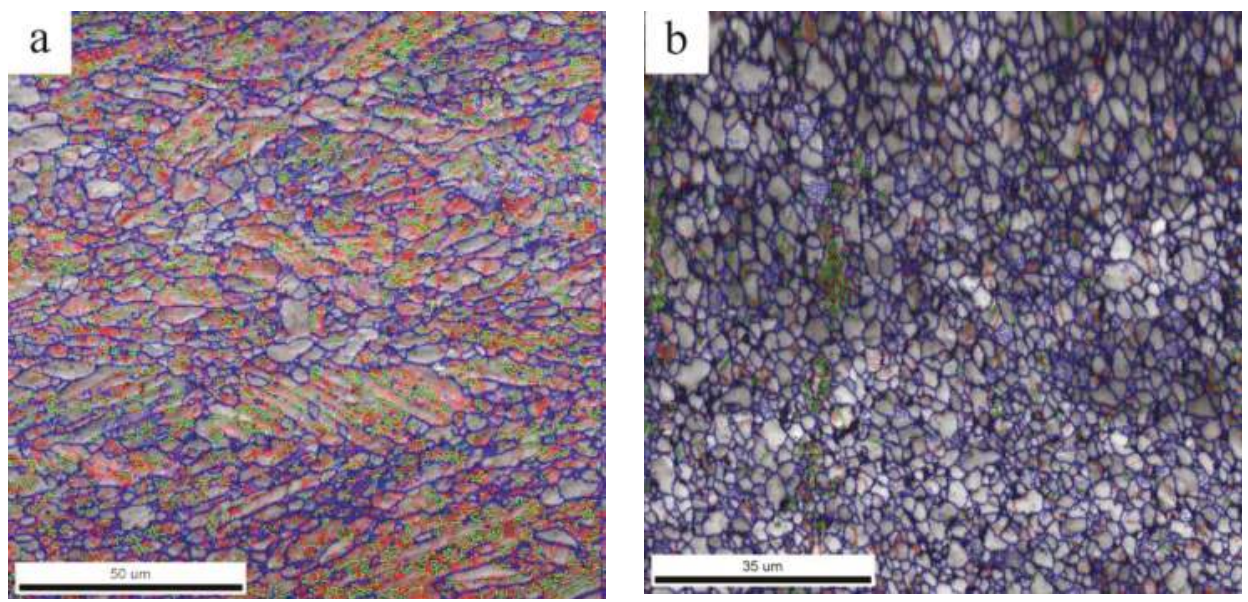

Figure 6. Cont. 

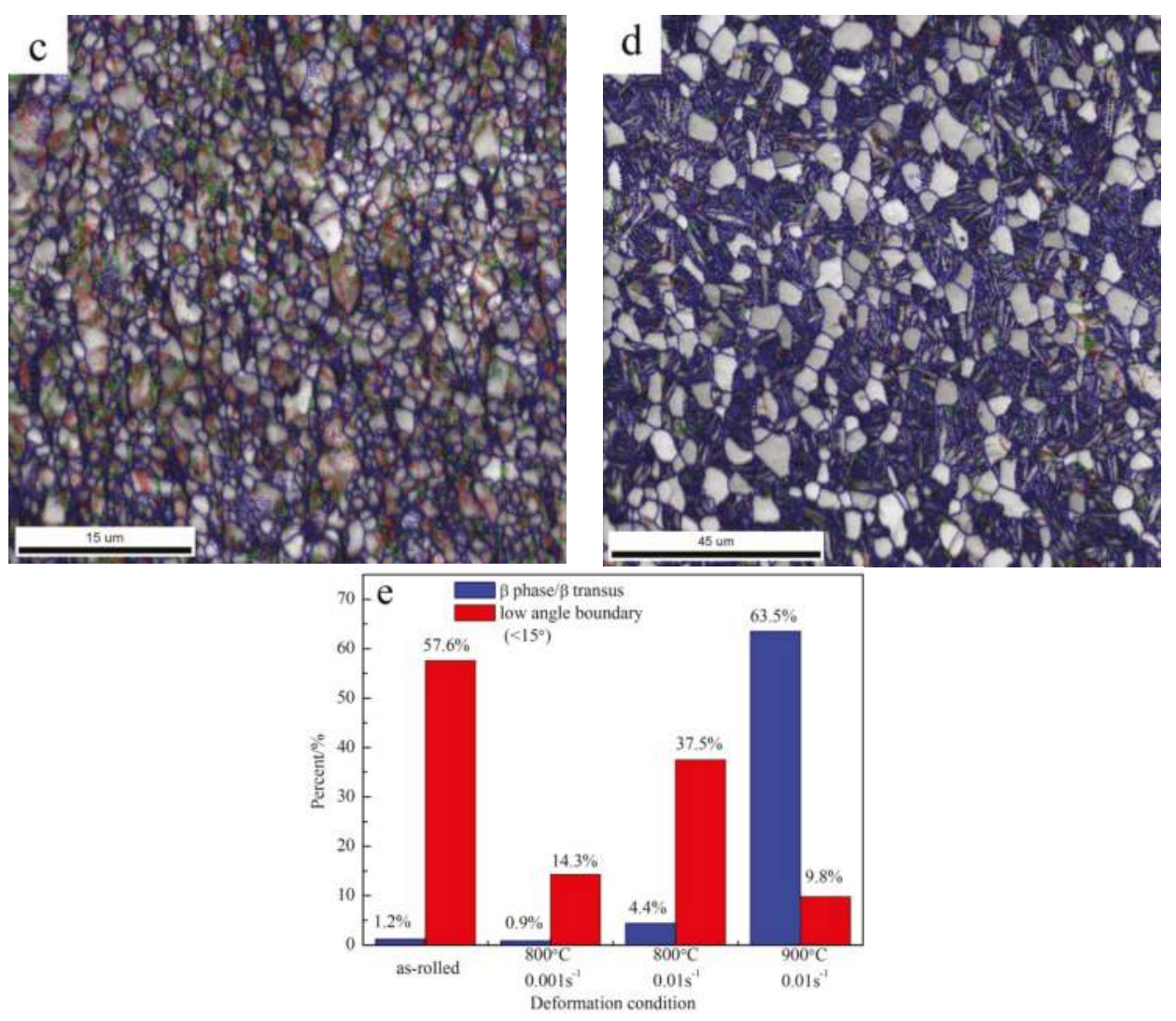

Figure 6. Electron back scattering diffraction (EBSD) images of the specimens deformed at different deformation conditions of the as-rolled Ti-55 alloy: (a) As-rolled; (b) $800{ }^{\circ} \mathrm{C}, 0.001 \mathrm{~s}^{-1}$; (c) $800{ }^{\circ} \mathrm{C}$, $0.01 \mathrm{~s}^{-1}$; (d) $900{ }^{\circ} \mathrm{C}, 0.01 \mathrm{~s}^{-1}$; (e) Percent of $\beta$ phase $/ \beta$ transus and low angle boundary.

Figure 7 shows the TEM images of the as-rolled sheet and hot compressed microstructure at different deformation conditions. It can be seen that dynamic recrystallization occurred in the microstructure of as-rolled sheet and the dislocations density was relatively low (Figure 7a). Besides, some secondary phase particles rich in $\mathrm{Mo}, \mathrm{Sn}, \mathrm{Nb}$ and Ta elements existed at the grain boundaries, as shown in Figure 7a and Table 1. When deformed at the strain rate of $0.01 \mathrm{~s}^{-1}$ under the temperature lower than $900^{\circ} \mathrm{C}$, there was no $\beta$-transus microstructure occurring because of relatively low deformation temperature, as shown in Figure $7 \mathrm{~b}, \mathrm{c}$. Especially at the temperature of $700{ }^{\circ} \mathrm{C}$, the $\alpha$ phase was elongated perpendicular to the compression direction and amounts of dislocations existed in the titanium matrix (see Figure $7 \mathrm{~b}$ ). As the deformation temperature increased to $800{ }^{\circ} \mathrm{C}$, some refined dislocation cells and dynamically recrystallized grains appeared, accompanied with the decrease of dislocations density, which indicated incomplete dynamic recrystallization appeared (see Figure 7c). Obviously, dynamic recrystallization proceeded more sufficiently and $\beta$-transus microstructure came into being at the temperature of $900{ }^{\circ} \mathrm{C}$ because of relatively high deformation temperature, as shown in Figure $7 \mathrm{~d}$. The phase transformation of $\alpha$ to $\beta$ occurred during hot compression, and the secondary $\alpha$ phase re-precipitated as needle shape in the cooling process. Generally, $\alpha+\beta$-transus microstructure was considered to be better for hot workability and mechanical property. But as the deformation temperature increased to $\beta$ phase region, the needle-shaped $\beta$-transus microstructure would be 
coarsened to lath-typed shape and no initial $\alpha$ phase could be found, thus the hot workability was worsened, as shown in Figure 7e.
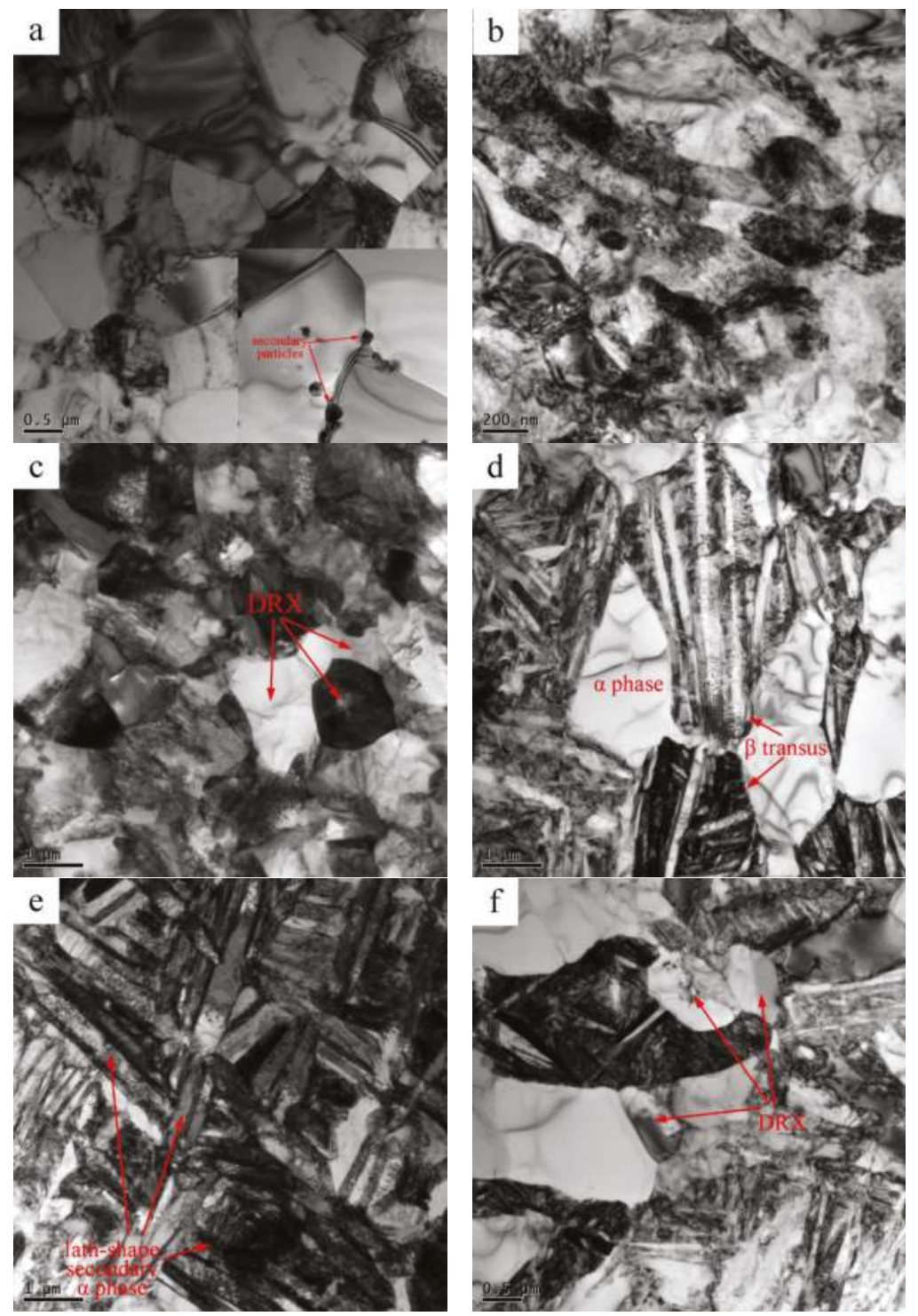

Figure 7. Transmission electron microscopy (TEM) microstructure of the specimens deformed at different deformation conditions of the as-rolled Ti-55 alloy: (a) As-rolled; (b) $700{ }^{\circ} \mathrm{C} / 0.01 \mathrm{~s}^{-1}$; (c) $800{ }^{\circ} \mathrm{C} / 0.01 \mathrm{~s}^{-1}$; (d) $900{ }^{\circ} \mathrm{C} / 0.01 \mathrm{~s}^{-1}$; (e) $1000{ }^{\circ} \mathrm{C} / 0.01 \mathrm{~s}^{-1}$; (f) $900{ }^{\circ} \mathrm{C} / 1 \mathrm{~s}^{-1}$. (DRX: Dynamic recrystallization.)

When the strain rate increased to $1 \mathrm{~s}^{-1}$ at the temperature of $900{ }^{\circ} \mathrm{C}$, the volume fraction of $\beta$-transus microstructure obviously decreased, in which the re-precipitated needle-shaped $\alpha$ phase became finer (see Figure 7d,f). Albeit deformed at higher strain rate, dynamic recrystallization could 
be observed within the initial $\alpha$ phase due to relatively high deformation temperature, as shown in Figure $7 \mathrm{f}$.

Table 1. The composition of secondary phase particles at the grain boundary.

\begin{tabular}{ccccccccc}
\hline Elements & Ti & Al & Sn & Zr & Mo & Ta & Nb & Si \\
\hline Weight \% & 67.86 & 1.26 & 4.83 & 2.32 & 16.98 & 2.55 & 3.41 & 0.75 \\
Atomic \% & 79.39 & 2.61 & 2.28 & 1.42 & 9.91 & 0.79 & 2.05 & 1.50 \\
\hline
\end{tabular}

It should be noted that the maximum yield drop appeared at the deformation temperature of $950^{\circ} \mathrm{C}$, as shown in Figure 3, which should be ascribed to the transformation of $\alpha$ to $\beta$ phase. Since the $\beta$-transus temperature was about $990^{\circ} \mathrm{C}$; there was a dramatic increase in $\beta$ phase as the deformation temperature increased from $900{ }^{\circ} \mathrm{C}$ to $950{ }^{\circ} \mathrm{C}$, which could be seen in Figure $5 \mathrm{~d}$,e. The $\beta$ phase with body-centered cubic (BCC) structure possessed more operative slip systems than $\alpha$ phase with hexagonal close-packed (HCP) structure. Owing to high stress concentration at grain boundary of $\beta$ and $\alpha$ phase, more mobile dislocations were easily generated to enhance the yield drop at the deformation temperature of $950{ }^{\circ} \mathrm{C}$. When the deformation temperature increased over $1000{ }^{\circ} \mathrm{C}$, the primary $\alpha$ phase totally transformed to $\beta$ phase, so the vanishing of $\alpha / \beta$ interphase boundary would reduce the magnitude of yield drop.

\subsection{Processing Map}

\subsubsection{Processing Map Theory}

The processing map has been established recently by Prasad et al. [24-28] on the basis of the dynamic material model, aiming at studying the microstructure evolution and avoiding flow instability of many materials. In the dynamic materials model (DMM), the workpiece subjected to hot working is considered as a nonlinear dissipator of power. The instantaneous total power dissipation $(P)$ at a given strain consists of two parts $G$ and $J$, wherein the $G$ represents the power dissipation for plastic deformation and $J$ co-content is related to the power dissipation through metallurgical mechanisms, such as dynamic recovery, dynamic recrystallization and phase transformation, which can be described as a function of flow stress and strain rate:

$$
P=\sigma \dot{\varepsilon}=G+J=\int_{0}^{\dot{\varepsilon}} \sigma d \dot{\varepsilon}+\int_{0}^{\sigma} \dot{\varepsilon} d \sigma .
$$

The power dissipation characteristics of workpiece usually depend on the materials' flow behavior, which follows the power law equation:

$$
\sigma=K \dot{\varepsilon}^{m}
$$

where $K$ is the material constant; $\sigma$ is the flow stress; $\dot{\varepsilon}$ is the strain rate; $m$ is the strain rate sensitivity, by which the content $G$ and $J$ can be related in the phenomenological model, and can be described as follows:

$$
m=\frac{d J}{d G}=\frac{\partial(\ln \sigma)}{\partial(\ln \dot{\varepsilon})} .
$$

The J co-content can be expressed as:

$$
J=\sigma \dot{\varepsilon} \mathrm{m} /(m+1)
$$

For the ideal linear dissipation body, $m=1$ and $J$ co-content reaches to the maximum: $J_{\max }=\frac{1}{2} \sigma \dot{\varepsilon}$. The power dissipation capacity of the material can be evaluated by the efficiency of power dissipation, $\eta$, which can be defined as: 


$$
\eta=\frac{J}{J_{\max }}=\frac{2 m}{m+1} .
$$

For the flow instability, Prasad developed a criterion from the extremum principle, which can be expressed as follows:

$$
\xi(\dot{\varepsilon})=\frac{\partial \ln \left(\frac{m}{m+1}\right)}{\partial(\ln \dot{\varepsilon})}+m<0 .
$$

The variation of the instability parameter $\xi(\dot{\varepsilon})$ with temperature and strain rate constitutes the instability map, from which the instability region can be obtained.

Predictably, for some materials, especially for metals with high content of alloying element and composites with high volume fraction of reinforcements, if the flow stress with respect to $\dot{\varepsilon}$ does not obey the power law in Equation (7), the computation of $\eta$ and $\xi$ in terms of $\mathrm{m}$ from Equations (10) and (11) becomes erroneous [29]. Hence, the DMM is further modified (MDMM) by Murty et al. [30], who suggests that the strain rate sensitivity parameter $m$ is a variable and redefined the efficiency of power dissipation in terms of $J$ co-content as:

$$
\begin{gathered}
\eta=J / J_{\max }=2\left(1-\frac{1}{\sigma \dot{\varepsilon}} \int_{0}^{\dot{\varepsilon}} \sigma d \dot{\varepsilon}\right), \\
\int_{0}^{\dot{\varepsilon}} \sigma d \dot{\varepsilon}=G=\int_{0}^{\dot{\varepsilon}_{\min }} \sigma d \dot{\varepsilon}+\int_{\dot{\varepsilon}_{\min }}^{\dot{\varepsilon}} \sigma d \dot{\varepsilon}=\left(\frac{\sigma \dot{\varepsilon}}{m+1}\right)_{\dot{\varepsilon}=\dot{\varepsilon}_{\min }}+\int_{\dot{\varepsilon}_{\min }}^{\dot{\varepsilon}} \sigma d \dot{\varepsilon} .
\end{gathered}
$$

The condition for the metallurgical instability is given as:

$$
2 m<\eta \text {. }
$$

The variation of $\eta$ and $\xi$ with deformation temperature and strain rate constitutes the power dissipation map and instability map. Hence, the processing map can be obtained through superimposing the instability map on the power dissipation map. Figure 8 shows the processing maps at the true strain of 0.8 of as-rolled Ti-55 alloy derived from different instability criteria.
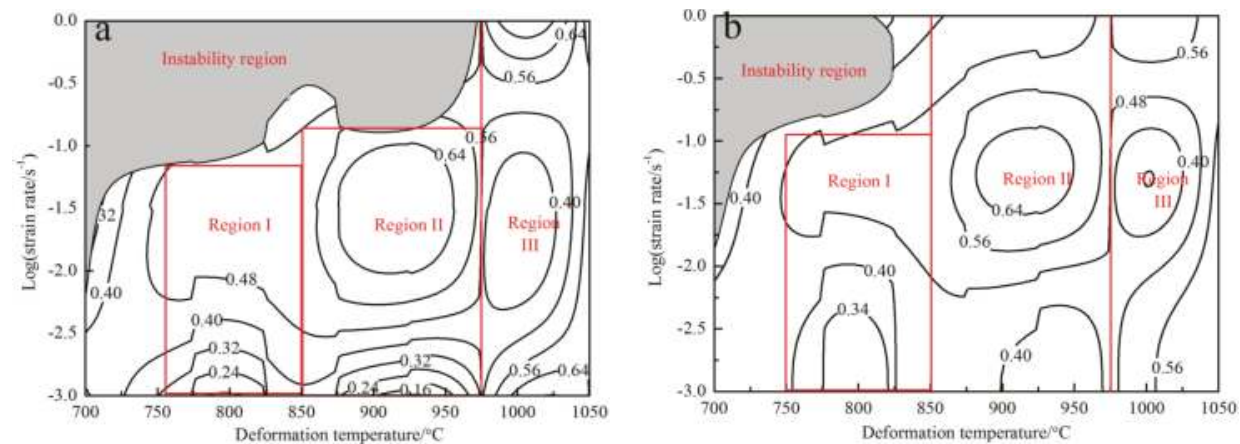

Figure 8. Processing maps at true strain of 0.8 of the as-rolled Ti-55 alloy derived from different instability criteria: (a) Dynamic materials model (DMM) and Prasad's instability criterion; (b) modified dynamic materials model (MDMM) and Murty's instability criterion.

\subsubsection{Instability Region}

Clearly, the flow instability region predicted by Prasad's instability criterion was located in the temperature region of $700-975{ }^{\circ} \mathrm{C}$ within the strain rate range of $0.1-1 \mathrm{~s}^{-1}$, while the instability region predicted by Murty's instability criterion was significantly narrower within the temperature range 
of $700-825^{\circ} \mathrm{C}$ and strain rate range of $0.1-1 \mathrm{~s}^{-1}$, as shown in Figure 8. Generally, the mechanism of flow instability should be related to cracking or localized plastic flow [31]. Obviously, shear cracking exhibiting the orientation of $\sim 45^{\circ}$ with the compression direction appeared when the specimen was deformed at $700{ }^{\circ} \mathrm{C} / 1 \mathrm{~s}^{-1}$, as shown in Figure 9. In this case, dynamic softening was difficult to take place completely or even operate due to low temperature and short deformation time, which was prone to induce flow instability. However, the microstructure at $900{ }^{\circ} \mathrm{C} / 1 \mathrm{~s}^{-1}$ and $900{ }^{\circ} \mathrm{C} / 0.1 \mathrm{~s}^{-1}$ exhibited partial dynamic recrystallization, restraining flow instability effectively, as shown in Figures $5 \mathrm{~g}$ and $7 \mathrm{f}$. It indicated that Murty's criterion was more precise in predicting the flow instability of the as-rolled Ti-55 alloy compared to Parasad's criterion. Hence, the flow instability region of the as-rolled Ti-55 alloy was located in the temperature range of $700-825^{\circ} \mathrm{C}$ and strain rate range of $0.1-1 \mathrm{~s}^{-1}$, and thus the processing map of as-rolled Ti-55 alloy derived from Murty's criterion was only discussed in the following section, which was thought to have a wider application range for the type of flow stress versus strain rate curves [29,31].

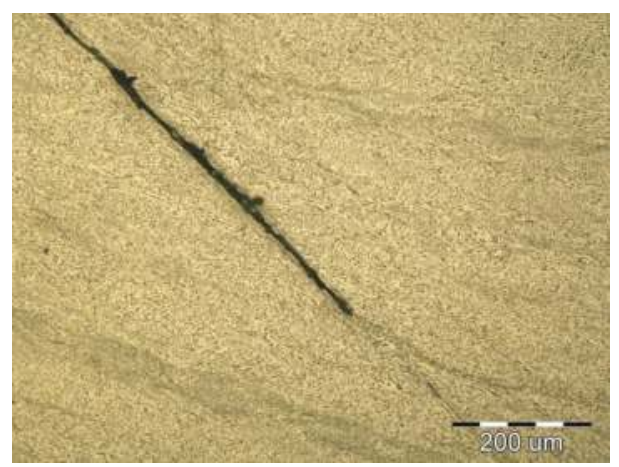

Figure 9. Microstructure of specimen deformed at $700{ }^{\circ} \mathrm{C} / 1 \mathrm{~s}^{-1}$ of the as-rolled Ti-55 alloy.

\subsubsection{Stability Region}

Figure $8 \mathrm{~b}$ shows the processing maps at the true strain of 0.8 of the as-rolled Ti- 55 alloy derived from Murty's instability criterion. It can be seen that the processing map exhibited three higher power dissipation regions with peak dissipation efficiency of $48-64 \%$ : Region I: $750-850{ }^{\circ} \mathrm{C} / 0.001-0.1 \mathrm{~s} \mathrm{~s}^{-1}$, Region II: $850-975^{\circ} \mathrm{C} / 0.001-1 \mathrm{~s}^{-1}$ and Region III: $975-1050{ }^{\circ} \mathrm{C} / 0.001-1 \mathrm{~s}^{-1}$. Although the stacking fault energy of the as-rolled Ti-55 alloy was relatively higher, the softening mechanism of the three steady deformation domains should be DRX because of the relatively higher dissipation efficiency of 48-64\% [32]. Besides this, the occurrence of phase transformation also increased the efficiency of power dissipation [33]. Hence, the greater efficiency of power dissipation in Region II and III indicated the occurrence of phase transformation of $\alpha$ to $\beta$, which could be verified by the microstructure evolution during hot compression.

The microstructures of the as-rolled Ti-55 alloy at $800{ }^{\circ} \mathrm{C} / 0.01 \mathrm{~s}^{-1}$ (Region I), $900{ }^{\circ} \mathrm{C} / 0.01 \mathrm{~s}^{-1}$ and $950{ }^{\circ} \mathrm{C} / 0.01 \mathrm{~s}^{-1}$ (Region II) and $1000{ }^{\circ} \mathrm{C} / 0.01 \mathrm{~s}^{-1}$ (Region III) are shown in Figure 5c-f. Clearly, the dynamic recrystallization in Region I was the least insufficient due to relatively low deformation temperature. When deformed at $900{ }^{\circ} \mathrm{C} / 0.01 \mathrm{~s}^{-1}$ (Region II), the microstructure of hot compressed specimens was consisted of $\alpha$ phase and $\beta$-transus microstructure, in which dynamic recrystallization took place sufficiently. Even when the strain rate increased to $1 \mathrm{~s}^{-1}$ at $900{ }^{\circ} \mathrm{C}$, dynamic recrystallization still occurred relatively sufficiently (see Figure 7f). However, the coarse $\beta$ grains formed and precipitated as coarsened lath-shaped secondary $\alpha$ microstructure after hot compression at $1000{ }^{\circ} \mathrm{C} / 0.01 \mathrm{~s}^{-1}$ (Region III), which was harmful for the mechanical properties of Ti-55 alloy. Therefore, Region II (850-975 $\left.{ }^{\circ} \mathrm{C} / 0.001-1 \mathrm{~s}^{-1}\right)$ was considered to be the optimum deformation region. 


\section{Conclusions}

The hot compression experiment of as-rolled Ti-55 alloy was conducted in the temperature range of $700-1050{ }^{\circ} \mathrm{C}$ and strain rate range of $0.001-1 \mathrm{~s}^{-1}$. The hot deformation behavior and workability of the as-rolled Ti-55 alloy were studied and the optimized hot deformation parameters were obtained through analyzing microstructure evolution and establishing hot processing map, the following conclusions can be drawn:

(1) The flow stress decreased gradually with the increase of temperature and decrease of strain rate. The deformation softening mechanism was primarily controlled by DRX of $\alpha$ phase and DRV of $\beta$ phase. The apparent activation energy $Q$ was determined to be $453.00 \mathrm{KJ} / \mathrm{mol}$ and $279.88 \mathrm{KJ} / \mathrm{mol}$ in $\alpha+\beta$ dual-phase region and $\beta$ single-phase region, respectively, which should be caused by lower deformation temperature and less slip system of $\alpha$ phase (HCP) than $\beta$ phase (BCC). The constitutive equation for hot deformation in $\alpha+\beta$ dual-phase region and $\beta$ single-phase region, respectively, was

$$
\dot{\varepsilon}=5.0129 \times 10^{18}\left[\sinh \left(5.73 \times 10^{-3} \sigma_{p}\right)\right]^{3.3851} \exp \left(-\frac{453000}{8.314 T}\right),
$$

and

$$
\dot{\varepsilon}=2.2101 \times 10^{9}\left[\sinh \left(2.69 \times 10^{-2} \sigma_{p}\right)\right]^{2.6125} \exp \left(-\frac{279880}{8.314 T}\right) .
$$

(2) Discontinuous yielding behavior occurred mainly in the temperature range of $950-1050{ }^{\circ} \mathrm{C}$ and strain rate range of $0.01-1 \mathrm{~s}^{-1}$. With the increase of deformation temperature, the yield drop decreased gradually due to the decrease of dislocation density and stress concentration, which restrained the generation of new mobile dislocation. Much higher strain rate could cause the reduction of yield drop since intense work hardening at higher strain rate may conceal the discontinuous yielding behavior. The increasing of $\beta$ phase content could enhance the yield drop in $\alpha+\beta$ phase region and the vanishing of $\alpha / \beta$ interphase boundary may reduce the yield drop in $\beta$ phase region.

(3) The processing map derived from Murty's instability criterion was more precise in predicting the hot workability of Ti-55 alloy compared to that based on Prasad's instability criterion. The processing map exhibited the optimized hot working region with sufficient dynamic recrystallization and $\alpha+$ $\beta$-transus microstructure: $850-975^{\circ} \mathrm{C} / 0.001-1 \mathrm{~s}^{-1}$. A coarsened lath-shape $\beta$-transus microstructure was formed at higher temperature, while at lower temperature, dynamic recrystallization was not sufficient, which contributed to appearance of shear cracking at higher strain rate $\left(\geq 0.1 \mathrm{~s}^{-1}\right)$ and resulted in flow instability.

Acknowledgments: This work was supported by the National Natural Science Foundation of China (No.51275131).

Author Contributions: Wenchen $\mathrm{Xu}$ and Xueze Jin conceived and designed the experiments; Xunmao Zhong and Xingjie Wan performed the experiments; Fengyong Wu analyzed the data and wrote the paper; Bin Guo and Debin Shan provided guidance and all sorts of support during the work.

Conflicts of Interest: The authors declare no conflict of interest.

\section{References}

1. Guan, S.X.; Kang, Q.; Wang, Q.J.; Liu, Y.Y.; Li, D. Influence of long-term thermal exposure on the tensile properties of a high-temperature titanium alloy Ti-55. Mater. Sci. Eng. A 1998, 243, 182-185. [CrossRef]

2. $\quad$ Fang, B.; Chen, Z.Y.; Chen, Z.Q.; Liu, J.H.; Wang, Q.J.; Liu, Y.; Feng, Z.W.; Liu, J.R.; Song, X.Y.; Wei, M.X.; et al. Continuous cooling transformation diagram and microstructure evolution of Ti-55 alloy. Chin. J. Nonferrous Met. 2010, 20, s32-s35.

3. Li, X.F.; Jiang, J.; Wang, S.; Chen, J.; Wang, Y.Q. Effect of hydrogen on the microstructure and superplasticity of Ti-55 alloy. Int. J. Hydrogen Energy 2017, 42, 6338-6349. [CrossRef]

4. Wanjara, P.; Jahazi, M.; Monajati, H.; Yue, S.; Immarigeon, J.P. Hot working behavior of near- $\alpha$ alloy IMI834. Mater. Sci. Eng. A 2005, 396, 50-60. [CrossRef] 
5. Wanjara, P.; Jahazi, M.; Monajati, H.; Yue, S. Influence of thermomechanical processing on microstructural evolution in near- $\alpha$ alloy IMI834. Mater. Sci. Eng. A 2006, 416, 300-311. [CrossRef]

6. Liu, Y.; Baker, T.N. Deformation characteristics of IMI685 titanium alloy under $\beta$ isothermal forging conditions. Mater. Sci. Eng. A 1995, 197, 125-131. [CrossRef]

7. Niua, Y.; Houb, H.L.; Li, M.Q.; Li, Z.Q. High temperature deformation behavior of a near alpha Ti600 titanium alloy. Mater. Sci. Eng. A 2008, 492, 24-28. [CrossRef]

8. Liu, Z.G.; Li, P.J.; Xiong, L.T.; Liu, T.Y.; He, L.J. High-temperature tensile deformation behavior and microstructure evolution of Ti-55 titanium alloy. Mater. Sci. Eng. A 2017, 680, 259-269. [CrossRef]

9. Seshacharyulu, T.; Medeiros, S.C.; Frazier, W.G.; Prasad, Y.V.R.K. Hot working of commercial Ti-6 Al-4 V with an equiaxed $\alpha-\beta$ microstructure: Materials modeling considerations. Mater. Sci. Eng. A 2000, 284, 184-194. [CrossRef]

10. Jia, W.J.; Zeng, W.D.; Zhou, Y.G.; Liu, J.R.; Wang, Q.J. High-temperature deformation behavior of Ti60 titanium alloy. Mater. Sci. Eng. A 2011, 528, 4068-4074. [CrossRef]

11. Balasubrahmanyam, V.V.; Prasad, Y.V.R.K. Deformation behaviour of beta titanium alloy Ti-10 V-4.5 Fe-1.5 $\mathrm{Al}$ in hot upset forging. Mater. Sci. Eng. A 2002, 336, 150-158. [CrossRef]

12. Philippart, I.; Rack, H.J. High temperature dynamic yielding in metastable Ti-6.8 Mo-4.5 F-1.5 Al. Mater. Sci. Eng. A 1998, 243, 196-200. [CrossRef]

13. Zhu, Y.C.; Zeng, W.D.; Zhao, Y.Q.; Shu, Y.; Zhang, X.M. Effect of processing parameters on hot deformation behavior and microstructural evolution during hot compression of Ti40 titanium alloy. Mater. Sci. Eng. A 2012, 552, 384-391. [CrossRef]

14. Li, L.X.; Lou, Y.; Yang, L.B.; Peng, D.S.; Rao, K.P. Flow stress behavior and deformation characteristics of Ti-3 Al-5 V-5 Mo compressed at elevated temperatures. Mater. Des. 2002, 23, 451-457. [CrossRef]

15. Wang, K.; Li, M.Q. Characterization of discontinuous yielding phenomenon in isothermal compression of TC8 titanium alloy. Trans. Nonferrous Met. Soc. China 2016, 26, 1583-1588. [CrossRef]

16. Robertson, D.G.; McShane, H.B. Isothermal hot deformation behaviour of $(\alpha+\beta)$ titanium alloy Ti-4 Al-4 Mo-2 Sn-0.5 Si (IMI 550). Mater. Sci. Technol. 1997, 13, 459-468. [CrossRef]

17. Fan, J.K.; Kou, H.C.; Lai, M.J.; Tang, B.; Chang, H.; Li, J.S. High Temperature Discontinuous Yielding in a New Near $\beta$ Titanium Alloy Ti-7333. Rare Metal Mater. Eng. 2014, 43, 0808-0812. [CrossRef]

18. He, G.A.; Liu, F.; Si, J.Y.; Yang, C.; Jiang, L. Characterization of hot compression behavior of a new HIPed nickel-based P/M superalloy using processing maps. Mater. Des. 2015, 87, 256-265. [CrossRef]

19. Zener, C.; Hollomon, J.H. Effect of strain rate upon plastic flow of steel. J. Appl. Phys. 1944, 15, $22-32$. [CrossRef]

20. Wang, K.L.; Lu, S.Q.; Fu, M.W.; Li, X.; Dong, X.J. Identification of the optimal $(\alpha+\beta)$ forging process parameters of Ti-6.5 Al-3.5 Mo-1.5 Zr-0.3 Si based on processing-maps. Mater. Sci. Eng. A 2010, 527, 7279-7285. [CrossRef]

21. Zhao, H.Z.; Xiao, L.; Ge, P.; Sun, J.; Xi, Z.P. Hot deformation behavior and processing maps of Ti-1300 alloy. Mater. Sci. Eng. A 2014, 604, 111-116. [CrossRef]

22. Li, M.Q.; Pan, H.S.; Lin, Y.Y.; Luo, J. High temperature deformation behavior of near alpha Ti-5.6 Al-4.8 Sn-2.0 Zr alloy. J. Mater. Process. Tech. 2007, 183, 71-76. [CrossRef]

23. Seshacharyulu, T.; Medeiros, S.C.; Morgan, J.T.; Mala, J.C.; Frazier, W.G.; Prasad, Y.V.R.K. Hot deformation mechanisms in ELI grade Ti-6 A1-4 V. Scripta Mater. 1999, 41, 283-288. [CrossRef]

24. Dong, Y.Y.; Zhang, C.S.; Zhao, G.Q.; Guan, Y.J.; Gao, A.J.; Sun, W.C. Constitutive equation and processing maps of an Al-Mg-Si aluminum alloy: Determination and application in simulating extrusion process of complex profiles. Mater. Des. 2016, 92, 983-997. [CrossRef]

25. He, D.G.; Lin, Y.C.; Chen, M.S.; Chen, J.; Wen, D.X.; Chen, X.M. Effect of pre-treatment on hot deformation behavior and processing map of an aged nickel-based superalloy. J. Alloy Compd. 2015, 649, 1075-1084. [CrossRef]

26. Zhao, Z.L.; Li, H.; Fu, M.W.; Guo, H.Z.; Yao, Z.K. Effect of the initial microstructure on the deformation behavior of Ti60 titanium alloy at high temperature processing. J. Alloy Compd. 2014, 617, 525-533. [CrossRef]

27. Xia, X.S.; Chen, Q.; Li, J.P.; Shu, D.Y.; Hu, C.K.; Huang, S.H.; Zhao, Z.D. Characterization of hot deformation behavior of as-extruded Mg-Gd-Y-Zn-Zr alloy. J. Alloy Compd. 2014, 610, 203-211. [CrossRef]

28. Liu, J.; Cui, Z.S.; Li, C.X. Analysis of metal workability by integration of FEM and 3-D processing maps. J. Mater. Process. Technol. 2008, 205, 497-505. [CrossRef] 
29. Gupta, R.K.; Narayana Murtya, S.V.S.; Panta, B.; Agarwalab, V.; Sinha, P.P. Hot workability of $\gamma+\alpha_{2}$ titanium aluminide: Development of processing map and constitutive equations. Mater. Sci. Eng. A 2012, 551, 169-186. [CrossRef]

30. Prasad, Y.V.R.K.; Gegel, H.L.; Doraivelu, S.M.; Malas, J.C.; Morgan, J.T.; Lark, K.A.; Barker, D.R. Modeling of Dynamic Material Behavior in Hot Deformation: Forging of Ti-6242. Metall. Trans. A 1984, 15, 1884-1891. [CrossRef]

31. Narayana Murty, S.V.S.; Nageswara Rao, B. Instability map for hot working of $6061 \mathrm{Al}-10 \mathrm{vol} \% \mathrm{Al}_{2} \mathrm{O}_{3}$ metal matrix composite. J. Phys. D 1998, 31, 3306-3311. [CrossRef]

32. Xia, X.S.; Chen, Q.; Zhang, K.; Zhao, Z.D.; Ma, M.L.; Li, X.G.; Li, Y.J. Hot deformation behavior and processing map of coarse-grained Mg-Gd-Y-Nd-Zr alloy. Mater. Sci. Eng. A 2013, 587, 283-290. [CrossRef]

33. Kong, F.T.; Cui, N.; Chen, Y.Y.; Wang, X.P.; Xiong, N.N. Characterization of hot deformation behavior of as-forged TiAl alloy. Intermetallics 2014, 55, 66-72. [CrossRef]

(c) 2017 by the authors. Licensee MDPI, Basel, Switzerland. This article is an open access article distributed under the terms and conditions of the Creative Commons Attribution (CC BY) license (http:/ / creativecommons.org/licenses/by/4.0/). 
Article

\title{
The Effect of Initial Structure on Phase Transformation in Continuous Heating of a TA15 Titanium Alloy
}

\author{
Xiaoguang Fan *, Qi Li, Anming Zhao, Yuguo Shi and Wenjia Mei \\ State Key Laboratory of Solidification Processing, School of Materials Science and Engineering, Northwestern \\ Polytechnical University, Xi'an 710072, China; rickey@mail.nwpu.edu.cn (Q.L.); zhaoanming117@126.com (A.Z.); \\ shiygupc@163.com (Y.S.); mwj725@163.com (W.M.) \\ * Correspondence: fxg3200@nwpu.edu.cn; Tel.: +86-029-8846-0212
}

Academic Editor: Mark T. Whittaker

Received: 20 April 2017; Accepted: 23 May 2017; Published: 1 June 2017

\begin{abstract}
The effect of initial structure on phase evolution in continuous heating of a near- $\alpha$ TA15 titanium alloy (Ti-6Al-2Zr-1Mo-1V) was experimentally investigated. To this end; three microstructures were obtained by multiple heat treatment: I-bimodal structure with $50 \%$ equaixed $\alpha$, II-bimodal structure with $15 \%$ equiaxed $\alpha$, III-trimodal structure with $18 \%$ equiaxed $\alpha$ and $25 \%$ lamellar $\alpha$. Differential scanning calorimetry (DSC), dilatometry and quantitative metallography were carried out on specimens with the three initial structures at heating rates from 5 to $40{ }^{\circ} \mathrm{C} / \mathrm{min}$. The transformation kinetics was modeled with the Johnson-Mehl-Avrami (JMA) approach under non-isothermal condition. It was found that there exists a four-stage transformation for microstructures I and III. The secondary and third stages overlap for microstructure II. The four stages of phase transformation overlap with increasing heating rate. In the presence of $\alpha$ laths, the phase transformation kinetics is affected by the composition difference between lamellar $\alpha$ and primary equiaxed $\alpha$. Phase transformation is controlled by the growth of existing large $\beta$ phase.
\end{abstract}

Keywords: titanium alloy; phase transformation; microstructure; DSC; dilatometry

\section{Introduction}

Titanium alloys have been gaining more applications in many industry fields due to the high specific strength, good thermal stability and excellent corrosion resistance [1]. The near- $\alpha$ TA15 titanium alloy which has moderate strength up to $400{ }^{\circ} \mathrm{C}$, excellent thermal stability, good weldability and low growth rate of fatigue crack has been widely used to manufacture structural components in airplanes. The mechanical properties of the titanium alloy are largely dependent on the microstructure [1-3]. The equiaxed and bimodal structures are commonly used for traditional $\alpha+\beta$ titanium alloys due to a balance in strength, ductility, creep and fatigue resistance (Table 1). The trimodal structure which consists of $10-20 \%$ equiaxed $\alpha, 30-50 \%$ lamellar $\alpha$ and transformed $\beta$ matrix may also be required after secondary working due to its superior low-cycle fatigue resistance [4]. The diversity in microstructure results from the $\alpha-\beta$ phase transformation along with deformation induced morphology evolution. Thus, the microstructure can be modulated by optimizing hot working parameters (e.g., heating rate, heating path, heating temperature, strain, strain rate and cooling path).

The phase evolution in hot working involves the $\alpha$-to- $\beta$ transformation in heating, the $\beta$-to- $\alpha$ transformation in cooling as well as the stress induced transformation during deformation. Numerous researches have been carried out on the phase transformation in cooling. Tang et al. [5] and Sun et al. [6] found that the $\alpha$ lamellae can nucleate in a sympathetic way or by interface instability during slow cooling. He et al. [7] examine the orientation relationship between $\alpha$ and $\beta$ phase after $\beta$ working 
and found that the Burger's orientation relationship is strictly obeyed. Though deformation has little influence on the orientation relationship, the deformation induced texture can result in variation selection and causes a strong texture of $\beta$ phase [8]. Kherrouba et al. [9] examined the transformation kinetics of Ti-6Al-4V alloy by Johnson-Mehl-Avrami (JMA) model and suggested that growth of $\beta$ lamellae may be controlled by the combination of solute diffusion and interface migration. The applied stress in machining and deformation can also cause phase transformation. Liu et al. [10] found that can trigger the formation of $\omega$ phase can be triggered even before plastic deformation. Jonas et al. [11] reported that dynamic transformation from $\alpha$ to $\beta$ occurs in hot deformation of several titanium alloys, resulting in significant flow softening during deformation.

Table 1. The mechanical properties of different microstructures for TA15 titanium alloy (compared to equiaxed structure).

\begin{tabular}{ccccccc}
\hline Microstructure & $\begin{array}{c}\text { Yield } \\
\text { Strength }\end{array}$ & Elongation & $\begin{array}{c}\text { Fracture } \\
\text { Toughness }\end{array}$ & $\begin{array}{c}\text { Creep } \\
\text { Strength }\end{array}$ & $\begin{array}{c}\text { HCF } \\
\text { Strength }\end{array}$ & $\begin{array}{c}\text { LCF } \\
\text { Strength }\end{array}$ \\
\hline Bimodal & ++ & $-/ \mathrm{o}$ & + & + & $+/ \mathrm{o}$ & + \\
Trimodal & + & $-/ \mathrm{o}$ & + & + & + & ++ \\
\hline
\end{tabular}

From the point of microstructure control, the phase transformation in heating is as important as that in cooling and deformation. Wang et al. [12] used the dilatometry to investigate phase evolution in a TC21 alloy during continuous heating. They found that the phase transformation includes three stages, residual $\beta \rightarrow$ acicular $\alpha$, acicular $\alpha \rightarrow \beta$ and equiaxed $\alpha \rightarrow \beta$. The activation energy for $\alpha \rightarrow \beta$ transformation was also estimated with the classical JMA equation. A similar transformation behavior was also reported for Ti-6Al-4V alloy by Sha and Guo [13]. Barriobero-Vila et al. [14] examined the element partitioning and related phase transformation kinetics in heating of a bimodal Ti-6Al-6V-2Sn alloy by in-situ high energy synchrotron X-ray diffraction. They found that partitioning of solutes leads to nonlinear variation of the lattice parameters of the $\beta$ phase. Elmer et al. [15] examined the phase transition during welding of a Ti-6Al-4V alloy. They found that a large superheat is necessary for the completion of $\alpha$-to- $\beta$ transformation due to the high heating rate. The overall transformation mechanism may be diverse because the starting assumption determines the calculated parameters in JMA equation. Guo et al. [16] investigated the microstructural developments by deformation induced temperature rise in TA15 titanium alloy. A diffusion model was developed to depict the variation of particle size and volume fraction of equiaxed $\alpha$ under different heating rates. Chen et al. [17] investigated the phase transformation in continuous heating of a near- $\beta$ titanium alloy. The phase transformation sequence and dominate mechanism were determined. The transformation kinetics and microstructural development in heating are not only dependent on the heating rate, but also greatly affected by the microstructure prior to heating, which needs further investigation.

In this work, the effect of initial structure on the phase evolution in continuous heating of TA15 titanium alloy was investigated. To this end, multiple heat treatments were employed to obtain three different microstructures from a wrought billet. The phase transformation process was determined by metallographic observation, differential scanning calorimetry (DSC) and dilatometry. The microstructure evolution under different heating rate and initial structures was studied. The effect of initial structure on phase transformation kinetics was also measured. The results can be used for quantative control of phase constitution in hot working.

\section{Material and Procedures}

\subsection{Material}

The as-received TA15 titanium alloy was a $1000 \mathrm{~mm} \times 400 \mathrm{~mm} \times 100 \mathrm{~mm}$ hot forged bar produced by western superconducting technologies $\mathrm{Co} ., \mathrm{Xi}^{\prime}$ an, China. The chemical composition of the alloy was measured to be $6.69 \mathrm{Al}, 2.25 \mathrm{Zr}, 1.77 \mathrm{Mo}, 2.25 \mathrm{~V}, 0.14 \mathrm{Fe}, 0.12 \mathrm{O}, 0.002 \mathrm{H}$ and balanced $\mathrm{Ti}$ (wt $\%$ ) by 
wet chemical analysis. The $\beta$ transus temperature was determined to be $985^{\circ} \mathrm{C}$ by metallography. The as-received material was annealed at $820^{\circ} \mathrm{C}$ to obtain a bimodal structure consisting of about $50 \%$ equiaxed $\alpha$ within transformed $\beta$ matrix (microstructure I, Figure 1a). The measured fraction and particle size of the equiaxed $\alpha$ are about 0.5 and $12.5 \mu \mathrm{m}$, respectively.

Two other microstructures were obtained by heat treatments from microstructure I. Specimen with initially microstructure I was heated at the rate of $10^{\circ} \mathrm{C} / \mathrm{min}$ up to $970{ }^{\circ} \mathrm{C}$, held for $30 \mathrm{~min}$ and then cooled in the air to get a bimodal structure composed of about $15 \%$ equiaxed $\alpha$ within transformed $\beta$ matrix (microstructure II, Figure 1b). The grain size of equiaxed $\alpha$ phases decreased to about $9.5 \mu \mathrm{m}$.

Usually, the trimodal structure can be obtained by a near $\beta$ hot working and a subsequent heat treatment in the $\alpha+\beta$ region. The hot working in the near $\beta$ region aims to control the fraction of equiaxed $\alpha$. The subsequent heat treatment produces the $\alpha$ lamellae. Thus, the material with bimodal structure was reheated to $940{ }^{\circ} \mathrm{C}$ and air cooled to obtain the trimodal structure (microstructure III, Figure 1c). The volume fraction of primary equiaxed and lamellar $\alpha$ were about $18 \%$ and $25 \%$, respectively.

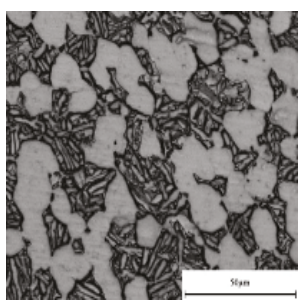

(a)

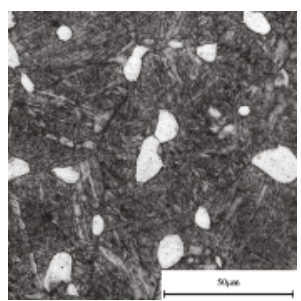

(b)

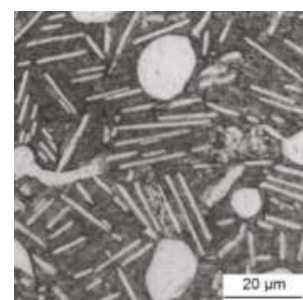

(c)

Figure 1. Optical microscopy images of the microstructures prior to heating: (a) microstructure I; (b) microstructure II; (c) microstructure III.

\subsection{Metallographic Examination}

The $\phi 10 \mathrm{~mm} \times 10 \mathrm{~mm}$ cylinder specimens were heated at the rates of 5 and $10^{\circ} \mathrm{C} / \mathrm{min}$ to the preset temperatures with a resistance furnace, and then water quenched to freeze the high temperature microstructure. The specimen was coated with glass lubricant to prevent oxidation at high temperature. The selected quenching temperatures were $700,750,800,860,900,940,970$ and $1100{ }^{\circ} \mathrm{C}$. The specimens were electrical discharge cut, mechanical grinded and polished, and etched in a solution of $13 \%$ $\mathrm{HNO}_{3}, 7 \% \mathrm{HF}$ and $80 \% \mathrm{H}_{2} \mathrm{O}$. Micrographs were taken on a LECIA DMI3000 microscope (LECIA, Shanghai, China). Moreover, the fine secondary lamellar $\alpha$ phases were examined using a scanning electron microscopy TESCAN VEGA3 LMU (TESCAN, Shanghai, China). The volume fraction and size of the $\alpha$ phase were determined by image-pro plus software. The fraction of the $\alpha$ phase was measured by the ratio of the area of $\alpha$ phase to the overall area on a micrograph. The Optical microscopy micrographs at 1000 times magnification were used to measure the fraction of equiaxed $\alpha\left(f_{1}\right)$. Scanning electronic microscopy (SEM, TESCAN, Shanghai, China) images at 5000 times magnification were employed to measure the fraction of $\alpha$ lamellae in $\beta$ matrix $\left(f_{2}\right)$. The overall volume fraction of $\alpha$ is calculated by $f=f_{1}+\left(1-f_{1}\right) \times f_{2}$. The grain size of equiaxed $\alpha$ is measured to be the average diameter of the equiaxed $\alpha$ particles on the micrograph. Due to the limitation of radiation heating, phase transformation at higher heating rate was examined by differential scanning calorimetry (DSC) and dilatometry.

\subsection{Differential Scanning Calorimetry}

The characteristic temperatures for phase transformation were measured by the differential scanning calorimetry with a Netzsch DSC-404 calorimeter (Netzsch, Shanghai, China). The specimens were $\phi 4 \mathrm{~mm} \times 0.5 \mathrm{~mm}$ disks with different initial structures. The specimens were heated at 10, 20 
and $40{ }^{\circ} \mathrm{C} / \mathrm{min}$ up to $1100{ }^{\circ} \mathrm{C}$ respectively. All tests were conducted under the shielding of high purity Ar flow.

\subsection{Dilatometry}

Dilatometry was carried out on a Netzsch DIL402C dilatometer (Netzsch, Shanghai, China). The specimens used in the experiment were $\phi 6 \mathrm{~mm} \times 25 \mathrm{~mm}$ cylinders. The specimens were heated at 5,10 and $20^{\circ} \mathrm{C} / \mathrm{min}$ up to $1100{ }^{\circ} \mathrm{C}$, respectively. The whole process was shielded under high purity Ar flow with the flow rate of $50 \mathrm{~mL} / \mathrm{min}$. The change in the length of the specimen was recorded and used to determine the linear thermal expansion.

\section{Results and Discussion}

\subsection{Microstructure Observations}

In continuously heating, there often exists a three stage phase transformation, including $\beta$ decompostion at low temperature, lamellar $\alpha$ to $\beta$ at intermediate temperature and equiaxed $\alpha$ to $\beta$ at high temperature. For initially microstructure I which was annealed at low temperature, the $\beta$-to- $\alpha$ transformation at low temperatures has little influence on the microstructure. The microstructure after heated up to $700{ }^{\circ} \mathrm{C}$ is close to the initial structure, as shown in Figure 2a. With increasing temperature, the primary equiaxed $\alpha$ remains unchanged. Meanwhile, the lamellar $\alpha$ is slightly thickened (Figure 2b). Significant $\beta$-to- $\alpha$ transformation occurs with further heating. Blocks of $\beta$ phases firstly appear between the equiaxed and lamellar $\alpha$ phases (Figure 2c). The volume fraction of equiaxed $\alpha$ decreases slightly while the lamellar $\alpha$ are shortened significantly (Figure $2 \mathrm{~d}$ ). The transformation rate of lamellar $\alpha$ is so high that there exists a large fraction of equiaxed $\alpha$ when the lamellar $\alpha$ has already dissolute (Figure 2e). The size of equiaxed $\alpha$ particles becomes more inhomogeneously distributed when the equiaxed $\alpha$ began to dissolve. For diffusion controlled phase transformation process, the dissolution rate of a secondary particle is inverse proportional to its radius. Therefore, the difference in particle size is strengthened during $\alpha$-to- $\beta$ transformation (Figure $2 \mathrm{f}$ ).

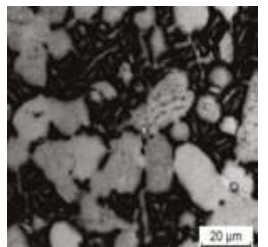

(a)

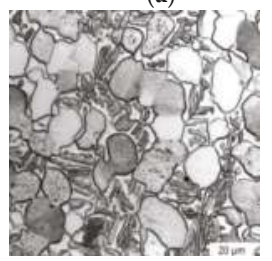

(d)

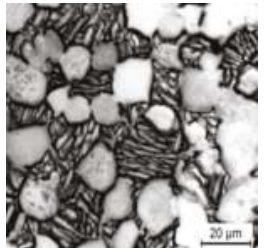

(b)

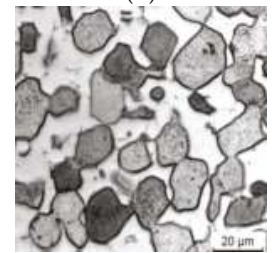

(e)

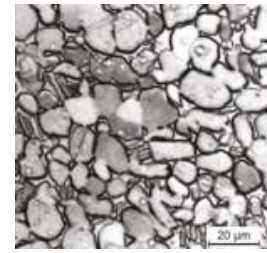

(c)

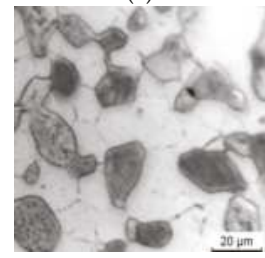

(f)

Figure 2. Optical microscopy micrographs of samples with initially microstructure I after heated up to (a) $700{ }^{\circ} \mathrm{C}$; (b) $800{ }^{\circ} \mathrm{C}$; (c) $860{ }^{\circ} \mathrm{C}$; (d) $900{ }^{\circ} \mathrm{C}$; (e) $940{ }^{\circ} \mathrm{C}$ and (f) $970{ }^{\circ} \mathrm{C}$ at $10^{\circ} \mathrm{C} / \mathrm{min}$.

Microstructure II was obtained by high temperature annealing followed by a rapid cooling. The microstructure is more affected by the phase transformation in heating. Metallographic observation suggests that the volume fraction of equiaxed $\alpha$ varies little until the heating temperature is high 
enough to transform all $\alpha$ lamellae, as shown in Figure 3. On the other hand, the fraction, size and morphology of the lamellar $\alpha$ change significantly.
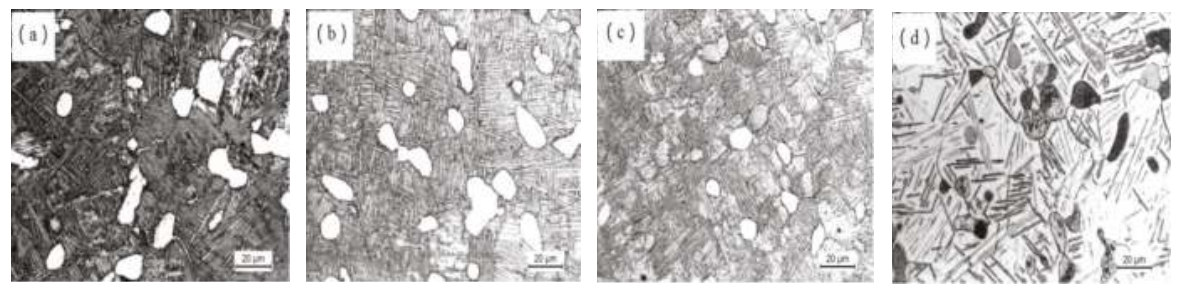

Figure 3. Optical microscopy micrographs of specimens with initially microstructure II after heated up to (a) $750{ }^{\circ} \mathrm{C}$; (b) $800{ }^{\circ} \mathrm{C}$; (c) $860{ }^{\circ} \mathrm{C}$; (d) $940{ }^{\circ} \mathrm{C}$ at $10{ }^{\circ} \mathrm{C} / \mathrm{min}$.

Figure 4 shows the change of lamellar $\alpha$ phase during continuous heating with initially microstructure II. The lamellae varied little up to $700{ }^{\circ} \mathrm{C}$ (Figure 4a). For Ti-6Al-4V alloy, the $\beta$-to- $\alpha$ transformation occurs around $500{ }^{\circ} \mathrm{C}$. The metastable $\beta$ phase may have already taken place before $700{ }^{\circ} \mathrm{C}$. However, it is hard to measure it by metallographic observation. Barriobero-Vila et al. [14] reported an increase of $3 \%$ in the volume fraction of $\alpha$ phase at a heating rate of $5{ }^{\circ} \mathrm{C} / \mathrm{min}$ for the Ti-6Al-4V alloy. The increase in volume fraction decreases to $1 \%$ at the heating rate of $20^{\circ} \mathrm{C} / \mathrm{min}$. It can be found from Figure $3 \mathrm{a}$ that the secondary grain boundary $\alpha$ becomes more continuous, which indicates the decomposition of residual $\beta$ phase. However, the increase in $\alpha$ fraction is trivial comparing to the overall volume fraction of $\alpha$ lamellae $(>60 \%)$. Meanwhile, the low heating temperature prohibits the coarsening of $\alpha$ lamellae. As a result, the microstructural change is not significant.

During temperature range of 700 to $900{ }^{\circ} \mathrm{C}$, the volume fraction of lamellar $\alpha$ decreases slightly with temperature and the fine lamellar $\alpha$ disappeared (Figure $4 \mathrm{~b}$ ). They either transform to $\beta$ phase or merge to become thicker lamellae, resulting in relatively thick $\alpha$ lamellae. The average thickness of the lamellar $\alpha$ increases significantly. Above $900{ }^{\circ} \mathrm{C}$, the transformation of lamellar $\alpha$ is greatly accelerated. Thin and short lamellae transform faster than the long and thick ones. The lamellae become isolated by the $\beta$ matrix. The thickness of the lamellae increases first and then decreases (Figure $4 \mathrm{c}, \mathrm{d})$ ). The dissolution of secondary $\alpha$ laths is dominated by the shortening along the major axis, which can be taken as a reverse process of the growth of the Widmanstatten $\alpha$.
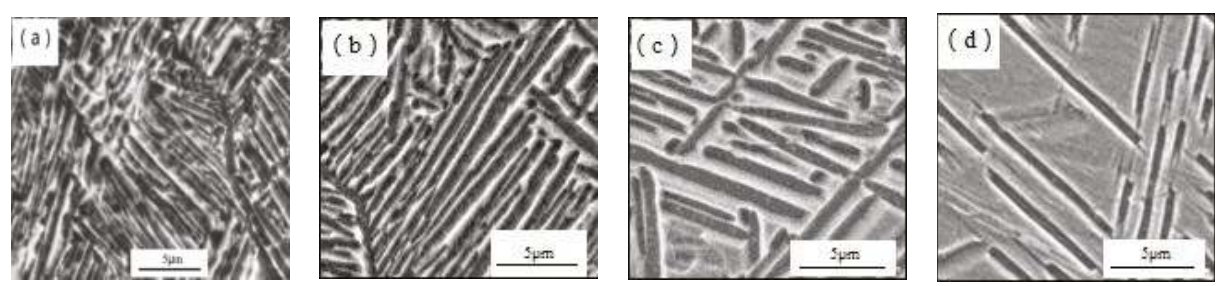

Figure 4. Secondary electron images of the lamellar $\alpha$ from initially microstructure II after heated up to (a) $700{ }^{\circ} \mathrm{C}$; (b) $900{ }^{\circ} \mathrm{C}$; (c) $940{ }^{\circ} \mathrm{C}$; (d) $970{ }^{\circ} \mathrm{C}$.

In continuous heating of the trimodal structure (microstructure III), the primary equiaxed $\alpha$ and lamellar $\alpha$ are unchanged when the heating temperature is below $700{ }^{\circ} \mathrm{C}$ (Figure $5 \mathrm{a}$ ). With increasing temperature, the significant increase in the fraction of secondary lamellar $\alpha$ is observed (Figure $5 b$ ), which is often interpreted in terms of lamellae thickening. The residual $\beta$ between the lamellar $\alpha$ consists of a large fraction of thin and disordered secondary $\alpha$ laths (Figure 6a). These $\alpha$ lathes 
transform preferentially to $\beta$ phase with increasing temperature, as shown in Figure $6 \mathrm{~b}$. Though the secondary $\alpha$ laths are stabilized by annealing at $940{ }^{\circ} \mathrm{C}$, the lower $\alpha$ stabilizer and the higher specific surface area, they transform more rapidly than the primary equiaxed $\alpha$ (Figure $6 \mathrm{c}, \mathrm{d})$ ). The dissolution behavior of the $\alpha$ laths is similar to that of initially microstructure II. The $\alpha$ laths in microstructure III are formed by additional heat treatment. Their properties (chemical composition, morphology, interfacial coherency, etc.) are similar to the high temperature $\alpha$ lamellae formed in continuous heating of microstructure II.
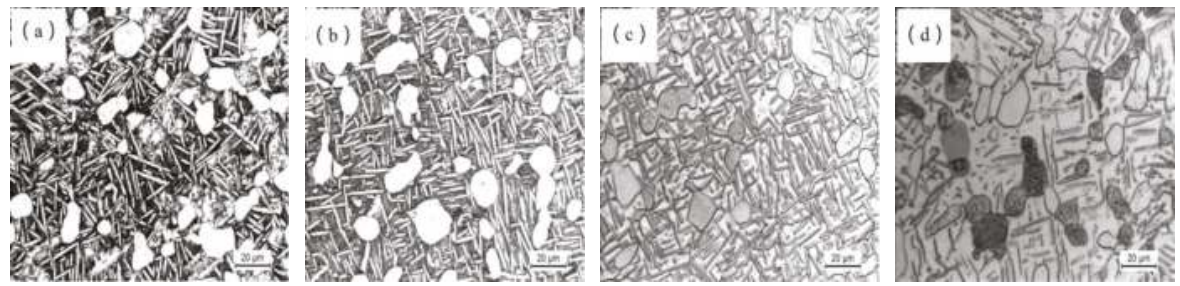

Figure 5. Optical microscopy images of the specimens after heated up from initially microstructure III: (a) $700{ }^{\circ} \mathrm{C}$, Water quenched (WQ); (b) $800{ }^{\circ} \mathrm{C}$, WQ; (c) $940{ }^{\circ} \mathrm{C}$, WQ; (d) $970{ }^{\circ} \mathrm{C}$, WQ.
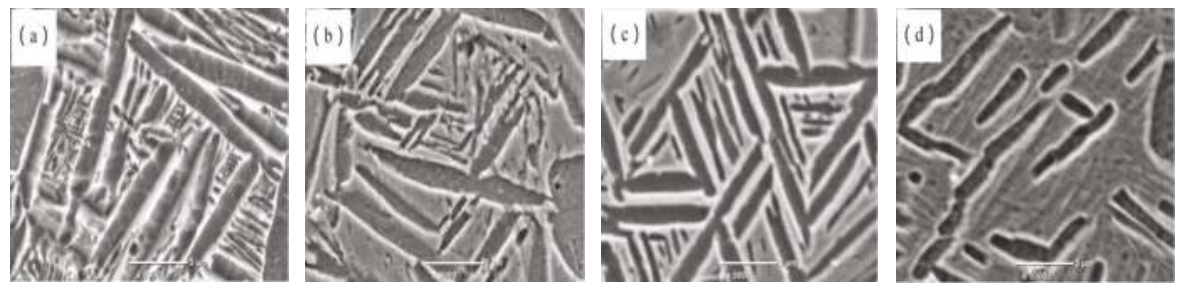

Figure 6. Secondary electron images of the lamellar $\alpha$ with initially microstructure III: (a) $800{ }^{\circ} \mathrm{C}$, WQ; (b) $860^{\circ} \mathrm{C}$, WQ; (c) $900^{\circ} \mathrm{C}$, WQ; (d) $970{ }^{\circ} \mathrm{C}$, WQ.

\subsection{Analysis of Differential Scanning Calorimetry and Dilatometry}

$\alpha-\beta$ phase transformations involve heat absorption or heat release, which correlate to the endothermic or exothermic peaks in DSC curve. The starting and ending temperatures of the transformation can be estimated from the onset and offset points of the peak. This method has been employed to investigate the phase transformation in continuous cooling and heating of Ti-6Al-4V titanium alloy $[13,18]$.

DSC curves of different initial structure heated at the rate of 10,20 and $40{ }^{\circ} \mathrm{C} / \mathrm{min}$ are given in Figure 7. From the DSC curves, it can be seen that there exists a slight exothermic peak around $500{ }^{\circ} \mathrm{C}$ at the heating rate of $10{ }^{\circ} \mathrm{C} / \mathrm{min}$ for all three initial structures. This peak corresponds to the decomposition of residual $\beta$ phase. The $\beta$-to- $\alpha$ transformation temperature ranges from 430 to $530{ }^{\circ} \mathrm{C}$ for a bimodal two-phase Ti-6Al-6V-2Sn alloy [14] and it ranges from 590 to $735{ }^{\circ} \mathrm{C}$ for a bimodal two-phase TC21 alloy [12] at a heating rate of $5^{\circ} \mathrm{C} / \mathrm{min}$, which are close to the current study. However, as the exothermic peak is not significant, it is impossible to determine the temperature range by DSC curves.

After the first exothermic peak, the heat flux increases continuously and reach the first endothermic peak at 760 to $780{ }^{\circ} \mathrm{C}$. The starting temperatures of endothermic peak for the bimodal and trimodal structures are similar $\left(<600^{\circ} \mathrm{C}\right)$, which are much lower than that for the equiaxed structure (about $730^{\circ} \mathrm{C}$ ). Metallographic observation suggested that $\alpha$-to- $\beta$ phase transformation has begun in this temperature range. The tiny $\alpha$ phase inside residual $\beta$ phase transforms prior to other $\alpha$ phases, as shown in Figure 7. Microstructure III has the highest exothermic peak because there are plenty of 
tiny $\alpha$ phase inside $\beta$ matrix (Figure 7a). On the other hand, microstructure I was annealed at the lowest temperature, which stabilizes the constituent phase. As a result, it has the lowest peak and highest starting temperature.

A second endothermic peak appears at 850 to $870{ }^{\circ} \mathrm{C}$. The tiny $\alpha$ phases inside residual $\beta$ matrix has transformed completely (Figure $7 \mathrm{~b}$ ). As this peak is not significant for microstructure II, it may correspond to the rapid transformation of larger secondary $\alpha$ lamellae. The lamellar $\alpha$ in microstructure II is not as stable as that in microstructure I and III because it is formed during cooling from high temperature annealing. Actually, it is the same to the tiny $\alpha$ phase in microstructure III. The transformation process would be smooth and continuous for microstructure II in this temperature range.

A third endothermic peak is observed at 950 to $970{ }^{\circ} \mathrm{C}$. Apparently, this corresponds to the transformation of equiaxed $\alpha$ to $\beta$ phase. Microstructure I has the highest peak and the corresponding temperature for the third peak is the lowest, which may be attributed to the large volume fraction of primary equiaxed $\alpha$ phase. The finishing points of the peaks are all around $1000{ }^{\circ} \mathrm{C}$, indicating the $\beta$ transus temperature at a specific heating rate may not be affected by the initial structure.

No matter what initial structure is, there are three obvious endothermic peaks between the room temperature and the $\beta$-transus temperature, which correspond to the transformation of tiny secondary $\alpha$ lamellae, the coarse secondary $\alpha$ lamellae and the primary equiaxed $\alpha$. The multiple forms of the $\alpha$ phase result in such a three stage $\alpha$-to- $\beta$ transformation behavior. The starting and ending points of each stage is affected by the initial structure. As the three stages of transformation overlap, it is impossible to obtain the specific starting and ending temperatures.

The three endothermic peaks can also be observed at the heating rate of $20^{\circ} \mathrm{C} / \mathrm{min}$. The temperature for each peak increases as expected. However, the temperature interval between different peaks is deceased, indicating the overlapping of the three stages of phase transformation. When the heating rate increases to $40{ }^{\circ} \mathrm{C} / \mathrm{min}$, only the first peak can be clearly observed. The high heating rate increases the driving force for $\alpha$-to- $\beta$ transformation, which promotes the transformation of equiaxed $\alpha$ and the coarse lamellar $\alpha$.

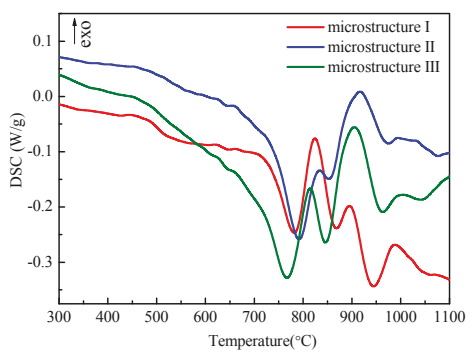

(a)

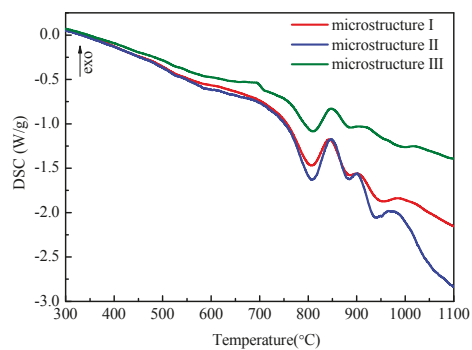

(b)

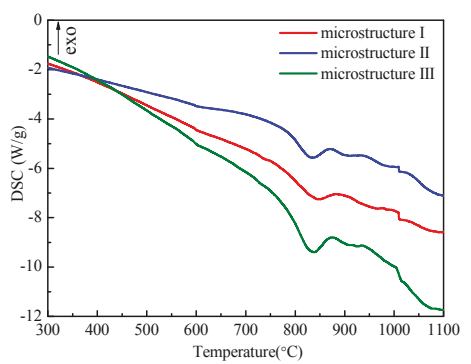

(c)

Figure 7. DSC curves of the different initially structures at the heating rate of (a) $10{ }^{\circ} \mathrm{C} / \mathrm{min}$; (b) $20^{\circ} \mathrm{C} / \mathrm{min} ;(\mathbf{c}) 40{ }^{\circ} \mathrm{C} / \mathrm{min}$. 
The $\beta$-to- $\alpha$ phase transformation is accompanied by a volume contraction of $0.15-0.3 \%$ [19]. In two-phase titanium alloy, the overall expansion was related to the expansions of the constituent phases and the relative volume fractions. During continuous heating, the length change of the specimens was influenced in the following aspects: the dilatation by lattice change, the thermal expansion of the lattice and additional expansion of the $\beta$ lattice due to the impoverishment of $\beta$ stabilizers [20]. Because the sample length variation during phase transformation was not apparent in two-phase titanium alloy, the derivatives of length change with respect to temperature $(d L / d T)$ were used to investigate $\beta-\alpha-\beta$ phase transformation, as shown in Figure 8. During continuous heating, the metastable $\beta$ matrix firstly decomposed to acicular $\alpha$ phases and an increase of length change may be observed in dilatometric curves [12]. However, due to the element partitioning, the lattice of the $\beta$ phase also contracts [20]. As a result, the thermal expansion rate varies little below $600{ }^{\circ} \mathrm{C}$ irrespective of initial structure and heating rate in this work. Due to the lattice expansion of $\beta$ phase, the TA15 titanium alloy shows a slight increase in expansion rate when the heating temperature is above $600{ }^{\circ} \mathrm{C}$. A similar behavior was also observed in the Ti- $6 \mathrm{Al}-4 \mathrm{~V}$ alloy. At the lowest heating rate of $5{ }^{\circ} \mathrm{C} / \mathrm{min}$, a substantial increase in expansion rate was observed for the initially microstructure I and III, while the variation in expansion rate was low for microstructure II. This is because the residual $\beta$ phase and lamellar $\alpha$ are cooled from the high temperature $\beta$ phase, which has a relatively low content of $V$. The lattice expansion would be low as the element partitioning is not significant. On the other hand, when the equiaxed $\alpha$ transforms to $\beta$ phase, $\beta$ stabilizers would diffuse over a long distance as the deviation of $\beta$ stabilizer content in equiaxed $\alpha$ and $\beta$ phase is very large. So the degree of enrichment of $\beta$ stabilizers in $\beta$ matrix would severely decrease, which increased the lattice parameter of $\beta$ phase. Therefore, there was an apparent expansion in dilatometric curves in the third stage.

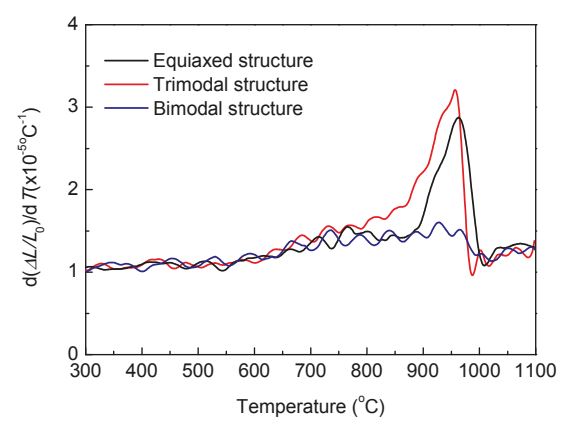

(a)

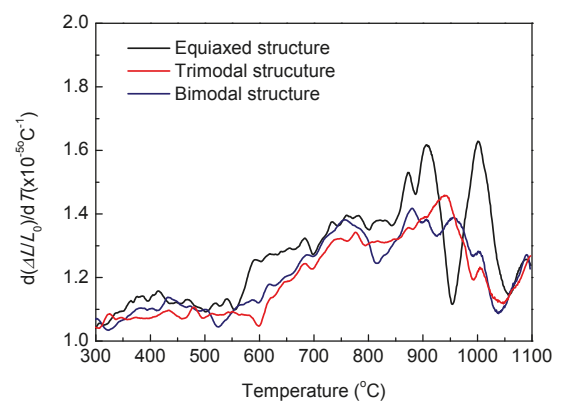

(b)

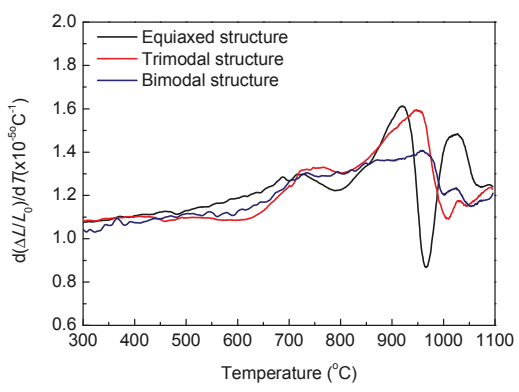

(c)

Figure 8. Derivatives of length change with respect to temperature $(\mathrm{d} L / \mathrm{d} T)$ of the different initially structures at the heating rate of (a) $5{ }^{\circ} \mathrm{C} / \mathrm{min} ;$ (b) $10^{\circ} \mathrm{C} / \mathrm{min}$; (c) $20^{\circ} \mathrm{C} / \mathrm{min}$. 
A sudden decrease in expansion rate occurs at about $950{ }^{\circ} \mathrm{C}$ for initially microstructure I and III. Barriobero-Vila et al. [14] found that the expansion in $\beta$ lattice is more significant when the fraction of $\beta$ phase is low. With the increase of $\beta$ fraction, the phase transformation has less effect on the composition of $\beta$ phase. The expansion of $\beta$ lattice is more sluggish. Meanwhile, the rapid phase transition may cause significant volume contraction. Thus, the expansion rate drops dramatically. As the $\alpha-\beta$ phase transition was dominant in the four stages of $\beta-\alpha-\beta$ transformation, the obvious peak (Figure $8 \mathrm{a}$ ) in the curves of derivative of length change corresponded with the starting and ending of the transformation from $\alpha$ to $\beta$ phase.

The phase transformation sequence in continuous heating is summaried in Table 2 . Microstructures I and III undergo a four stage phase transformation: the decomposition of residual $\beta$ phase to the tiny secondary $\alpha$ laths, the transformation of tiny $\alpha$ laths, the transformation of coarse $\alpha$ laths and the transformation of equiaxed $\alpha$. The secondary and third stages overlap for microstructure II because the existed $\alpha$ laths are thin. The four stages of phase transformation overlap with increasing heating rate.

Table 2. Phase transformation sequence in continuous heating of TA15 alloy.

\begin{tabular}{cc}
\hline Microstructure & Phase Transition \\
\hline I & residual $\beta$-secondary $\alpha$, secondary $\alpha-\beta$, lamellar $\alpha$ - $\beta$, equaixed $\alpha-\beta$ \\
II & residual $\beta$-secondary $\alpha$, secondary $\alpha /$ lamellar $\alpha$ - $\beta$, equaixed $\alpha-\beta$ \\
III & residual $\beta$-secondary $\alpha$, secondary $\alpha$ - $\beta$, lamellar $\alpha$ - $\beta$, equaixed $\alpha-\beta$ \\
\hline
\end{tabular}

Dilatometry and DSC can be used to quantify the kinetics of phase transformations [21,22]. In this paper, the dilatometric methods have been adopted. Commonly, the transformed rate increases with temperature in a sigmoidal way. So the results are not presented in this work. In fact, the transformation rate was not measured by the volume contraction in $\alpha$ to $\beta$ transformation but evaluated by the rapid increase in lattice parameter of $\beta$ phase, as an increase in expansion rate during transformation is observed at all heating rates. Due to the nonlinearity in lattice expansion and the volume contraction by transformation, it may be concluded that the dilatometry can not be used to estimate the transformation kinetics in TA15 titanium alloy.

\subsection{Transformation Kinetics}

The kinetics measured for different initial structures showed that the effect of initial microstructure is negligible especially when the transformation of equiaxed $\alpha$ becomes dominant, as shown in Figure 9 . For each initial structure, the volume fraction of $\beta$ phase increases slowly with the temperature before $800{ }^{\circ} \mathrm{C}$ and the increases sharply until all the $\alpha$ phase was transformed. At the heating rate of $5^{\circ} \mathrm{C} / \mathrm{min}$, the volume fraction of $\beta$ phase around $940^{\circ} \mathrm{C}$ was the highest for microstructure I. With increasing heating rate, the specimen with microstructure I has the lowest fraction of $\beta$ phase.

In this temperature range, there still exists a large fraction of lamellar $\alpha$ in specimens with initially microstructure II and III (Figure 10). On the contrast, only the equiaxed $\alpha$ phase is left for microstructure I. At a low heating rate, the phase fraction is more close to the equilibrium value. The phase fraction is more affected by the chemical compositions of the constituent phases. The content of $\beta$ stabilizers in $\alpha$ lamellae is higher than that in equiaxed $\alpha$. In the presence of lamellar $\alpha$, the fraction of $\alpha$ phase is larger according to the lever rule. At a higher heating rate, the transformation rate is more determined by the diffusion of the $\beta$ stabilizer (Mo and V for the TA15 alloy). The $\alpha$ lamellae are thin and distributed in the residual $\beta$ matrix. Along with the high content of $\beta$ stabilizer, the phase transformation is faster when there are large amount of $\alpha$ lamellae. 


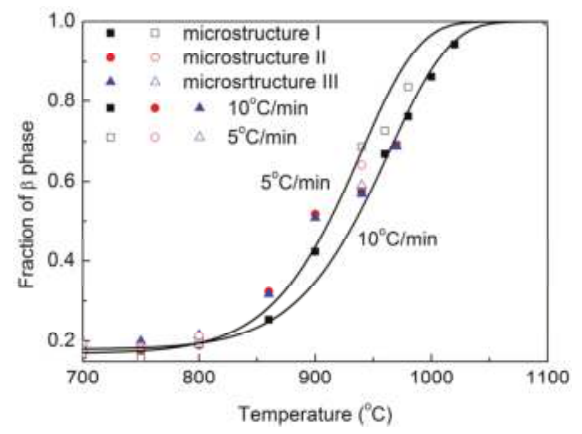

Figure 9. Measured fraction $\beta$ with temperature at different heating rates.

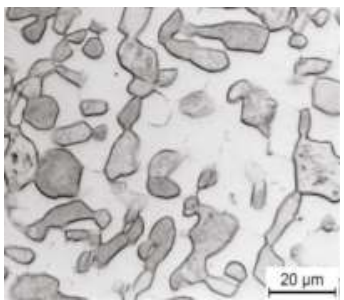

(a)

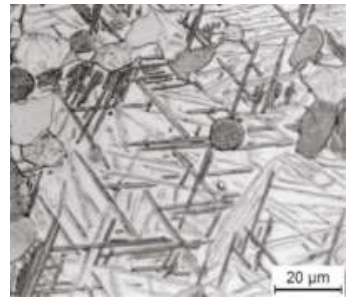

(b)

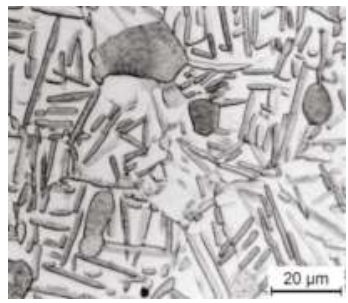

(c)

Figure 10. Optical microscopy micrographs of specimens after heated up to $940{ }^{\circ} \mathrm{C}$ at $5{ }^{\circ} \mathrm{C} / \mathrm{min}$ : (a) equiaxed structure; (b) bimodal structure; (c) trimodal structure.

The phase transformation kinetics in isothermal condition is often depicted by the Johnson-Mehl-Avrami (JMA) approach:

$$
f(t)=1-\exp \left(-(k t)^{n}\right)
$$

where $f(t)$ is the transformed fraction at a specific time $t, n$ is the JMA exponent, and $k$ is a rate constant. In non-isothermal conditions, $k$ is taken to be a function of temperature which is given by:

$$
k=\mathrm{k}_{0} \exp \left(-\frac{Q}{R T}\right)
$$

where $\mathrm{k}_{0}$ is a constant, $Q$ is the activation energy of the transformation, $R$ is the gas constant, and $T$ is the absolute temperature. Elmer et al. [15] suggested that a unique activation energy under non-isothermal conditions is not always possible because the nucleation and growth of the $\beta$ phase are simultaneously operating. Their contributions are temperature and rate dependent and influenced by the initial structure. However, the $\alpha$-to- $\beta$ transformation in titanium alloys often has a large growth component and it is possible to simplify it by using the activation energy of growth. It has been found in the continuous cooling of TA15 titanium alloy that Mo diffusion through $\beta$ matrix controls the epitaxial growth of primary $\alpha$ due to its slowest diffusivity [23]. Assuming the diffusion of $\mathrm{V}$ in $\beta$ phase controls the transformation and the mobility of the $\alpha-\beta$ interface is high, Elmer [15] suggested to use the activation energy for the diffusion of $\mathrm{V}$ to represent the activation energy for phase transformation in a Ti-6Al-4V alloy. These assumptions are also valid in the TA15 titanium alloy [23].The activation energy for diffusion of Mo is determined to be $154 \mathrm{~kJ} / \mathrm{mol}$ [24]. It is used as a starting value for parameter identification. The JMA exponent $n$ also has physical significance. Elmer et al. [15] used a value of 
$n=4$ to represent a transformation mechanism involving both growth and nucleation. For diffusion controlled transformation under isothermal condition, the value should be larger than 2.5 . The value of 4 is also employed as a starting value.

Using the numerical procedure in Ref. [18], the optimized parameters are given in Table 3. The calculated JMA exponent is near 1 . This means the phase transformation is controlled by the growth of existing large $\beta$ phase. This is in accordance with the microstructural developments in the current work. Elmer [15] reported a much higher value of JMA exponent. In their work, the heating rate is hundreds of times larger than the current work, which may change the mechanism of phase transformation.

Table 3. Calculated Johnson-Mehl-Avrami (JMA) parameters for the continuous heating of TA15 titanium alloy.

\begin{tabular}{ccc}
\hline $\ln \left(\mathbf{k}_{\mathbf{0}}\right)$ & $n$ & $Q(\mathbf{k J} / \mathbf{m o l})$ \\
\hline 26.9 & 0.75 & 333 \\
\hline
\end{tabular}

\section{Conclusions}

Experimental study was carried out on the effect of initial structure on microstructure evolution in continuous heating of a near- $\alpha$ TA15 titanium alloy. The following conclusions were drawn:

(1) A four stage phase transformation occurs during continuous heating of the TA15 titanium alloy for microstructure I and III: the decomposition of residual $\beta$ phase, the transformation of tiny $\alpha$ laths, the transformation of coarse $\alpha$ laths and the transformation of equiaxed $\alpha$. The secondary and third stages overlap for microstructure II. The four stages of phase transformation overlap with increasing heating rate.

(2) The $\alpha$-to- $\beta$ transformation is accompanied by the coarsening of secondary $\alpha$ laths for microstructure II, resulting in significant changes in the size and volume fraction of $\alpha$ laths.

(3) The phase transformation kinetics is not affected by the initial structure when the transformation of equiaxed $\alpha$ becomes dominant. In the presence of lamellar $\alpha$, the specimen with initially microstructure I has the highest transformed fraction under slow heating but the lowest transformed fraction under rapid heating.

(4) The transformed fraction increases with temperature in a sigmoidal way which can be fitted by the JMA model. The determined JMA exponent is close to 1 , suggesting phase transformation is controlled by the growth of existing large $\beta$ phase.

Acknowledgments: This work is supported by the National Natural Science Foundation of China (No. 51575449), Research Fund of the State Key Laboratory of Solidification Processing (NWPU), China (No. 104-QP-2014), and 111 Project (B08040).

Author Contributions: Xiaoguang Fan conceived and designed the experiments and interpret the data, Qi Li and Xiaoguang Fan wrote the paper, Anming Zhao analyzed the data and Yuguo Shi performed the experiments, Wenjia Mei collected the literatures.

Conflicts of Interest: The authors declare no conflict of interest.

\section{References}

1. Lütjering, G.; Williams, J.C. Titanium; Springer: Berlin, Germany, 2007.

2. Beranoagirre, A.; Lacalle, L.N.L. Grinding of gamma TiAl intermetallic alloys. Procedia Eng. 2013, 63, 489-498. [CrossRef]

3. Beranoagirre, A.; Olvera, D.; Lacalle, L.N.L. Milling of gamma titanium-aluminum alloys. Int. J. Adv. Manuf. Technol. 2012, 62, 83-88. [CrossRef]

4. Zhou, Y.G.; Zeng, W.D.; Yu, H.Q. An investigation of a new near-beta forging process for titanium alloys and its application in aviation components. Mater. Sci. Eng. A 2005, 393, 204-212. [CrossRef] 
5. Tang, B.; Kou, H.; Zhang, X.; Gao, P.; Li, J. Study on the formation mechanism of $\alpha$ lamellae in a near $\beta$ titanium alloy. Prog. Nat. Sci. Mater. Int. 2016, 26, 385-390. [CrossRef]

6. Sun, Z.; Guo, S.; Yang, H. Nucleation and growth mechanism of $\alpha$-lamellae of Ti alloy TA15 cooling from an $\alpha+\beta$ phase field. Acta Mater. 2013, 61, 2057-2064. [CrossRef]

7. He, D.; Zhu, J.C.; Zaefferer, S.; Raabe, D.; Liu, Y.; Lai, Z.L.; Yang, X.W. Influences of deformation strain, strain rate and cooling rate on the Burgers orientation relationship and variants morphology during $\beta \rightarrow \alpha$ phase transformation in a near $\alpha$ titanium alloy. Mater. Sci. Eng. A 2012, 549, 20-29. [CrossRef]

8. Zhao, Z.B.; Wang, Q.J.; Hu, Q.M.; Liu, J.R.; Yu, B.B.; Yang, R. Effect of $\beta$ (110) texture intensity on $\alpha$-variant selection and microstructure morphology during $\beta / \alpha$ phase transformation in near $\alpha$ titanium alloy. Acta Mater. 2017, 126, 372-382. [CrossRef]

9. Kherrouba, N.; Bouabdallah, M.; Badji, R.; Carron, D.; Amir, M. $\beta$ to $\alpha$ transformation kinetics and microstructure of Ti-6Al-4V alloy during continuous cooling. Mater. Chem. Phys. 2016, 181, 462-469. [CrossRef]

10. Liu, H.H.; Niinomi, M.; Nakai, M.; Cho, K.; Fujii, H. Deformation-induced omega-phase transformation in a beta-type titanium alloy during tensile deformation. Scr. Mater. 2017, 130, 27-31. [CrossRef]

11. Jonas, J.J.; Aranas, C.; Fall, A.; Jahazi, M. Transformation softening in three titanium alloys. Mater. Des. 2017, 113, 305-310. [CrossRef]

12. Wang, Y.H.; Kou, H.C.; Chang, H.; Zhu, Z.; Su, X.; Li, J.; Zhou, L. Phase transformation in TC21 alloy during continuous heating. J. Alloys Compd. 2009, 472, 252-256. [CrossRef]

13. Sha, W.; Guo, Z.L. Phase evolution of Ti-6Al-4V during continuous heating. J. Alloys Compd. 1999, 290, L3-L7. [CrossRef]

14. Barriobero-Vila, P.; Requena, G.; Buslaps, T.; Alfeld, M.; Boesenberg, U. Role of element partitioning on the $\alpha-\beta$ phase transformation kinetics of a bi-modal Ti-6Al-6V-2Sn alloy during continuous heating. J. Alloys Compd. 2015, 626, 330-339. [CrossRef]

15. Elmer, J.W.; Palmer, T.A.; Babu, S.S.; Zhang, W.; DebRoy, T. Phase transformation dynamics during welding of Ti-6Al-4V. J. Appl. Phys. 2004, 95, 8327-8339. [CrossRef]

16. Guo, L.G.; Zhu, S.; Yang, H.; Fan, X.G.; Chen, F.L. Quantitative analysis of microstructure evolution induced by temperature rise during $(\alpha+\beta)$ deformation of TA15 titanium alloy. Rare Met. 2016, 35, 223-229. [CrossRef]

17. Chen, F.; Xu, G.; Zhang, X.; Zhou, K. Exploring the phase transformation in $\beta$-quenched Ti-55531 alloy during continuous heating via, dilatometric measurement, microstructure characterization, and diffusion analysis. Metall. Mater. Trans. A 2016, 47, 5383-5394. [CrossRef]

18. Malinov, S.; Guo, Z.; Sha, W.; Wilson, A. Differential scanning calorimetry study and computer modeling of $\beta \Rightarrow \alpha$ phase transformation in a Ti-6Al-4V alloy. Metall. Mater. Trans. A 2001,32,879-887. [CrossRef]

19. Motyka, M.; Kubiak, K.; Sieniawski, J.; Ziaja, W. Phase transformations and characterization of $\alpha+\beta$ titanium alloys. In Comprehensive Materials Processing; Hashmi, S., Ed.; Elsevier: Amsterdam, The Netherlands, 2014; Volume 2, pp. 7-36.

20. Elmer, J.W.; Palmer, T.A.; Babu, S.S.; Specht, E.D. In situ observations of lattice expansion and transformation rates of $\alpha$ and $\beta$ phases in Ti-6Al-4V. Mater. Sci. Eng. A 2005, 391, 104-113. [CrossRef]

21. Guo, Z.; Keong, K.G.; Sha, W. Crystallisation and phase transformation behaviour of electroless nickel phosphorus platings during continuous heating. J. Alloys Compd. 2003, 358, 112-119. [CrossRef]

22. Liu, Y.C.; Sommer, F.; Mittemeijer, E.J. Abnormal austenite-ferrite transformation behavior in substitutional Fe-based alloys. Acta Mater. 2003, 51, 507-519. [CrossRef]

23. Meng, M.; Yang, H.; Fan, X.G.; Yan, S.L.; Zhao, A.M.; Zhu, S. On the modeling of diffusion-controlled growth of primary $\alpha$ in heat treatment of two-phase Ti-alloys. J. Alloys Compd. 2016, 691, 67-80. [CrossRef]

24. Semiatin, S.L.; Lehner, T.M.; Miller, J.D.; Doherty, R.D.; Fueere, D.U. $\alpha / \beta$ heat treatment of a titanium alloy with a nonuniform microstructure. Metall. Mater. Trans. A 2007, 38, 910-921. [CrossRef]

(C) 2017 by the authors. Licensee MDPI, Basel, Switzerland. This article is an open access article distributed under the terms and conditions of the Creative Commons Attribution (CC BY) license (http:/ / creativecommons.org/licenses/by/4.0/). 


\title{
Article \\ Effect of Hybrid Reinforcements on the Microstructure and Mechanical Properties of Ti-5Al-5Mo-5V-Fe-Cr Titanium Alloy
}

\author{
Shuyu Sun ${ }^{1, *}$ and Weijie $\mathrm{Lu}^{2}$ \\ 1 School of Mechanical Engineering, Taizhou University, Taizhou 318000, China \\ 2 State Key Laboratory of Metal Matrix Composites, Shanghai Jiao Tong University, Shanghai 200240, China; \\ luweijie@sjtu.edu.cn \\ * Correspondence: sunshuyu@tzc.edu.cn; Tel.: +86-571-8866-1911
}

Received: 27 May 2017; Accepted: 27 June 2017; Published: 5 July 2017

\begin{abstract}
In order to investigate the different effects of trace $\mathrm{TiB}$ and $\mathrm{TiC}$ on the microstructure and the mechanical properties of Ti-5Al-5Mo-5V-1Fe-1Cr Ti alloy, two different modified Ti-5Al-5Mo-5V-1Fe-1Cr Ti alloys are fabricated via a consumable vacuum arc-remelting furnace in this work. Though the volume fractions of the reinforcements are the same in the two alloys, the molar ratio of short fibers to particles is different. The materials are subjected to thermomechanical processing and heat treatment. The effects of $\mathrm{TiB}$ short fibers and $\mathrm{TiC}$ particles on the spheroidization of $\alpha$ phase or the refinement of $\beta$ phase have no obvious difference during heat treatment. Subsequently, the room temperature tensile test is carried out. The area covered by the $\sigma-\varepsilon$ curve of the tensile test is used to compare toughness. It is revealed that the refinement of the $\beta$ phase and the load bearing of TiB play key roles in promoting the toughness of the alloys. TiB tends to parallel the external load during tensile tests. The distribution of TiB also changes during isothermal compression test. Owing to the competition of dynamic softening with dynamic hardening, the length direction of TiB tends to parallel to the direction of maximum shear stress during the compression, which makes TiB play the role of load bearing better.
\end{abstract}

Keywords: Ti-5Al-5Mo-5V-Fe-Cr titanium alloy; trace TiB and TiC; microstructure; toughness

\section{Introduction}

Ti-5Al-5Mo-5V-1Fe-1Cr titanium alloy is an important aviation structural material. The alloy composition results in the tendency of the spheroidization of $\alpha$ phase during heat treatment. Owing to the special microstructural characteristics, the alloy presents a good combination of strength and plasticity after heat treatment [1,2]. The most common processing method for this alloy is isothermal forging. However, it may appear serious microstructural heterogeneity during isothermal compression. The experiment shows that reinforcement can solve the problem by accelerating the spheroidization of $\alpha$ phase [2].

While continuous-SiC fiber-reinforced Ti alloys have significantly superior mechanical properties, widespread application of them has been hindered by economic factors associated with high processing costs, as well as design limitations imposed by the anisotropy of properties (exacerbated by the presence of relatively weak fiber/matrix interfaces) [3,4]. Conventional Ti alloys modified with discontinuous reinforcements, on the other hand, have been widely used in recent years [5-7]. The application of the hybrid reinforcements can achieve better results in improving mechanical properties [8-10]. However, little information is available to date concerning the different effects of short fibers and particles on Ti-5Al-5Mo-5V-Fe-Cr Ti alloy. 
Two different compositions of Ti-5Al-5Mo-5V-Fe-Cr Ti alloys are fabricated in this work. One alloy is modified with only $\mathrm{B}_{4} \mathrm{C}$, the other is modified with $\mathrm{B}_{4} \mathrm{C}$ and $\mathrm{C}$. The volume fractions of the reinforcements in the two alloys are the same. Addition of $\mathrm{B}_{4} \mathrm{C}$ to Ti produces $\mathrm{TiB}$ and $\mathrm{TiC}$ during solidification by in situ chemical reaction. $\mathrm{C}$ to Ti also produces TiC. The reinforcements are both thermomechanically stable and essentially insoluble in Ti at all temperatures in the solid state. The in situ synthesized intermetallic reinforcements have good interfacial bonding strength due to the orientation relationships [11-13]. The advantages of the reinforced alloys also include reaction-free interfaces and ease of processing. In order to obtain good toughness, the addition of $\mathrm{B}_{4} \mathrm{C}$ or $\mathrm{C}$ is very small.

The solid solubility of B and C is low in Ti alloy during the solidification. Solute enrichment results in constitutional supercooling which in turn provides the driving force for nucleation and increases the nucleation rate. Furthermore, excess B and C in the solid-liquid interface also lower the growth rate of the grains [11]. The refinement of $\beta$ grains and intersection of different orientated acicular $\alpha$ colonies within $\beta$ grains retard the further growth of $\alpha[1,14]$.

The area covered by $\sigma-\varepsilon$ curve of room temperature tensile test is used to compare toughness. The experiments show that the toughness of the modified alloys is superior to that of the alloy. The different toughening effects of trace short fibers and particles are investigated by studying the improvement of the plasticity and the strength of the modified alloys.

The $\beta$ phase with BCC structure is considered with high stacking fault energy, which could accelerate dislocation climbing and crossing-slipping for dynamic softening process during isothermal compression [15]. The dynamic softening dominates the competition with the work hardening. The distribution of the reinforcements changes during isothermal compression. For comparison, the alloy specimen with the two ends not polished is used. The specimen preserves the shallow circular groove caused by turning machining on the two ends, which causes serious microstructural heterogeneity during the compression. Some $\alpha$ grains are elongated obviously along the direction of maximum shear stress [16]. The length direction of $\mathrm{TiB}$ in the $\mathrm{B}_{4} \mathrm{C}$-modified alloy is almost the same as that of the elongated $\alpha$ phase in the alloy after the compression. The distribution variation of the reinforcements can promote the effective aspect ratio (length/diameter) of TiB. Therefore, the distribution variation law of the reinforcements is also the key research of this work.

\section{Experimental Procedure}

The modified alloys are fabricated by in situ synthesis method. The stoichiometric weight fractions of the raw materials including sponge $\mathrm{Ti}, \mathrm{B}_{4} \mathrm{C}$ powder, $\mathrm{Al}, \mathrm{Al}-\mathrm{Mo}, \mathrm{Al}-\mathrm{V}, \mathrm{Fe}$, and $\mathrm{Cr}$ are blended uniformly, and then are compacted into pellets by forging press. The pellets are melted in a consumable vacuum arc-remelting furnace (Model VCF-10, Shanghai, China). Small addition of $\mathrm{B}_{4} \mathrm{C}$ to Ti produces $\mathrm{TiB}$ and TiC during solidification by chemical reaction [12]:

$$
5 \mathrm{Ti}+\mathrm{B}_{4} \mathrm{C}=4 \mathrm{TiB}+\mathrm{TiC}
$$

The molar ratio of $\mathrm{TiB}$ to $\mathrm{TiC}$ is $4: 1$. In addition to $\mathrm{B}_{4} \mathrm{C}$, small addition of $\mathrm{C}$ powder is added in the other modified alloy. The molar ratio of $\mathrm{TiB}$ to $\mathrm{TiC}$ is $1: 1 . \mathrm{C}$ to Ti produces $\mathrm{TiC}$ by chemical reaction [12]:

$$
\mathrm{Ti}+\mathrm{C}=\mathrm{TiC}
$$

The volume fractions of the reinforcements in the two alloys are the same. The weight fractions of the reinforcements are shown in Table 1.

The as-cast ingots are forged at $1150{ }^{\circ} \mathrm{C}$ and are rolled at $840{ }^{\circ} \mathrm{C}$ into rods with a diameter of $15 \mathrm{~mm}$. Then the rod is subjected to heat treatment. In order to control the overgrowth of grains and obtain good mechanical properties, the triplex heat treatment is employed with the following process: $830^{\circ} \mathrm{C} / 1.5 \mathrm{~h}+$ furnace cooling, $750{ }^{\circ} \mathrm{C} / 1.5 \mathrm{~h}+$ air cooling, $600^{\circ} \mathrm{C} / 4 \mathrm{~h}+$ air cooling. 
Ti-5Al-5Mo-5V-1Fe-1Cr Ti alloy is also prepared with the same method. The ingot of the alloy is subjected to the same thermomechanical processing and heat treatment as the modified alloys.

Table 1. Program materials and weight fractions of reinforcements.

\begin{tabular}{cccccc}
\hline Sample & $\mathbf{B}_{\mathbf{4}} \mathrm{C} / \mathbf{w t} \%$ & $\mathbf{C} / \mathbf{w t} \%$ & $\mathrm{TiB} / \mathbf{w t} \%$ & TiC/wt $\%$ & TiB/TiC Molar Ratio \\
\hline Alloy A & 0.1 & 0 & 0.4 & 0.1 & $4: 1$ \\
Alloy B & 0.06 & 0.04 & 0.27 & 0.27 & $1: 1$ \\
\hline
\end{tabular}

The specimens for the tensile test and the isothermal compression test are machined from the heat-treated rods.

For tensile testing, $30 \mathrm{~mm}$ gage length cylindrical specimens ( $6 \mathrm{~mm}$ wide) is used. Tensile tests are performed in a servohydraulic testing machine (Model YF28A-315/200, Shanghai, China) with a strain rate of $0.001 \mathrm{~s}^{-1}$. An extensometer is mounted on the specimens to measure the tensile strains.

The compression specimens are $8 \mathrm{~mm}$ in diameter and $12 \mathrm{~mm}$ in height. The two ends of the alloy compression specimen are not polished. The isothermal compression tests are performed on a Gleeble simulator (Model GLEEBLE 3500, Shanghai, China). The compression condition is $840{ }^{\circ} \mathrm{C} / 0.01 \mathrm{~s}^{-1} / 60 \%$ (temperature/strain rate/deformation reduction). The specimens are water quenched at room temperature immediately after the compression and then are axially sectioned.

Microstructure observations by optical microscope (OM, Model CM12, Shanghai, China), scanning electron microscope (SEM, Model JSM-6460, Shanghai, China) are conducted after the specimens are polished and etched. Moreover, transmission electron microscope (TEM, Model JZM-100CX, Shanghai, China) is also used to observe the microstructure of the specimens.

\section{Results and Discussion}

\subsection{Microstructure of the Materials after Heat Treatment}

Figure 1a shows the microstructure of alloy A after thermomechanical processing. The reinforcements can accelerate the recrystallization of $\beta$ grains by providing nucleation sites and accelerating diffusion. However, the microstructure is still very heterogenerous due to the segregation of the alloying elements.
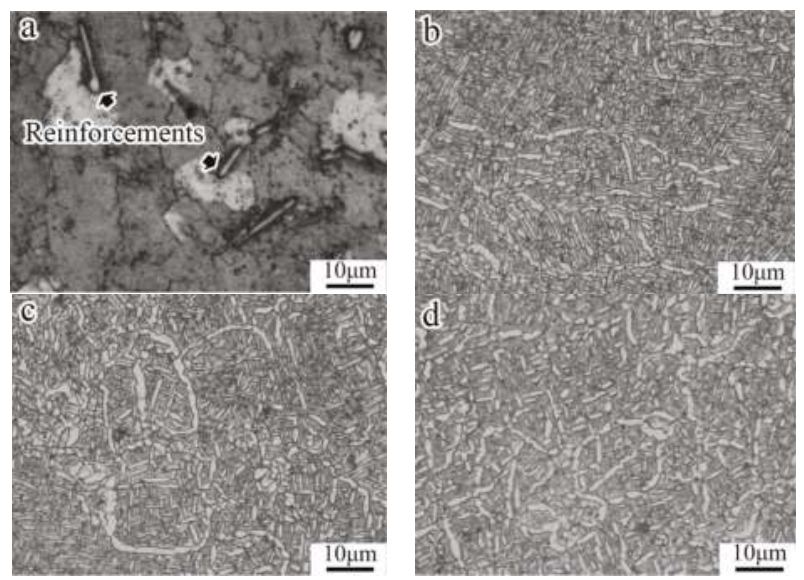

Figure 1. Optical microscope (OM) images of (a) alloy A after thermomechanical processing; (b) unmodified alloy after heat treatment; (c) alloy A after heat treatment; and (d) alloy B after heat treatment. 
In order to measure the average grain size, the other heat treatment is used with the following process: $910{ }^{\circ} \mathrm{C} / 1.5 \mathrm{~h}+$ furnace cooling, $750{ }^{\circ} \mathrm{C} / 1.5 \mathrm{~h}+$ air cooling, $600{ }^{\circ} \mathrm{C} / 4 \mathrm{~h}+$ air cooling. $910^{\circ} \mathrm{C}$ is higher than the phase transformation temperature. Therefore, it shows the characteristics of the Widmannstatten structure in the alloys after the heat treatment [1]. The average grain size of $\beta$ in alloy A is decreased by about $56 \%$, and in alloy B it is decreased by about $59 \%$. This is mainly ascribed to the Zener dragging force exerted by the reinforcements [2]. The length scales of the reinforcements are nearly the same since the additions of $\mathrm{B}_{4} \mathrm{C}$ and $\mathrm{C}$ are very small. TiB has an average length of $7.9 \mu \mathrm{m}$ after heat treatment, while TiC $2.6 \mu \mathrm{m}$. The size of TiC ranges from less than $200 \mathrm{~nm}$ to more than $4 \mu \mathrm{m}$. A broad size distribution of particles gives rise to a larger Zener dragging force than a narrow size distribution of particles [17]. Moreover, the segregation can also exert a pinning effect on the boundary migration of $\beta$ grain during heat treatment.

Figure $1 \mathrm{~b}-\mathrm{d}$ show the microstructures of the materials after heat treatment. The phase contrast is $\alpha$ phase, white; $\beta$ phase, black. The dislocation density in $\alpha$ decreases significantly during the heat treatment. It appears the tendency of the spheroidization process to decrease interfacial energy due to the dispersivity of $\alpha$ [1]. However, it is observed that trace reinforcements have no obvious effect on the spheroidization of $\alpha$ phase during heat treatment. The decisive factor affecting the spheroidization of the $\alpha$ phase is the first stage temperature during triplex heat treatment [18]. The increase in temperature can accelerate the boundary migration of $\alpha$ grain, which helps to overcome the dragging force of the segregation on the boundary migration of the $\alpha$ grain. Since the weight fraction of the reinforcements is very small, the segregation caused by the reinforcements counteracts the promoting effect of the reinforcements on the spheroidization of $\alpha$ phase. When the temperature approaches to the phase transformation temperature, the degree of the recrystallization of $\alpha$ phase is enhanced greatly. The reinforcements may overcome their negative effect on the spheroidization of the $\alpha$ phase by accelerating recrystallization [18].

Figure 2 shows the microstructure of the alloy after thermomechanical processing. The phase contrast is $\alpha$ phase, black; $\beta$ phase, white. Primary $\alpha$ phase almost shows as rod shaped. The $\alpha$ phase cannot be spheroidized due to insufficient recrystallization. It appears the division of $\alpha$ grain during heat treatment [18]. It is suggested that the rod-shaped $\alpha$ formed during thermomechanical processing should be an important source of spheroidization grain after splitting.

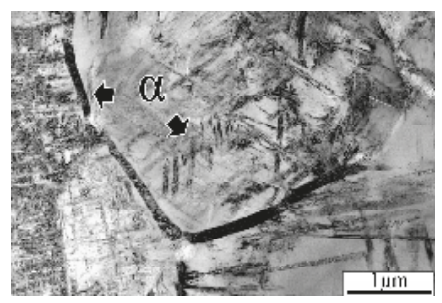

Figure 2. Transmission electron microscope (TEM) image of the alloy after thermomechanical processing.

\subsection{Effect of Reinforcements on the Toughness of the Alloy}

Figure 3 shows $\sigma-\varepsilon$ curves of the alloy, alloy A, and alloy B. The results in Figure 3 are the average values of three tensile tests for each material. The yield stresses of the materials are 1195, 1232, and $1224 \mathrm{MPa}$, respectively. If the area covered by the curve is used to compare toughness, the toughness of the reinforced alloys is superior to that of the alloy (in Figure 3). The average aspect ratio of $\mathrm{TiB}$ is 7.1. The critical aspect ratio of $\mathrm{TiB}$ can be calculated by the Kelly formula, approximately [19]:

$$
l_{c} / d=\sigma_{f} /\left(2 \sigma_{y m}\right)
$$


where $l_{c}$ is critical length of $\mathrm{TiB}, d$ is radius of $\mathrm{TiB}, \sigma_{f}$ is tensile strength of $\mathrm{TiB}$ (3500 $\mathrm{MPa}$ ), and $\sigma_{y m}$ is yield stress of matrix (1195 MP). The critical aspect ratio of TiB is about 1.46 , which is lower than the average aspect ratio of $\mathrm{TiB}$, significantly.

The promotion of the strengths of the modified alloys is ascribed to the load bearing of TiB, the dispersion strengthening of $\mathrm{TiC}$ and the grain refinement strengthening [18,20-22].

$\mathrm{TiB}$ short fibers tend to parallel the external force during the tensile test, which promotes the load bearing effect. The load bearing of TiB extends the strengthening process of the modified alloys. Meanwhile, the load bearing of $\mathrm{TiB}$ and the increase of the number of the $\beta$ grains can improve the homogeneity of the loads applied to each $\beta$ grain. The deformation homogeneity helps to decrease the crack nucleation.

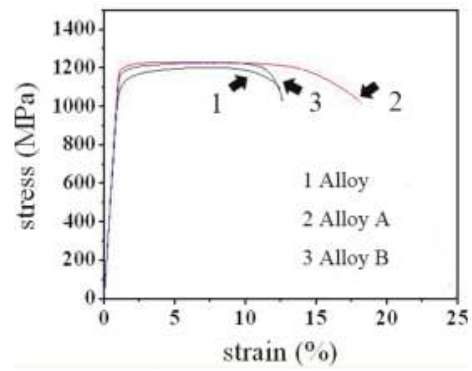

Figure 3. Stress-strain curves of the alloy, alloy A and alloy B.

Since the weight fraction of the reinforcements is very small, the negative effect of the reinforcements on the plasticity is limited. The elongation of the modified alloys is still increased during the strengthening process.

The broken $\mathrm{TiB}$ short fibers and $\mathrm{TiC}$ particles increase the propagation of crack during the necking process. Therefore, the toughening effect of the load bearing of the short fibers is mainly reflected in the strengthening process. The improvement of the reduction of area is mainly attributed to microstructural refinement during the necking process. The increase of $\beta$ grain boundary contributes to retard crack propagation.

The tensile properties of alloy A are different from those of alloy B. The weight fraction of TiB in alloy $\mathrm{A}$ is higher than that in alloy $\mathrm{B}$. Therefore, the load bearing of short fibers plays a more important role in alloy A. The effect of the microstructural refinement plays more important role in alloy B.

\subsection{Microstructure of the Modified Alloy after Isothermal Compression}

Figure 4 shows the microstructure of the alloy after isothermal compression. The phase contrast is $\alpha$ phase, black; $\beta$ phase, white. The compression specimen shows as a drum shape due to the friction between the specimen and the push rod. The macrosegregation in Figure $4 \mathrm{a}$ is induced by the shallow circular groove on the two ends of the specimen [16]. The metal at the center of the specimen is extruded towards the side of the specimen. Therefore, in addition to the spheroidized $\alpha$, some $\alpha$ grains are elongated. Moreover, the distribution of the reinforcements in the modified alloys changes for the same reason.

The elongation of $\alpha$ phase in Figure $4 \mathrm{~b}$ is associated with vacancy flow. It produces a vacancy chemical potential gradient in the direction parallel to the maximum shear stress during the compression. The atomic motion is opposite to the vacancy flow. The dynamic softening dominates the competition with the dynamic hardening in $\alpha$. Therefore, the obstacles to the vacancy flow that caused by the dislocations is greatly reduced. The length direction of the elongated $\alpha$ is approximated as the direction of maximum shear stress. 
As shown in Figures 5 and 6, the distribution of TiB is similar to the elongated $\alpha$ in the alloy specimen. The distribution of TiB continuously changes in order to seek the equilibrium of forces until the length direction tends to parallel to the direction of maximum shear stress during the compression.
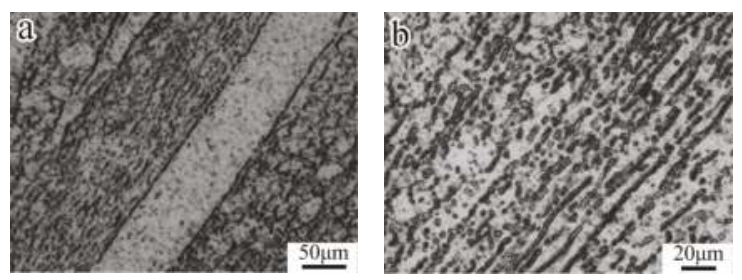

Figure 4. OM images of the longitudinal section of the alloy specimen after isothermal compression (a) the macrosegregation; and (b) the spheroidized and the elongated $\alpha$.

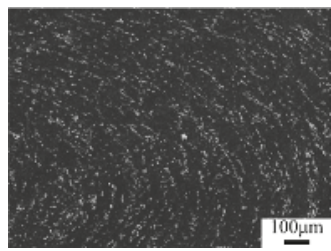

Figure 5. Scanning electron microscope (SEM) image of the distribution of the reinforcements in alloy A after isothermal compression.

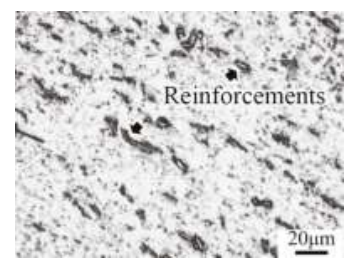

Figure 6. OM image of the distribution of the reinforcements in alloy A after isothermal compression.

Figure 7 shows TEM images of TiB and TiC in alloy A after isothermal compression. There also exists the competition of dynamic softening with dynamic hardening in $\beta$ phase. As shown in Figure 7a, the end of TiB induces relatively large lattice distortion. The lattice distortion is nearly the largest when the length direction approximately parallels to the direction of maximum shear stress. Thus, the dynamic hardening gets the advantage in the competition at the ends of TiB. This plays a pinning effect on the distribution variation of TiB.
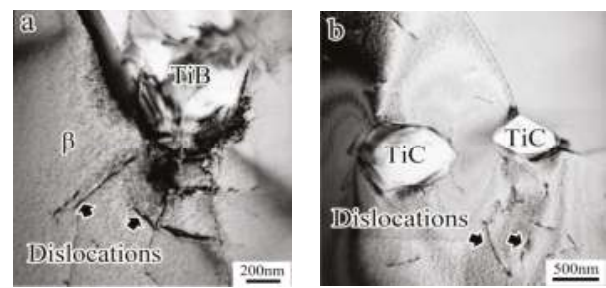

Figure 7. TEM images of the reinforcements in alloy A after isothermal compression (a) TiB (b) TiC. 
The distribution variation of the reinforcements increases the effective aspect ratio of $\mathrm{TiB}$, which allow TiB short fibers to play the role of load bearing better.

\section{Conclusions}

(1) The load bearing of TiB extends the strengthening process of the modified alloys. Moreover, the load bearing of $\mathrm{TiB}$ and the increase of the number of $\beta$ grains can improve deformation homogeneity of the modified alloys, which decreases the crack nucleation. Therefore, the reinforcements increase the plasticity of the modified alloys. The toughening effect of the load bearing of $\mathrm{TiB}$ is mainly reflected in the strengthening process. The improvement of the toughness of the modified alloys is mainly attributed to the microstructural refinement during the necking process.

(2) The distribution of $\mathrm{TiB}$ constantly changes in order to seek the equilibrium of forces until the length direction tends to parallel to the direction of maximum shear stress during isothermal compression. Moreover, the lattice distortion is nearly the largest when the length direction of TiB approximately parallels to the direction of maximum shear stress. This plays a pinning effect on the distribution variation of TiB. Therefore, the length direction of TiB tends to parallel the direction of maximum shear stress during the compression, which can promote the effective aspect ratio of TiB.

Acknowledgments: We would like to acknowledge the financial support provided by Foundation of Zhejiang Educational Committee (grant No. Y201533396).

Author Contributions: Shuyu Sun and Weijie Lu designed and conducted the experiments. Shuyu Sun analysed the results.

Conflicts of Interest: The authors declare no conflict of interesting, and the founding sponsor has no role in the design of the study; in the collection; analyses, or interpretation of data; in the writing of the manuscript, and in the decision to publish the results.

\section{References}

1. Sun, S.-Y.; Lv, W.-J. Microtructure and mechanical properties of TC18 Titanium alloy. Rare Met. Mater. Eng. 2016, 45, 1138-1141.

2. Sun, S.-Y.; Lv, W.-J. Effects of trace reinforcements on microstructure and tensile properties of in-situ synthesized TC18 Ti matrix composite. J. Comp. Mater. 2017. [CrossRef]

3. Tamirisakandala, S.; Bhat, R.-B.; Miracle, D.-B.; Boddapati, S.; Bordia, R.; Vanover, R.; Vasudevan, V.-K. Effect of boron on the beta transus of Ti-6Al-4V alloy. Scr. Mater. 2005, 53, 217-222. [CrossRef]

4. Tanaka, Y.; Kagawa, Y.; Liu, Y.-F.; Masuda, C. Interface damage mechanism during high temperature fatigue test in sic fiber-reinforced Ti alloy matrix composite. Mater. Sci. Eng. A 2001, 314, 110-117. [CrossRef]

5. Ni, D.-R.; Geng, L.; Zhang, J.; Zheng, Z.-Z. Effect of $\mathrm{B}_{4} \mathrm{C}$ particle size on microstructure of in situ titanium matrix composites prepared by reactive processing of Ti-B ${ }_{4}$ C system. Scr. Mater. 2006, 55, 429-432. [CrossRef]

6. Wang, B.; Huang, L.-J.; Geng, L.; Rong, X.-D. Compressive behaviors and mechanisms of TiB whiskers reinforced high temperature Ti60 alloy matrix composites. Mater. Sci. Eng. A 2015, 648, 443-451. [CrossRef]

7. Qi, J.-Q.; Chang, Y.; He, Y.-Z.; Sui, Y.-W.; Wei, F.-X.; Meng, Q.-K.; Wei, Z.-J. Effect of Zr, Mo and TiC on microstructure and high-temperature tensile strength of cast titanium matrix composites. Mater. Des. 2016, 99, 421-426. [CrossRef]

8. Zhang, C.; Li, X.; Zhang, S.; Chai, L.; Chen, Z.; Kong, F.; Chen, Y. Effects of direct rolling deformation on the microstructure and tensile properties of the $2.5 \mathrm{vol} \%\left(\mathrm{TiB}_{\mathrm{w}}+\mathrm{TiC}_{\mathrm{p}}\right) / \mathrm{Ti}$ composites. Mater. Sci. Eng. A 2016, 684, 645-651. [CrossRef]

9. Shufeng, L.-I.; Kondoh, K.; Imai, H.; Chen, B.; Jia, L.; Umeda, J. Microstructure and mechanical properties of P/M titanium matrix composites reinforced by in-situ synthesized TiC-TiB. Mater. Sci. Eng. A 2015, 628, 75-83.

10. Rahoma, H.-K.-S.; Chen, Y.-Y.; Wang, X.-P.; Xiao, S.-L. Influence of (TiC + TiB) on the microstructure and tensile properties of Ti-B20 matrix alloy. J. Alloys Compd. 2015, 627, 415-422. [CrossRef] 
11. Sen, I.; Tamirisakandala, S.; Miracle, D.-B.; Ramamurty, U. Microstructural effects on the mechanical behavior of B-modified Ti-6Al-4V alloys. Acta Mater. 2007, 55, 4983-4993. [CrossRef]

12. Lu, W.; Zhang, D.; Zhang, X.; Wu, R.; Sakata, T.; Mori, H. HREM study of TiB/Ti interfaces in a TiB-TiC in situ, composite. Scr. Mater. 2001, 44, 1069-1075. [CrossRef]

13. Ozerov, M.; Klimova, M.; Vyazmin, A.; Stepanov, N.; Zherebtsov, S. Orientation relationship in a Ti/TiB metal-matrix composite. Mater. Lett. 2016, 186, 168-170. [CrossRef]

14. Lütjering, G. Influence of processing on microstructure and mechanical processing. Mater. Sci. Eng. A 1998, 243, 32-45. [CrossRef]

15. Sun, Z.-C.; Yang, H.; Han, G.-J.; Fan, X.-G. A numerical model based on internal-state-variable method for the microstructure evolution during hot-working process of TA15 titanium alloy. Mater. Sci. Eng. A 2010, 527, 3464-3471. [CrossRef]

16. Sun, S.-Y.; Lv, W.-J. Microstructure heterogeneity of TC18 Ti alloy during hot deformation. Rare Met. Mater. Eng. 2016, 45, 1545-1548.

17. Eivani, A.-R.; Valipour, S.; Ahmed, H.; Zhou, J.; Duszczyk, J. Effect of the size distribution of nanoscale dispersed particles on the zener drag Pressure. Metall. Mater. Trans. A 2011, 42, 1109-1116. [CrossRef]

18. Sun, S.-Y.; Wang, L.-Q.; Qin, J.-N.; Chen, Y.-F.; Lv, W.-J.; Zhang, D. Microstructural characteristics and mechanical properties of in situ synthesized (TiB + TiC)/TC18 composites. Mater. Sci. Eng. A 2011, 530, 602-606. [CrossRef]

19. Baxter, W.-J. The strength of metal matrix composites. Metall. Mater. Trans. A 1992, 23, 3045-3053. [CrossRef]

20. Boehlert, C.-J.; Tamirisakandala, S.; Curtin, W.-A.; Miracle, D.-B. Assessment of in situ TiB whisker tensile strength and optimization of TiB-reinforced titanium alloy design. Scr. Mater. 2009, 61, 245-248. [CrossRef]

21. Tjong, S.-C.; Ma, Z.-Y. Microstructural and mechanical characteristics of in situ metal matrix composites. Mater. Sci. Eng. R 2000, 29, 49-113. [CrossRef]

22. Soboyejo, W.-O.; Shen, W.; Srivatsan, T.-S. An investigation of fatigue crack nucleation and growth in a Ti-6Al-4V/TiB in situ composite. Mech. Mater. 2004, 36, 141-159. [CrossRef]

(C) 2017 by the authors. Licensee MDPI, Basel, Switzerland. This article is an open access article distributed under the terms and conditions of the Creative Commons Attribution (CC BY) license (http:/ / creativecommons.org/licenses/by/4.0/). 


\title{
Article \\ Effects of Trace Si Addition on the Microstructures and Tensile Properties of Ti-3Al-8V-6Cr-4Mo-4Zr Alloy
}

\author{
Hongbo Ba, Limin Dong *, Zhiqiang Zhang and Xiaofei Lei \\ Institute of Metal Research, Chinese Academy of Sciences, 72 Wenhua Road, Shenyang 110016, China; \\ bahongbo@sina.com (H.B.); zqzhang@imr.ac.cn (Z.Z.); xflei13b@imr.ac.cn (X.L.) \\ * Correspondence: lmdong@imr.ac.cn; Tel.: +86-242-397-1942
}

Received: 16 June 2017; Accepted: 24 July 2017; Published: 27 July 2017

\begin{abstract}
The microstructural evolution and tensile properties of Ti-3Al-8V-6Cr-4Mo-4Zr titanium alloys with various $\mathrm{Si}$ contents were investigated. The results revealed that the addition of trace $\mathrm{Si}$ and the presence of $\mathrm{Zr}$ induced the formation of $(\mathrm{TiZr})_{6} \mathrm{Si}_{3}$ silicides, in the size range from $100 \mathrm{~nm}$ to $300 \mathrm{~nm}$. The fine silicide precipitates refined $\beta$ grains. The tensile strength increased about $40 \mathrm{MPa}$ due to precipitation strengthening and grain refinement, and the ductility of the two alloys was similar. The tensile fracture mode of the alloys was dimple ductile fracture.
\end{abstract}

Keywords: titanium alloy; microstructure; silicide; tensile properties

\section{Introduction}

Titanium alloys are widely used in aerospace applications due to their high strength to weight ratio and excellent corrosion resistance [1-3]. Except for compressor disks and blades, a considerable fraction of fasteners and springs are fabricated from $\alpha+\beta$ and $\beta$ titanium alloys, because they exhibit a favorable strength/toughness combination and high fatigue strength $[4,5]$. Among these titanium alloys, the $\beta$ type Ti-3Al-8V-6Cr-4Mo-4Zr (known as Beta C) alloy has attracted the attention of researchers in recent years [6,7]. This alloy is developed from Ti-13V-11Cr-3Al, and it is easier to melt and exhibits less segregation due to a low $\mathrm{Cr}$ content [8]. In addition, the alloy can be hardened by solution plus aging treatment, and its ultimate tensile strength can reach $1380 \mathrm{MPa}[8,9]$. It can be utilized in either solution-treated or solution-aging-treated conditions; thus, a wide variation in mechanical properties can be obtained for different applications. However, the rapid $\beta$ grain coarsening is still an open problem when they are solution-treated above the $\beta$ transus, especially for $\beta$ type titanium alloys.

The changes in microstructures and phase structures influence the mechanical properties of titanium alloys significantly. For $\beta$ type titanium alloys, the body-centered cubic $\beta$ phases possess good ductility, and precipitated $\alpha$ phases enhance their strength after aging treatment. For high-temperature titanium alloys, such as Ti-5.8Al-4Sn-3.5Zr-0.7Nb-0.35Si-0.06C [10] or Ti-6.3Al-1.6Zr-3.4Mo-0.3Si [11], the addition of Si can improve their creep performances due to the precipitation of silicides. Up to now, two different types of Ti-Zr-Si ternary silicides have been recognized in titanium alloys, $\mathrm{S} 1(a=0.780 \mathrm{~nm}$, $c=0.544 \mathrm{~nm})$ and S2 $(a=0.701 \mathrm{~nm}, c=0.368 \mathrm{~nm})$, with stoichiometries $(\mathrm{TiZr})_{5} \mathrm{Si}_{3}$ and $(\mathrm{TiZr})_{6} \mathrm{Si}_{3}[12-14]$, respectively. Flower et al. [15] reported that they have a hexagonal crystal structure in aged Ti-5Zr-1Si alloy, using X-ray diffraction.

Apart from improving the creep properties, the addition of Si also plays an important role in inhibiting $\beta$ grain growth. Bermingham et al. [16] showed that a small amount of $\mathrm{Si}$ addition to commercial purity Ti produced fine prior- $\beta$ grains. Tavares et al. [17] presented that the $\mathrm{Si}$ addition to the $\beta$ type Ti-35Nb alloy made beta phases more stable and achieved grain refinement. However, the addition of high amounts of $\mathrm{Si}$ 
will decrease the ductility of titanium alloys at room temperature. Ramachandra and Singh [18,19] showed that the presence of 0.25 wt \% Si in Ti-6Al-5Zr-0.5Mo-0.25Si alloy led to a drastic reduction in tensile ductility at room temperature. In terms of Ti-3Al-8V-6Cr-4Mo-4Zr alloy, Morito et al. [20] also investigated the effect of higher than $0.2 \mathrm{wt} \% \mathrm{Si}$ addition on the microstructure and aging behavior, but high contents of Si was found to possibly embrittle this alloy. In order to obtain the balance of strength and ductility for industrial applications, it is necessary to gain more insight into the effect of trace Si addition on the microstructures and properties of Ti-3Al-8V-6Cr-4Mo-4Zr alloy.

Based on the above, trace $\mathrm{Si}$ as an alloying element was added to Ti-3Al-8V-6Cr-4Mo-4Zr alloy, and the objective of the experiment was to investigate the influence of Si either in solution or in the form of silicides on its microstructures and performances.

\section{Materials and Methods}

In this study, Ti-3Al-8V-6Cr-4Mo-4Zr (designated C1) and Ti-3Al-8V-6Cr-4Mo-4Zr-0.05Si (designated C2) alloys were fabricated from pure Ti, Al, V, Cr, Mo, Zr and Si ( $\geq 99.9 \%$ purity) by three times vacuum arc melting and conventional rolling. The chemical compositions of the two alloys are listed in Table 1 . The $\beta$ transus for the alloys was $\sim 740{ }^{\circ} \mathrm{C}$, as measured by a metallographic technique. The rolled bars, $12 \mathrm{~mm}$ in diameter, for both alloys were cut and subjected to solution treatment at $800{ }^{\circ} \mathrm{C}$ for $1 \mathrm{~h}$, and were then water quenched to room temperature.

Table 1. Chemical composition of the alloys.

\begin{tabular}{cccccccc}
\hline \multirow{2}{*}{ Alloy } & \multicolumn{7}{c}{ Composition (wt \%) } \\
\cline { 2 - 8 } & $\mathbf{A l}$ & $\mathbf{V}$ & $\mathbf{C r}$ & $\mathbf{M o}$ & $\mathbf{Z r}$ & $\mathrm{Si}$ & $\mathrm{Ti}$ \\
\hline C1 & 3.54 & 8.00 & 6.02 & 4.05 & 4.00 & 0.02 & Bal. \\
C2 & 3.48 & 8.00 & 5.95 & 4.05 & 4.00 & 0.06 & Bal. \\
\hline
\end{tabular}

The microstructures were characterized using an optical microscope (OM, ZEISS Axiovert 200MAT, Carl Zeiss Shanghai Co., Ltd, Shanghai, China) and scanning electron microscope (SEM, ShimadzuSSX-550, Shimadzu Corporation, Tokyo, Japan) equipped with an Energy Dispersive X-ray (EDX) detector, after samples were manually grounded, polished and chemically etched for $30 \mathrm{~s}$ in a solution of $5 \% \mathrm{HF}, 10 \% \mathrm{HNO}_{3}$, and $85 \%$ water at room temperature. The back-scattered electron (BSE) mode was utilized for the observation of precipitates, and the polished samples were not be etched to avoid the dissolution of silicides into the HF etchant. Image-Pro Plus software was utilized for grain size analysis, and the grain size distributions were obtained. The average grain size and standard deviation were calculated on the basis of the grain diameter. TEM specimens were manually ground down to a thickness of $50 \mu \mathrm{m}$, punched into discs of $\Phi 3 \mathrm{~mm}$, and then ion-milled to electron transparency in a Gatan ion miller. TEM observation was performed on a Tecnai G2 20 transmission electron microscope (TEM) (FEI Company, Hillsboro, OR, USA) with an Energy Dispersive Spectroscopy (EDS).

Tensile tests at room temperature were carried out on an Instron 5582 testing machine (Instron, Chicago, IL, USA) at a constant cross-head speed of $1 \mathrm{~mm} / \mathrm{min}$. Two specimens were tested for each alloy. Tensile specimens with a gage diameter of $5 \mathrm{~mm}$ and a gage length of $30 \mathrm{~mm}$ were used. The fracture morphologies were observed by SEM.

\section{Results and Discussion}

\subsection{Microstructure Characteristics}

Figure 1 presents the optical microstructures of the alloys after solution treatment at $800{ }^{\circ} \mathrm{C}$ for $1 \mathrm{~h}$. The microstructures were composed of equi-axed $\beta$ grains, and the grain size of alloy C2 was finer than that of alloy $\mathrm{C} 1$. The grain size distribution histograms, average grain size, and standard 
deviation of both alloys are shown in Figure 2. It can be observed that the grain size distribution is markedly different for the two alloys. In C1, the average grain size was $58 \mu \mathrm{m}$, the grain size ranged from $10 \mu \mathrm{m}$ to $140 \mu \mathrm{m}$, and over $44 \%$ of the grains were larger than $60 \mu \mathrm{m}$. In C2, the average grain size was $31 \mu \mathrm{m}$, and almost all grains were in the grain size range between $10 \mu \mathrm{m}$ and $60 \mu \mathrm{m}$. The standard deviation of the alloys was $25 \mu \mathrm{m}$ and $9 \mu \mathrm{m}$, respectively. These results indicate that the grain size uniformity of alloy $\mathrm{C} 2$ is superior to that of $\mathrm{C} 1$.
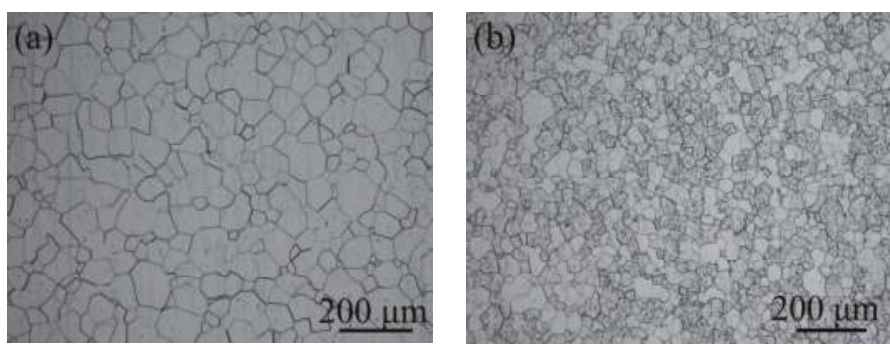

Figure 1. Optical microstructures of the alloys after solution treatment at $800{ }^{\circ} \mathrm{C}$ for $1 \mathrm{~h}$ : (a) alloy C1; (b) alloy C2.
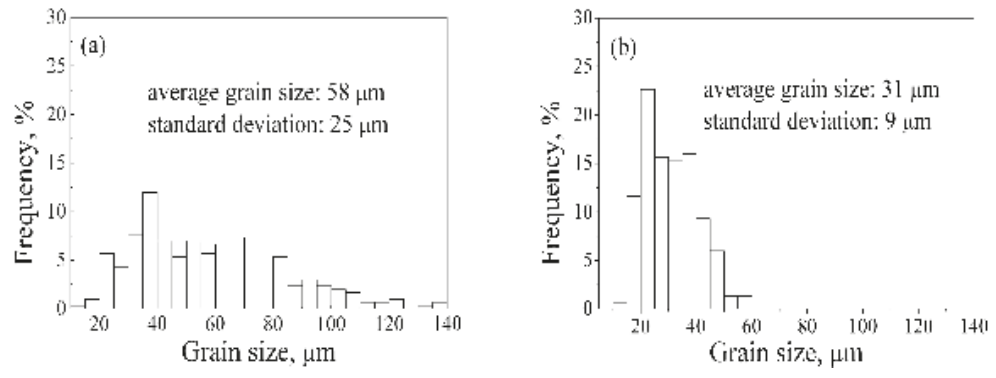

Figure 2. Grain size distributions of alloys: (a) alloy $\mathrm{C} 1$; (b) alloy $\mathrm{C} 2$.

Figure 3 shows the BSE images and EDX spectra of the alloys in solution-treated condition before etching. No resolvable precipitates are observed in C1 (Figure 3a), while white particles are clearly observed in C2 (Figure 3b). Although the distribution and morphologies of particles are not exactly confirmed in polished C2 samples, the size is very tiny. By comparison, no Si peak is found in the EDX spectra for the matrix (Figure 3c), but the white precipitates are rich in Zr and Si (Figure 3d). This confirms that the white particles are Ti-Zr-Si silicides.
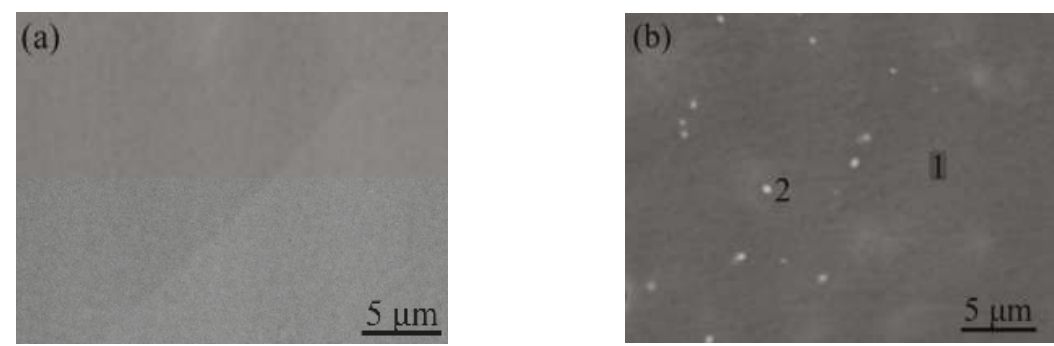

Figure 3. Cont. 

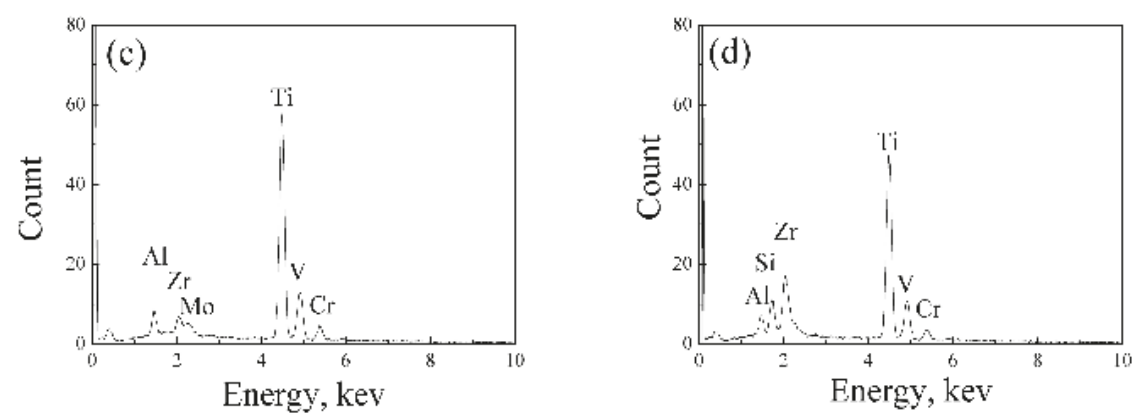

Figure 3. BSE (Back-Scattered Electron) images of microstructures of C1 (a) and C2 (b) before etching; EDX (Energy Dispersive X-ray) spectra of matrix marked by 1 (c) and white precipitates marked by 2 (d).

The selected area electron diffraction (SAED) and EDS analysis were carried out on TEM, and the precipitate was particle shaped, about $200 \mathrm{~nm}$ in size (Figure 4a). The precipitate is rich in $\mathrm{Zr}$ and $\mathrm{Si}$, identified as the $(\mathrm{TiZr})_{6} \mathrm{Si}_{3}$ silicides through the electron diffraction pattern (Figure $4 \mathrm{~b}$ ) and composition information (Figure 4c,d).
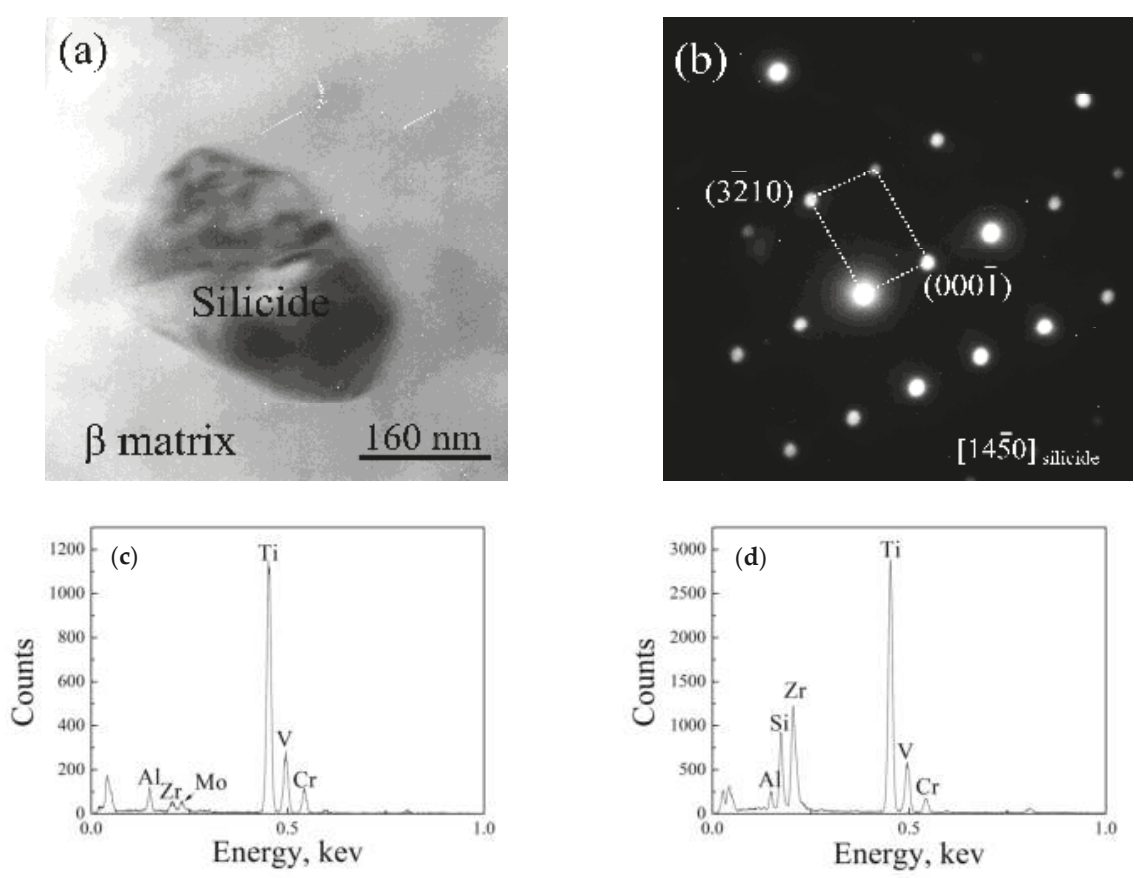

Figure 4. TEM image (a); corresponding SAED (Selected Area Electron Diffraction) pattern for the silicide (b); EDS (Energy Dispersive Spectroscopy) spectra of $\beta$ matrix (c) and silicide (d) for solution-treated alloy C2.

Earlier studies demonstrated that $\mathrm{Zr}$ addition will promote the formation of silicides in titanium alloys $[11,12,21]$. Therefore, the precipitation of silicides resulted from the addition of $\mathrm{Si}$ and the presence of $\mathrm{Zr}$ in alloy $\mathrm{C} 2$. However, the $\mathrm{Si}$ content in $\mathrm{C} 1$ is only $~ 0.02 \mathrm{wt} \%$ from raw materials, which is below the saturation concentration of $\mathrm{Si}$ in the alloy, therefore Si dissolves in the $\beta$ matrix. 
Figure 5 shows the SEM morphologies of microstructures of both alloys after etching. There are no etch pits in C1, but a large number of etch pits are observed in alloy C2, marked by the arrow. It is a common chemical phenomenon that silicides are dissolved by the HF etchant, hence the formation of etch pits should result from the dissolution of silicides. Meanwhile, it is reasonable that the quantity and sites of etch pits correspond to those of silicides in alloy C2. According to the distribution of etch pits, it is deduced that silicides precipitate both on the $\beta$ grain boundaries and in the interior of grains (Figure 5b).
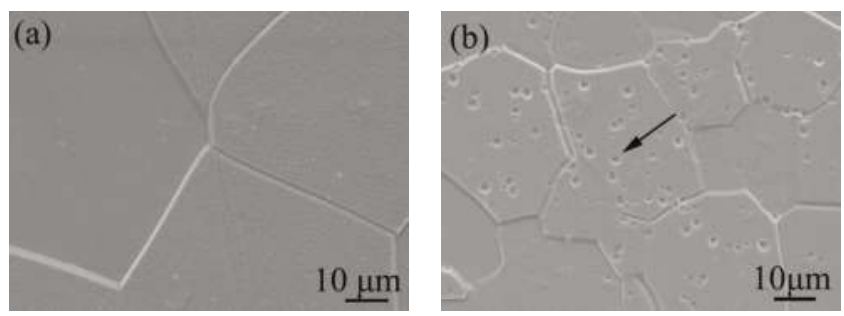

Figure 5. SEM morphologies of microstructures of the alloys after etching: (a) alloy C1; (b) alloy C2.

Singh et al. [22] reported that the kinetics of silicide precipitation in Ti-6Al-1.6Zr-3.3Mo-0.3Si (VT9) alloy was faster than in Ti-6Al-5Zr-0.5Mo-0.25Si (IMI685), which was attributed to the higher content of strong $\beta$-stabilizing element Mo in the former alloy. Therefore, it is understandable that the kinetics of the precipitation of silicides is fast in C2. On one hand, fine dispersed silicide precipitates promote the recrystallization nuclei during solution treatment at $800{ }^{\circ} \mathrm{C}$. On the other hand, fine silicides play an important role in hindering the movement of the grain boundaries during the grain growth. This is the reason why alloy $\mathrm{C} 2$ has a much finer grain size.

\subsection{Tensile Properties}

The tensile stress-strain curves of both alloys are presented in Figure 6. A summary of the data is given in Table 2. Based on these data, it can be seen that the yield strength (YS) and ultimate tensile strength (UTS) of alloy C2 are about $40 \mathrm{MPa}$ higher than those of $\mathrm{C} 1$, respectively. Meanwhile, there is a slight decrease in the elongation (El) and the reduction in area (RA). These results are similar to those found in the literature [23-25], where the silicide precipitates are considered to lead to an increase in strength and a slight drop in ductility for near $\alpha$ titanium alloys.

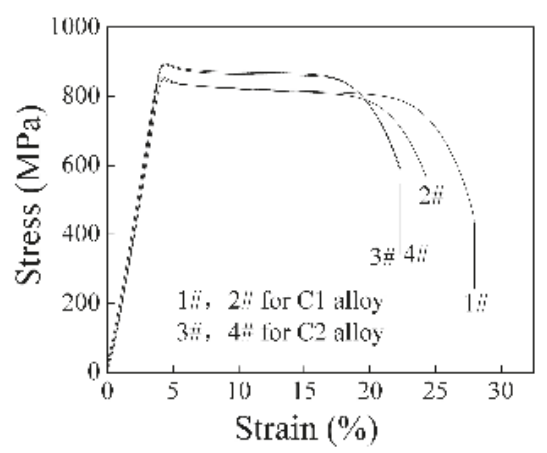

Figure 6. Tensile stress-strain curves of $\mathrm{C} 1$ and $\mathrm{C} 2$ alloys solution-treated at $800{ }^{\circ} \mathrm{C}$ for $1 \mathrm{~h}$. 
Table 2. Tensile properties of both alloys solution treated at $800^{\circ} \mathrm{C}$ for $1 \mathrm{~h}$.

\begin{tabular}{ccccc}
\hline Alloy & YS, MPa & UTS, MPa & El, \% & RA, \% \\
\hline \multirow{2}{*}{ C1 } & 852 & 853 & 29.0 & 73 \\
& 852 & 854 & 27.5 & 76 \\
C2 & 888 & 891 & 23.5 & 62 \\
& 893 & 896 & 24.0 & 61 \\
\hline
\end{tabular}

The differences in the tensile properties of the alloys are largely due to their microstructures. Firstly, the $\beta$ grain size of alloy $\mathrm{C} 2$ was finer than that of $\mathrm{C} 1$. According to the Hall-Petch law, grain refinement enhances yield strength [26,27]. Secondly, a large number of fine silicides dispersed in alloy $\mathrm{C} 2$, which have an effect of precipitation strengthening. These explain the difference in the tensile properties of the alloys.

The changes in ductility also result from the precipitation of dispersed silicides, which would hinder the dislocation motion during tensile deformation. The precipitates tend to induce local stress concentration and crack initiation, resulting in the slightly low plasticity of alloy C2.

Figure 7 shows the fracture morphologies of both alloys. The fracture consists of fiberous and shear lip zones (Figure 7a,b). A large number of dimples spread across the fracture surfaces, which are the characteristic of ductile fracture. Dimples are more uniform and smaller in alloy C2 than those in $\mathrm{C} 1$ (Figure 7c,d). This is related to the presence of the dispersed silicides in alloy C2. Compared with $\mathrm{C} 2$, alloy $\mathrm{C} 1$ experiences a larger plastic deformation before fracture, resulting from its single $\beta$ phase microstructure.

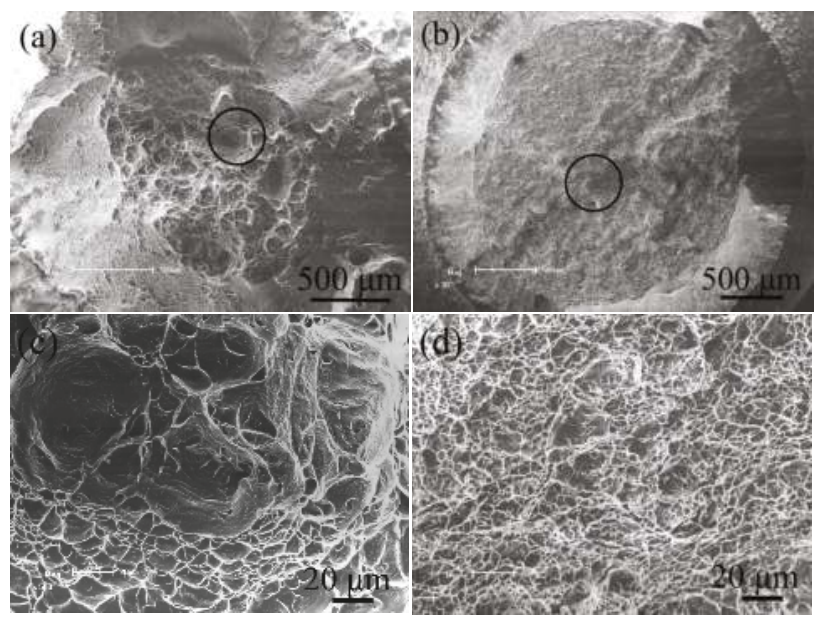

Figure 7. Tensile fractographies of the alloys: $(\mathbf{a}, \mathbf{c})$ : alloy $\mathrm{C} 1 ; \mathbf{( b , d ) : ~ a l l o y ~} \mathrm{C} 2$.

\section{Conclusions}

(1) The addition of trace amount of Si $(\sim 0.05 \mathrm{wt} \%)$ and the presence of $4 \mathrm{wt} \% \mathrm{Zr}$ induced the formation of $(\mathrm{TiZr})_{6} \mathrm{Si}_{3}$ silicides in Ti-3Al-8V-6Cr-4Mo-4Zr-0.05Si alloy.

(2) The dispersed silicides refined $\beta$ grains, and the average grain size of Ti-3Al-8V-6Cr-4Mo- $4 \mathrm{Zr}-0.05 \mathrm{Si}$ alloy was more uniform than that of Ti-3Al-8V-6Cr-4Mo-4Zr alloy. Adding Si was an effective way to refine $\beta$ grains for the Ti-3Al-8V-6Cr-4Mo- $4 \mathrm{Zr}$ alloy. 
(3) The silicide precipitates enhanced the tensile strength of Ti-3Al-8V-6Cr-4Mo-4Zr-0.05Si alloy, and the change in ductility was slight. The increase in strength was attributed to both precipitation strengthening and grain refinement. The fracture mode of both alloys was ductile.

Author Contributions: Hongbo Ba and Limin Dong conceived and designed the experiments; Hongbo Ba, Zhiqiang Zhang, and Xiaofei Lei performed the experiments and analyzed the data; Hongbo Ba wrote the paper.

Conflicts of Interest: The authors declare no conflict of interest.

\section{References}

1. Williams, J.C.; Starke, E.A. Progress in structural materials or aerospace systems. Acta Mater. 2003, 51, 5775-5799. [CrossRef]

2. Banerjee, D.; Williams, J.C. Perspectives on titanium science and technology. Acta Mater. 2013, 61, 844-879. [CrossRef]

3. Lei, X.F.; Dong, L.M.; Zhang, Z.Q.; Liu, Y.J.; Hao, Y.L.; Yang, R.; Zhang, L.C. Microstructure, texture evolution and mechanical properties of VT3-1 titanium alloy processed by multi-pass drawing and subsequent isothermal annealing. Metals 2017, 7, 131. [CrossRef]

4. Kim, J.H.; Lee, C.H.; Hong, J.K.; Kim, J.H.; Yeom, J.T. Effect of surface treatment on the hot forming of the high strength Ti-6Al-4V fastener. Mater. Trans. 2009, 50, 2050-2056. [CrossRef]

5. Kume, K.; Furui, M.; Ikeno, S.; Ishisaka, Y.; Yamamoto, M. Screw form rolling of beta type titanium alloy preliminary worked by torsion. Mater. Sci. Forum 2010, 654, 906-909. [CrossRef]

6. Solek, A.L.; Krawczyk, J. The analysis of the hot deformation behaviour of the Ti-3Al-8V-6Cr-4Zr-4Mo alloy, using processing maps, a map of microstructure and of hardness. Mater. Des. 2015, 65, 165-173. [CrossRef]

7. Salam, A.; Hammond, C. Superplasticity and associated activation energy in Ti-3Al-8V-6Cr-4Mo-4Zr alloy. J. Mater. Sci. 2005, 40, 5475-5482. [CrossRef]

8. Boyer, R.; Welsch, G.; Collings, E.W. Materials Properties Handbook: Titanium Alloys, 1st ed.; ASM International: Materials Park, OH, USA, 1994; pp. 797-828.

9. Scmidt, P.; El-chaikl, A.; Christ, H.J. Effect of duplex aging on the initiation and propagation of fatigue cracks in the solute-rich metastable $\beta$ titanium alloy Ti 38-644. Metall. Mater. Trans. A 2011, 42, 2652-2667. [CrossRef]

10. Es-souni, M. Creep behaviour and creep microstructures of a high-temperature titanium alloy Ti-5.8Al-4.0Sn-3.5Zr-0.7Nb-0.35Si-0.06C (Timetal 834): Part I. Primary and steady-state creep. Mater. Charact. 2001, 46, 365-379. [CrossRef]

11. Gu, Y.; Zeng, F.H.; Qi, Y.L.; Xia, X.Q.; Xiong, X. Tensile creep behavior of heat-treated TC11 titanium alloy at 450-550 ․ C. Mater. Sci. Eng. A 2013, 575, 74-85. [CrossRef]

12. Singh, A.K.; Ramachandra, C. Characterization of silicides in high-temperature titanium alloys. J. Mater. Sci. 1996, 32, 229-234. [CrossRef]

13. Li, J.X.; Wang, L.Q.; Qin, J.N.; Chen, Y.F.; Lu, W.J.; Zhang, D. The effect of heat treatment on thermal stability of Ti matrix composite. J. Alloys Compd. 2011, 509, 52-56. [CrossRef]

14. Ramachandra, C.; Singh, V. Silicide precipitation in alloy Ti-6Al-5Zr-0.5Mo-0.25Si. Metall. Trans. A 1982, 13, 771-775. [CrossRef]

15. Flower, H.M.; Swann, P.R.; West, D.R.F. Silicide precipitation in the Ti-Zr-Al-Si system. Metall. Mater. Trans. B 1971, 2, 3289-3297. [CrossRef]

16. Bermingham, M.J.; Mcdonald, S.D.; Dargusch, M.S.; Stjohn, D.H. The mechanism of grain refinement of titanium by silicon. Scr. Mater. 2008, 58, 1050-1053. [CrossRef]

17. Tavares, A.M.G.; Ramos, W.S.; Blas, J.C.G.; Lopes, E.S.N.; Caram, R.; Batista, W.W.; Souza, S.A. Influence of $\mathrm{Si}$ addition on the microstructure and mechanical properties of $\mathrm{Ti}-35 \mathrm{Nb}$ alloy for applications in orthopedic implants. J. Mech. Behav. Biomed. Mater. 2015, 51, 74-87. [CrossRef] [PubMed]

18. Ramachandra, C.; Singh, V. Effect of silicide precipitation on tensile properties and fracture of alloy Ti-6Al-5Zr-0.5Mo-0.25Si. Metall. Trans. A 1985, 16, 227-231. [CrossRef]

19. Ramachandra, C.; Singh, V. Effect of silicides on tensile properties and fracture of alloy Ti-6Al-5Zr-0.5Mo-0.25Si from 300 to 823 K. J. Mater. Sci. 1988, 23, 835-841. [CrossRef] 
20. Morito, F.; Muneki, S.; Takahashi, J.; Kainuma, T. The effect of Silicon Addition on the Microstructure and the Aging Behavior of Ti-3Al-8V-6Cr-4Mo-4Zr Alloy. In Proceedings of the Titanium 95: Eighth World Congress on Titanium, Birmingham, UK, 22-26 October 1995; pp. 2494-2501.

21. Singh, A.K.; Roy, T.; Ramachandra, C. Microstructural stability on aging of an $\alpha+\beta$ titanium alloy: Ti-6Al-1.6Zr-3.3Mo9-0.30Si. Metall. Mater. Trans. A 1996, 27, 1167-1173. [CrossRef]

22. Singh, A.K.; Ramachandra, C.; Tavafoghi, M.; Singh, V. Microstructure of $\beta$-solution-treated, quenched and aged $\alpha+\beta$ titanium alloy Ti-6Al-1.6Zr-3.3Mo9-0.30Si. J. Alloys Compd. 1992, 179, 125-135. [CrossRef]

23. Jayaprakash, M.; Ping, K.H.; Yamabe-mttaeai, Y. Effect of $\mathrm{Zr}$ and $\mathrm{Si}$ addition on high temperature mechanical properties of near- $\alpha$ Ti-Al-Zr-Sn based alloys. Mater. Sci. Eng. A 2014, 612, 456-461. [CrossRef]

24. Popov, A.; Rossina, N.; Popova, M. The effect of alloying on the ordering processes in near-alpha titanium alloys. Mater. Sci. Eng. A 2013, 564, 284-287. [CrossRef]

25. Jia, W.; Zeng, W.; Yu, H. Effect of aging on the tensile properties and microstructures of a near-alpha titanium alloy. Mater. Des. 2014, 58, 108-115. [CrossRef]

26. Tsai, Y.L.; Wang, S.F.; Bor, H.Y.; Hsu, Y.F. Effects of Zr addition on the microstructure and mechanical behavior of a fine-grained nickel superalloy at elevated temperatures. Mater. Sci. Eng. A 2014, 607, 294-301. [CrossRef]

27. Muszka, K.; Majta, J.; Bienias, L. Effect of grain refinement on mechanical properties of microalloyed steels. Metall. Found. Eng. 2006, 32, 87-97. [CrossRef]

(C) 2017 by the authors. Licensee MDPI, Basel, Switzerland. This article is an open access article distributed under the terms and conditions of the Creative Commons Attribution (CC BY) license (http:/ / creativecommons.org/licenses/by/4.0/). 


\title{
Article \\ The Effects of Prestrain and Subsequent Annealing on Tensile Properties of CP-Ti
}

\author{
Le Chang, Chang-Yu Zhou * and Xiao-Hua He \\ School of Mechanical and Power Engineering, Nanjing Tech University, Nanjing 211816, China; \\ chellechang@163.com (L.C.); xh_he@njtech.edu.cn (X.-H.H.) \\ * Correspondence: changyu_zhou@163.com; Tel./Fax: +86-25-5813-9951 \\ Academic Editor: Mark T. Whittaker \\ Received: 14 February 2017; Accepted: 14 March 2017; Published: 17 March 2017
}

\begin{abstract}
The aim of the present work is to investigate the effects of prestrain and subsequent annealing on tensile properties of commercial pure titanium (CP-Ti). According to tensile test results, yield strength and ultimate tensile strength increase with the increase of prestrain. Elongation and uniform strain decrease linearly with prestrain. In the case of prestrain that is higher than $3.5 \%$, the macro-yield of specimens changes from gradual yielding to discontinuous yielding. It is supposed that considerable numbers of dislocations introduced into the material lead to the appearance of yield plateau. The quantitative analysis of the contribution of dislocation hardening to the strain hardening shows that dislocation-associated mechanisms play an important role in strain hardening. Moreover, a modified Fields-Backofen model is proposed to predict the flow stress of prestrained $\mathrm{CP}-\mathrm{Ti}$ at different strain rates. Both strain rate sensitivity and strain hardening exponent decrease with prestrain. Fracture surfaces of the specimens show that fracture mechanism of all tested specimens is dimple fracture. The more ductile deformation in prestrained CP-Ti after annealing indicates that its ductility is improved by annealing.
\end{abstract}

Keywords: CP-Ti; prestrain; yield plateau; tensile properties; flow stress; fracture

\section{Introduction}

During the manufacture of materials (stamping, cold rolling, equal channel angular pressing, bending) and the installation and service history of the equipment components (such as creep, overload), different degrees of plastic deformation will happen in the materials. The extent of prior plastic strain introduced into the material can significantly change the mechanical properties and consequently affect the plastic deformation behavior. At present, the investigation of the influence of prestrain on the materials has been focused on steels [1-7], titanium alloys [8-10], aluminum alloys [11,12], magnesium alloys [13-15], Zr-based alloys [16] and so on. Usually, prior heavy cold work leads to a considerable increase in strength by creating dislocation barriers to inhibit subsequent dislocation movement during plastic deformation at room temperature. For instance, Zhang et al. [2] found that by pre-straining and bake hardening, the strength of C-Mn-Si TRIP steel was enhanced. Further, they supposed that the unlocking from weak carbon atmospheres of dislocations newly formed during prestraining led to the appearance of yield point on the stress-strain curve [3]. Lee et al. [6,7] found that work hardening rate and strain rate sensitivity (SRS) of 304 L stainless steel were dependent on the variation of prestrain. Sarker et al. $[13,14]$ suggested that the variation of strain hardening rate of AM30 magnesium alloy with pre-straining was related to deformation twinning and detwinning. Thus, it can be seen that prestrain has important effects on the subsequent plastic deformation behavior for many materials. Also, it provides that the effects of prestrain on the performance of hexagonal close-packed materials are associated with twinning structures produced in the prior deformation [13-15]. Many researchers have studied the effects of prior severe 
plastic deformation, such as cold rolling and equal channel angular pressing (ECAP) on mechanical properties of CP-Ti [17-19]. The activation of twinning in CP-Ti is affected by many factors, such as deformation temperature, strain rate, deformation value, deformation direction [20,21]. Prior deformation (cold rolling and ECAP) produces many twins in the initial microstructure of $\mathrm{CP}-\mathrm{Ti}$, which is different from tensile prestrain $[18,19,22-24]$. The effects of stretching prestrain on the mechanical properties of CP-Ti have not been examined. Thus, in this paper, different amounts of prestrain were applied to $\mathrm{CP}-\mathrm{Ti}$ and a uniaxial tensile experiment was conducted to investigate the effects of prestrain on mechanical properties, work hardening rate, flow stress and fracture mechanism.

\section{Experimental Materials and Procedures}

The materials used in the present study were CP-Ti in the form of a cold-rolled and annealed plate. The chemical composition was given in Table 1 . The specimens with $3 \mathrm{~mm}$ thickness (see Figure 1) were machined from the as-received plate by wire electrical discharge machining. In order to exclude the effect of surface roughness, the specimens were ground and polished by metallographic abrasive paper. The tensile testing was carried out by Instron tensile experimental equipment (INSTRON, Norwood, MA, USA). The strain was automatically measured by extensometer (INSTRON, Norwood, MA, USA). Different levels of pre-deformation along rolling direction were applied at the same strain rate $\left(0.0005 \mathrm{~s}^{-1}\right)$ with the control of extensometer. Then, the specimens were unloaded and reloaded to fracture. The strain rate during reloading ranged from 0.00005 to $0.004 \mathrm{~s}^{-1}$. In addition, to investigate the effects of subsequent annealing on tensile properties of prestrained samples, isothermal heat-treatment was conducted using a vacuum furnace equipped with an auto tune temperature controller (HUAHONG, Suzhou, China). The annealing temperatures were $500{ }^{\circ} \mathrm{C}$ and $600{ }^{\circ} \mathrm{C}$ with dwell times ranging from $30 \mathrm{~min}$ to $1 \mathrm{~h}$. The detailed annealing experimental scheme was listed in Table 2. The microstructure was characterized using optical metallography. The specimens were mechanically ground and chemically etched in a solution consisting of $10 \mathrm{~mL}$ nitric acid, $2 \mathrm{~mL}$ hydrofluoric acid and $88 \mathrm{~mL}$ distillated water. Study on the fracture surface of tensile specimens was carried out using a JSM-6360LV scanning electron microscope (JEOL, Tokyo, Japan).

Table 1. Chemical composition of used commercial pure (CP)-titanium (wt. \%).

\begin{tabular}{ccccccc}
\hline Element & Ti & Fe & C & N & H & O \\
\hline Composition & Balance & 0.06 & 0.01 & $<0.01$ & 0.001 & 0.12 \\
\hline
\end{tabular}

Table 2. Annealing experimental scheme.

\begin{tabular}{ccccc}
\hline \multirow{2}{*}{ Prestrain $\left(\varepsilon_{\text {pre }}\right) / \%$} & \multicolumn{4}{c}{ Annealing } \\
\cline { 2 - 5 } & $\mathbf{5 0 0}{ }^{\circ} \mathbf{C}, \mathbf{3 0} \mathbf{~ m i n}$ & $\mathbf{5 0 0}{ }^{\circ} \mathrm{C}, \mathbf{4 0} \mathbf{m i n}$ & $\mathbf{5 0 0}{ }^{\circ} \mathbf{C}, \mathbf{6 0} \mathbf{~ m i n}$ & $\mathbf{6 0 0}{ }^{\circ} \mathbf{C}, \mathbf{3 0} \mathbf{~ m i n}$ \\
\hline 1 & $\sqrt{ }$ & $\sqrt{ }$ & - & $\sqrt{ }$ \\
2 & $\sqrt{ }$ & $\sqrt{ }$ & $\sqrt{ }$ & - \\
3.5 & $\sqrt{ }$ & $\sqrt{ }$ & $\sqrt{ }$ & $\sqrt{ }$ \\
5 & $\sqrt{ }$ & $\sqrt{ }$ & $\sqrt{ }$ & - \\
6.5 & $\sqrt{ }$ & $\sqrt{ }$ & - & $\sqrt{ }$ \\
\hline
\end{tabular}

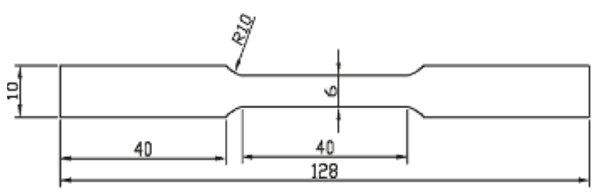

Figure 1. The geometry of the test specimens. 


\section{Results and Discussion}

\subsection{Tensile Properties of As-Received Commercial Pure (CP)-Ti}

According to uniaxial tensile experiment, mechanical properties of CP-Ti were determined. Engineering stress-strain curves of the as-received material were given in Figure 2. Plastic deformation process can be divided into three stages by the three characteristic points $(A, B, C)$ on the tensile curve. The first feature point is yield strength point (point A), deformation before this point is the elastic deformation stage. Obviously, in the range of $0.00005-0.004 \mathrm{~s}^{-1}$, the yield of CP-Ti is continuous as no yield plateau appears. The second feature point is the highest point (point B). Generally, when maximum tensile force reaches, sample necking starts, the corresponding point B is the demarcation between uniform plastic deformation and non-uniform plastic deformation. When plastic deformation is concentrated, load-bearing capacity decreases quickly, the corresponding feature point is point C. The strain of diffuse necking and localized necking were expressed as follows:

$$
\begin{gathered}
\varepsilon_{d}=n \\
\varepsilon_{l}=2 n
\end{gathered}
$$

where $\varepsilon_{d}$ is initial strain of diffuse necking, $\varepsilon_{l}$ is initial strain of localized necking and $n$ is strain hardening index. The stress-strain curve in plastic stage is divided into three stages, via uniform deformation, diffuse necking stage and localized necking stage by the two perpendicular lines. As the work hardening exponent is different under different strain rates, distinguish area of stress-strain curve was only given at strain rate of $0.0005 \mathrm{~s}^{-1}$, as shown in Figure 2. It can be seen that CP-Ti has obvious strain rate sensitivity. With the increase of strain rate, tensile stress-strain curve of CP-Ti ascends. Moreover, the yield strength and tensile strength increase and the elongation decreases.

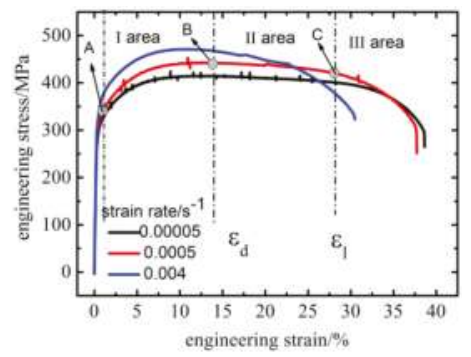

Figure 2. Engineering stress-strain curves of as-received CP-Ti.

\subsection{Tensile Properties of Prestrained Specimens}

The prestrain was taken from the uniform plastic deformation zone and the dispersion instability region $(1 \%, 2 \%, 3.5 \%, 5 \%, 6.5 \%, 10 \%, 15 \%$, respectively). According to tensile stress-strain curves of different prestrained specimens, as shown in Figure 3a, it can be seen that, after pre-stretching, tensile stress-strain curve ascends. Both yield strength and ultimate tensile strength increase. The strength of $\mathrm{CP}-\mathrm{Ti}$ is enhanced at the cost of ductility, as fracture strain decreases a lot with prestrain. By comparing the engineering stress-strain curves of 3.5\%,5\% and $6.5 \%$ prestrained specimens, it can be seen that engineering stress-strain curves of these specimens are close, that means when prestrain is ranging from $3.5 \%$ to $6.5 \%$, flow stress increases slightly with prestrain. When prestrain reaches $10 \%$ and above, the ultimate strength is rapidly reached and yield strength is very close to tensile strength. It is worth noting that as prestrain reaches $3.5 \%$, the macro-yield changes from gradual yielding to discontinuous yielding, as shown in Figure 3b. The discontinuous increase of flow stress shows the appearance of yield plateau. 

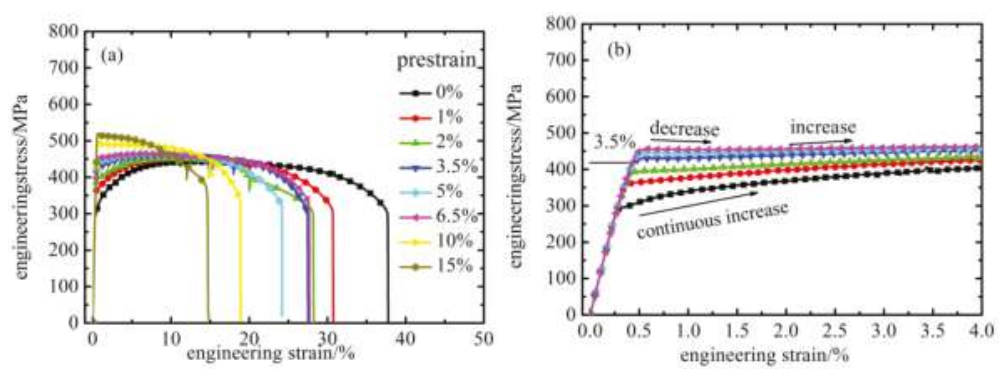

Figure 3. Engineering stress-strain curves of different prestrained specimens. (a) $0 \%-15 \%$ prestrained $\mathrm{CP}-\mathrm{Ti}$ and $(\mathbf{b})$ the appearance of yield plateau.

In order to evaluate the variation of flow stress with true strain, work hardening rate $\theta(\mathrm{d} \sigma / \mathrm{d} \varepsilon)$ is derived from the true stress-strain curve. Figure 4 displays variations of $\theta$ with true strain for as-received and prestrained CP-Ti. An often reported feature for pure titanium, in particular in compression conditions, consists in a three-stage character of deformation curve $[25,26]$. Work hardening rate of as-received CP-Ti shows three decrease stages (A, B and C stage), as shown in Figure 4a. Work hardening rate decreases sharply at the beginning of plastic deformation (stage A) and then decreases gradually at moderate strain (stage B). In stage $C$, work hardening rate decreases slowly with strain, as the slopes flatten with the increase of true strain. Between stages A and B the transition occurs at a true plastic strain of 0.018 , between stages $B$ and $C$ at a true plastic strain of 0.096 . The transition points between stages $A$ and $B$ and that between stages $B$ and $C$ of as-received CP-Ti are consist with results of Becker et al. [27] and Hama et al. [28]. For prestrained CP-Ti in Figure 4b, its $\theta$ is dependent on true strain and prestrain. With the increase of prestrain $\left(\varepsilon_{\text {pre }} \geq 2 \%\right)$, a rise stage $B$ of work hardening rate occurs. Stage B is characterized by an increasing strain hardening rate with true strain at the range of $0.5 \%-2 \%$. With increasing prestrain, the rise tendency in stage $\mathrm{B}$ is more remarkable. In the case of $\varepsilon_{\text {pre }} \geq 3.5 \%$, strain hardening rate at the end of stage $\mathrm{A}$ is negative, also indicates that yield plateau appears in tensile stress-strain curves, which is consist with Figure 3b. Additionally, compared with as-received CP-Ti, $\theta$ of prestrained CP-Ti decreases, indicating the decrease of work hardening ability. Li et al. [29] and Ghaderi et al. [30] investigated the effect of grain size on the tensile deformation mechanisms of CP-Ti and found that as grain size decreased to about $26 \mu \mathrm{m}$, yield plateau occurred. In this paper, the grain size of CP-Ti is about $30 \mu \mathrm{m}$, as shown in Figure 5a, determined by linear intercept method. Li et al. [29] supposed there were two possible reasons for the observed variation of the macro-yield. First is the high number of dislocation tangles and the mobile dislocation density. The second reason is the presence of deformation twinning. However, as grain size decreases to $30 \mu \mathrm{m}$, the activation of twinning in CP-Ti during tensile deformation is non-significant [29]. Thus, ascribing the initial yield plateau of CP-Ti during tensile deformation to the presence of twinning is unreasonable. It is no doubt that dislocation structure exists in the prestrained samples and its density increases with prestrain. However, the volume fraction of twinning is tremendously small, as shown in Figure $5 \mathrm{~b}-\mathrm{f}$, though its density increases with prestrain. Almost no twinning structure can be observed in $2 \%-3.5 \%$ prestrained samples and few twins exists in $5 \%-15 \%$ prestrained samples indicated by white arrows. According to quantitative statistical analysis of microstructure in the process of tensile deformation along rolling direction [31-34], the twin volume fraction is always considerably small and the plastic deformation can be attributed to dislocation slip. Therefore, as prestrain reaches $3.5 \%$, high dislocation density in the initial microstructure leads to the presence of yield plateau. 

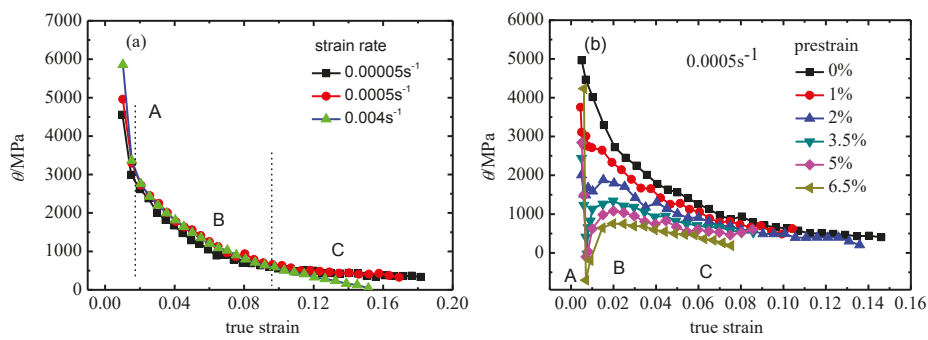

Figure 4. The variation of work hardening rate with true strain. (a) As-received CP-Ti at different strain rates and (b) prestrained CP-Ti at $0.0005 \mathrm{~s}^{-1}$.

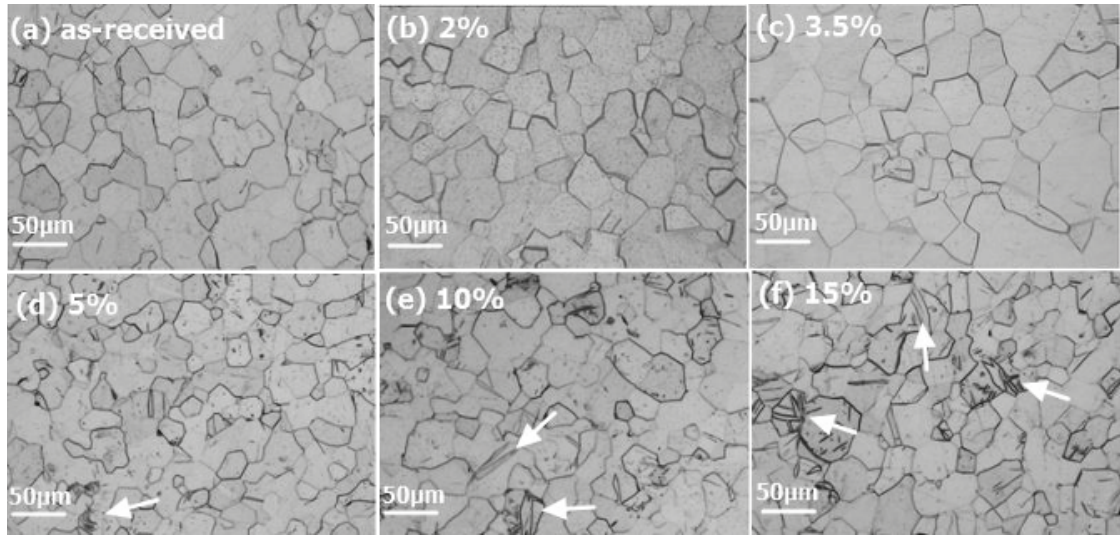

Figure 5. Metallographic figures of different prestrained samples: (a) as-received; (b) 2\%; (c) $3.5 \%$; (d) $5 \%$; (e) $10 \%$ and (f) $15 \%$ prestrained specimens. Twins are indicated by white arrows in Figure $5 \mathbf{d}-\mathbf{f}$.

The variations of strength and ductility of $\mathrm{CP}-\mathrm{Ti}$ as functions of tensile prestrain are shown in Figures 6 and 7 respectively. It is observed that with the increase of prestrain, both yield strength and tensile strength increase. The increment in yield strength with the amount of prestrain is gradually slow, which can be seen from the slope of variation of yield strength with the increase of prestrain. The increase of yield strength with prestrain can be rationalised by following two reasons. One is that dislocation density increases quickly with increasing prestrain. As a result, the resistance to start plastic deformation on reloading increases sharply with increasing prestrain. The other is that as prestrain increases, few twins also contribute to the increase of yield strength. The yield strength increases more and more slowly with prestrain. The logarithmic curve of the yield strength versus the prestrain is linear. Thus, a power law can be used to describe the relationship between prestrain and yield strength, expressed as follow:

$$
\sigma=68.08 \varepsilon_{\text {pre }} 0.43+305.34
$$

It is shown that the curve of the Equation (3) is consistent with the original data point, and the correlation coefficient $R$ is 0.999 . When prestrain is less than $6.5 \%$, ultimate tensile strength increases slowly with prestrain. As prestrain increases up to $10 \%$, ultimate tensile strength increases rapidly and yield strength is close to tensile strength. According to relationships between uniform strain, elongation $(\varepsilon)$, total elongation $\left(\varepsilon_{\text {total }}=\varepsilon_{\text {pre }}+\varepsilon\right)$ and prestrain, both uniform strain and elongation decrease linearly with prestrain. As prestrain increases up to $10 \%$, plastic deformation of CP-Ti quickly develops into the diffuse necking stage. However, total elongation of CP-Ti remains constant about $30.5 \%$, slightly less than the as-received material, that means the total ductility keeps in constant. During the initial prestrain process the higher the prestrain is, the lower elongation on reloading is. 


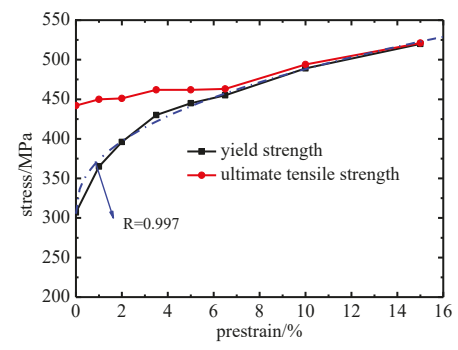

Figure 6. Variation of strength parameters.

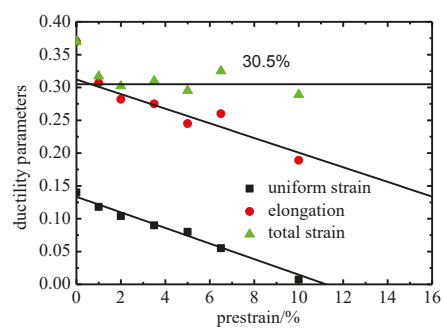

Figure 7. Variation of ductility parameters with amount of prestrain.

\subsection{Tensile Properties of Prestrained Specimens after Annealing}

In order to further analyze the phenomenon of discontinuous yielding occurs in higher prestrained specimens, subsequent annealing was conducted to remove dislocations. According to National military standard of the People's Republic of China [35], stress relieving temperature is in the range of $445-595{ }^{\circ} \mathrm{C}$ and heating holding time is from 15 to $360 \mathrm{~min}$. In order to establish proper heating parameters, the prestrained specimens were conducted heat-treatment at the temperature of $500{ }^{\circ} \mathrm{C}$ with 30-60 min and $600{ }^{\circ} \mathrm{C}$ with $30 \mathrm{~min}$ respectively. The results show that when prestrained specimens are heated at $500{ }^{\circ} \mathrm{C}$, the yield and tensile strength no longer decrease as holding time up to $40 \mathrm{~min}$. Additionally, compared with prestrained specimens without annealing, yield and tensile strength decrease. That means when holding time reaches to $40 \mathrm{~min}$ at $500{ }^{\circ} \mathrm{C}$, most of dislocations can be eliminated. At the same time, after heat treatment at $600{ }^{\circ} \mathrm{C}$ and $30 \mathrm{~min}$ holding time, yield and tensile strength of prestrained specimens are equal to those of the as-received material. That indicates that recrystallization process of grain could be realized and both dislocations, twinning structures and other defects have been removed through heat-treatment at $600{ }^{\circ} \mathrm{C}$ and $30 \mathrm{~min}$ holding time. According to metallographic figures of different prestrained samples after annealing at $500^{\circ} \mathrm{C}$ and $40 \mathrm{~min}$, grain size and shape do not change, as shown in Figure 8. No twinning is observed in the two percent prestrained specimen and twinning structures in the five percent prestrained specimen keep same as these without annealing. This also implies that twinning structures in prestrained specimens couldn't be annealing twins. Therefore, the heat treatment temperature and holding time were established as $500{ }^{\circ} \mathrm{C}$ and $40 \mathrm{~min}$, which can eliminate the dislocations generated by prestrain and remain the twins. Engineering stress-strain cures of prestrained specimens after annealing are shown in Figure 9. It is observed that yield plateau of relative higher prestrain $\left(\varepsilon_{\text {pre }} \geq 3.5 \%\right)$ specimens disappears after annealing. Also, work hardening rate of prestrained CP-Ti after annealing is calculated according to true stress-strain curve. As most of dislocations is eliminated after annealing, it is expected that the variation of $\theta$ for prestrained specimens with annealing is consist with that of as-received CP-Ti, as shown in Figure 10. Work hardening rates of all specimens are positive and no rising stage can be observed. Additionally, the transitions between different stages of $\theta$ are consistent with those in Figure 4. Therefore, it is 
obviously demonstrated that the high dislocation density in prestrained specimens results in the appearance of yield plateau on reloading and rising stage of work hardening rate.

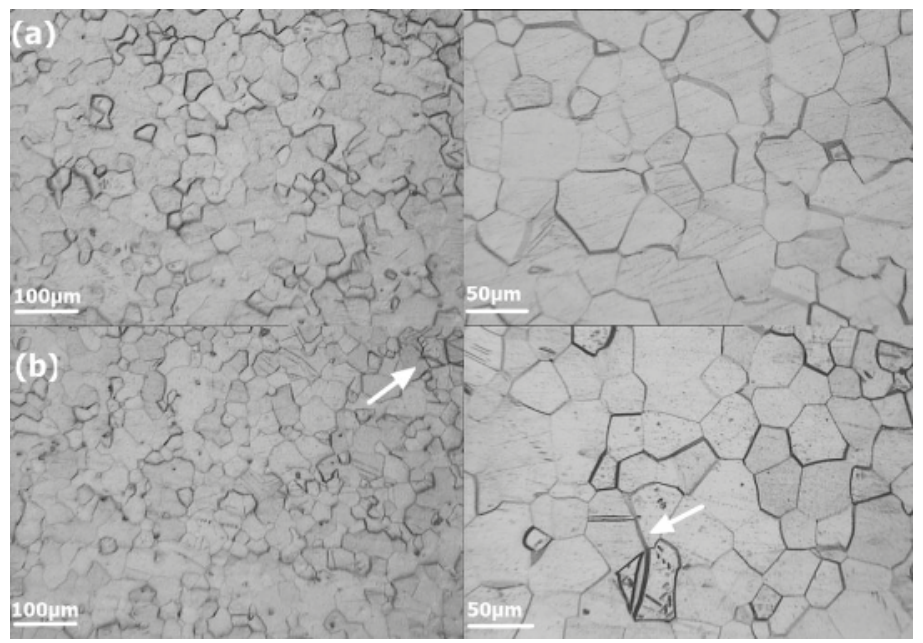

Figure 8. Metallographic figures of different prestrained samples after heat-treatment $\left(500{ }^{\circ} \mathrm{C}, 40 \mathrm{~min}\right)$ : (a) two percent prestrain with annealing; (b) five percent prestrain with annealing. Twins are indicated by white arrows in Figure 8 b.

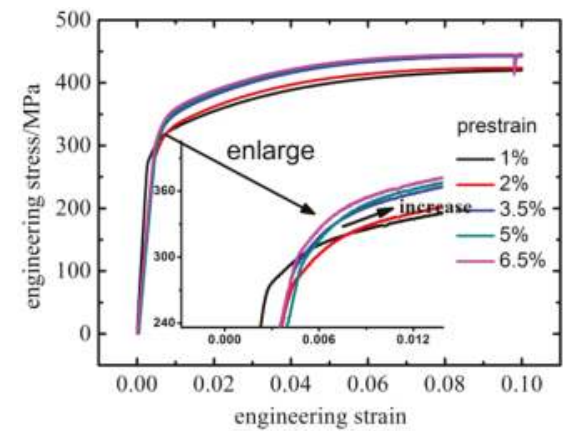

Figure 9. Engineering stress-strain cures of prestrained specimens after annealing $\left(500{ }^{\circ} \mathrm{C}, 40 \mathrm{~min}\right)$.

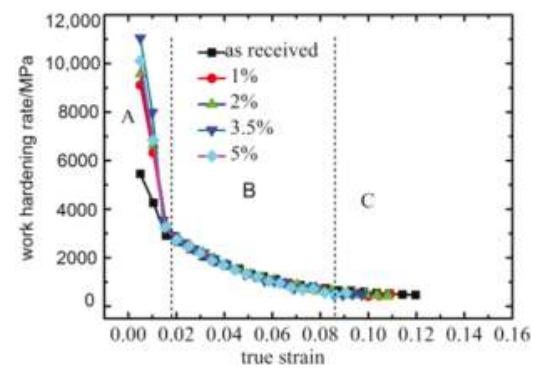

Figure 10. Three stages of work hardening rate in prestrained specimens after annealing: Sharp decrease in stage $\mathrm{A}$, moderate decrease in stage $\mathrm{B}$ and slow decrease in stage $\mathrm{C}$. 
Further quantitative analysis of the contribution of dislocation hardening to the strain hardening of the material was made. In this paper, two parameters $\left(\Delta \sigma_{1}, \Delta \sigma_{2}\right)$ were introduced, expressed as follows:

$$
\begin{aligned}
\Delta \sigma_{1} & =\sigma_{R}-\sigma_{R A} \\
\Delta \sigma_{2} & =\sigma_{R A}-\sigma_{S}
\end{aligned}
$$

$\Delta \sigma_{1}, \Delta \sigma_{2}$ represents hardening contributions from dislocations associated mechanisms and other mechanisms, respectively. $\sigma_{S}, \sigma_{R}$ and $\sigma_{R A}$ refer to yield strength of as-received CP-Ti, prestrained specimens and prestrained specimens with annealing, respectively. From Figure 11, it can be seen that below the strain of two percent, the hardening mainly comes from the dislocations associated mechanisms and other hardening mechanisms are not important at this stage (about 3-4 MPa). As strain increases to $3.5 \%, \Delta \sigma_{2}$ (about 21-31 MPa) increases fast. With the increase of strain, the contribution on strain hardening from both the dislocations associated mechanisms and other mechanisms increases. Nevertheless, according to the variation of $\Delta \sigma_{1} /\left(\Delta \sigma_{1}+\Delta \sigma_{2}\right)$ with prestrain in Figure 11, despite the decrease of contribution from dislocation hardening, dislocations associated mechanisms still occupy $80 \%$ of the overall strain hardening. Therefore, dislocations play an important role in strain hardening of $\mathrm{CP}$-Ti during room temperature tensile along rolling direction. Also, it indicates that dislocation slip is the predominant plastic deformation mechanism. This is consistent with the results of Amouzou [31] and Roth et al. [33]. Based on Taylor-type relations between dislocation density and local flow stress, the quantified contribution of dislocation density to the increase of strength is expressed as follows:

$$
\sigma_{p}=\sigma_{0}+M \alpha G b \rho^{1 / 2}
$$

where $M, \alpha, G$ and $b$ are the Taylor factor, Taylor constant, shear modulus and Burgers vector, respectively; and $\sigma_{0}$ is the lattice friction stress. According to the literature [31], the relation between dislocation density $(\rho)$ and tensile strain $(\varepsilon)$ is linear:

$$
\rho=a_{1}+a_{2} \varepsilon
$$

where $a_{1}$ and $a_{2}$ are constants. Thus, the variation of dislocation hardening stress $\left(\Delta \sigma_{1}\right)$ with prestrain $\left(\varepsilon_{\text {pre }}\right)$ should satisfy the following relationship:

$$
\Delta \sigma_{1}=c_{1}+c_{2}\left(a_{1}+a_{2} \varepsilon_{\text {pre }}\right)^{1 / 2}
$$

where $c_{1}$ and $c_{2}$ are constants. From Figure 11, it is obviously that the relationship between $\Delta \sigma_{1}$ and $\varepsilon_{\text {pre }}$ satisfies Equation (8) and the correlation coefficient $R$ is 0.97 . After annealing treatment, ultimate tensile strength decreases, compared with prestrained specimens. The decrease of ultimate tensile strength in the 3.5\% prestrained specimen is maximum, as shown in Figure 12. The elongation of prestrained specimens increases after annealing, as shown in Figure 13. When prestrain is less than $3.5 \%$, the elongation of prestrained specimens after annealing is higher than the as-received CP-Ti. However, when prestrain is above five percent, the elongation of prestrained specimens after annealing starts to decrease compared with the as-received CP-Ti. This indicates that by proper heat treatment and certain prior plastic deformation, both the strength and ductility of $\mathrm{CP}-\mathrm{Ti}$ can be improved. 


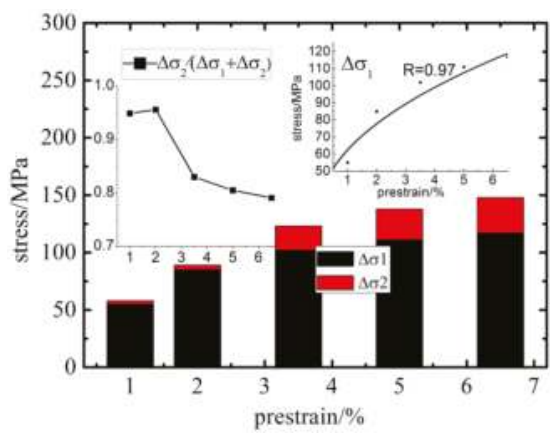

Figure 11. The quantified analysis of effects of dislocations associated mechanisms $\left(\Delta \sigma_{1}\right)$ and other mechanisms $\left(\Delta \sigma_{2}\right)$ on strain hardening.

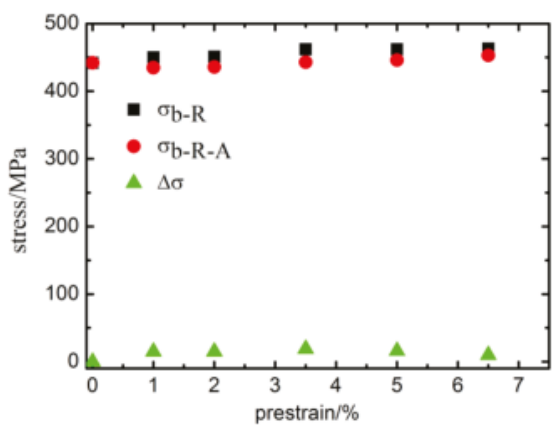

Figure 12. Decline of ultimate tensile strength after annealing: $\sigma_{b-R}, \sigma_{b-R-A}, \Delta_{\sigma}$ represent tensile strength of prestrained specimens, prestrained specimens with annealing and the difference between prestrained and prestrained specimens with annealing.

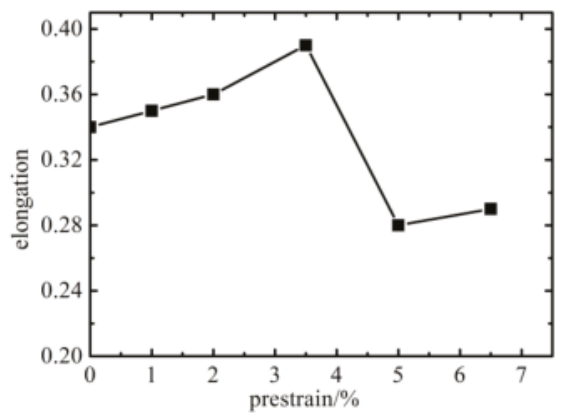

Figure 13. Elongation of prestrained specimens with annealing.

\subsection{Constitutive Model of Prestrained CP-Ti}

The Fields-Backofen model [36], expressed as follows:

$$
\sigma=k \varepsilon^{n} \dot{\varepsilon}^{m}
$$

is commonly used to quantitatively describe the effects of strain rate sensitivity and strain strengthening on stress-strain curves of the homogeneous strain strengthening region, where $k$ is the strength 
coefficient, $n$ is the strain hardening exponent, and $m$ is the strain rate sensitivity exponent. According to true stress-strain curves of prestrained CP-Ti at different strain rates, the variation of strain rate sensitivity index $m(\log \sigma / \log \dot{\varepsilon})$ with prestrain is presented in Figure 14a. SRS of prestrained CP-Ti decreases linearly with prestrain. Strain hardening exponent $n(\log \sigma / \log \varepsilon)$ and strength coefficient $k\left(\sigma / \varepsilon^{n} \dot{\varepsilon}^{m}\right)$ of prestrained CP-Ti at different strain rates are calculated in Figure 14b,c. The values of strain hardening exponent and strength coefficient almost keep constant at different strain rates, as shown in Figure $14 \mathrm{~b}, \mathrm{c}$. Both $n$ and $k$ decrease with prestrain. Based on experiment data, $m, n$ and $k$ as functions of prestrain were fitted as follows:

$$
\begin{gathered}
m=-0.17 \varepsilon_{\text {pre }}+0.03 \\
n=-1.19 \varepsilon_{\text {pre }}{ }^{0.87}+0.14 \\
k=-4440.70 \varepsilon_{\text {pre }}+859.49
\end{gathered}
$$
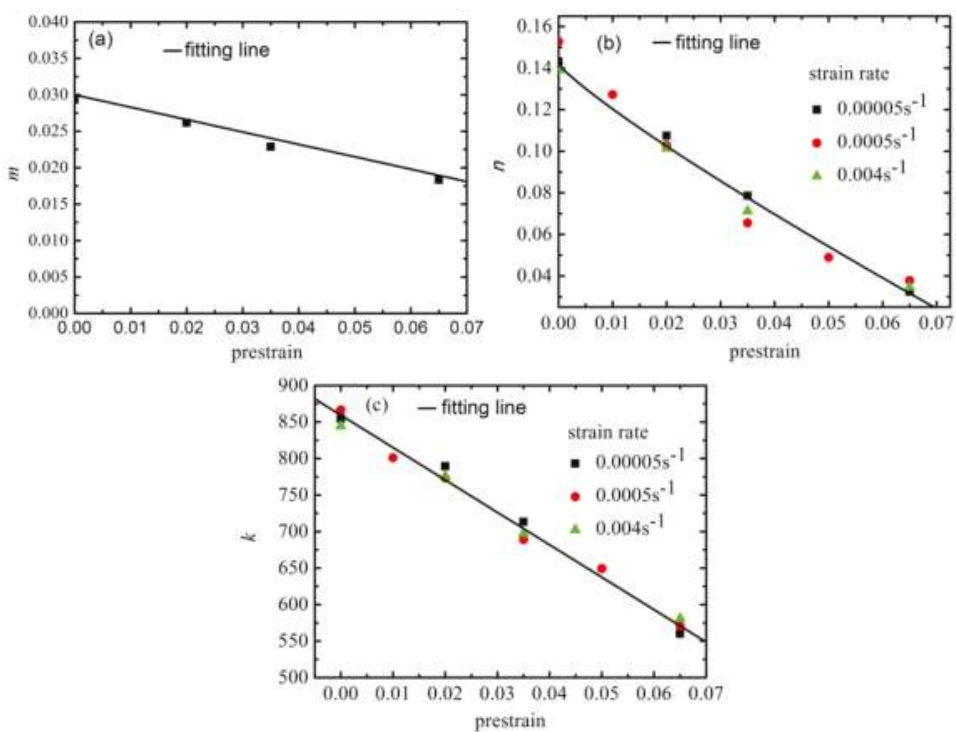

Figure 14. Variation of parameters with prestrain: (a) Strain rate sensitivity; (b) strain hardening exponent and (c) strength coefficient.

Thus, the modified Fields-Backofen model containing prestrain is finally obtained as follows:

$$
\sigma=\left(-4440.70 \varepsilon_{\text {pre }}+859.49\right) \varepsilon^{-1.19 \varepsilon_{\text {pre }}{ }^{0.87}+0.14} \dot{\varepsilon}^{-0.17 \varepsilon_{\text {pre }}+0.03}
$$

In order to investigate the prominence of the modified constitutive model, comparisons between the experimental data and the flow stress predicted by the modified constitutive model at different strain rates are shown in Figure 15. In addition, the predictability of the constitutive equation is verified via employing standard statistical parameters, such as absolute deviation $(\Delta A)$ and correlation coefficient $(R)$, as shown in Figure $15 \mathrm{a}-\mathrm{d}$. At different strain rates, the values of correlation coefficient $R$ in Figure 15a-d are above 0.97, hence the modified Fields-Backofen model shows a very high degree of goodness of fit. It is found that the absolute deviation of flow stress obtained from the modified constitutive model varies from 1.87 to $6.88 \mathrm{MPa}$. The constitutive equations gives the least absolute deviation of 1.87 at $0.004 \mathrm{~s}^{-1}$ of as-received CP-Ti and the largest absolute deviation of 6.88 
at $0.00005 \mathrm{~s}^{-1}$ of $3.5 \%$ prestrained sample. Thus, the proposed constitutive equation presents a good estimate of the plastic flow stress for prestrained CP-Ti at different strain rates.
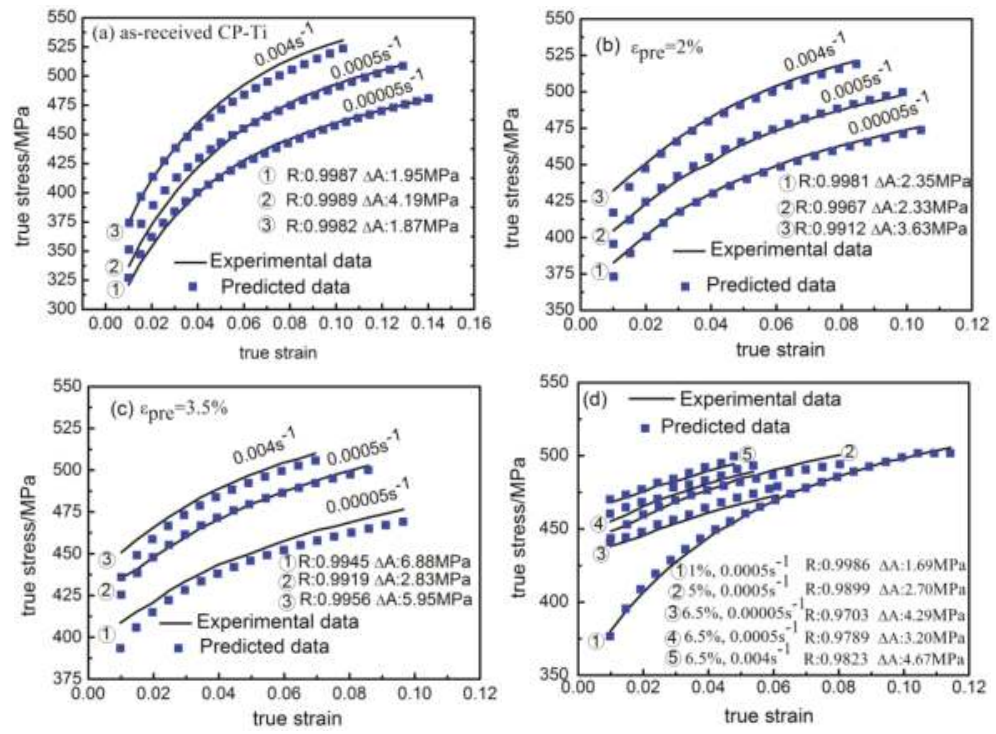

Figure 15. Comparison between the experimental and predicted flow stress data from the modified Fields-Backofen model: (a) as-received CP-Ti; (b) 2\% prestrained CP-Ti; (c) 3.5\% prestrained CP-Ti; (d) $1 \%, 5 \%, 6.5 \%$ prestrained CP-Ti.

\subsection{Fracture Behavior}

Scanning electron microscopy (SEM) images of the fracture surfaces of as-received CP-Ti were presented in Figure 16. SEM images of the fracture surfaces show that the fracture mode of as-received $\mathrm{CP}-\mathrm{Ti}$ is mostly ductile at room temperature. In Figure 16a, the central region is a crack propagation area with massive strong nests, and the outer region is a shear lip zone with shallow dimples and micro-pores. The central region shows more ductile deformation features than the outer shear-lip region, which has a flat surface with shallow dimples, as shown in Figure 16c,d. The mechanism for ductile crack growth can be characterized by micro-void nucleation, growth and coalescence. As the specimen is loaded, local strains and stresses at the crack tip become sufficient to nucleate void. These voids grow and link with the main crack [37].

The failure locations of prestrained and prestrained samples with annealing present pronounced necking feature, as shown in Figure 17 from macro view. The failure locations of all tested samples show that ragged fracture surface with some macro voids across the whole cross section of fracture surface, and relatively flat shear lip zone was detected in marginal area. Magnified images of central region of fracture surfaces were presented in Figure 18. It is obvious that the size of dimples shown in Figure 18d,f is larger than that in Figure $18 \mathrm{a}-\mathrm{c}$, the depth of dimples is much deeper and its distribution is more uniform. The more ductile deformation in prestrained CP-Ti after annealing indicates that the ductility of prestrained CP-Ti is improved by annealing. The increase in ductility is a result of high dislocation mobility, where the crack tip is proceeded by a plastic deformation mechanism that forms dense arrays of dimples without cleavage steps and facets [38]. 


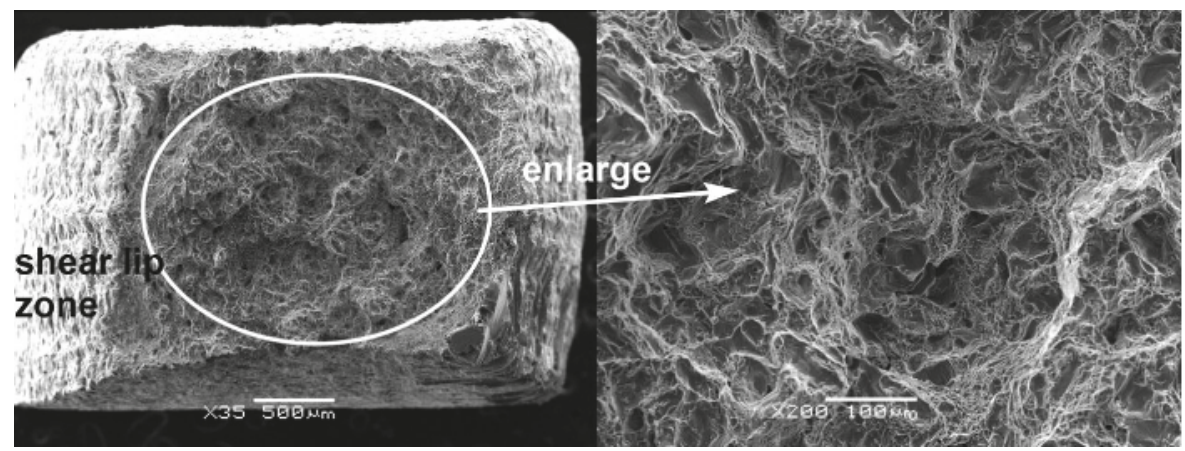

(a)

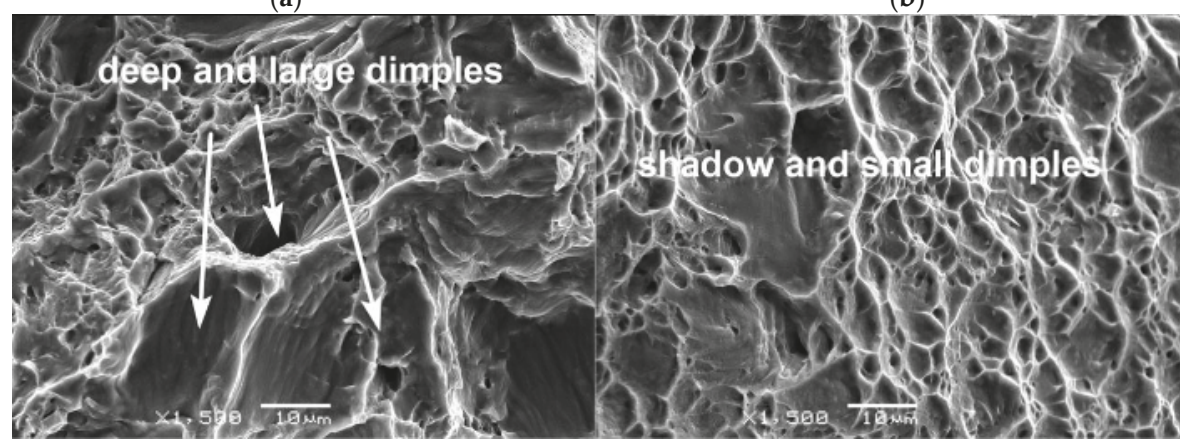

(c)

(d)

Figure 16. Micrographs of fractured surfaces of as-received CP-Ti with no prestrain: (a) macro view showing necking with microcracks and shear lip zone at the outer area; (b) magnified view of crack propagation region from central region in Figure 16a; (c) magnified image showing deep and large dimples from central region; (d) magnified image showing the shallow dimples at the shear-lip region.
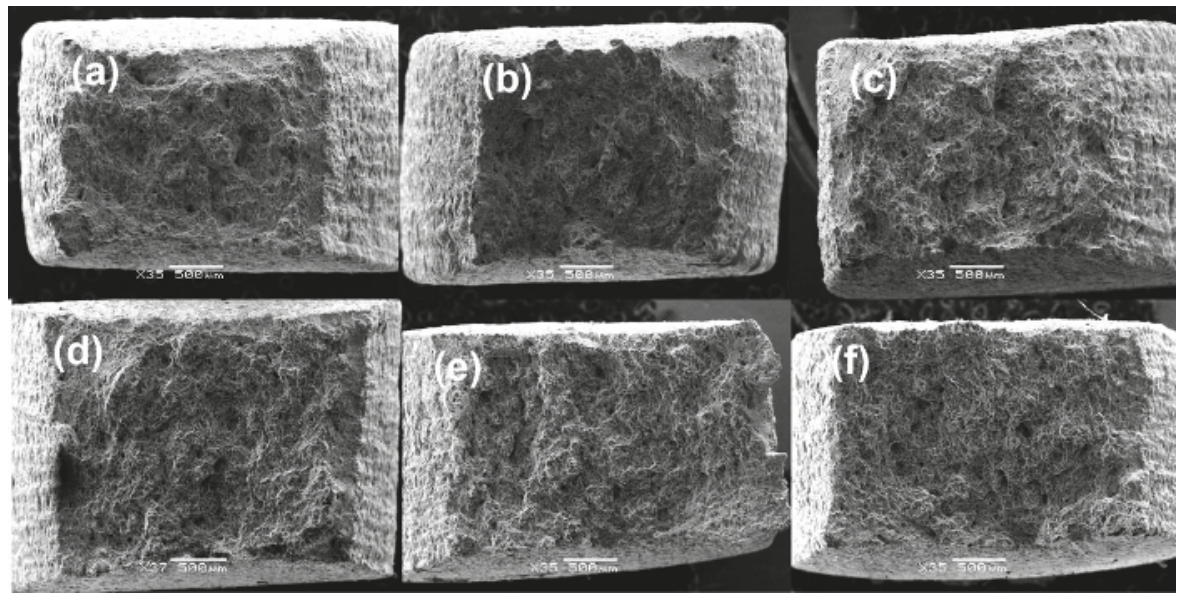

Figure 17. Macro view of fractured surfaces of prestrained CP-Ti: (a) $1 \%$ prestrained; (b) $3.5 \%$ prestrained; (c) $6.5 \%$ prestrained; (d) $1 \%$ prestrained with annealing; (e) $3.5 \%$ prestrained with annealing; (f) $6.5 \%$ prestrained with annealing. 


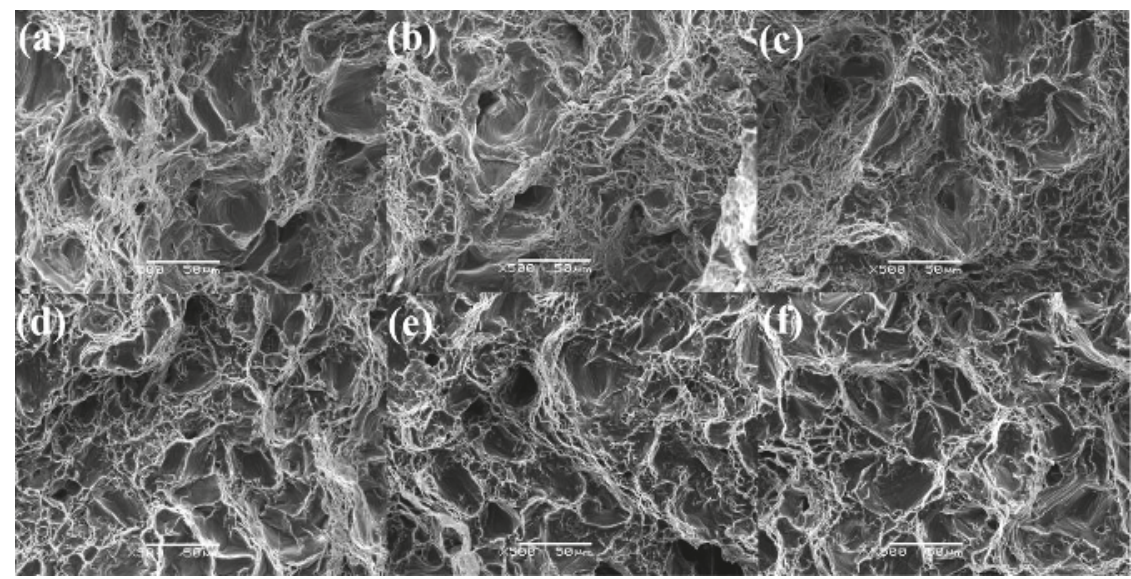

Figure 18. Micrographs of fractured surfaces of prestrained CP-Ti: (a) 1\% prestrained; (b) $3.5 \%$ prestrained; (c) $6.5 \%$ prestrained; (d) $1 \%$ prestrained with annealing; (e) $3.5 \%$ prestrained with annealing; (f) $6.5 \%$ prestrained with annealing.

\section{Conclusions}

In the present paper, the effect of prestrain and subsequent annealing on the mechanical behaviors of CP-Ti along cold rolling direction was investigated. The main results presented in this paper are as follows:

- Engineering yield strength and tensile strength increase with the tensile prestrain. The relationship between prestrain and yield strength can be described by power law. Elongation and uniform strain decrease linearly with increasing the tensile prestrain, and total strain is almost constant, which is slightly less than as-received CP-Ti.

- At the condition of prestrain higher than 3.5\%, yield plateau is observed in the engineering stress-strain curves. Through metallographic observations and heat treatment, considerable number of dislocations produced in prestrain is determined as the factor account for the appearance of yield plateau during reloading.

- Dislocations play an important role in strain hardening along cold rolling direction tension. With the increase of strain, the contribution on strain hardening from both the dislocation-associated mechanisms and other mechanisms increases.

- The strain rate sensitivity exponent, strain hardening exponent and strength coefficient decrease with the increase of prestrain. Flow stress of prestrained CP-Ti is predicted accurately by the modified Fields-Backofen model.

- With annealing at $500{ }^{\circ} \mathrm{C}$ and $40 \mathrm{~min}$, the $3.5 \%$ prestrained specimen shows the highest ductility, and its yield strength is enhanced. The more ductile deformation features on the fracture surfaces after annealing confirms that the ductility of prestrained CP-Ti can be improved by annealing.

Acknowledgments: The authors gratefully acknowledge the financial supports of the National Natural Science Foundation of China (51475223) and the Graduate Student Scientific Innovative Project of Jiangsu Province (KYLX15_0801).

Author Contributions: All contributed to the design of the experimental plan. Le Chang performed the experiments; Chang-Yu Zhou and Xiao-Hua He analyzed the data; Le Chang wrote the paper.

Conflicts of Interest: The authors declare no conflict of interest. 


\section{References}

1. Ahmed, I.I.; Grant, B.; Sherry, A.H.; Quinta, J. Deformation path effects on the internal stress development in cold worked austenitic steel deformed in tension. Mater. Sci. Eng. A 2014, 614, 326-337. [CrossRef]

2. Zhang, L.C.; Timokhina, I.B.; La Fontaine, A.; Ringer, S.P.; Hodgson, P.D.; Pereloma, E.V. Effect of pre-straining and bake hardening on the microstructure and mechanical properties of CMnSi TRIP steels. Metall. Ital. 2009, 101, 49-55.

3. Pereloma, E.; Beladi, H.; Zhang, L.C.; Timokhina, I. Understanding the behavior of advanced high-strength steels using atom probe tomography. Metall. Mater. Trans. A 2012, 43, 3958-3971. [CrossRef]

4. Baeka, J.; Kim, Y.; Kim, C.; Kim, W.; Seok, C. Effects of pre-strain on the mechanical properties of API 5L X65 pipe. Mater. Sci. Eng. A 2010, 527, 1473-1479. [CrossRef]

5. Robertson, L.T.; Hilditch, T.B.; Hodgson, P.D. The effect of prestrain and bake hardening on the low-cycle fatigue properties of TRIP steel. Int. J. Fatigue 2008, 30, 587-594. [CrossRef]

6. Lee, W.S.; Lin, C.F. Effects of prestrain and strain rate on dynamic deformation characteristics of 304L stainless steel: Part 1-Mechanical behavior. Mater. Sci. Technol. 2002, 18, 869-876. [CrossRef]

7. Lee, W.S.; Lin, C.F. Effects of prestrain and strain rate on dynamic deformation characteristics of $304 \mathrm{~L}$ stainless steel: Part 2-Microstructural study. Mater. Sci. Technol. 2002, 18, 877-884. [CrossRef]

8. Whittaker, M.T.; Evans, W.J. Effect of prestrain on the fatigue properties of Ti834. Int. J. Fatigue 2009, 31, 1751-1757. [CrossRef]

9. Whittaker, M.; Jones, P.; Pleydell-Pearce, C.; Rugg, D.; Williams, S. The effect of prestrain on low and high temperature creep in Ti834. Mater. Sci. Eng. A 2010, 527, 6683-6689. [CrossRef]

10. Song, Z.Y.; Sun, Q.Y.; Xiao, L.; Liu, L.; Sun, J. Effect of prestrain and aging treatment on microstructures and tensile properties of Ti-10Mo-8V-1Fe-3.5Al alloy. Mater. Sci. Eng. A 2010, 527, 691-698. [CrossRef]

11. Werber, A.; Liewald, M. Measurement and analysis of differential work hardening behavior of pure titanium sheet using spline function. Int. J. Mater. Form. 2011, 4, 193-204.

12. Wowk, D.; Pilkey, K. Effect of prestrain with a path change on the strain rate sensitivity of AA5754 sheet. Mater. Sci. Eng. A 2009, 520, 174-178. [CrossRef]

13. Sarker, D.; Friedman, J.; Chen, D.L. Influence of pre-strain on de-twinning activity in an extruded AM30 magnesium alloy. Mater. Sci. Eng. A 2014, 605, 73-79. [CrossRef]

14. Sarker, D.; Chen, D.L. Dependence of compressive deformation on pre-strain and loading direction in an extruded magnesium alloy: Texture, twinning and de-twinning. Mater. Sci. Eng. A 2014, 596, 134-144. [CrossRef]

15. Hama, T.; Nagao, H.; Kuchinomachi, Y.; Takuda, H. Effect of pre-strain on work-hardening behavior of magnesium alloy sheets upon cyclic loading. Mater. Sci. Eng. A 2014, 591, 69-77. [CrossRef]

16. Chen, L.; Li, J.; Zhang, Y.; Lu, W.; Zhang, L.C.; Wang, L.; Zhang, D. Effect of low-temperature pre-deformation on precipitation behavior and microstructure of a $\mathrm{Zr}-\mathrm{Sn}-\mathrm{Nb}-\mathrm{Fe}-\mathrm{Cu}-\mathrm{O}$ alloy during fabrication. J. Nucl. Sci. Technol. 2016, 53, 496-507. [CrossRef]

17. Zherebtsov, S.V.; Dyakonov, G.S.; Salem, A.A.; Malysheva, S.P.; Salishchev, G.; Semiatin, S.L. Evolution of grain and subgrain structure during cold rolling of commercial-purity titanium. Mater. Sci. Eng. A 2011, 528, 3474-3479. [CrossRef]

18. Chun, Y.B.; Yu, S.H.; Semiatin, S.L.; Hwang, S.K. Effect of deformation twinning on microstructure and texture evolution during cold rolling of CP-titanium. Mater. Sci. Eng. A 2005, 398, 209-219. [CrossRef]

19. Nasiri-Abarbekoh, H.; Ekrami, A.; Ziaei-Moayyed, A.A.; Shohani, M. Effects of rolling reduction on mechanical properties anisotropy of commercially pure titanium. Mater. Des. 2012, 34, 268-274. [CrossRef]

20. Chichili, D.R.; Ramseh, K.T.; Hemker, K.J. The high-strain-rate response of alpha-titanium: Experiments, deformation mechanisms and modeling. Acta Mater. 1998, 46, 1025-1043. [CrossRef]

21. Peng, J.; Zhou, C.Y.; Dai, Q.; He, X.H. The temperature and stress dependent primary creep of CP-Ti at low and intermediate temperature. Mater. Sci. Eng. A 2014, 611, 123-135. [CrossRef]

22. Zhao, X.C.; Yang, X.R.; Liu, X.Y.; Wang, C.T.; Huang, Y.; Langdon, T.G. Processing of commercial purity titanium by ECAP using a 90 degrees die at room temperature. Mater. Sci. Eng. A 2014, 607, 482-489. [CrossRef]

23. Sordi, V.L.; Ferrante, M.; Kawasaki, M.; Langdon, T.G. Microstructure and tensile strength of grade 2 titanium processed by equal-channel angular pressing. J. Mater. Sci. 2012, 47, 7870-7876. [CrossRef] 
24. Roodposhit, P.S.; Farahbakhsh, N.; Sarkar, A.; Murty, K.L. Microstructural approach to equal channel angular processing of commercially pure titanium-A review. T. Nonferr. Metal. Soc. 2015, 25, 1353-1366. [CrossRef]

25. Salem, A.A.; Kalidindi, S.R.; Doherty, R.D. Strain hardening of titanium: Role of deformation twinning. Acta Mater. 2003, 51, 4225-4237. [CrossRef]

26. Salem, A.A.; Kalidindi, S.R.; Doherty, R.D. Strain hardening regimes and microstructure evolution during large strain compression of high purity titanium. Scr. Mater. 2002, 46, 419-423. [CrossRef]

27. Becker, H.; Pantleon, W. Work-hardening stages and deformation mechanism maps during tensile deformation of commercially pure titanium. Comp. Mater. Sci. 2013, 76, 52-59. [CrossRef]

28. Hama, T.; Nagao, H.; Kobuki, A.; Fujimoto, H.; Takuda, H. Work-hardening and twinning behaviors in a commercially pure titanium sheet under various loading paths. Mater. Sci. Eng. A 2015, 620, 390-398. [CrossRef]

29. Li, L.; Zhang, Z.; Shen, G. Effect of Grain Size on the Tensile Deformation Mechanisms of Commercial Pure Titanium as Revealed by Acoustic Emission. J. Mater. Eng. Perform. 2015, 24, 1975-1986. [CrossRef]

30. Ghaderi, A.; Barnett, M. Sensitivity of deformation twinning to grain size in titanium and magnesium. Acta Mater. 2011, 59, 7824-7839. [CrossRef]

31. Amouzou, K.E.A.; Richeton, T.; Roth, A.; Lebyodkin, M.A.; Lebedkina, T.A. Micromechanical modeling of hardening mechanisms in commercially pure $\alpha$-titanium in tensile condition. Int. J. Plast. 2016, 80, 222-240. [CrossRef]

32. Won, W.J.; Park, K.T.; Hong, S.G.; Lee, C.S. Anisotropic yielding behavior of rolling textured high purity titanium. Mater. Sci. Eng. A 2015, 637, 215-221. [CrossRef]

33. Roth, A.; Lebyodkin, M.A.; Lebedkina, T.A.; Lecomte, J.S.; Richeton, T.; Amouzou, K.E.A. Mechanisms of anisotropy of mechanical properties of $\alpha$-titanium in tension conditions. Mater. Sci. Eng. A 2014, 596, 236-243. [CrossRef]

34. Barkia, B.; Doquet, V.; Couzini, J.; Guillot, I.; Hripre, E. In situ monitoring of the deformation mechanisms in titanium with different oxygen contents. Mater. Sci. Eng. A 2015, 636, 91-102. [CrossRef]

35. Shi, J.; Sha, A.X. GJB 3763A. In Heat Treatment for Titanium and Titanium Alloys; Defense Science and Technology Industry Committee: Beijing, China, 2004.

36. Fields, D.S.; Backofen, W.A. Determination of strain hardening characteristics by torsion testing. Proc. Am. Soc. Test. Mater. 1957, 57, 1259-1272.

37. Chuluunbat, T.; Lu, C.; Kostryzhev, A.; Tieu, K. Investigation of X70 line pipe steel fracture during single edge-notched tensile testing using acoustic emission monitoring. Mater. Sci. Eng. A 2015, 640, 471-479. [CrossRef]

38. Chauhan, A.; Litvinov, D.; Aktaa, J. High temperature tensile properties and fracture characteristics of bimodal 12Cr-ODS steel. J. Nucl. Mater. 2016, 468, 1-8. [CrossRef]

(c) 2017 by the authors. Licensee MDPI, Basel, Switzerland. This article is an open access article distributed under the terms and conditions of the Creative Commons Attribution (CC BY) license (http://creativecommons.org/licenses/by/4.0/). 


\title{
Article \\ High Temperature Oxidation and Wear Behaviors of Ti-V-Cr Fireproof Titanium Alloy
}

\author{
Guangbao Mi ${ }^{1}$, Kai Yao ${ }^{2}$, Pengfei Bai ${ }^{2}$, Congqian Cheng ${ }^{2}$ and Xiaohua Min ${ }^{2, *}$ \\ 1 Key Laboratory of Science and Technology on Advanced Titanium Alloys, AECC Beijing Institute of \\ Aeronautical Materials, Beijing 100095, China; miguangbao@163.com \\ 2 School of Materials Science and Engineering, Dalian University of Technology, Dalian 116024, China; \\ kaiyao@mail.dlut.edu.cn (K.Y.); bpf2014@mail.dlut.edu.cn (P.B.); cqcheng@dlut.edu.cn (C.C.) \\ * Correspondence: minxiaohua@dlut.edu.cn; Tel.: +86-411-8470-8189
}

Received: 26 April 2017; Accepted: 14 June 2017; Published: 19 June 2017

\begin{abstract}
The high temperature oxidation and wear behaviors of Ti-35V-15Cr-0.3Si-0.1C fireproof titanium alloy were examined at 873 and $1073 \mathrm{~K}$. The oxidation weight gain after oxidation at $1073 \mathrm{~K}$ for $100 \mathrm{~h}$ was significantly larger than that at $873 \mathrm{~K}$. Based on the analyses of the oxidation reaction index and oxide layer, the oxidation process at $1073 \mathrm{~K}$ was mainly controlled by oxidation reaction at the interface between the substrate and oxide layer. Dry sliding wear tests were performed on a pin-on-disk tester in air conditions. The friction coefficient was smaller at $1073 \mathrm{~K}$ than that at $873 \mathrm{~K}$, while the volume wear rate at $1073 \mathrm{~K}$ was larger due to formation of amount of oxides on the worn surface. When the wearing temperature increased from 873 to $1073 \mathrm{~K}$, the wear mechanism underwent a transition from a combination of abrasive wear and oxidative wear to only oxidative wear.
\end{abstract}

Keywords: titanium alloy; fireproof; oxidation; high temperature wear; mechanism

\section{Introduction}

Titanium and its alloys are widely used in aerospace, chemical, and biomedical industries because of high specific strength and excellent corrosion resistance, especially for their applications in aero-engines [1-3]. However, conventional titanium alloys can be ignited and burned, known as "titanium fire," under specific conditions of high temperature, high pressure, and high-speed airflow, which limits their application for advanced aero-engines [4-6]. With the improvement of the thrust-weight ratio, the work conditions of components such as the case, blade, and disk becomes more complex and severe, resulting in an increase in the occurrence of titanium fire. Compared with other techniques including structural optimization design, surface alloying, and surface coating, the development of advanced fireproof titanium alloys is more desirable to completely prevent the occurrence of titanium fire in aero-engines, as well as to meet its high thrust-weight ratio $[4,7]$.

Titanium fire is known to a typical accident of igniting, which occurs usually through high-energy friction and load impact as an ignition source, for example, between the blade and case. The whole combustion behavior goes through high temperature oxidation, super high temperature oxidation, burning, self-sustained combustion, and burning out [4]. If titanium alloys are ignited, the components in the compressor burn continually only for 4-20 s under gas flow with high temperature and pressure. The burning time is too short to take extinguishing measures. There are two types of fireproof titanium alloys: Ti-V-Cr base alloys, such as Ti-35V-15Cr (Alloy C), Ti-35V-15Cr-0.6Si-0.05C (Alloy $\mathrm{C}^{+}$), Ti-25V-15Cr-2Al-0.2C, Ti-25V-15Cr-0.2Si (Ti40), and Ti-35V-15Cr-0.3Si-0.1C (TF550) alloys [8-11]; and Ti-Cu-Al base alloys, such as Ti-13Cu-4Al-4Mo-2Zr (BTT-1), Ti-18Cu-2Al-2Mo (BTT-3), and Ti-13Cu-1Al-0.2Si (Ti14) [12-14]. Note that abovementioned and other compositions in this study are expressed in mass $\%$. Ti-V-Cr base alloys are highly stabilized $\beta$-type titanium alloys with better performance than that of $\mathrm{Ti}-\mathrm{Cu}-\mathrm{Al}$ base alloys. 
In case of TF550 fireproof titanium alloy, we previously investigated the fireproof behavior by the frictional ignition method, and found that the presence of oxides on the worn surface such as $\mathrm{TiO}_{2}$, $\mathrm{V}_{2} \mathrm{O}_{5}$, and $\mathrm{Cr}_{2} \mathrm{O}_{3}$ affected the lubrication behavior in the local area of friction [15-17]. However, the high temperature oxidation and wear behaviors remain unclear for this alloy, which are considered to be closely associated with their fireproof properties. The shortage of studies results in uncertainty of the fireproof level of titanium alloys used in aero-engines and restricts the material selection of fireproof titanium alloys for engine designers. Thus, the purpose of present study is to examine the oxidation and wear behaviors of TF550 alloy at high temperatures of 873 and $1073 \mathrm{~K}$, and to discuss the mechanisms of high temperature oxidation and wear.

\section{Experimental Procedures}

\subsection{Materials Preparation}

An ingot of approximately $150 \mathrm{~kg}$ of TF550 alloy was fabricated by consumable vacuum arc melting (ZHT-650, Baoji institute of rare metal research, Baoji, China) with the raw materials of titanium sponge, pure vanadium rods, and chromium sponge. Subsequently, it was subjected to sheathed extrusion, forging and rolling, and its actual composition was Ti-35.5V-14.6Cr-0.32Si-0.11C. For oxidation testing, samples with a dimension of $12 \mathrm{~mm}(l) \times 10 \mathrm{~mm}(w) \times 6 \mathrm{~mm}(t)$ were cut from the rolled plate and their surfaces were mechanically polished with $\mathrm{SiC}$ abrasive paper in order to evaluate their high temperature oxidation behavior. As-received Ti-6Al-4V alloy was used to evaluate the oxidation behavior as a comparison. For wear testing, pins and disks were also cut from the rolled plate (HQ1UP, Hanqi Company, Suzhou, China). The rod as pins was designed in the form of a cylinder with a diameter of $5 \mathrm{~mm}$ and a height of $9 \mathrm{~mm}$, and the contact surface was a half-ball with a diameter of $5 \mathrm{~mm}$. Disks with the dimensions of $25 \mathrm{~mm}$ diameter and $10 \mathrm{~mm}$ thickness were used. The contact surfaces of pins and disks were mechanically polished (UNIPOL-1200M, Kejing Company, Shenyang, China) with $\mathrm{SiC}$ abrasive paper and then cleaned in alcohol.

\subsection{Oxidation Testing}

Before oxidation testing, the samples and crucibles were ultrasonically cleaned (XY-CS-S, Xinyi Company, Shanghai, China) in alcohol. In addition, the crucibles were baked at $1373 \mathrm{~K}$ for $20 \mathrm{~h}$ to ensure their constant weight during the whole oxidation process. Oxidation tests were carried out at 873 and $1073 \mathrm{~K}$ for a total oxidation time of $100 \mathrm{~h}$. During the oxidation period, they were cooled down to room temperature at an interval of $10 \mathrm{~h}$ in order to measure their weight and observe their surface morphology. Oxidation kinetics were examined based on the weight gain per unit area versus oxidation time.

\subsection{Wear Testing}

Dry sliding wear tests were performed on a pin-on-disk tester (THT-04015, CSM Company, Carouge, Switzerland) in air conditions at temperatures of 873 and $1073 \mathrm{~K}$. A pin was loaded against a rotating disk through the mechanical loading system with a normal load of $4.9 \mathrm{~N}$ for $30 \mathrm{~min}$. The sliding velocity was $0.2 \mathrm{~m} / \mathrm{s}$ along a diameter of $10 \mathrm{~mm}$ circular path with total sliding distance of $3.6 \times 10^{2} \mathrm{~m}$, which was proved to be sufficient to attain a steady-state condition [18-21]. The friction coefficient was recorded by the tester automatically, and the mean friction coefficient was calculated based on the whole data, which was recorded during the sliding wear tests. Volume wear rate was calculated as follows:

$$
W s=\Delta V /(P L)
$$

where $\Delta V, P$, and $L$ are the volume loss of disk, applied loading and sliding distance, respectively. For the disk, four different regions of the wearing indent were measured by using nanomap-3D microscopy (AEP Company, Columbus, OH, USA) for 3D micrograph and the corresponding cross-section area of the wearing indent, and then the volume loss was obtained by the mean 
cross-section area multiplied by the circumference of the wearing indent. For the pin, the volume loss was obtained by the wearing volume of the half-ball of pin.

\subsection{Microstructural Characterization}

Phase identification was made by X-ray diffraction analysis (XRD) using an EMPYREN diffractometer with $\mathrm{Cu}-\mathrm{K} \alpha$ radiation operated at $40 \mathrm{kV}$ and $300 \mathrm{~mA}$ (Panalytical, Almelo, The Netherlands). Morphologies including backscattered electron image (BEI) and secondary electron image (SEI), and chemical compositions were examined by a SUPRA55 type scanning electron microscope (SEM, Carl Zeiss Jena Company, Oberkochen, Germany) equipped with an energy dispersive spectrometer (EDS).

\section{Results and Discussion}

Figure 1 shows the oxidation kinetics curves of TF550 alloy along with Ti-6Al-4V alloy after oxidation at 873 and $1073 \mathrm{~K}$ for $100 \mathrm{~h}$. As shown in Figure 1a, with increasing oxidation time, the oxidation weight gain of each alloy showed an increase tendency, and it was much larger at $1073 \mathrm{~K}$ than that at $873 \mathrm{~K}$. The oxidation weight gain of TF550 alloy was $2 \mathrm{mg} / \mathrm{cm}^{2}$ after oxidation at $873 \mathrm{~K}$ for $100 \mathrm{~h}$, which was similar with that $\left(1.4 \mathrm{mg} / \mathrm{cm}^{2}\right)$ of Ti-6Al-4V alloy, while the oxidation weight gain of TF550 alloy $\left(90 \mathrm{mg} / \mathrm{cm}^{2}\right)$ was larger than that $\left(40 \mathrm{mg} / \mathrm{cm}^{2}\right)$ of Ti-6Al-4V alloy at $1073 \mathrm{~K}$. The smaller oxidation weight gain of Ti-6Al-4V alloy was attributed to the formation of the compact $\mathrm{Al}_{2} \mathrm{O}_{3}$ layer, which could prevent the further oxidation of the substrate [22,23]. Although the oxidation weight gain of Ti-6Al-4V alloy was smaller than that of TF550 alloy, the oxide layer of Ti-6Al-4V alloy flaked seriously at $1073 \mathrm{~K}$, as shown in Figure 2a. While $\mathrm{V}_{2} \mathrm{O}_{5}$ which formed in the oxide layer of TF550 alloy, it melted and flowed into the crucible (yellow matters in Figure 2b) due to its low melting point (about $948 \mathrm{~K}$ ) [24,25]. The formation of $\mathrm{V}_{2} \mathrm{O}_{5}$ in TF550 alloy at high temperatures improved the wear properties resulting from their lubrication, which could enhance its burn-resistant behavior. The detailed discussion is shown in Section 3.

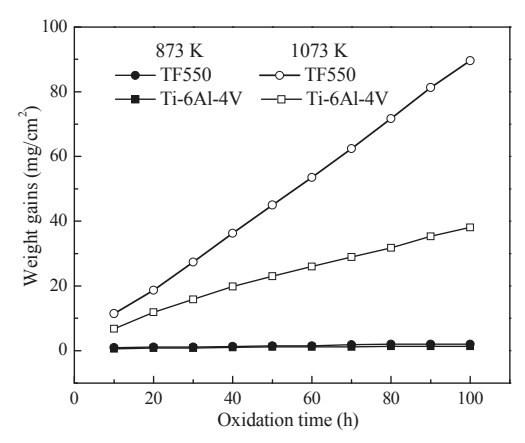

(a)

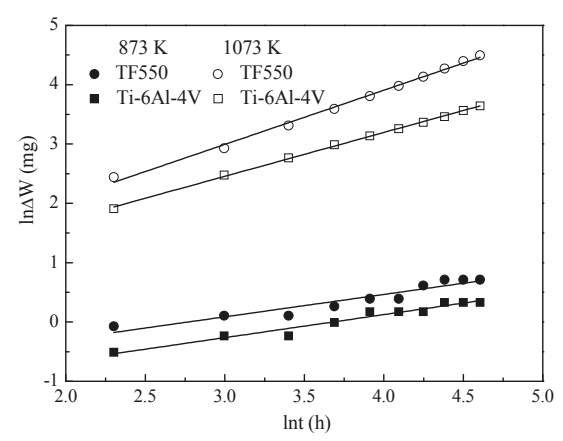

(b)

Figure 1. Oxidation kinetics curves of TF550 alloy along with Ti-6Al-4V alloy at temperatures of 873 and 1073 K. (a) Oxidation weight gain curves and (b) double logarithmic curves. 


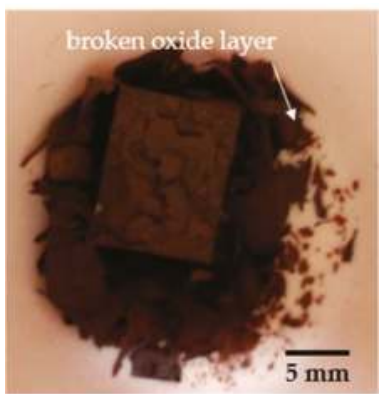

(a)

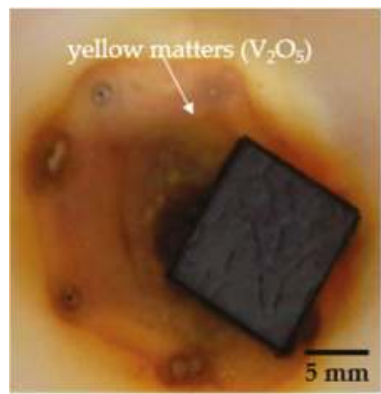

(b)

Figure 2. Macroscopic morphologies of TF550 alloy along with Ti-6Al-4V alloy after oxidation at $1073 \mathrm{~K}$ for $100 \mathrm{~h}$. (a) Ti-6Al-4V and (b) TF550.

Figure 3 shows the $\mathrm{X}$-ray diffraction profiles of TF550 alloy at 873 and $1073 \mathrm{~K}$ for $100 \mathrm{~h}$. The surface oxide product was identified as $\mathrm{TiO}_{2}$ and $\mathrm{V}_{2} \mathrm{O}_{5}$ at $873 \mathrm{~K}$, while it was detected to be only $\mathrm{TiO}_{2}$ at $1073 \mathrm{~K}$. In addition, the peak intensity of $\mathrm{V}_{2} \mathrm{O}_{5}$ was weaker than that of $\mathrm{TiO}_{2}$ at $873 \mathrm{~K}$. Based on the oxidation kinetic relationship [26],

$$
\Delta W=k t^{n}
$$

where $\Delta W$ is the oxidation weight gain, $n$ is the oxidation reaction index and $t$ is the oxidation time, respectively. The oxidation reaction index $(n)$ could be obtained to discuss the oxidation mechanism [26-29]. For example, when $n$ is equal to 1 , the oxidation reaction rate follows the linear law and the oxidation process is controlled by the reaction rate of oxygen and the substrate. When $n$ is equal to 0.5 , the oxidation reaction rate follows the parabolic law and the oxidation process is controlled by the diffusion of reactants in the oxide film. Based on the oxidation weight gain curves (Figure 1a), oxidation reaction indices were obtained through double logarithmic transformation, as shown in Figure 1b. However, considering the influencing factors of a lower oxidation weight gain and measurement deviation at $873 \mathrm{~K}$, it was difficult to discuss the oxidation mechanism of TF550 alloy based only on the oxidation reaction index.

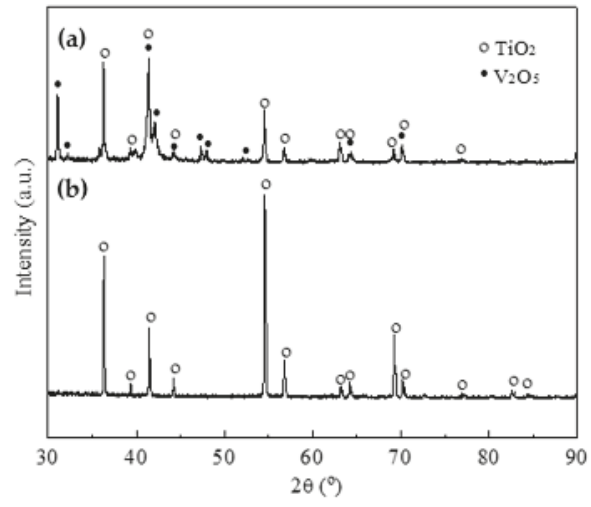

Figure 3. X-ray diffraction (XRD) profiles of TF550 alloy after oxidation at different temperatures for 100 h. (a) $873 \mathrm{~K}$ and (b) $1073 \mathrm{~K}$.

Figure 4a shows the morphology of the oxide layer in TF550 alloy after oxidation at $873 \mathrm{~K}$ for $100 \mathrm{~h}$, by SEM observation. The average thickness of the oxide layer was measured to be $7 \mu \mathrm{m}$. Figure $4 \mathrm{~b}-\mathrm{f}$ 
show the EDS mapping of main elements of $\mathrm{Ti}, \mathrm{V}, \mathrm{Cr}, \mathrm{Si}$, and $\mathrm{O}$. The concentration of $\mathrm{O}$ element in the oxide layer was higher than that of the substrate, while those of Ti and $\mathrm{V}$ elements in the oxide layer were lower. Combined with XRD results (Figure 3), the surface oxide layer consisted of $\mathrm{TiO}_{2}$ and $\mathrm{V}_{2} \mathrm{O}_{5}$. Consequently, the oxidation process of TF550 alloy at $873 \mathrm{~K}$ was deduced to be controlled by the oxidation reaction at the interface between the substrate and oxide layer.

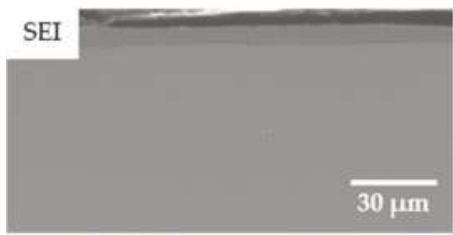

(a)

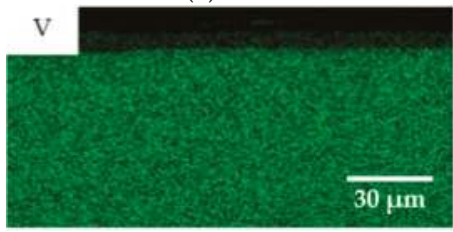

(c)

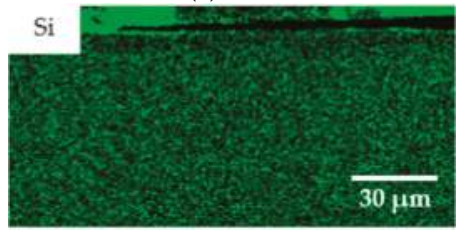

(e)

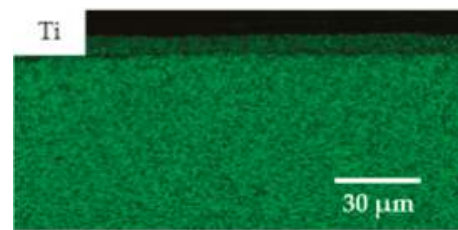

(b)

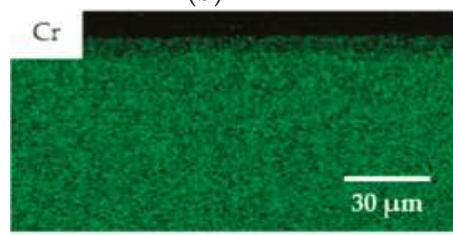

(d)

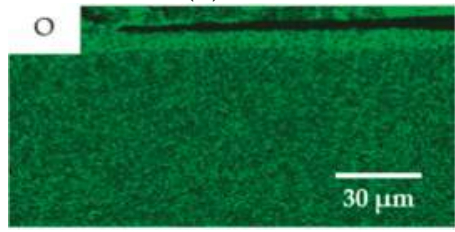

(f)

Figure 4. Scanning electron microscope (SEM) morphology and energy dispersive spectrometer (EDS) mapping of the oxide layer in TF550 alloy after oxidation at $873 \mathrm{~K}$ for $100 \mathrm{~h}$. (a) Secondary electron image (SEI); (b) Ti element; (c) V element; (d) Cr element; (e) Si element; and (f) O element.

After oxidation at $1073 \mathrm{~K}$ for $100 \mathrm{~h}$, the oxidation reaction index of TF550 alloy was analyzed to be 0.91 , which was slightly larger than that $(0.71)$ of Ti- $6 \mathrm{Al}-4 \mathrm{~V}$ alloy. The average thickness of the oxide layer as shown in Figure $5 \mathrm{a}$ was $460 \mu \mathrm{m}$ after oxidation at $1073 \mathrm{~K}$, which was much thicker than that of the oxide layer at $873 \mathrm{~K}$. Based on the EDS mapping from Figure $5 \mathrm{~b}-\mathrm{f}$, the Ti and $\mathrm{O}$ elements were clearly detected in the oxide layer, indicating that the oxide layer mainly consisted of $\mathrm{TiO}_{2}$ combined with XRD results (Figure 3). The detected $\mathrm{Si}$ element on the top of Figures $4 \mathrm{e}$ and $5 \mathrm{e}$ was a residual polishing solution $\left(\mathrm{SiO}_{2}\right)$, which was considered to have no effect on the oxidation mechanism. Thus, the oxidation reaction rate at $1073 \mathrm{~K}$ followed the linear law and its oxidation process was controlled by the oxidation reaction at the interface between the substrate and oxide layer [26]. As shown in Figure $5 c$, the $\mathrm{V}$ element was clearly identified in the oxide layer, while the $\mathrm{V}_{2} \mathrm{O}_{5}$ was not detected by XRD as shown in Figure 3. Due to the low melting point of $\mathrm{V}_{2} \mathrm{O}_{5}$, they flowed into the crucible rather than adhered to the specimen, resulting in an absence of $\mathrm{V}_{2} \mathrm{O}_{5}$, which was in accordance with aforementioned occurrence of yellow matters in the crucible (Figure 2b). Furthermore, a positive concentration gradient of $\mathrm{V}$ occurred from the substrate to the surface due to the continuous consumption of $\mathrm{V}_{2} \mathrm{O}_{5}$ in the oxide layer, which accelerated the diffuse rate of $\mathrm{V}$ [30]. Consequently, $\mathrm{V}$ element was clearly detected in the oxide layer in terms of the EDS analysis. 


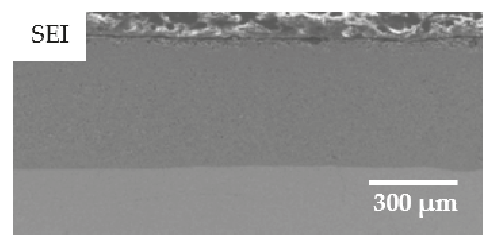

(a)

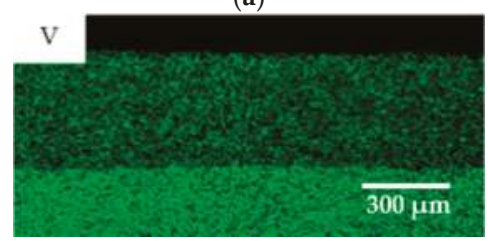

(c)

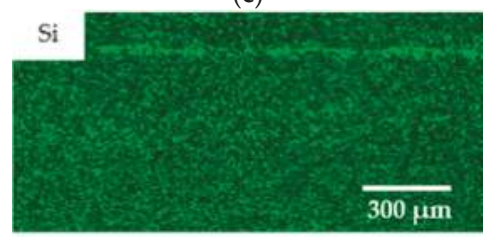

(e)

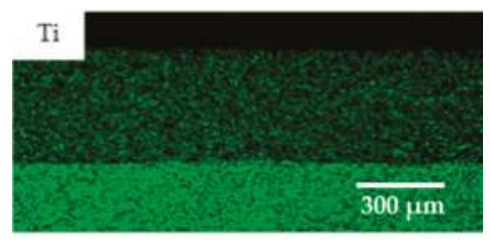

(b)

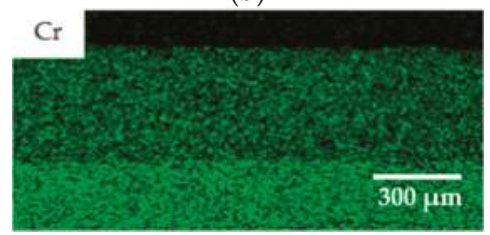

(d)

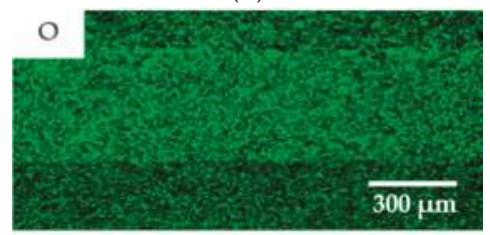

(f)

Figure 5. SEM morphology and EDS mapping of the oxide layer in TF550 alloy after oxidation at 1073 K for 100 h. (a) SEI; (b) Ti element; (c) V element; (d) Cr element; (e) Si element; and (f) O element.

Figure 6 shows the friction coefficients of TF550 alloy as a function of wearing time at 873 and $1073 \mathrm{~K}$. The friction coefficient at $873 \mathrm{~K}$ was largely fluctuated with wearing time up to $10 \mathrm{~min}$, and then reached a steady-state condition. Compared with $873 \mathrm{~K}$, the friction coefficient at $1073 \mathrm{~K}$ became smaller, and its fluctuation became much weaker. The mean friction coefficient $\left(f_{\mathrm{m}}\right)$ at 873 and $1073 \mathrm{~K}$, as listed in Table 1, were calculated to be 0.394 and 0.286 , respectively. On the other hand, the volume wear rate of the disk $\left(W_{\mathrm{sd}}\right)$ at $873 \mathrm{~K}$ was obtained to be $2.21 \times 10^{-13} \mathrm{~m}^{3} / \mathrm{Nm}$ (Table 1$)$, while it could not be measured at $1073 \mathrm{~K}$ because of the amount of oxides formed on the worn surface. For a comparison, the volume wear rate of the pin $\left(W_{\mathrm{sp}}\right)$ at $873 \mathrm{~K}$ was $0.197 \times 10^{-13} \mathrm{~m}^{3} / \mathrm{Nm}$, which was smaller than that $\left(0.566 \times 10^{-13} \mathrm{~m}^{3} / \mathrm{Nm}\right)$ of the pin at $1073 \mathrm{~K}$ (Table 1$)$. Figure 7 shows the XRD profiles of worn surfaces for disks at different testing temperatures. Besides the $\beta$-phase, weak peaks of $\mathrm{TiO}_{2}$ were detected on the worm surface at $873 \mathrm{~K}$. Only peaks for both oxides, i.e., $\mathrm{TiO}_{2}$ and $\mathrm{V}_{2} \mathrm{O}_{5}$, were present at $1073 \mathrm{~K}$, while the peaks of the $\beta$-phase disappeared.

Table 1. Mean friction coefficient $\left(f_{\mathrm{m}}\right)$, volume wear rate of the disk $\left(W_{\mathrm{sd}}\right)$, and the pin $\left(W_{\mathrm{sp}}\right)$ in TF550 alloy after wearing at high temperatures of 873 and $1073 \mathrm{~K}$.

\begin{tabular}{|c|c|c|c|}
\hline Temperature (K) & $f_{\mathrm{m}}$ & $W_{\text {sd }}\left(10^{-13} \cdot \mathrm{m}^{3} / \mathrm{Nm}\right)$ & $W_{\mathrm{sp}}\left(10^{-13} \cdot \mathrm{m}^{3} / \mathrm{Nm}\right)$ \\
\hline 873 & $0.394 \pm 0.095$ & $2.21 \pm 0.35$ & $0.197 \pm 0.072$ \\
\hline 1073 & $0.286 \pm 0.050$ & - & $0.566 \pm 0.039$ \\
\hline
\end{tabular}




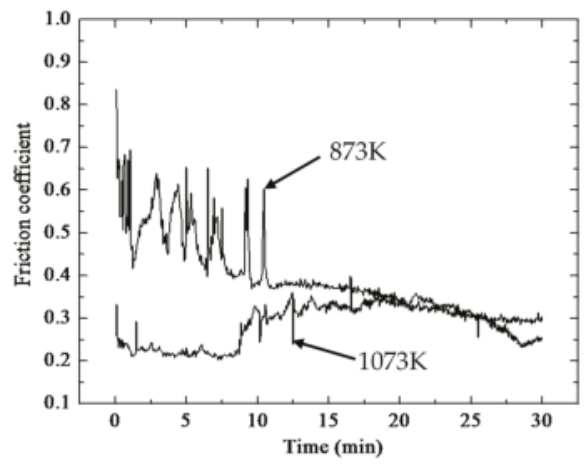

Figure 6. Friction coefficient curves of TF550 alloy as a function of wearing time at high temperatures of 873 and $1073 \mathrm{~K}$.

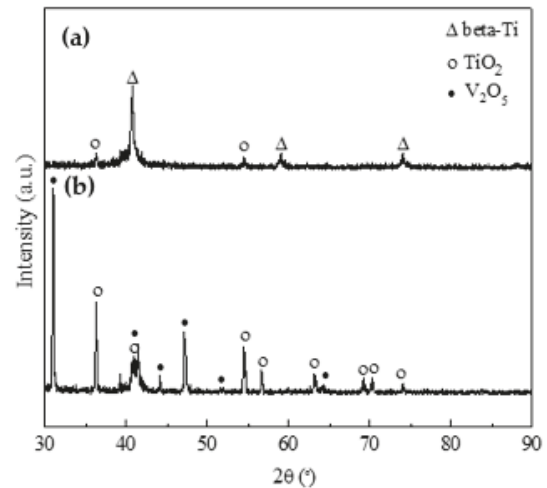

Figure 7. X-ray diffraction profiles of worn surfaces in TF550 alloy after wearing at high temperatures.

(a) $873 \mathrm{~K}$ and (b) $1073 \mathrm{~K}$.

Figure 8a shows the morphology of worn surfaces with a width of the wearing indent equal to about $1.2 \mathrm{~mm}$ at $873 \mathrm{~K}$. Furrows indicated by arrows in Figure $8 \mathrm{~b}$ were readily identified on the worn surface. Black smooth regions were also observed, which were regarded as tribo-layers containing the oxide of $\mathrm{TiO}_{2}$ in terms of the EDS analysis (Figure 8c). In addition, some white particles consisting of not only metal debris but also the oxide of $\mathrm{TiO}_{2}$ were confirmed by the EDS analysis as well (Figure 8d). Figure 9 shows the morphologies and compositions of worn surfaces at $1073 \mathrm{~K}$. An average width of the wearing indent was $1.6 \mathrm{~mm}$, and snowflake-like features were present on the worn surface (Figure 9a). The furrows were not observed and few black smooth regions appeared, as shown in Figure $9 \mathrm{~b}$; instead, a large amount of particles were present on the worn surface. The particles were further observed in Figure $9 \mathrm{c}$ and they were confirmed to be a mixture of the oxides of $\mathrm{TiO}_{2}$ and $\mathrm{V}_{2} \mathrm{O}_{5}$, as shown in Figure 9d. Figure 10 shows the morphologies of the cross-section near the worn surfaces at 873 and $1073 \mathrm{~K}$. The tribo-layer with an average thickness of $4 \mu \mathrm{m}$ formed on the worn surface at $873 \mathrm{~K}$ (Figure 10a). However, this tribo-layer was not compact and it contained trace oxide of $\mathrm{TiO}_{2 .}$, identified by EDS in Figure 10b. At $1073 \mathrm{~K}$, the tribo-layer became thicker $(7 \mu \mathrm{m})$ and more continuous, and it contacted with the matrix compactly in Figure 10c. This tribo-layer was identified as both $\mathrm{TiO}_{2}$ and $\mathrm{V}_{2} \mathrm{O}_{5}$ oxides by EDS in Figure $10 \mathrm{~d}$. 


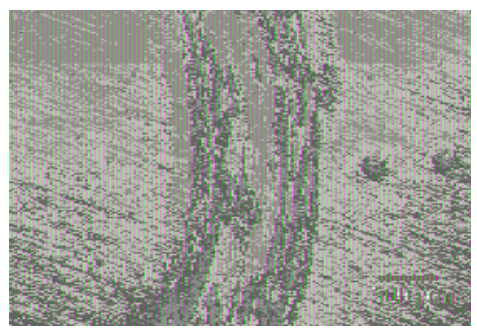

(a)

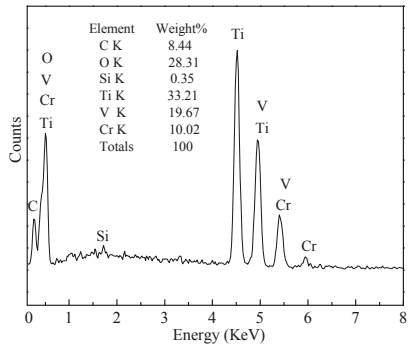

(c)

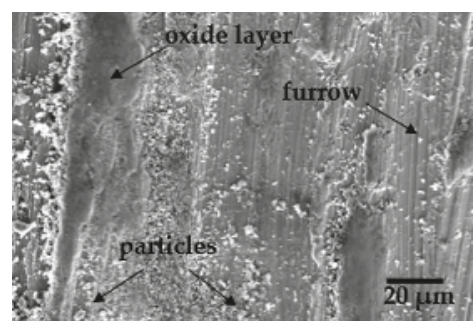

(b)

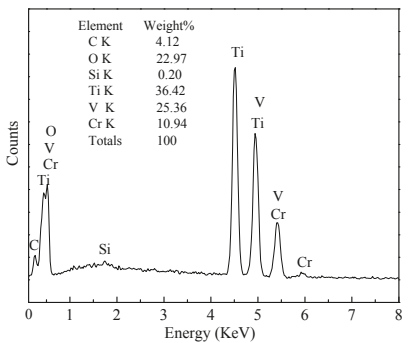

(d)

Figure 8. SEM morphologies and EDS spot-analyses of the worn surface in TF550 alloy after wearing at $873 \mathrm{~K}$. (a) Low magnification SEI; (b) high magnification SEI; (c) compositions of the oxide layer region; and (d) compositions of the particles region.

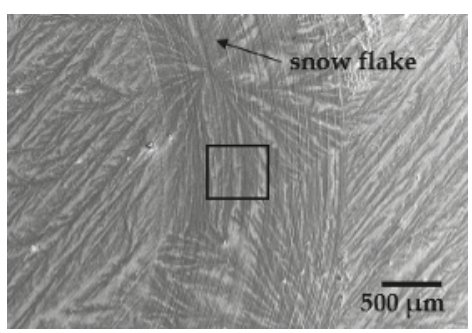

(a)

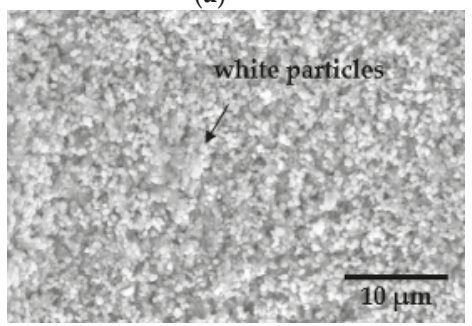

(c)

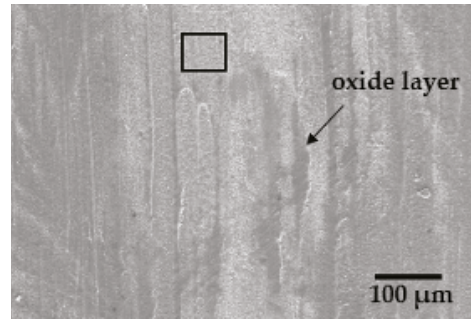

(b)

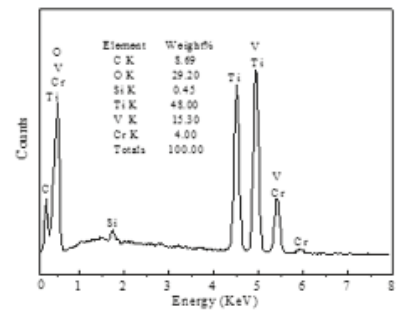

(d)

Figure 9. SEM morphologies and EDS spot-analysis of the worn surface in TF550 alloy after wearing at 1073 K. (a) Low magnification SEI; (b) high magnification SEI of area in black square in (a); (c) SEI of area in black square in (b); (d) compositions of the white particles region. 


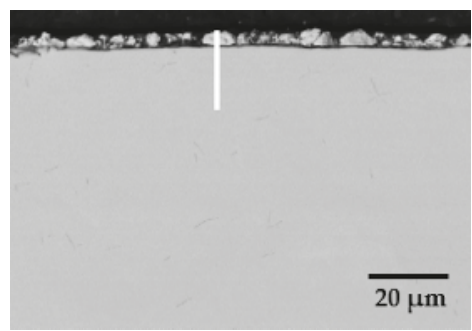

(a)

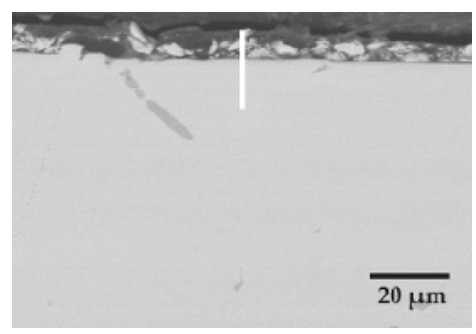

(c)

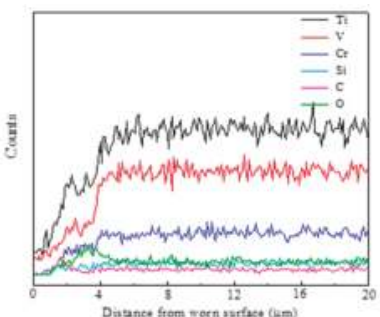

(b)

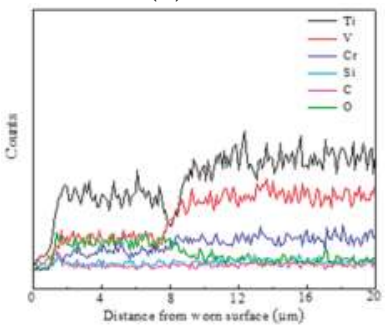

(d)

Figure 10. SEM cross-section morphologies and EDS line-analyses of the worn surface in TF550 alloy after wearing at high temperatures. (a) backscattered electron image (BEI) at $873 \mathrm{~K}$; (b) compositions along the white line at $873 \mathrm{~K}$; (c) BEI at $1073 \mathrm{~K}$; and (d) compositions along the white line at $1073 \mathrm{~K}$.

Based on the results of the friction coefficients, volume wear rates, and morphologies of worn surfaces, TF550 alloy presented different dry sliding wear behaviors at different testing temperatures. At $873 \mathrm{~K}$, the tribo-oxide layer was not formed in the initial stage of dry sliding wear, and direct contact was not avoided completely, which resulted in a large friction coefficient. With an extension of wear time, a tribo-layer containing the oxide of $\mathrm{TiO}_{2}$, i.e., black smooth regions formed, as shown in Figure 8b [31]. This tribo-oxide layer presented a partial protection from wearing for a decrease in the friction coefficient and its fluctuation. Some furrows appeared on the worn surface, while they were not covered with the tribo-oxide layer. Thus, the wear mechanism at $873 \mathrm{~K}$ was dominated by a combination of abrasive wear and oxidative wear. Amounts of oxides formed on the worn surface before the sliding test wear at $1073 \mathrm{~K}$, because the temperature rose to the testing value in advance. The oxides formed before the sliding wear were loose, and thus were easily peeled off under the sliding in the initial period. Furthermore, $\mathrm{V}_{2} \mathrm{O}_{5}$ oxides could be melted during the sliding wear according to the oxidation morphology of TF550 alloy at $1073 \mathrm{~K}$ (Figure $2 \mathrm{~b}$ ). The molten $\mathrm{V}_{2} \mathrm{O}_{5}$ as a soft phase provided a lubricating effect, which led to a decrease in the friction coefficient, leading to a reduction of calorific value. Also, they filled defects between the hard phases, such as $\mathrm{TiO}_{2}$ and metal debris, which could release the internal force between them, as shown in Figure 10c. Not only the loose oxides but also the molten $\mathrm{V}_{2} \mathrm{O}_{5}$ acted as a lubricant, leading to the absence of the running-in period and a relatively small friction coefficient during the wear process. The molten $\mathrm{V}_{2} \mathrm{O}_{5}$ flowed into the wear scratch and was subjected to solidification after wear testing, to exhibit the aforementioned snowflake-like features (Figure 9a), which was not in agreement with that of the single oxidation at $1073 \mathrm{~K}$. In addition, the presence of amounts of oxides at relatively high temperatures made it difficult to measure the volume wear rate of the disk and resulted in an overestimated volume wear rate of the pin (Table 1). The furrows were not observed on the worn surface and amounts of oxide particles were present at $1073 \mathrm{~K}$, indicating a typical feature of the oxidative wear mechanism. 


\section{Conclusions}

In this study, the oxidation and wear characteristics of TF550 fireproof titanium alloy were investigated at high temperatures of 873 and $1073 \mathrm{~K}$, and corresponding high temperature oxidation and wear mechanisms were also discussed. The main results are summarized as follows.

(1) The oxidation gain of TF550 alloy was much larger than that of Ti64 alloy, attributed the abundant addition of vanadium, which was regarded as a positive factor to improve the burn resistance. The oxidation weight gain of TF550 alloy after oxidation at $873 \mathrm{~K}$ for $100 \mathrm{~h}$ was much smaller than that at $1073 \mathrm{~K}$ for $100 \mathrm{~h}$. The thin surface oxide film was identified as oxides of $\mathrm{TiO}_{2}$ and $\mathrm{V}_{2} \mathrm{O}_{5}$ at $873 \mathrm{~K}$, while the thick one was detected to be $\mathrm{TiO}_{2}$ only at $1073 \mathrm{~K}$. The oxidation reaction rate at $1073 \mathrm{~K}$ followed the linear law, indicating that the oxidation process of this alloy was mainly controlled by the oxidation reaction at the interface between the substrate and oxide layer.

(2) The friction coefficient at $873 \mathrm{~K}$ was larger than that at $1073 \mathrm{~K}$, while the volume wear rate at $1073 \mathrm{~K}$ was larger because a large amount of oxides formed on the worn surface. The $\mathrm{TiO}_{2}$ oxide was detected on the worn surface at $873 \mathrm{~K}$, and both oxides of $\mathrm{TiO}_{2}$ and $\mathrm{V}_{2} \mathrm{O}_{5}$ were present at $1073 \mathrm{~K}$.

(3) The presence of furrows and a tribo-oxide layer at $873 \mathrm{~K}$ indicated that the wear mechanism was dominated by a combination of abrasive wear and oxidative wear. The continuous tribo-oxide layer was present at $1073 \mathrm{~K}$, indicating that the wear mechanism was dominated by oxidative wear.

Acknowledgments: This work was financially supported by the National Natural Science Foundation of China, China (Grants Nos. 51471155 and 51471040). The authors would like to thank Jie Zhao and Wei Zhang of Dalian University of Technology for their assistance.

Author Contributions: Xiaohua Min and Guangbao Mi conceived and designed the experiments; Kai Yao and Pengfei Bai performed the experiments, analyzed the data and wrote the paper; Congqian Cheng contributed some analysis tools.

Conflicts of Interest: The authors declare no conflict of interest.

\section{References}

1. Banerjee, D.; Williams, J.C. Perspectives on Titanium Science and Technology. Acta Mater. 2013, 61, 844-879. [CrossRef]

2. Min, X.H.; Tsuzaki, K.; Emura, S.; Tsuchiya, K. Heterogeneous twin formation and its effect on tensile properties in Ti-Mo based $\beta$ titanium alloys. Mater. Sci. Eng. A 2012, 554, 53-60. [CrossRef]

3. Min, X.H.; Emura, S.; Zhang, L.; Tsuzaki, K.; Tsuchiya, K. Improvement of strength-ductility tradeoff in $\beta$ titanium alloy through pre-strain induced twins combined with brittle $\omega$ phase. Mater. Sci. Eng. A 2015, 646, 279-287. [CrossRef]

4. Luo, Q.S.; Li, S.F.; Pei, H.P. Progress in titanium fire resistant technology for aero-engine. J. Aerosp. Power 2012, 27, 2763-2767.

5. Zhang, P.Z.; Xu, Z.; Zhang, G.H.; He, Z.Y. Surface plasma chromized burn-resistant titanium alloy. Surf. Coat. Technol. 2007, 201, 4884-4887. [CrossRef]

6. Lv, D.S.; Xu, J.H.; Ding, W.F.; Fu, Y.C.; Yang, C.Y.; Su, H.H. Tool wear in milling Ti40 burn-resistant titanium alloy using pneumatic mist jet impinging cooling. J. Mater. Process. Technol. 2016, 229, 641-650. [CrossRef]

7. Zhang, X.J.; Cao, Y.H.; Ren, B.Y.; Tsubaki, N. Improvement of high-temperature oxidation resistance of titanium-based alloy by sol-gel method. J. Mater. Sci. 2010, 45, 1622-1628. [CrossRef]

8. Wang, M.M.; Zhao, Y.Q.; Zhou, L.; Zhang, D. Study on creep behavior of Ti-V-Cr burn resistant alloys. Mater. Lett. 2004, 58, 3248-3252. [CrossRef]

9. Xin, S.W.; Zhao, Y.Q.; Zeng, W.D.; Wu, H. Research on thermal stability of Ti40 alloy at $550{ }^{\circ}$ C. Mater. Sci. Eng. A 2008, 477, 372-378. [CrossRef]

10. Li, Y.G.; Blenkinsop, P.A.; Loretto, M.H.; Walkern, N.A. Structure and stability of precipitates in $500{ }^{\circ} \mathrm{C}$ exposed in Ti-25V-15Cr-xAl. Acta Mater. 1998, 46, 5777-5794. [CrossRef]

11. Seagle, S.R. The state of the USA titanium industry in 1995. Mater. Sci. Eng. A 1996, 213, 1-7. [CrossRef] 
12. Chen, Y.N.; Huo, Y.Z.; Song, X.D.; Bi, Z.Z.; Gao, Y.; Zhao, Y.Q. Burn-resistant behavior and mechanism of Ti14 alloy. Int. J. Miner. Metall. Mater. 2016, 23, 215-221. [CrossRef]

13. Campo, K.N.; Lima, D.D.; Lopes, E.S.N.; Caram, R. On the selection of Ti-Cu alloys for thixoforming processes: Phase diagram and microstructural evaluation. J. Mater. Sci. 2015, 50, 8007-8017. [CrossRef]

14. Chen, Y.N.; Yang, W.Q.; Zhan, H.F.; Zhang, F.Y.; Huo, Y.Z.; Zhao, Y.Q.; Song, X.D.; Gu, Y.T. Tailorable burning behavior of Ti14 alloy by controlling semi-solid forging temperature. Materials 2016, 9, 697. [CrossRef]

15. Mi, G.B.; Huang, X.; Cao, J.X.; Wang, B.; Cao, C.X. Microstructure characteristics of burning products of Ti-V-Cr fireproof titanium alloy by frictional ignition. Acta Phys. Sin. 2016, 65, 1-10.

16. Cao, J.X.; Huang, X.; Mi, G.B.; Sha, A.X.; Wang, B. Research progress on application technique of Ti-V-Cr burn resistant titanium alloys. J. Aeronaut. Mater. 2014, 34, 92-97.

17. Mi, G.B.; Cao, C.X.; Huang, X.; Cao, J.X.; Wang, B.; Sui, N. Non-isothermal oxidation characteristic and fireproof property prediction of Ti-V-Cr type fireproof titanium alloy. J. Mater. Eng. 2016, 44, 1-10.

18. Molinari, A.; Straffelini, G.; Tesi, B.; Bacci, T. Dry sliding wear mechanisms of the Ti6Al4V alloy. Wear 1997, 208, 105-112. [CrossRef]

19. Cui, X.H.; Mao, Y.S.; Wei, M.X.; Wang, S.Q. Wear Characteristics of Ti-6Al-4V Alloy at 20-400 ${ }^{\circ}$ C. Tribol. Trans. 2012, 5, 185-190. [CrossRef]

20. Sun, Q.C.; Hu, T.C.; Fan, H.Z.; Zhang, Y.S.; Hu, L.T. Dry sliding wear behavior of TC11 alloy at $500{ }^{\circ} \mathrm{C}$ : Influence oflaser surface texturing. Tribol. Int. 2015, 92, 136-145. [CrossRef]

21. Mao, Y.S.; Wang, L.; Chen, K.M.; Wang, S.Q.; Cui, X.H. Tribo-layer and its role in dry sliding wear of Ti-6Al-4V alloy. Wear 2013, 297, 1032-1039. [CrossRef]

22. Zeng, S.W.; Jiang, H.T.; Zhao, A.M. High Temperature Oxidation Behavior of TC4 Alloy. Rare Met. Mater. Eng. 2015, 44, 2812-2816.

23. Zeng, S.W.; Zhao, A.M.; Jiang, H.T.; Fan, X.; Duan, X.G.; Yan, X.Q. Cyclic Oxidation Behavior of the Ti-6Al-4V Alloy. Oxid. Met. 2014, 81, 467-476. [CrossRef]

24. Mendez, S.F.O.; Rodriguez, C.R.S.; Venegas, K.C.; Aquino, J.A.M.; Magana, F.E. Magnetism and decarburization-like diffusion process on $\mathrm{V}_{2} \mathrm{O}_{5}$-doped $\mathrm{ZnO}$ ceramics. Ceram. Int. 2015, 41, 6802-6806. [CrossRef]

25. Li, Y.; Bai, C.Y.; Deng, X.Y.; Li, J.B.; Jing, Y.N.; Liu, Z.M. Effect of $\mathrm{V}_{2} \mathrm{O}_{5}$ addition on the properties of reaction-bonded porous $\mathrm{SiC}$ ceramics. Ceram. Int. 2014, 40, 16581-16587. [CrossRef]

26. Birks, N.; Meier, G.H.; Pettit, F.S. Introduction of Metal Oxidation at High Temperature; Higher Education Press: Beijing, China, 2010; p. 43.

27. Tomasi, A.; Gialanella, S. Oxidation phenomena in a Ti 3 Al base-alloy. Therm. Acta 1995, 269, $133-143$. [CrossRef]

28. Frangini, S.; Mignone, A.; De Riccardis, F. Various aspects of the air oxidation behavior of a Ti6Al4V alloy at temperatures in the range $600-700^{\circ} \mathrm{C}$. J. Mater. Sci. 1994, 29, 714-720. [CrossRef]

29. Jia, W.J.; Zeng, W.D.; Zhang, X.M.; Zhou, Y.G.; Liu, J.R.; Wang, Q.J. Oxidation behavior and effect of oxidation on tensile properties of Ti60 alloy. J. Mater. Sci. 2011, 46, 1351-1358. [CrossRef]

30. Huang, X.; Cao, C.X.; Ma, J.M.; Wang, B.; Gao, Y. High temperature oxidation behavior of a fire-resistant titanium alloy. Rare Met. Mater. Eng. 1997, 26, 27-30.

31. Wang, L.; Zhang, Q.Y.; Li, X.X.; Cui, X.H.; Wang, S.Q. Dry Sliding Wear Behavior of Ti-6.5Al-3.5Mo-1.5Zr0.3Si Alloy. Metall. Mater. Trans. A 2014, 45A, 2284-2296. [CrossRef]

(C) 2017 by the authors. Licensee MDPI, Basel, Switzerland. This article is an open access article distributed under the terms and conditions of the Creative Commons Attribution (CC BY) license (http:/ / creativecommons.org/licenses/by/4.0/). 


\title{
Article \\ Fretting Behavior of SPR Joining Dissimilar Sheets of Titanium and Copper Alloys
}

\author{
Xiaocong He *, Cong Deng and Xianlian Zhang \\ Innovative Manufacturing Research Centre, Kunming University of Science and Technology, \\ Kunming 650500, China; d_c8745@163.com (C.D.); zxlian4gd@163.com (X.Z.) \\ * Correspondence: x_he@kmust.edu.cn; Tel.: +86-871-65930928 \\ Academic Editor: Mark T. Whittaker \\ Received: 18 October 2016; Accepted: 2 December 2016; Published: 9 December 2016
}

\begin{abstract}
The fretting performance of self-piercing riveting joining dissimilar sheets in TA1 titanium alloy and H62 copper alloy was studied in this paper. Load-controlled cyclic fatigue tests were carried out using a sine waveform and in tension-tension mode. Scanning electron microscopy and energy-dispersive $\mathrm{X}$-ray techniques were employed to analyze the fretting failure mechanisms of the joints. The experimental results showed that there was extremely severe fretting at the contact interfaces of rivet and sheet materials for the joints at relatively high loads levels. Moreover, the severe fretting in the region on the locked sheet in contact with the rivet was the major cause of the broken locked sheet for the joints at low load level.
\end{abstract}

Keywords: titanium alloy; copper alloy; fretting; self-piercing riveting; SEM; EDX

\section{Introduction}

Facing a decreasing amount of resources, lightweight design principles continue to prosper rapidly in different engineering fields. As a result, lightweight materials for different applications have been developed. Fusion welding and friction stir welding techniques are normally used to join lightweight metal sheets [1,2]. However, it is not easy to weld dissimilar metal sheets due to the formation of intermetallic phases. Self-piercing riveting (SPR) is a new high-speed mechanical fastening technique suitable for point-joining advanced lightweight sheet materials that are dissimilar, coated, and hard to weld [3].

In the past few years, the mechanical properties of SPR joints and the SPR technique itself have been studied by many scholars. Kang et al. [4] aimed to evaluate the static and fatigue strengths of the joints using coach-peel, cross-tension and tensile-shear specimens with experimental tests and numerical analysis. Su et al. [5] investigated the fracture and fatigue behaviors of SPR and clinch joints in lap-shear specimens of 6111-T4 aluminum sheets based on experimental observations, and examined the optical micrographs of both types of joints before and after failure under quasi-static and cyclic loading conditions. Calabrese et al. [6] conducted a long-time salt spray corrosion test for steel/aluminum hybrid joints obtained by SPR technique to evaluate the mechanical degradation in these critical environmental conditions. The influence of resistance heating on dissimilar SPR joints with unequal thickness was studied systematically by Lou et al. [7]. They reported that SPR joints using rivet-welding could obtain higher tensile-shear strength than with conventional SPR joints. Haque et al. [8] developed a simple geometrical method to calculate rivet flaring without having to cross-section a joint. It is a nondestructive testing method to determine rivet flaring based on the characteristic force-displacement curve, and could be a very useful tool in joint product development and process optimization.

A newly developed solid state joining technique-friction self-piercing riveting (F-SPR)-has been applied for joining high strength aluminum alloy to magnesium alloy $[9,10]$. The process was 
performed on a specially designed machine where the spindle can achieve a sudden stop. The effects of rivet rotating rate and punch speed on axial plunge force, torque, joint microstructure, and quality were analyzed systematically. A 3-D thermo-mechanical finite-element (FE) model of F-SPR process was developed using an LS-DYNA code [11]. Temperature-dependent material parameters were utilized to calculate the material yield and flow in the joint formation. A preset crack failure method was used to model the material failure of the top sheet. The calculated joint geometry exhibited a good agreement with the experimental measurement.

In a recent study, Haque and Durandet [12] described a parametric study of the mechanical behavior of SPR joints of steel sheets in two loading conditions (lap-shear and cross-tension). An empirical model was developed to predict the joint strength in cross-tension loading using characteristic joint data determined directly from the SPR process (force-displacement) curve. The tensile and fatigue behavior of SPR in carbon fiber reinforced plastic (CFRP) to aluminum 6111 T82 alloys were evaluated by Kang et al. [13]. The SPR lap-shear joints under fatigue loads failed predominantly due to kinked crack growth along the width of the bottom aluminum sheet. The fatigue cracks initiated in the plastically deformed region of the aluminum sheet close to the rivet shank in the rivet-sheet interlock region. Mucha and Witkowski [14] discussed the strength of riveted joints of various sheet materials: DC01 steel, AW-5754 aluminum alloy, and their hybrid arrangements. The fracture mechanism of riveted joints in unilateral tensile tests of T-shaped specimens made of various sheet materials was also analyzed. Chung and Kim [15] investigated the fatigue strength of SPR joints in tensile-shear specimens with dissimilar Al-5052 and steel sheets. A structural analysis of the specimen was conducted. For this specimen, the upper steel sheet with stood applied load in a monotonic test and played a major role in the low-cycle region. In the high-cycle region, however, the harder surface of the upper steel sheet reduced the fatigue strength by enhancing fretting crack initiation on the opposite softer aluminum surface.

Titanium alloy sheets and copper alloy sheets have been widely used in different engineering fields due to excellent strength, ductility, and corrosion resistance. However, it is not easy to weld titanium sheets with copper alloys, as their melting points and thermal conductivity are very different. It is widely accepted that dissimilar metal sheets of titanium with copper alloys can be jointed well by SPR. In a previous paper by He et al. [16], the static strength of SPR joints in dissimilar sheets of titanium and copper alloys was studied. However, no investigation on fretting behavior of such SPR joints has been reported so far.

The present paper deals with the fretting performance of SPR joints in dissimilar sheets of titanium (TA1) and copper (H62) alloys (defined as STH joints). Fatigue load-fatigue life curves were obtained via tension-tension fatigue tests to characterize the fatigue properties of the joints. The typical fracture interfaces were analyzed by scanning electron microscopy (SEM) and energy-dispersive X-ray spectroscopy (EDX) techniques. The results showed that there was extremely severe fretting at the contact interfaces of rivet and sheet materials for the joints at relatively high load levels. In addition, the severe fretting in the region of the locked sheet in contact with the rivet was the major cause of broken locked sheets for the joints at low load level.

\section{Experimental Procedure}

\subsection{Materials}

The materials used in this study were TA1 titanium alloy (TA1) sheets (Baoji Chuangxin Metal Materials Co. Ltd., Baoji, China) and H62 copper alloy (H62) sheets (Baoji Chuangxin Metal Materials Co. Ltd., Baoji, China) with the dimensions $110 \mathrm{~mm}$ length $\times 20 \mathrm{~mm}$ width $\times 1.5 \mathrm{~mm}$ thickness. To obtain the sheet mechanical properties, material tests were conducted using an MTS 634.31F-24 extensometer (MTS System Corporation, Eden Prairie, MN, USA) with a $20 \mathrm{~mm}$ gauge length on an MTS servo hydraulic test machine (MTS System Corporation, Eden Prairie, MN, USA). The chemical 
compositions of TA1 and H62 sheets are shown in Table 1, and the stress-strain curves at a constant crosshead speed of $5 \mathrm{~mm} / \mathrm{min}$ are exhibited in Figure 1.

Table 1. Chemical compositions of TA1 and H62 sheet materials.

\begin{tabular}{ccccccc}
\hline Material & $\mathbf{F e}$ & $\mathbf{C}$ & $\mathbf{N}$ & $\mathbf{H}$ & $\mathbf{O}$ & Ti \\
\hline TA1 & 0.02 & 0.01 & 0.01 & 0.001 & 0.08 & Rest \\
Material & $\mathrm{Zn}$ & $\mathrm{Fe}$ & $\mathrm{Pb}$ & $\mathrm{P}$ & $\mathrm{Cu}$ & - \\
H62 & 36.8 & 0.15 & 0.08 & 0.01 & Rest & - \\
\hline
\end{tabular}

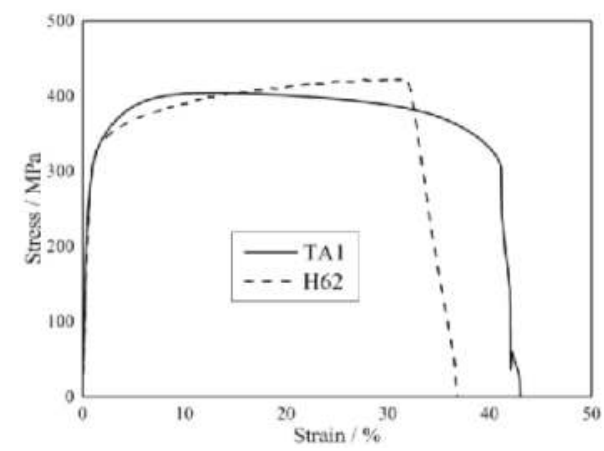

Figure 1. Stress-strain curves for TA1 and H62 sheet materials.

\subsection{Specimens Preparation}

As mentioned previously, SPR is a new high-speed mechanical fastening technique for point joining of sheet materials. To date, no agreed standard for testing SPR joints exists. The most common test configuration performed in previous studies was the single overlap joint, since it is simple and quick to fabricate. All specimen designs and joint tests referred to China welding standard (GB-2649). As shown in Figure 2, the specimens used for experimental investigation were of the lap-shear type. All specimens were produced with a rivet and a flat bottom die on a RIVSET VARIO-FC servo-driven riveting machine by Böllhoff (Böllhoff Produktion GmbH \& Co. KG, Bielefeld and Sonnewalde, Germany). Both the rivet and the die were fabricated from high-strength steel, and were supplied by Böllhoff Produktion $\mathrm{GmbH} \& \mathrm{Co}$. The mechanical properties of the rivets used in present paper were as follows: Young's modulus $206 \mathrm{GPa}$, Poisson's ratio 0.3, yield strength $1720 \mathrm{MPa}$, compressive strength $1595.6 \mathrm{MPa}$, and Rockwell hardness $44 \mathrm{HRC}$. The dimensions of the rivet and the die are shown in Figure 3.

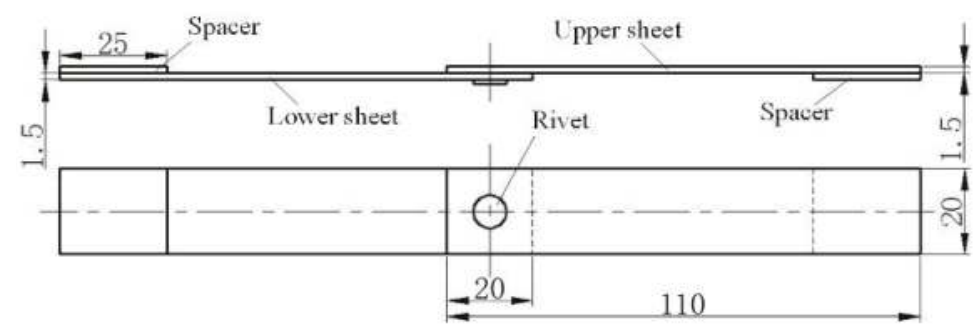

Figure 2. Specimen geometry (dimensions in $\mathrm{mm}$ ).

To increase the material formability, TA1 sheets in STH joints were heated to $700{ }^{\circ} \mathrm{C}$ by an oxyacetylene flame gun. The temperature was controlled by an infrared thermometer (Shenzhen 
Jumaoyuan Science And Technology Co., Ltd., Shenzhen, China). The SPR processes were produced immediately after heat treatment. The quality of specimens was monitored by an online window monitoring system (Böllhoff Produktion GmbH \& Co. KG, Bielefeld and Sonnewalde, Germany) in the riveting equipment during the SPR process. The monitoring was carried out by measuring the actual SPR setting force through a force sensor and the punch travel through a position sensor, and generating a force-travel curve for one SPR joint [17]. The force-travel curves should be almost identical under the same working conditions for different joints. This indicates that the quality of corresponding joints is good. Through the online window monitoring system, all specimens used were judged as qualified. The satisfied joining parameters of STH joints in terms of punch travel, pre-clam pressure, riveting pressure, and compressing pressure were $131.20 \mathrm{~mm}, 50 \mathrm{bar}, 195 \mathrm{bar}$, and $110 \mathrm{bar}$, respectively. Twenty-five STH joints were made, ten of which were selected randomly for the static tests. The rest were prepared for the fatigue tests.

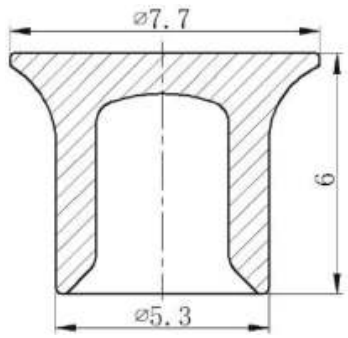

(a)

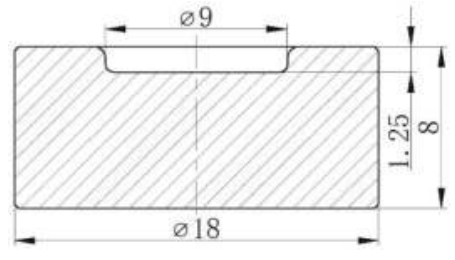

(b)

Figure 3. Dimensions of the rivet and the die (dimensions in mm): (a) Rivet; (b) Die.

\section{Static Tests and Results Analysis}

The static tests were conducted on an MTS servo hydraulic testing machine using tensile-shear mode. Spacers with dimensions of $25 \mathrm{~mm}$ length $\times 20 \mathrm{~mm}$ width $\times 1.5 \mathrm{~mm}$ thickness were glued on both ends of the specimens to reduce the influence of additional bending and to centralize the load. Ten tests for the STH joints were conducted in turn. The tests were performed with a constant displacement rate of $5 \mathrm{~mm} / \mathrm{min}$ and terminated when the sheets were separated or the force dropped to $5 \%$ of the peak force value. Continuous records of the applied force-displacement curves were obtained during each test. The tensile process of the STH joints is exhibited in Figure 4.
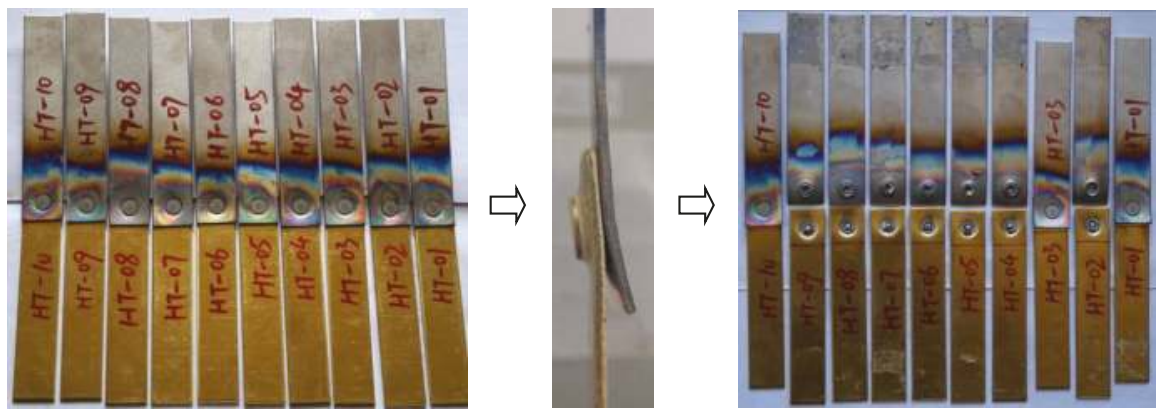

Figure 4. Tensile process of the STH joints.

Figure 5 shows the force-displacement curves and histogram of maximum shear strength of the STH joints. It can be seen from Figure 4 that in static tests of the STH joints, rivets were broken for 
seven samples, corresponding to the seven relatively low maximum load force-displacement curves in Figure 5. Three joints were not separated completely, which correspond to the force-displacement curve characterized by both high maximum load and high failure deflection in Figure 5.

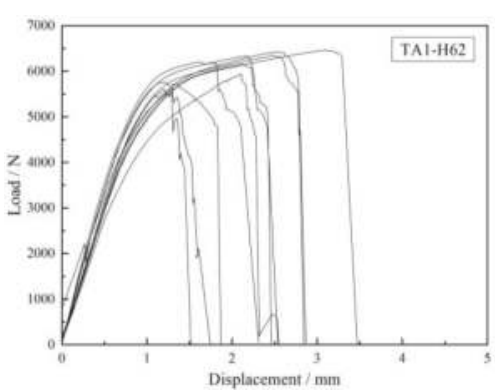

(a)

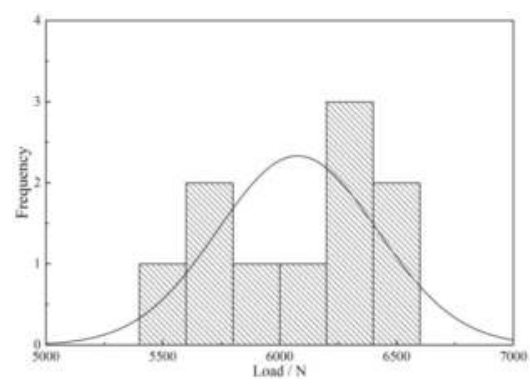

(b)

Figure 5. Force-displacement curves and histogram of maximum shear strength of the STH joints.

(a) Force-displacement curves; (b) Histogram of maximum shear strength.

From Figure 5, it can be seen that the data for the failure load and failure displacement of the STH joints were relatively stable, showing that the results were reliable and repeatable. To examine the rationality of the test data, the normal hypothesis tests were performed using MATLAB software (MathWorks Inc., Natick, MA, USA). As shown in Figure 5, the results show that the tensile-shear strength of the STH joints follow normal distributions. All test data fitting the region bounded by the $95 \%$ confidence limits.

\section{Fatigue Tests and Results Analysis}

It can be obtained from Figure 5a that the average peak load of the STH joints was $6.076 \mathrm{kN}$. The fatigue test parameters were determined based on the average peak load. The load-controlled cyclic fatigue tests were carried out on the MTS servo hydraulic testing machine using a sine waveform and in tension-tension mode. The load ratio $R=0.1$ and the frequency $f=10 \mathrm{~Hz}$ were employed for all specimens. Each test was run until 2 million cycles were attained or visible failure occurred. Three load levels of $35 \%$ (around $2.1 \mathrm{kN}$ ), 30\% (around $1.8 \mathrm{kN}$ ), and 25\% (around $1.5 \mathrm{kN}$ ) were performed for the STH joints. Three specimens tested at each load level were randomly selected from the fifteen joints prepared well. To reduce the bending of the sheets and ensure straight-line load paths, spacers were glued to both ends of all specimens in the clamping area. Figure 6 shows the fatigue process of the STH joints.
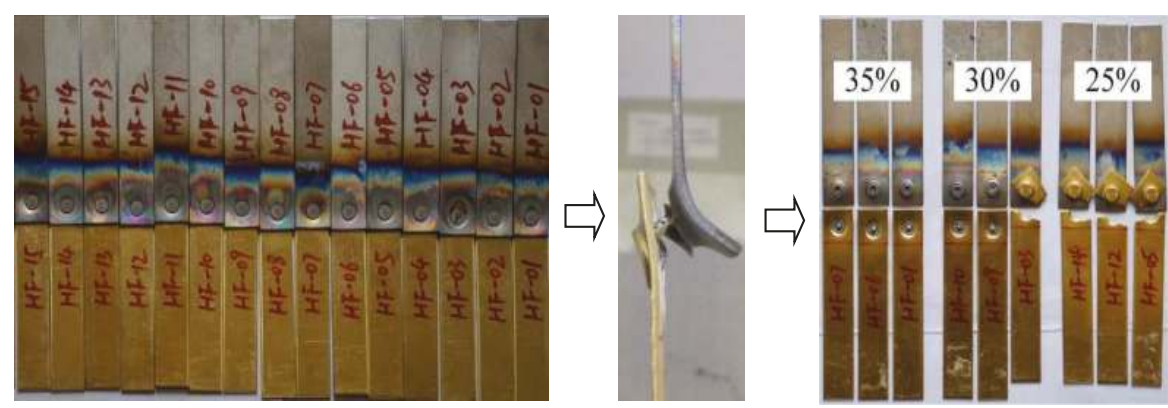

Figure 6. Fatigue process of the STH joints. 
The fatigue data and the fatigue load-fatigue life $(F-N)$ curve fitted by the least square method are presented in Figure 7. The calculated linear equation of the STH joints is $F=4.739-0.549 \lg N$. It can be seen from Figure 7 that the STH joints had an average cycle number of $72,102(\lg N=4.9)$ at the fatigue load of approximately $2.1 \mathrm{kN}$.

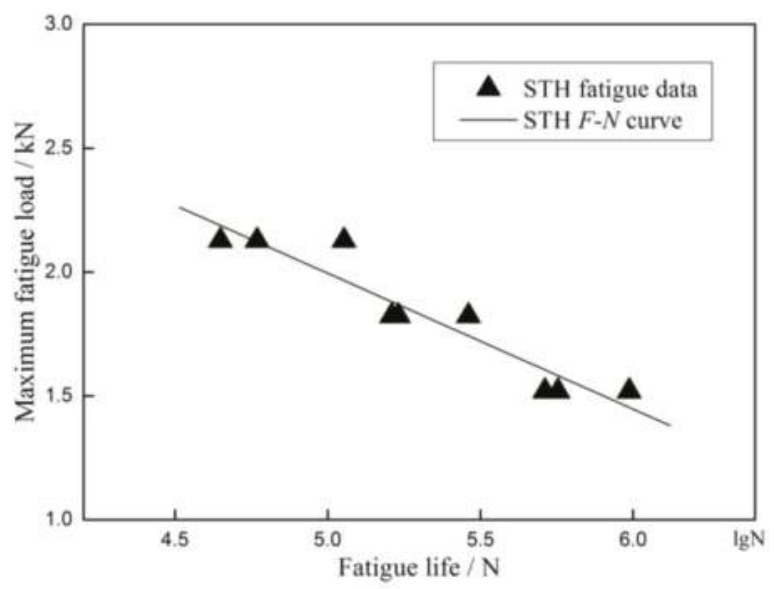

Figure 7. F-N curve of the STH joints.

During the static tensile-shear tests, the most STH joints failed with the rivets broken as shown in Figure 4. However, as presented in Figure 6, the failures during the fatigue tests were quite different. At the load level of $35 \%$, all three specimens fractured in the rivet. At the load level of $25 \%$, the locked sheets were broken for all specimens. At the load level of 30\%, however, specimens fractured in both failure models.

\section{Fretting Failure Mechanism}

To analyze the fretting failure mechanisms of the STH joints, SEM (A.S. Tescan Inc., Brno, Czech Republic) and EDX (EDAX Inc., San Diego, CA, USA) techniques were employed to examine the typical fatigue fracture surfaces. As stated previously, the STH joints had an average cycle number of 72,102 at the fatigue load of approximately $2.1 \mathrm{kN}$. Thus, the macroscopic fatigue fracture surfaces of the STH specimens that failed in the rivet at $2.1 \mathrm{kN}$ were chosen to discuss in detail.

The SEM image of the rivet fracture surface is exhibited in Figure 8, from which the fatigue striations can be obviously observed. This characteristic belongs to the ductile fatigue fracture. It can be seen from the direction marked by an arrow in Figure 8 that fatigue cracks propagated from the outside of the rivet to the inside.

As shown in Figure 9a, the fretting debris could be found in the region near the broken rivet. The corresponding local images of fretting debris are shown in Figure 9b. Based on these features of wear debris, it is inferred that there was extremely severe fretting in the STH joints at load levels of $35 \%$ and $30 \%$. Moreover, the severe fretting in the region on the locked sheet in contact with the rivet was the major cause of the broken locked sheet for the STH joints at low load level of $25 \%$. 


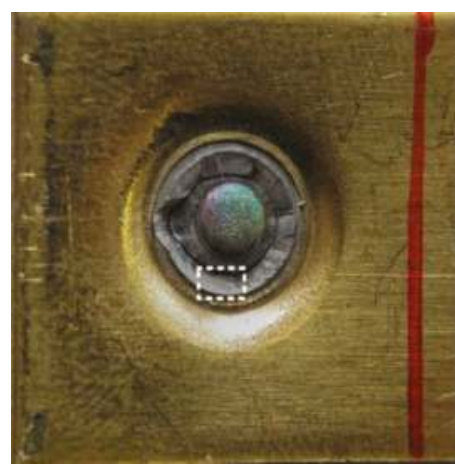

(a)

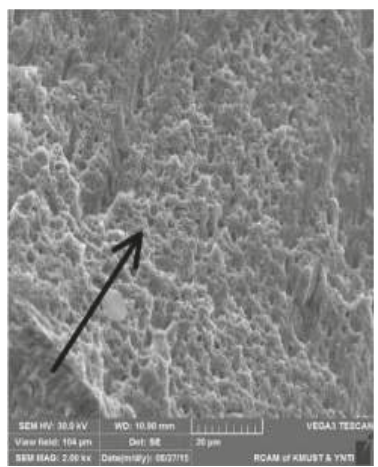

(b)

Figure 8. SEM (scanning electron microscopy) images of fracture surface for the STH specimens (load level of 35\%). (a) Fracture surface of the rivet; (b) Enlarged fracture area.

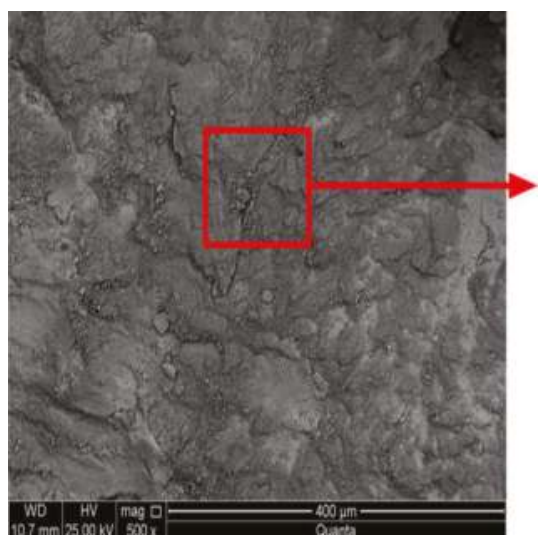

(a)

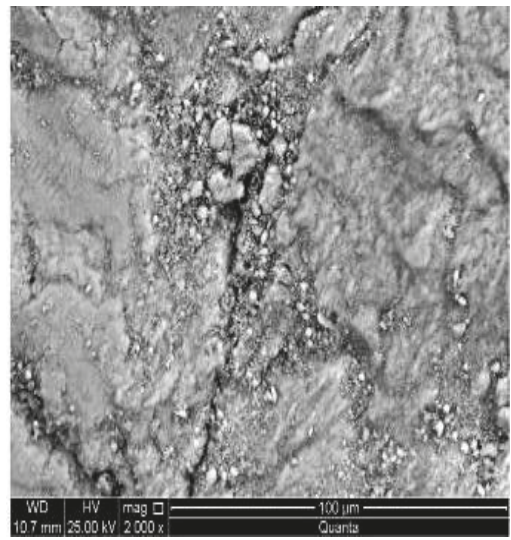

(b)

Figure 9. An example of SEM analysis of oxide debris in the STH specimens (load level of 35\%). (a) Fretting debris; (b) Enlarged fretting debris.

Figure 10 shows the spectrum of fretting debris near the broken rivet on the locked sheet for STH joints by EDX (EDAX Inc., San Diego, CA, USA) tests. The main ingredient of the fretting debris was deemed to be $\mathrm{CuO}$, and some zinc, stannum, ferrum, and titanium and other elements in smaller quantities were tested. It could be deduced that the metallic oxide at the contact interface was caused by the continuous cyclic load and micro-movement between the rivet and the sheet. In short, the corresponding elements were fallen off from the sheet or the rivet by the fretting wear processes and oxidized to the relevant oxide: $\mathrm{TiO}_{2}$ and $\mathrm{CuO}$. 


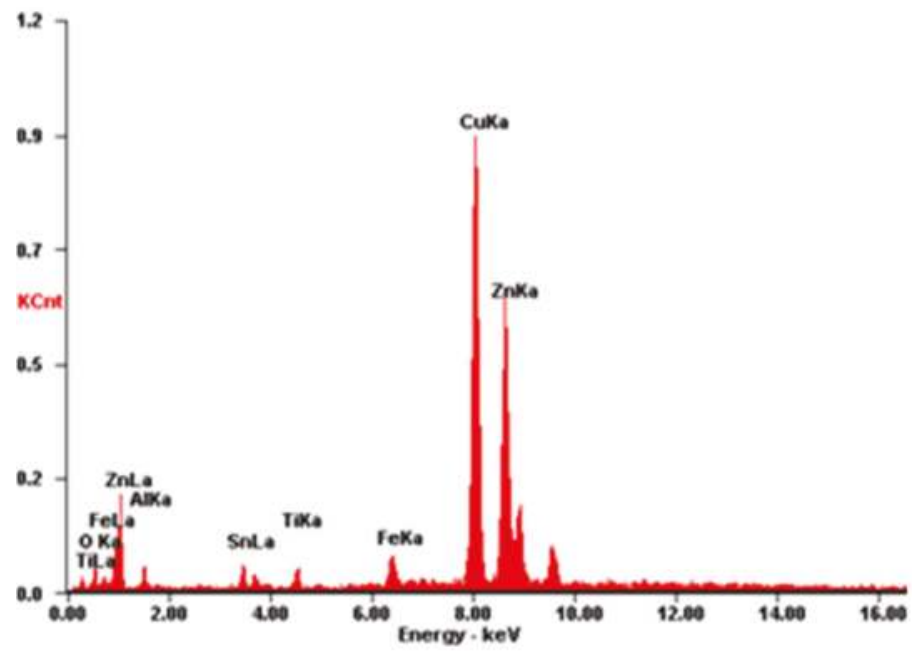

Figure 10. An example of energy-dispersive X-ray spectroscopy (EDX) analysis of oxide debris in the STH specimens.

\section{Summary}

In this paper, the fretting performance of SPR joining dissimilar sheets in TA1 titanium alloy and H62 copper alloy was studied. The static tests were conducted using tensile-shear mode, and the histograms of maximum shear strength of the STH joints were obtained. Fatigue load-fatigue life curves were obtained via tension-tension fatigue tests to characterize the fatigue properties of the joints. To study the fretting behavior of the STH joints, the typical fracture interfaces were analyzed by SEM and EDX techniques. The results showed that there was extremely severe fretting at the contact interfaces of rivet and sheet materials for the joints at relatively high load levels. Moreover, the severe fretting in the region of the locked sheet in contact with the rivet was the major cause of the broken locked sheets for the joints at low load level. It could be deduced that the metallic oxide at the contact interface was caused by the continuous cyclic load and micro-movement between the rivet and the sheet.

Acknowledgments: This study is supported by the National Natural Science Foundation of China (Grant No. 51565023) and Major Program Foundation of the Education Department of Yunnan Province, China (Grant No. ZD201504).

Author Contributions: Xiaocong He conceived and designed the experiments; Cong Deng and Xianlian Zhang performed the experiments and analyzed the data; Xianlian Zhang contributed reagents/materials/analysis tools; Xiaocong He wrote the paper.

Conflicts of Interest: The authors declare no conflict of interest. The founding sponsors had no role in the design of the study; in the collection, analyses, or interpretation of data; in the writing of the manuscript, and in the decision to publish the results.

\section{References}

1. He, X.; Gu, F.; Ball, A. A review of numerical analysis of friction stir welding. Prog. Mater. Sci. 2014, 65, 1-66. [CrossRef]

2. He, X. Finite Element Analysis of Laser Welding: A State of Art Review. Mater. Manuf. Process. 2012, 27, 1354-1365. [CrossRef]

3. Mucha, J. The failure mechanics analysis of the solid self-piercing riveting joints. Eng. Fail. Anal. 2015, 47, 77-88. [CrossRef] 
4. Kang, S.; Kim, H. Fatigue strength evaluation of self-piercing riveted Al-5052 joints under different specimen configurations. Int. J. Fatigue 2015, 80, 58-68. [CrossRef]

5. Su, Z.; Lin, P.; Lai, W.; Pan, J. Fatigue analyses of self-piercing rivets and clinch joints in lap-shear specimens of aluminum sheets. Int. J. Fatigue 2015, 72, 53-65. [CrossRef]

6. Calabrese, L.; Proverbio, E.; Pollicino, E.; Galtieri, G.; Borsellino, C. Effect of galvanic corrosion on durability of aluminium/steel self-piercing rivet joints. Corros. Eng. Sci. Technol. 2015, 50, 10-17. [CrossRef]

7. Lou, M.; Li, Y.; Wang, Y.; Wang, B.; Lai, X. Influence of resistance heating on self-piercing riveted dissimilar joints of AA6061-T6 and galvanized DP590. J. Mater. Process. Technol. 2014, 214, 2119-2126. [CrossRef]

8. Haque, R.; Williams, N.; Blacket, S.; Durandet, Y. A simple but effective model for characterizing SPR joints in steel sheet. J. Mater. Process. Technol. 2015, 223, 225-231. [CrossRef]

9. Li, Y.B.; Wei, Z.Y.; Wang, Z.Z.; Li, Y.T. Friction self-piercing riveting of aluminum alloy AA6061-T6 to magnesium alloy AZ31B. J. Manuf. Sci. Eng. Trans. ASME 2013, 135, 6. [CrossRef]

10. Liu, X.; Lim, Y.C.; Li, Y.B.; Tang, W.; Ma, Y.W.; Feng, Z.L.; Ni, J. Effects of process parameters on friction self-piercing riveting of dissimilar materials. J. Mater. Process. Technol. 2016, 237, 19-30. [CrossRef]

11. Ma, Y.W.; Li, Y.B.; Hu, W.; Lou, M.; Lin, Z.Q. Modeling of Friction Self-Piercing Riveting of Aluminum to Magnesium. J. Manuf. Sci. Eng. Trans. ASME 2016, 138, 6. [CrossRef]

12. Haque, R.; Durandet, Y. Strength prediction of self-pierce riveted joint in cross-tension and lap-shear. Mater. Des. 2016, 108, 666-678. [CrossRef]

13. Kang, J.; Rao, H.; Zhang, R.; Avery, K.; Su, X. Tensile and fatigue behaviour of self-piercing rivets of CFRP to aluminium for automotive application. IOP Conf. Ser. Mater. Sci. Eng. 2016, 137, 1. [CrossRef]

14. Mucha, J.; Witkowski, W. Mechanical Behavior and Failure of Riveting Joints in Tensile and Shear Tests. Strength Mater. 2015, 47, 755-769. [CrossRef]

15. Chung, C.-S.; Kim, H.-K. Fatigue strength of self-piercing riveted joints in lap-shear specimens of aluminium and steel sheets. Fatigue Fract. Eng. Mater. Struct. 2016, 39, 1105-1114. [CrossRef]

16. He, X.; Wang, Y.; Lu, Y.; Zeng, K.; Gu, F.; Ball, A. Self-piercing riveting of similar and dissimilar titanium sheet materials. Int. J. Adv. Manuf. Technol. 2015, 80, 2105-2115. [CrossRef]

17. Zhao, L.; He, X.; Xing, B.; Lu, Y.; Gu, F.; Ball, A. Influence of sheet thickness on fatigue behavior and fretting of self-piercing riveted joints in aluminum alloy 5052. Mater. Des. 2015, 87, 1010-1017. [CrossRef]

(C) 2016 by the authors. Licensee MDPI, Basel, Switzerland. This article is an open access article distributed under the terms and conditions of the Creative Commons Attribution (CC BY) license (http:/ / creativecommons.org/licenses/by/4.0/). 

MDPI

St. Alban-Anlage 66

4052 Basel

Switzerland

Tel. +41 616837734

Fax +41 613028918

www.mdpi.com

Metals Editorial Office

E-mail: metals@mdpi.com www.mdpi.com/journal/metals

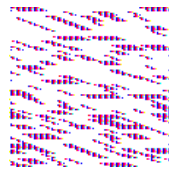





\section{MDPI}

St. Alban-Anlage 66

4052 Basel

Switzerland

Tel: +41 616837734

Fax: +41 613028918 